\title{
On the procoagulant effect of fibrin : a resonance loop between fibrin - von Willebrand factor - platelets and thrombin
}

Citation for published version (APA):

Kumar, R. (1997). On the procoagulant effect of fibrin : a resonance loop between fibrin - von Willebrand factor - platelets and thrombin. [Doctoral Thesis, Maastricht University]. Universiteit Maastricht. https://doi.org/10.26481/dis.19970619rk

Document status and date:

Published: 01/01/1997

DOI:

10.26481/dis.19970619rk

Document Version:

Publisher's PDF, also known as Version of record

Please check the document version of this publication:

- A submitted manuscript is the version of the article upon submission and before peer-review. There can be important differences between the submitted version and the official published version of record.

People interested in the research are advised to contact the author for the final version of the publication, or visit the DOI to the publisher's website.

- The final author version and the galley proof are versions of the publication after peer review.

- The final published version features the final layout of the paper including the volume, issue and page numbers.

Link to publication

\footnotetext{
General rights rights.

- You may freely distribute the URL identifying the publication in the public portal. please follow below link for the End User Agreement:

www.umlib.nl/taverne-license

Take down policy

If you believe that this document breaches copyright please contact us at:

repository@maastrichtuniversity.nl

providing details and we will investigate your claim.
}

Copyright and moral rights for the publications made accessible in the public portal are retained by the authors and/or other copyright owners and it is a condition of accessing publications that users recognise and abide by the legal requirements associated with these

- Users may download and print one copy of any publication from the public portal for the purpose of private study or research.

- You may not further distribute the material or use it for any profit-making activity or commercial gain

If the publication is distributed under the terms of Article 25fa of the Dutch Copyright Act, indicated by the "Taverne" license above, 


\section{ON THE PROCOAGULANT EFFECT OF FIBRIN}

A resonance loop between fibrin - von Willebrand factor platelets and thrombin 
On the procoagulant effect of fibrin: A resonance loop between fibrin - von Willebrand factor - platelets and thrombin

Rachana Kumar - Maestricht:

Thesis Maastricht - With ref. - With summary in Dutch

ISBN 90-9010707-X

NUGI 743

Druk/Print: Unigraphic, Maastricht

(c) Rachana Kumar 1997 


\section{ON THE PROCOAGULANT EFFECT OF FIBRIN}

\section{A resonance loop between fibrin - von Willebrand factor - platelets and thrombin}

\section{PROEFSCHRIFT}

ter verkrijging van de graad van doctor aan de

Universiteit Maastricht,

op gezag van de Rector Magnificus, Prof. Mr. M.J. Cohen,

volgens het besluit van het College van Decanen, in het openbaar te verdedigen op

donderdag 19 juni 1997 om 14.00 uur

door

Rachana Kumar 
Promotor : Prof. Dr. H.C. Hemker

Co-promotor : Dr. S. Béguin

Beoordelingscommissie:

Prof.dr. R.W. Stockbrigger (voorzitter)

Prof. B.S. Coller (Mount Sinai School of Medicine, New York, USA)

Dr. J. Heenskerk

Prof. U. Seligsohn (The Chaim Sheba Medical Center, Tel Hashomer, Israel)

Prof.dr. H.A.J. Struijker Boudier

Prof.dr. G.J. van der Vusse

Financial support by the Dr. Ir. J.H.J. van de Laar Foundation and the Netherlands Heart Foundation towards the publication of this thesis is gratefuily acknowledged. 


\section{कर्मण्येवाधिकारस्ते मा फलेषु कदाचन ।}

One should concentrate on performing one's duty well without bothering about the rewards; they follow.

(Sri Bhagavad Gita, Chapter 2, St.47)

For the memory of

my beloved mother 


\section{Contents}

Chapter 1: Introduction 1

Chapter 2: The Influence of Fibrinogen and Fibrin on Thrombin Generation - Evidence for Feedback Activation of the Clotting System by Clot Bound Thrombin

Chapter 3: The Effect of Fibrin Clots and Clot-bound Thrombin on the Development of Platelet Procoagulant Activity

Chapter 4: Inhibition of Platelet-mediated, Tissue Factor-induced Thrombin Generation by the Mouse/Human Chimeric TE3 Antibody: Potential Implications for the Effect of c7E3 Fab Treatment on Acute Thrombosis and "Clinical Restenosis"

Appendix: Effect of Antibodies against Platelet Membrane Glycoproteins on the Resonance Loop between Platelet Activation and Thrombin Generation in Platelet Rich Plasma

Chapter 5: Fibrin Induced Platelet Procoagulant Activity in Clotting Plasma - Role of GPIIb/llla and GPIb-IX

Receptors and von Willebrand Factor

Chapter 6: Summary and Conclusions

Curriculum Vitae 
The plasma proteins of the coagulation and related systems.

\begin{tabular}{|l|c|c|c|}
\hline Name & Abbreviation & Mol. Weight & Conc. (nM) \\
\hline Fibrinogen & & & \\
Prothrombin & I fibrin monomer & 340,000 & 7000 \\
Factor V & II Ila (thrombin) & 68,700 & 1500 \\
Factor VII & V Va & 330,000 & 30 \\
Factor VIII & VII VIla & 48,000 & 10 \\
Factor IX & VIII VIIla & 330,000 & 0.3 \\
Factor X & IX IXa & 55,400 & 80 \\
Factor XI & XXa & 59,000 & 160 \\
Factor XII & XI Xla & 160,000 & 30 \\
Prekallikrein & XII XIIa & 80,000 & 370 \\
High MW kininogen & PK & 86,000 & 500 \\
Factor XIII & HMWK & 120,000 & 700 \\
& XIII XIIla & 320,000 & 90 \\
Tissue factor pathway & TFPI & 40,000 & 2.5 \\
inhibitor & & & \\
Protein C & Prot.C -APC & 57,000 & 70 \\
Protein S & Prot.S & 75,000 & 300 \\
Protein Z & Prot.Z & 50,000 & 45 \\
von Willebrand factor & WWF & $1 * 106-$ & \\
Vitronectin & VN & $20 * 106$ & \\
Fibronectin & FN & 45,000 & 5000 \\
\hline
\end{tabular}

Source: based on Blomback et al 1994. 


\section{Chapter 1}

\section{Introduction}

Everyone knows about blood coagulation, at least in an elementary way, from seeing a scab form at the site of a wound. That scab is a fibrin mesh in which blood elements are incorporated and from which the plasma liquid has disappeared. It arises from the close interaction of the plasmatic coagulation system and blood platelets. Under physiological conditions, circulating platelets do not adhere to each other or to the vessel wall. However, on coming across a site of vascular injury (accidental or surgical) or a ruptured atherosclerotic plaque they are immediately activated, which leads to adhesion (sticking to the exposed subendothelium) and aggregation (sticking to each other). A haemostatic plug is thus formed which arrests haemorrhage. Activation of the platelet is an extremely complicated event, that at this moment has been only partly elucidated. Profound changes take place in the cell membrane as well as in the cell interior. We will not even attempt to discuss it in any detail here but only mention processes that are relevant for the studies to be presented hereafter. Upon activation the platelet changes its shape from a smooth disc to a spiny sphere with extended pseudopodia, then it interacts with other platelets to form aggregates. In the presence of a surface it sticks to that surface and spreads out. It also releases the contents of its dense granules (e.g. serotonin and ADP) and a granules (e.g. platelet derived growth factor, platelet factor 4, factor $\mathrm{V}$, fibrinogen, von Willebrand factor (WWF) and thrombospondin). In a final stage of the process the cell membrane becomes procoagulant and sheds procoagulant microvesicles. In the first moments of its existence a haemostatic plug is quite unstable. It can be quickly swept away, unless it is consolidated by a supporting fibrin network. The formation of fibrin requires the generation of thrombin by the plasmatic coagulation system. Apart from being the fibrin-forming enzyme, thrombin is known to be a platelet 
activator. It renders the platelet procoagulant and in this way enhances its own formation.

Traditionally, the platelet reactions are pooled under primary haemostasis while the coagulation reactions are viewed as secondary haemostasis. However, there are many interactions between the platelets and coagulation proteins that tend to blur this distinction. One is the fact, mentioned above, that thrombin evokes a procoagulant reaction in the plateletmembrane and that the platelets, thus activated, foster thrombin generation. Another is the dual roles played by the adhesive macromalecules: fibrinogen and WWF. Fibrinogen serves as adhesive platelet protein as well as thrombin substrate. WWF, acts as a carrier protein for factor VIII apart from being crucial for platelet adhesion to subendothelium.

This thesis deals with the effect of the fibrin clot on thrombin generation via its impact on the expression of platelet procoagulant activity. In this chapter, we first present a brief overview of coagulation system with a focus on the procoagulant activity of the platelets. A description of fibrinogen and von Willebrand factor mediating platelet - fibrin(ogen) interactions follows. Lastly, we introduce the work done in different chapters of this study.

It will be shown in this thesis that not only thrombin but also fibrin can render the platelet procoagulant. We think that this process is of a certain pathophysiological importance, because it may account for the well known tendency of a haemostatic plug to increase in size until the severed vessel is occluded, but also for a thrombus to grow, if not always to occlusion, at least to a size much larger than the first layer of platelets sticking to the bare subendothelium.

\subsection{The coagulation mechanism: an overview}

The coagulation process was originally conceived as a cascade i.e. a sequential series of proteolytic conversions of proenzymes into enzymes, each product of such an activation being the enzyme in the next reaction 
(Macfarlane 1964, Davie and Ratnoff 1964). When there is a damaged site in the vessel wall, tissue factor (TF), an integral membrane protein of cells beyond the endothelium, is exposed to the plasma proteins (see Davie et al. 1991 for a review). As one of these, factor VII (VII), comes in contact with tissue factor (TF) a complex of VII and TF is formed in the presence of $\mathrm{Ca}^{2+}$. This complex has a certain proteolytic activity towards factor $X$ (Fujikawa 1974, Nemerson 1983). Alternatively it may be conceived that very low concentrations of Vla always circulate and are responsible for the reaction to start. Small amounts of Xa thus generated, back activate VII into VIla (Radcliffe and Nemerson 1976). The Vlla-TF complex activates factor $X$ to $X a$. In addition, the VIla-TF complex has been shown to activate factor IX (Josso and Prou-Wartelle 1965, Østerud and Rapaport 1977). Factor IX can also activate $X$ to $X a$. The contribution of this reinforcement loop for $X a$ generation becomes more significant at low concentrations of TF.

Factor Xa has only minimal activity in the absence of activated cofactors and the low amount of procoagulant phospholipids that must be exposed by damaged cells, but it can convert some prothrombin into thrombin. The initial traces of thrombin thus generated produce feedback reactions: they convert the plasma factors, V and VIII into activated forms Va and VIIla (Newcomb and Hoshida 1965, Biggs et al.1965, Suzuki et al. 1982, Vehar and Davie 1980). In addition, thrombin activates platelets and makes them expose abundant procoagulant phospholipids and membrane binding sites (see Hemker 1994 for a review). Massive formation of prothombinase ( $\mathrm{Va}, \mathrm{Xa}, \mathrm{Ca}^{24}$, phospholipids) and tenase (VIIla, $\mathrm{IXa}, \mathrm{Ca}^{2+}$, phospholipids) is then possible and leads to burst of thrombin formation as described in the next section.

\section{Contact activation}

Certain negatively charged surfaces like glass, kaolin, ellagic acid etc. induce coagulation in plasma by the intrinsic pathway. The plasma proteins, Factor XII, Factor $\mathrm{XI}$, prekalikrein (PK) and high molecular weight kininogen

\footnotetext{
"The clotting factors will be designated by roman numerals, their activated forms by the numeral with a suffixed a. The abreviations for the inhibitory factors are as indicated in Table 'The plasma proteins of the coagulation and related systems'.
} 
(HMWK) are activated and interact in a series of reactions leading to formation of Xla (Griffin and Cochrane 1976 . Ratnoff and Saito 1979). Factor Xla then activates factor IX. At this point, the two pathways (extrinsic and intrinsic) merge. The physiological significance of contact pathway remains debatable but patients with factor $X I$ deficiency exhibit haemorrhagic symptoms, not necessarily because of the contact induced activation of factor $\mathrm{XI}$ but more probably because thrombin activates this factor, thus forming an additional reinforcement loop.

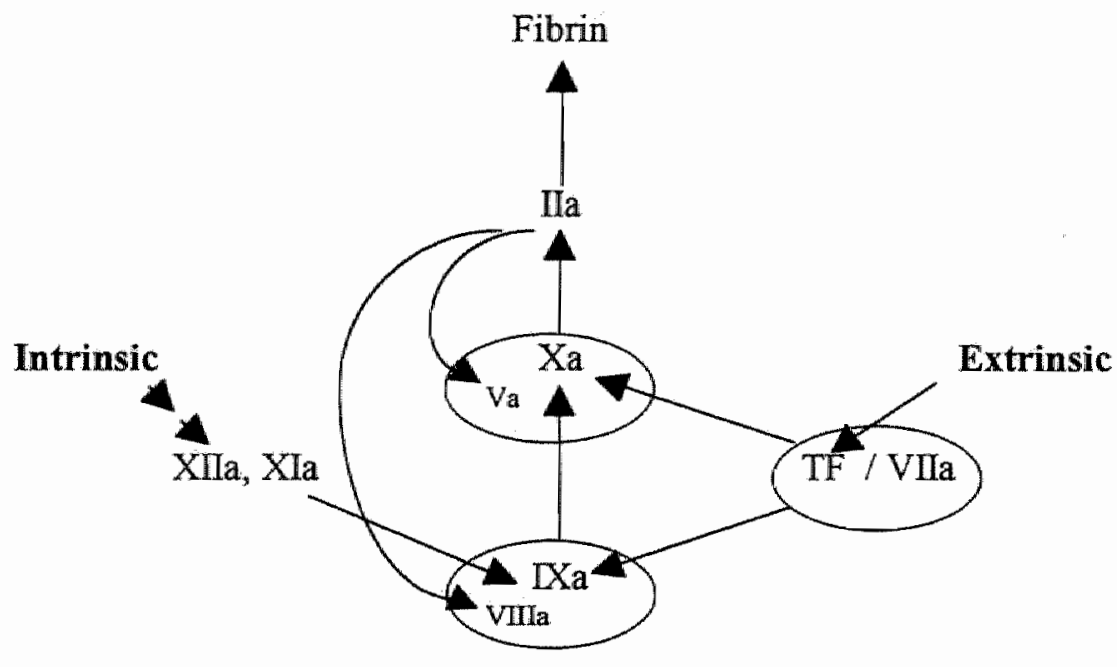

Fig.1 A representation of blood coagulation. The elliptical surface indicates the reactions occuring on a phospholipid surface in the presence of $\mathrm{Ca}^{2+}$.

\section{Control mechanisms}

If thrombin generation would not be damped, general thrombosis would result on the slightest trigger. A precarious balance between thrombin formation and inactivation keeps the process confined to the wound site. Thrombin e.g. inhibits its own formation. It can bind to thrombomodulin, a protein present on the surface of intact endothelium. On adsorption onto thrombomodulin, thrombin loses its procoagulant properties and activates protein C. Activated protein C (APC) together with its cofactor protein S leads 
to destruction of factor Va and Villa (Esmon 1983). Tenase and prothombinase are thus inactivated calling a halt to further thrombin formation.

Another regulation mechanism operates via factor $\mathrm{Xa}$ which combines with a plasma protein named tissue factor pathway inhibitor (TFPI) or extrinsic pathway inhibitor (Rao and Rappaport 1987). The complex inhibits TF-VIla complex as soon as sufficient $X a$ is present.

A number of antiproteases present in the plasma are also responsible for rapid inactivation of thrombin and factor $\mathrm{Xa}$. Antithrombin is the most important of these inhibitors (Travis and Salvesen 1983) contributing $64 \%$ of total antithrombin activity. $\alpha_{2}$-macroglobulin results in $23 \%$ and the remaining antiproteases chiefly $c_{1}$-antitrypsin are responsible for the remaining $13 \%$ of antithrombin activity (Béguin et al.1988).

\subsection{Procoagulant activity of platelets}

\section{Exposure of procoagulant phospholipids}

Platelets upon activation provide a procoagulant surface necessary for prothrombin and factor $X$ activation (Walsh 1978). These reactions need a surface that exposes negatively charged (anionic) phospholipids, chiefly phosphatidylserine. In non-activated platelets, phospholipids are asymmetrically distributed with negatively charged phaspholipids, in particular phosphatidylserine (PS) and phosphatidylethanolamine (PE), being almost entirely in the inner leaflet of the membrane (see Schroit and Zwaal 1991 for a review). The membrane phospholipid asymmetry is at least partially regulated by an ATP-dependent enzymatic activity called aminophospholipid translocase which selectively transports PS and PE from the outer to the inner leaflet of membrane bilayer (Seigneuret and Devaux 1984, Zachowski et al. 1989). Platelet activation by certain activators has been found to result in increased exposure of phosphatidy/serine at the outer surface, as a result of a transbilayer movement (flip-flop) of phospholipids (Bevers et al. 1982, 1991 , Zwaal et al. 1989); the combined action of thrombin and collagen appears to 
be the most potent physiological stimulus in this respect. This scrambling of phospholipids has been shown to result from membrane fusion events in response to increased intracellular $\mathrm{Ca}^{2+}$ levels and concurrent inhibition of aminophospholipid translocase (Zwaal et al. 1988, Willamson et al. 1992). Platelet activation also results in shedding of phospholipid rich microparticles that expose PS at the outside and that are procoagulant (Sandberg et al. 1982, Sims et al. 1989, Zwaal et al. 1992).

The role of the phospholipid surface; formation of the prothombinase and tenase complexes

Negatively charged phospholipid surfaces promote the assembly of the substrate, the enzyme and the cofactor in the two main activation reactions in coagulation. A complex of phospholipids, $\mathrm{Ca}^{2+}$, factor $\mathrm{Va}$ and factor $\mathrm{Xa}$ (prothombinase) was seen to be the active entity in thrombin formation (Papahadjopoulos \& Hanahan 1964, Hemker et al. 1967a). The activation of factor $X$ was shown to be brought about by a comparable complex consisting of phospholipids, $\mathrm{Ca}^{2+}$, factor VIIla and factor IXa (tenase) (Hemker \& Kahn 1967b).

The adsorbtion of the clotting factors takes place via $\mathrm{Ca}^{2+}$ mediated binding of $\gamma$ - carboxyglutamic residues of vitamin K-dependent coagulation factors (II, VII, IX,$X)$ to the polar head groups of the negatively charged phospholipid surface. The protein cofactors (V, VIII) bind to the phospholipid by mixed charge- and hydrophobic interaction.

The kinetic consequence of the binding of the substrates $(I I, X)$ to the same surface as the enzyme complex is a dramatic decrease of $\mathrm{Km}$ of the substrate to much below its plasma concentration (Rosing et al. 1980, Van Rijn et al. 1984, van Dieijen et al. 1981). A surface restricts the movement of prothrombin molecules to two dimensions so they have a greater probability of collision with prothombinase complex as compared to free prothrombin molecules. In small unilamellar vesicles the $\mathrm{Km}$ is higher then with a planar macroscopic phospholipid surface (Giesen et al. 1991). This is explained by the fact that the surrounding phospholipid surface acts like a funnel (Giesen et 
al. 1991): because the lateral diffusion of the prothrombin molecules to the complex is much more efficient than the three dimensional diffusion in solution so the larger the phospholipid surface around the enzyme is the higher the collision frequency with the substrate. In other words, the diffusion path of a prothrombin molecule in solution to the adsorbed enzyme complex is travelled the faster the more of the way can be on the phospholipid surface.

Interaction of the cofactors (factor Va and factor VIIla) with the enzyme (factor Xa and factor (Xa respectively) on the phospholipid surface manifest in an increase of $k_{\text {cat }}$ (turnover number). For factor $\mathrm{Va}$, the effect has been shown to result from an increase in one of the forward rate constants of prothrombin activation (Rosing et al.1980). Additionally, factor Va interacts with both factor $X a$ and prothrombin (Mann et al.1988, Lindhout et al.1982) and this mutual interaction results in a favorable alignment of active site of factor $\mathrm{Xa}$ with target sites of prothrombin.

The extremely high efficiency of the adsorbed prothrombinase complex makes that, with a macroscopic surface (i.e. a surface that is very large compared to the dimensions of the clotting factor molecules, such as the surface of a wound or thrombus covered with procoagulant platelets), the rate of thrombin generation easily becomes limited by the diffusion velocity of prothrombin to the surface (Billy et al. 1995)

Thrombin generation in platelet rich plasma

The main tool to be used in the experimental part of this thesis is thrombin generation in platelet rich plasma. A typical thrombin generation curve is shown in Fig. 2. It is characterised by a long lag-phase after which a burst of thrombin is seen that disappears due to the action of the natural antithrombins.

Béguin et al. (1989) have shown that under these experimental circumstances procoagulant phospholipids are the rate limiting factor for thrombin generation and not factors $V$ or VIII. The moment of the thrombin burst therefore is the moment at which the platelets massively expose their procoagulant surface. They also showed that addition of nanomolar quantities of thrombin enhance the appearance of the thrombin burst, while addition of 
similar concentrations of the specific thrombin inhibitor hirudin postpones it, indicating that thrombin is the trigger of platelet activity under these conditions.

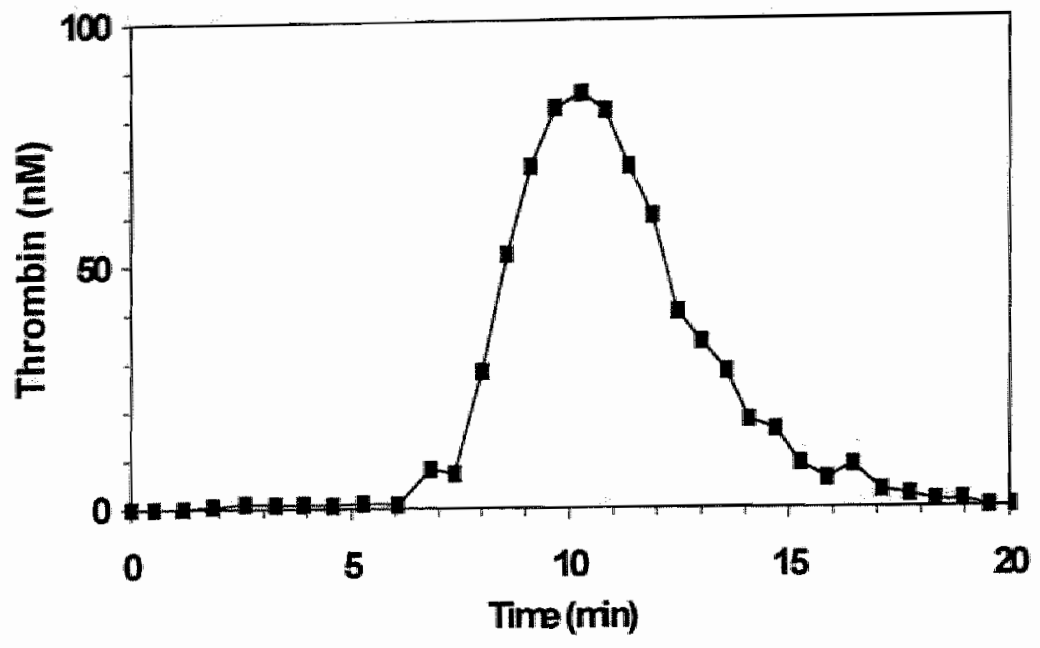

Fig. 2 Thrombin generation carried out in normal platelet rich plasma. Coagulation was triggered with $\mathrm{CaCl}_{2}(16.7 \mathrm{mM})$.

We depict the course of events as follows: Freshly prepared platelet rich plasma is to be regarded as platelet poor plasma in which unactivated, hence non procoagulant platelets are suspended. Traces of tissue factor from the venipuncture wound and some damaged cells (platelets or others) allow for minute traces ( $<1 \mathrm{nM}$ ) of thrombin to be generated in this situation. These traces act on the platelets, that, in this way, will become activated. Once platelet activation reaches a (low) threshold value, thrombin generation accelerates, the platelets are activated en masse and provide the phospholipid that allows explosive thrombin generation, up to about $100 \mathrm{nM}$.

In platelet rich plasma, the thrombin induced procoagulant effect is seen to be critically dependent upon traces of thrombin formed but not to be 
significantly altered by collagen addition (Béguin et al. 1989). This was the key observation to the research reparted here, because it suggested that in plasma the role of collagen might be played by another molecule and posed the question of what molecule this might be.

\subsection{Role of adhesive macromolecules: Fibrinogen and WWF}

\section{Fibrinagen}

Fibrinogen is a dimeric glycoprotein comprising of 6 polypeptide chains i.e. two each of $A \alpha, B \beta$ and $\gamma$ chains (Caspary and Kekwick 1957, Henschen 1964). The structure of fibrinogen is known in detail (Fig. 3, from Doolittle

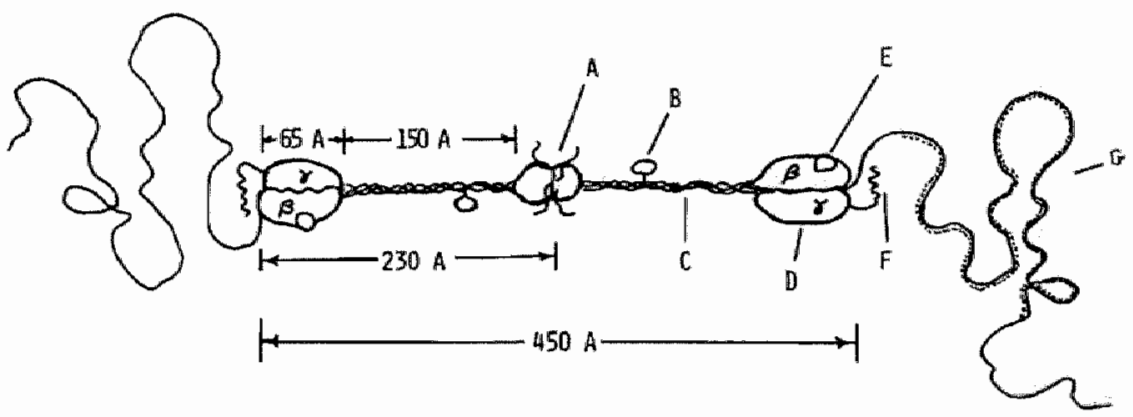

Fig. 3 Schematic representation of the human fibrinogen moleculle. A: Central domain including fibrinopeptides; B: Bound carbohydrate; C: "coilled coils" of the three chains; D: $y$ chain portion of terminal domain, principal polymerisation site; $E$ : Bound carbohydrate; $F$ : $\gamma$ chain cross linking site; $G$ : exposed part of $\alpha$ chain.

Source: Doolittle 1994.

1994). It is synthesized in the liver and in the megacarocyte and the blood concentration is $2-3 \mathrm{~g} / \mathrm{l}$ in plasma. Fibrinogen is also present in platelets and platelet fibrinogen ( $14 \mathrm{mg} / 10^{11}$ platelets) is indistinguishable from plasma fibrinogen (Doolittle et al. 1974). In a rare congenital disease, 
afibrinogenaemia there is am apparent lack of fibrinogen in blood (review: Al Mondhiry and Ehmann 1994), however hypofibrinogenaemia (low fibrinogen level) is a more common condition.

Interaction of fibrinogen with its platelel receptor: Role in platelet aggregation

The binding of fibrinogen to its platelet receptor is necessary for the adhesion of platelets to glass surfaces (Zucker and Vroman 1969) and platelet aggregation (Bennett and Vilarie 1979). Glycoprotein GPllb/llla complex on the platelet surface has been characterized as the fibrinogen receptor.

On unstimulated platelets, GPllb/llla complex has no ligand binding activity, Upon activation, GPllb/llla complex undergoes divalent-cation dependent conformational changes and expresses fibrinogen binding sites (Marguerie et al. 1979). The bound fibrinogen supports platelet aggregation by bridging adjacent platelets.

GPIIb/llla complex can also serve as a receptor for fibronectin, von Willebrand factor ( $V W F$ ) and vitronectin (Plow and Ginsberg 1981, Berlinger et al. 1988, Pytela et al. 1986, Thiagarajan and Kelly 1988). However, fibrinogen remains the chief ligand possibly because it is the most abundant. Each of these ligands have in common a tripeptide sequence $\mathrm{H}$-Arg-Gly-Asp-OH (RGD) that mediates their interaction with the GPIIb/lla (Ruoslahti and Pierschbacher 1987).

Congenital qualitative or quantitative defects in GPIIb/lila receptors (Caen et al. 1966, Karpatkin et al. 1984, Nurden 1988, George and Reimann 1982, George et al. 1990) lead to Glanzmann Thrombasthenia (GT), a bleeding disorder. The platelets of these patients fail to aggregate in response to physiologic stimuli (Nurden and Caen 1979). Another aspect of GT is a martked reduction in platelet fibrinogen levels $<10 \%$ of normal (Dejana et al. 1990, Coller at al. 1991a). A subdivision of GT patients is taken as type I, charactarised by the absence of clat retraction. Type II showing subnormal clot retraction (Caen 1972). Study of GT patients from Israel has led to further subcategorization (Coller et al.1991b). Patients from the Arab population were found to have a deficiency of GPIlb/llla receptors while having normal to 
increased number of $\alpha_{4} \beta_{3}$ vitronectin receptors. Patients from that of Iraqi-jew descent had a profound deficiency of $\alpha_{w} \beta_{3}$ receptors in addition to GPIIb/llla receptors.

\section{Generation of the fibrin clot}

In the presence of thrombin, fibrinogen is converted into insoluble fibrin network structure. This process involves three steps (Fig. 4):

1. By the proteolytic action of thrombin, fibrinogen is converted into the fibrin monomer with the release of fibrinopeptide A (FPA) and fibrinopeptide B (FPB) from the $\mathrm{NH}_{2}$ - terminal of $\mathrm{A \alpha}$ and $\mathrm{B} \beta$ chains respectively (Blomback 1978). Snake venoms (arvin, reptilase, agihal and others) only release FPA. The resulting monomer still polymerizes (Shainoff and Dardik 1979). The fibrinogen without FPA is known as Fibrin I or des AA fibrin, while that without FPA and FPB is designated Fibrin II or des AABB fibrin.

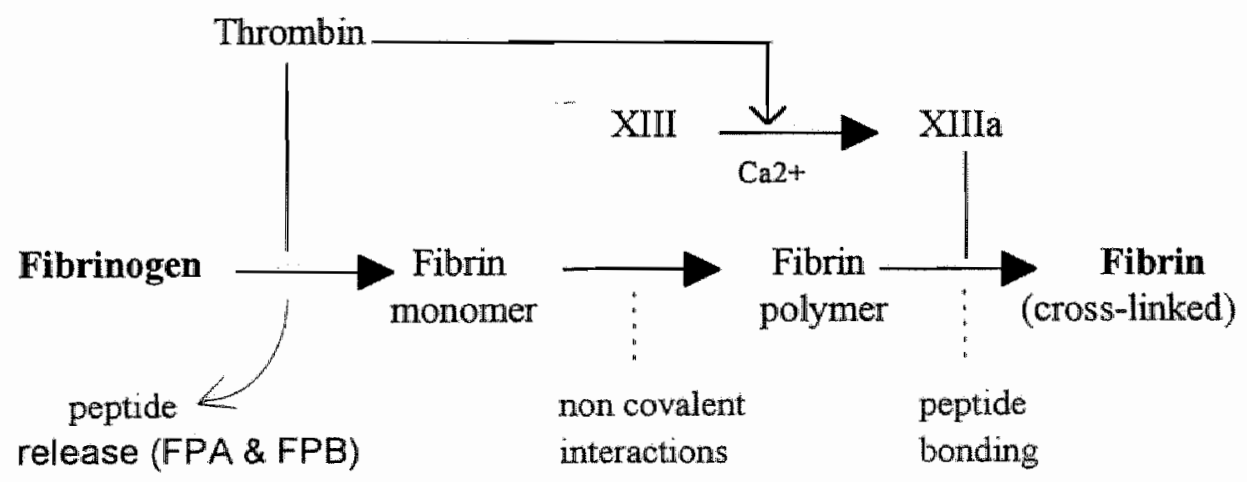

Fig.4 Conversion of fibrinagen to fibrin.

2. Fibrin monomers spontaneously polymerize by aggregation; intermediate polymers interact to form a three dimensional fibrin gel network.

3. Factor XIII is converted to active XIIla by thrombin. Factor Xllla then produces covalent cross links; by formation of $\gamma$-glutamyl lysine bridges within the fibrin mess. Absence of step 3 , as in clots prepared from purified fibrinogen 
and thrombin results in their lack of tensile strength and solubility in acid and urea.

\section{Binding of thrombin by the frorin clot}

Thrombin is known to get incorporated into the fibrin clot during its formation. Indeed this action of fibrin was first described as antithrombin I (Seegers 1962). Fibrin bound thrombin retains its enzymatic activity and has been shown to be relatively protected from inactivation by (heparin)antithrombin III (Liu et al. 1979, Hogg and Jackson 1989, Weitz et al. 1990).

\section{von Willebrand factor ( $W W F$ )}

The WWF is a polymeric plasma glycoprotein comprised of a series of large multimers. It is synthesized in megakarocytes and endothelial cells and is found in plasma, in the subendothelium and in platelet $\alpha$-granules (Wagner 1990). Congenital abnormalities show as von Willebrand disease (WWD) originally called "pseudohaemophilia", a hereditary bleeding disorder (Von Willebrand 1926, Ruggeri and Zimmerman 1987, Nishino et al. 1989, Mazurier et al. 1990).

VWF has two known haemostastic functions. In the first place it serves as a carrier protein for the antihaemophilic factor, factor VIII (Sakariassen et al. 1979, Sixma et al. 1984). Reduced levels of plasma WWF in von Willebrand disease lead to factor VIII deficiency even when the factor VIII synthesis of the body is normal.

Secondly, WWF is required for platelet adhesion to subendothelium at high shear rates ( $>800 \mathrm{sec}-1$ ) (Weiss et al. 1974,78, Caen et al. 1976, Meyer and Baumgartner 1983). WWF binds to elements of the interstitial matter of cell wall connective tissue (collagen) (Meyer and Girma 1993). This adsorption induces a conformational change by which it acquires the property to interact with the platelets via binding to glycoprotein lb receptors (Ruggeri 1983, Fujimoto 1982). In vitro, ristocetin induces the same conformational change and consequently binding of WWF to GPIb and thereby platelet agglutination. 
Patients with Bernard Soulier syndrome have platelets deficient in GPIb receptors and cannot bind WWF (Moake et al.1980).

WWF can also bind to GPllb-llla receptors (Ruggeri et al. 1983, Nokes et al. 1984, Girma et al. 1986). This binding has been shown to play a role in platelet aggregation and possibly serves as an alternative aggregation mechanism in afibrinogenaemia (De Marco et al. 1986).

\subsection{The present study}

In chapter 2 (Kumar et al. 1994), we have investigated the effect of the addition of a fibrin clot on thrombin generation in plasma. It is demonstrated that clots promote thrombin formation in platelet poor and platelet rich plasma via (i) activation of plasma cofactor proteins factor $V$, factor VIII and (ii) activation of blood platelets respectively. An intriguing observation was that fibrin clots without adsorbed thrombin (produced by action of non-thrombin fibrinogen cllotting enzyme) were able to exert an activating influence on platelets. It could be excluded that this activation was due to an action of the clotting enzyme used. Our results thus indicate a new role of fibrin i.e. that of inducing platelet procoagulant activity in platelets.

In chapter 3 (Kumar et al. 1995), various types of fibrin clots are tested for their ability to generate platelet procoagulant response. The activity of the clots produced by thrombin and non-thrombin enzymes has been differentiated. The underlying mechanism behind the observed action of the clots has been explored. With the purpose to directly demonstrate "flip-flop", the influence of the clots has been studied on generation of procoagulant activity in washed platelets. It could be shown, however, that washed platelets are an unsuitable experimental model for studying the fibrin effect, so that further studies were to be carried out with platelet rich plasma (PRP). Part of the action of fibrin on the platelets could be shown to be due to generation of procoagulant microparticles. 
In chapter 4 (Reverter et al. 1996), we have studied the effect of blocking platelet receptors (GPIlb/lla for fibrinogen, GPlba for WWF. GPla/la for collagen) on thrombin generation in the absence of fibrin clot. The effect was studied both in native platelet rich plasma and in reconstituted, fibrinogenfree plasma obtained by adding gel-filtered platelets to defibrinated plasma. Platelets from patients with Glanzmann Thrombasthenia (GT) have also been studied. The experiments presented show that interference with fibrinogen binding to GPIIb-IIla heterodimer results in inhibition of platelet mediated thrombin generation. Our results support an unconventional role of GPIlb/llla receptors i.e. promotion of the expression of platelet procoagulant activity. Inhibition of GPIb or GPla/lla was without effect.

In chapter 5 (Kumar et al.; submitted for publication), the effect of receptor blockade on the fibrin-effect has been studied. Platelet rich plasma has again been incubated with antibodies (7E3: anti-GPIlb/llla $+\alpha_{V} \beta_{3}, 6 \mathrm{D} 1$ : anti-GPIba, 6F1: anti-GPla/lla), now in the presence and absence of fibrin clots. Platelet procoagulant activity in serum and the consumption of the prothrombin have also been measured. The effect of fibrin addition on thrombin generation in Glanzmann Thrombasthenia patients (Iraqi-jewish and Arab type) and hypofibrinogenaemia patients has been evaluated. Our experiments lead to the identification of the receptor through which the action of fibrim on the platelets is mediated, i.e. GPIb. In the later part of this chapter, the possible role of von Willebrand factor in the fibrin-platelet receptor associated effect has been explored, using an antibody against VWF as well as plasma of patients with von Willebrand disease. Our results suggest two parallel mechanisms for the development of platelet procoagulant activity: a fibrin independent one that requires the presence of functional GPIlb/llla receptors, and a fibrin dependent one mediated through GPIb receptor. In both mechanisms, wWF seems to play a role.

Finally, chapter 6 summarises and concludes the thesis. 


\section{References}

Al-Mondhiry $H$, Ehmann CW. Congenital afibrinogenemia AM $J$ Hematol $46: 340$, 1994

Bennett JS, Vilarie G. Exposure of platelet fibrinogen receptors by ADP andepinepherine. J Clin Invest 64: 1393, 1979

Béguin $\mathrm{S}$, Lindhout $\mathrm{T}$. Hemker HC. The mode of action of heparin in plasma. Thromb Haemast 60: 457, 1988

Béguin $S$, Lindhout $T$, Hemker $H C$. The effect of trace amounts of tissue factor on thrombin generation in platelet rich plasma, its inhibition by heparin. Thromb Haemost 61: 25,1989

Berlinger S, Niiya $K$, Roberts JR, Hougten RA, Ruggeri ZM. Generation and chacterization of peptide-specific antibodies that inhibit von Willebrand factor binding to glycoprotein GPIlb-Illa without interacting with other adhesive molecules. J Biol Chem 263: 7500,1988

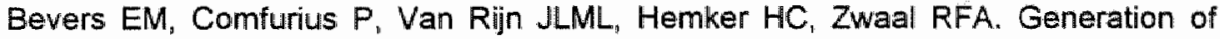
Prothrombin converting activity and the exposure of phosphatidylserine at the outer surface of platelets. Eur J Biochem 122: 429 , 1982

Bevers EM, Comfurius P, Zwaal RFA. Platelet procoagulant activity: physiological significance and mechanisms of exposure. Blood Review 5: 146 4991.

Biggs $R$, Macfarlane RG, Denson KWE, Ash BJ. Thrombin and the interaction of Factors VIII and IX. Brit J Haemat 11:276, 1965

Billy $D$, Speijer $H$, Willems GM, Hemker $H C$, Lindhout T. Prothrombin activation by prothrominase in a tubular flow reactor. J Biol Chem 270: 1029, 1995

Blomback B. Fibrinogen and fibrin formation. In: Handbuch der Experimentellen Pharmacologie Vol 46. Fibrinolytics and antifibrinolytics. F Markwardt (ed) pp 49*79. Springer Verlag, Berlin-Heideiberg 1978.

Blombäck M, Abildgaard U, van der Besselaar AMHP, Clementson KJ, Dahlback B, Exner $T$, Francis CW, Gaffney $P$, Gralnick $H_{*}$ Hoyer LW, Johnson GJ, Kasper $C$, Lane D, Lijnen HR, Lusher JM, Mannucci PM, Poller L, Rapaport SI, Saito H, Stocker $K$, Thomas D. Nomenclature of quantities and units in thrombosis and haemostasis (Recommendations 1993). Thromb Haemostas 71:375, 1994

Caen JP, Castaldi PA, Leclerc JC, Inceman S, Probst MJ, Bernard J. Congenital bleeding disorders with long bleeding time and normal platelet count. I. Glanzmann's thrombasthenia (report of fifteen patients). Am J Med 41:4, 1966

Caen JP. Glanzmann's thrombasthenia. Clinics in Haematology 1, 383, 1972

Caen JP, Niurden AT, Jeanneau C, Michel H, Tobelem G, Levy-Toledano S, Sultan $Y$, Valensi $F$, Bernard J. Bernard-Soulier syndrome: a new platelet glycoprotein abnormality. Its relationship with platelet adhesion to subendothelium and with the factor VIII/ von Willebrand protein. J Lab Clin Med 87: 586, 1976 
Caspary EA, Kekwick RA. Some phsicochemical properties of human fibrinogen. Biochem J 67: 41, 1957

Coller BS, Seligshon U, West SM, Scudder LE, Norton KJ. Platelet fibrinogen and vitronectin in Glanzmann thrombasthenia: Evidence consistent with specific roles for glycoprotein $\mathrm{Ilb} / \mathrm{Illa}$ and $\alpha_{4} \beta_{3}$ integrins in platelet protein trafficking. Blood $78: 2603$, 1991

Coller BS, Cheresh DA, Asch E, Seligsohn U. Platelet vitronectin receptor expression differentiates Iraqi-Jewish from Arab patients with Glanzmann thrombasthenia in Israel. Blood 77: 75, 1991

Davie EW, Ratnoff OD. Waterfall sequence for intrinsic blood coagulation. Science 145: 1310,1964

Davie EW, Fujikawa $K$, Kisiel W. The coagulation cascade: initiation, maintenance and regulation. Biochemistry 30: 10363 1991

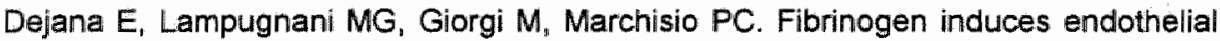
cell adhesion and spreading via the release of endogenous matrix proteins and the recruitment of more than one integrin receptor. Blood 75: 1509, 1990

De Marco L, Girolam A, Zimmerman TS, Ruggeri ZM. Von Willebrand factor interaction with glycoprotein Ilb-1lla complex. Its role in platelet function demonstrated in patients with congenital afibrinogenemia. $J$ Clin Invest $77: 1272,1986$

Doolittle RF, Takagi T, Cottrell BA. Platelet and plasma fibrinogens are identical gene products. Science 185: 368,1974

Doolittle RF. Fibrinogen and fibrin. In: Haemastasis and thrombosis, $A L$ Bloom, $C D$ Forbes, DP Thomas and EGD Tuddenham edts. Churchill Livingstone, Edinburgh etc. pp 491, 1994

Esmon CT. Protein C: Biochemistry, physiology and clinical implications. Blood 62: 1155,1983

Fujikawa K, Coan MH, Legaz ME, Davie EW. The mechanism of activation of bovine factor $X$ (Stuart factor) by intrinsic and extrinsic pathways. Blochemistry 13: 5290 , 1974

George JN, Reimann TA. Inherited disorders of the platelet membrane: Glanzmann thrombasthenifa and Bernard Soulier disease in RW Colman V, Marder J, Salzman EW, Hirsh $J$ (eds) : Thrombosis and Haemostasis, Basic Principles and Clinical Practice. Philadelphia, PA, Lippincott; pp 496, 1982

Gerorge JN, Caen JP. Nurden AT. Glanzmann's thrombasthenia : The spectrum of clinical disease. Blood 75: 1383, 1990

Giesen PLA, Willems GM, Hermens $W$ Th. Production of thrombin by the prothombinase complex is regulated by membrane-mediated transport of prothrombin. J Biol Chem 266: 1379, 1991 
Girma JP, Kalafatis $M_{n}$ Pietu G, Laergne JM, Chopek MW, Edgington TS, Meyer D. Mapping of distinct von Willebrand factor domains interacting with platelet GPIb and GPIIb/lla and with collagen using monoclonal antibodies. Blood 67: 1356, 1986

Griffin $\mathrm{JH}_{\mathrm{B}}$ Cochrane CG. Mechanism for invovement of high molecular weight kininogen in surface-dependent reactions of Hageman factor (coagulation factor XII). Proc Natl Acad Sci USA. 73: 2554, 1976

Hemker HC. Esnouf MP, Hemker PW, Swart ACW, MacFarlane RG. Formation of prothrombin converting activity. Nature 215: 248, 1967

Hemker HC, Kahn MJP. Reaction sequence of blood coagulation. Nature 215: 1201, 1967

Hemker HC.Thrombin generation, an essential step in haemostasis and thrombosis. In: Haemostasis and thrombosis, AL Bloom, CD Forbes, DP Thomas and EGD Tuddenham eds. Churchill Livingstone, Edinburgh etc. pp 477, 1994

Henschen A. Paper electrophoretic patterns and mobilities of unmodified, sulfitolyzed and reduced and alkylated fibrinogen and fibrin in buffered $6 \mathrm{M}$ urea. Arkiv Kemi 22: 397,1964

Hogg PJ. Jackson CM. Fibrin monomer protects thrombin from inactivation by heparin-antithrombin 1Il: implications for heparin efficacy. Proc Natl Acad Sci USA 86: 3619,1989

Josso $F$, Prou-Wartelle $O$. Interaction of Tissue factor and Factor $V I I l$ at the earliest phase of coagulation. Thomb Diath Haemorr Suppl 17: 35, 1965

Karpatkin $M_{3}$ Howard $L$, Karpatkin $S$. Studies of the origin of platelet-associated fibrinogen. J Lab Clin Med 104: 223, 1984

Kumar $R$, Béguin $S$, Hemker HC. The influence of fibrinogen and fibrin on thrombin generation-evidence for feedback activation of the clotting system by clot bound thrombin. Thromb Haemost $72: 713,1994$

Kumar R, Béguin S, Hemker HC. The effect of fibrin clots and clot bound thrombin on the development of platelet procoagulant activity. Thromb Haemost 74: 962, 1995

Liu CY, Nossel HL, Kaplan KL. The binding of thrombin by fibrin. J Biol Chem 254: 10421,1979

Lindhout T, Govers-Riemslag JWP, van de Waart P, Hemker HC, Rosing J. Factor Va-Factor Xa interaction. Effects of phospholipid vesicles of varying composition. Biochemistry 21: 5494,1982

Macfarlane RG. An enzyme cascade in the blood clotting mechanism and its function as a biochemical amplifier. Nature 202: 498,1964

Mann KG, Jenny RJ, Krishnaswamy $\mathrm{S}$. Cofactor proteins in the assembly and expression of blood clotting enzyme complexes. Annu Rev Biochem 57: 915, 1988 
Marguerie GA, Plow EF, Edington TS. Human platelets posses an inducible and saturable receptor specific for fibrinogen. J Biol Chem $254: 5357,1979$

Mazurier $C$, Dievall J, Jorieux $S$, Delobel $J$, Goudemand $M$. A new von Willebrand factor ( $(W W F)$ defect in a patient with factor VIII (FVIII) deficiency but with normal levels and multimeric patterns of both plasma and platelet WWf. Characterization of abnormal WWF/FV/II interaction. Blood 75: 20, 1990

Meyer D, Baumgartner HR. Role of von Willebrand factor in platelet adhesion to the subendothellum. Br.J Haematol 54: 1, 1983

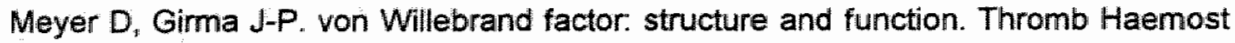
70: $99,1993$.

Moake $\mathrm{J} L$, Olson JD, Troll $\mathrm{JH}_{\mathrm{H}}$ Tang SS, Funicella T, Peterson DM. Bindling of radiolodinated human von Willebrand factor to Bernard-Soulier, thrombasthenic and von Willebrand's disease platelets. Thromb Res 19:21, 1980

Nemerson Y. Regulation of the initiation of coagulation by factor VII. Haemostasis 13: 150,1983

Newcomb TF, Hoshida M. Factor $V$ and thrombin. Scad $\downarrow$ Clin Lab Invest. 17 suppl 84: 61,1965

Nishino $M$, Girma JP, Rothschild $C$, Fressinaud $E$. Meyer $D$. New variant of von Willebrand disease with defective binding to factor VIII. Blood 74: 1591, 1989

Nokes TC, Mahmoud NA, Savidge GF, Goodall AH, Meyer D, Edgington TS, Hardisty RM. Von Willebrand factor has more than one binding site for platelets. Thromb Res 34: 361,1984

Nurden AT, Caen JP. Different glycoprotein abnormalities in thrombasthenia and Bernard-Soulier platelets. Semin Hematol 16: 234, 1979

Nurden AT. Congential abnormalities of platelet membrane glycoproteins, in Kunicki $T J_{a}$ George JN (eds): Platelet Immunobiology: Molecular and Clinical Aspects. Philadelphia, PA, Lippincott, p 63, 1988

Bsterud B, Rapaport SI. Activation of factor IX by the reaction product of tissue factor and factor VII: Additional pathway for initiating blood coagulation. Proc Natl Acad Sci USA $74: 5260,1977$

Papahadjopoulos D, Hahahan D.J. Observations on the interaction of phospholipids and certain clotting factors in prothrombin activator formation. Biochim Biophys Acta 90: 436,1964

Peerschke El, Zucker MB, Grant RA, Egan JJ, Johnson MM. Correlation between fibrinogen binding to human platelets and platelet aggregability. Blood 55: 841, 1980

Plow EF, Ginsberg MH. Specific and saturable binding of plasma fibronectin to thrombin-stimulated human platelets. J Biol Chem 256: 9477,1981 
Pytela $R_{8}$ Pierschbacher MD, Ginsberg MH, Plow EF, Ruoslahti E. Platelet membrane glycoprotein Ilb/llla: Member of a family of Arg-Gly-Asp-specific adhesion receptors. Science 231: 1559, 1986

Radcliffe $R$, Nemerson $Y$. Mechanism of activation of bovine factor VIl. Products of cleavage by factor Xa. J Biol Chem $251: 479,1976$

Ratnoff $O D$, Saito $H$. Interactions between Hageman factor, plasma prekallikrein, high molecular weight kininogen, and plasma thmboplastin antecedent. Proc Natl Acad Sci USA 76: 958, 1979

Rao LVM, Rapaport SI. Studies of a mechanism inhibiting the initiation of the extrisic pathway of coagulation. Blood 69: 645,1987

Reverter JC, Béguin $S$, Kessels $H_{1}$ Kumar $R$, Hemker $H C$, Coller BS. Inhibition of platelet-mediated, tissue factor-induced thrombin generation by the mouse/human chimeric 7E3 antibody. J Clin Invest 98: 863, 1996

Rosing J. Tans G, Govers -Riemslag JWP, Zwaall RFA, Hemker HC. The role of phospholipids and factor $\mathrm{Va}$ in the prothombinase complex. I Biol Chem 255: 274,1980

Ruggeri ZM, De Marco L, Gatti L, Bader R, Montgomeny RR. Platelets have more than one binding site for von Willebrand factor. J Clin Invest 72: 1, 1983

Ruggeri ZM, Zimmerman TS. Von Willebrand factor and von Willebrand disease. Blood 70: 895,1989

Ruoslahti $E$, Pierschbacher MD. New perpectives in cell adhesion: RGD and integrins. Science 238: 491,1987

Sandberg $H$, Anderson L, Höglund $S$. Isolation and characterization of lipid-protein particles containing platelet factor 3 released from thuman platelets. Biochem $\mathrm{J} 203$ : 303, 1982

Sakariassen $\mathrm{KS}$, Bolhuis $\mathrm{PA}_{\text {in }}$ Sixma JJ. Human blood platelet adhesion to artery subendothelium is mediated by factor VIII-von Willebrand factor bound to the subendothelium. Nature 279: 635, 1979

Schroit AJ, Zwaal RFA. Transbilayer movement of phospholipids in red cell and platelet membranes. Biochim Biophys Acta 1071: 313, 1991

Seegers WH. Prothrombin Massachusetts: Harvard University Press pp286, 1962.

Seigneuret M, Devaux PF. ATP-dependent asymmteric distribution of spin-labeled phospholipids in the erythrocyte membrane: relation to shape changes. Proc Natl Acad Sci USA 81: $3751,1984$.

Shainoff JR and Dardick BN. Fibrinopeptide B and aggregation of fibrinogen. Science $204: 200,1979$ 
Sims PJ, Miedmer $T$, Esmon CT, Weiss HJ. Shattil SJ. Assembily of the platelet prothombinase complex is linked to vesiculation of the platelet plasma membrane. $J$ Biol Chem 264: 17049, 1989

Sixma JJ, Sakariassen KS, Stel HV, Houdijk WPM, In der Maur DW, hamer RJ, de Groot $P G$, van Mourik JA. Functional domains on von Willebrand factor. Recognition of discrete trypic fragments by monoclonal antibodies that inhibit interaction of yon Willebrand factor with platelets and with collagen. J Clin Invest $74: 736,1984$

Suzuki $K$, Dahback $B$, Stenflo J. Thrombin catalyzed activation of human coagulation Factor V. J Biol Chem 257: 6556, 1982

Thiagarajan $P_{*}$ Kelly $\mathrm{KL}$. Exposure of binding sites for vitronectin on platelets following stimulation. J Biol Chem 263: 3035,1988

Travis J, Salvesen GS. Human plasma protease inhibitors. Annu Rev Biochem 52 : 655,1983

Van Rijn JLML, Govers-Riemslag JWP, Zwaal RFA, Rosing J. Kinetic studies of prothrombin activation: Effect of factor $V a$, phospholipids on the formation of the enzyme-substrate complex. Biochemistry 23: 4557, 1984

Van Dieijen $G$, Tans $G$, Rosing J, Hemker HC. The role of phospholipid and factor Villa in the activation of bovine factor $X . J$ Biol Chem $256: 3433,1981$

Von Willebrand EA. Hereditar pseudohemofili. Finska Lakeresällskapets Handlingar 67: 7, 1926

Vehar GA, Davie EW. Preparation and properties of bovine factor VIII (antihaemophilic factor). Blochemistry 19: 401, 1980

Wagner DD. Cell biology of von Willebrand factor. Annu Rev Cell Biol 6:217, 1990

Walsh PN. Different requirements for intrinsic factor $X a$ forming activity and platelet factor 3 activity and their relationship to platelet aggregation and secretion. $\mathrm{Br} J$ Haematol 40: 311,1978

Weitz Jl. Hudoba M, Massel D, Maraganore J, Hirsh J. Ciot-bound thrombin is protected from inhibition by heparin-antithrombin 111 but is susceptible to inactivation by antithrombin III-independent inhibitors. J Clin Invest $86: 385,1990$

Weiss HJ, Tschopp TB, Baumgartner HR, Sussman II, Johnson MM, Egan JJ. Decreased adhesion of giant (Bernard-Soulier) platelets to subendothelium. Further implications on the role of the von Willebrand factor in haemostasis. Am J Med 57: 920,1974

Weiss $H J$, Turritto $V T$, Baumgartner HR. Effect of shear rate on platelet interaction with subendothelium in citrated and native blood. Shear rate dependent decrease of adhesion in von Willebrand's disease and the Bemard-Soulier syndrome. J Lab Clin Med 92: 750,1978 
Willamson $P$, Kulick $A$, Zachowski $A$, Schlegel RA, Devaux PF. $C^{2 *}$ induces transilayer redistribution of all major phospholipids in human erythrocytes. Biochemistry 31: 6355, 1992.

Zachowski A, Henry JP, Schlegel RA, Williamson P. A novel subfamily of P-type ATPases with aminophospholipid transporting activity. Nature 340:75, 1989.

Zucker MB, Vroman L. Platelet adhesion induced by fibrinogen adsorbed onto glass. Proc Soc Exp Biol Med 131: 318, 1969

Zwaal RFA. Scrambling membrane phaspholipids and local control of blood clotting. NIPS 3: 57, 1988.

Zwaal RFA, Bevers EM, Comfurius P, Rosing J, Tilly RHJ, Verhallen PFJ. Loss of membrane phospholipid asymmetry during activation of blood platelets and sickled red cells: Mechanisms and physiological significance. Mol Cell Biochem 91: 23, 1989

Zwaal RFA, Comfurius P, Bevers EM. Platelet procoagulant activity and microvesicle formation. Its putative role in hemostasis and thrombosis. Biochim Biophys Acta 1180: 1, 1992 


\section{Chapter 2}

\section{The Influence of Fibrinogen and Fibrin on Thrombin Generation - Evidence for Feedback Activation of the Clotting System by Clot Bound Thrombin*}

\section{Summary}

In plasma the bulk of thrombin generation takes place after a clot has formed. We therefore investigated in what way the clot influences thrombin generation in plasma. The forming clot withdraws thrombin from free solution. Consequently less thrombin activity is found and less thrombin-inhibitor complexes are formed. The thrombin that is adsorbed to the clot reduces the lag time before thrombin generation in intrinsically or extrinsically triggered platelet poor plasma as well as in platelet rich plasma. We investigated the mechanism of this activation.

Clots were obtained by recalcification of plasma or by the addition of thrombin-like enzymes (Reptilase, Agihal) from snake venoms. They were thoroughly washed until the washing fluid was devoid of any detectable clotting enzyme activity. In platelet poor plasma (PPP), thrombin-induced clots shorten the factor Va-dependent lag-time of thrombin generation in the extrinsic system as well as the factor VIlla-dependent thrombin generation in the intrinsic system. Factor $V$ or factor VIII preparations that in itself hardly influence thrombin generation patterns acquire the capacity to shorten these lag-times when incubated with clot. The last washing fluid of the clot is inactive. Snake venom induced clots are not active either. Clots that are incubated in heparinised plasma for $1 \mathrm{~h}$ or more are as active as clots from normal plasma are. A role of factor Xa can not be excluded but must be minor because a clot

\footnotetext{
"Based on Kumar R, Béguin S. and Hemker H.C. Thromb Haemost 1994; 72(5):713-21.
} 
madie by addition of thrombin to plasma from which the factors $I I, V I I, I X$ and $X$ have been removed is as active as a clot from normal plasma is.

When added to recalcified platelet rich plasma (PRP), in which the lagtime of thrombin formation is dependent upon activation of platelet procoagulant phospholipid activity, any type of clot shortens the lag-time before the burst of thrombin generation. Clots that are obtained by snake venom enzymes are also active in this system. This indicates that fibrin alone is capable to induce the procoagulant phospholipid activity in platelets.

We conclude that three known thrombin-dependent feedback activations in the clotting system (factor V, factor VIII and platelets) are efficientiy supported by thrombin bound to the fibrin clot and that there is an additional effect of fibrin on the procoagulant action of platelets.

\section{Introduction}

The clotting of fibrinogen by thrombin is caused by the enzymatic removal of fibrinopeptides $A$ and $B(1)$. In this process thrombin is adsorbed on the fibrin (2-6). This property of fibrin is known as Antithrombin I action (7). The clot bound thrombin remains enzymatically active, as has been shown by its ability to release FPA from fibinogen (8-10), to clot fibrinogen, to induce the platelet release reaction (10) and to hydrolyse chromogenic substratte $\$ 2238$ (9). It also has been reported that a washed clot will shorten the coagulation time of blood and plasma $(10,11)$. It is the purpose of this article to investigate the mechanism(s) by which clot bound thrombin influences thrombin generation in plasma.

The inhibition characteristics of clot bound thrombin are reportedlly different from those of free thrombin in that it seems protected from inactivation by antithrombin III (AT III) even in the presence of heparin (5) but remains accessible to antithrombin Ili-independent inhibitors like hirudin, hirudin dodecapeptide (Hirugen), D-Phe-Pro-Arg-Chloromethyl ketone (PPACK) (8) and Dermatan Sulphate (12). 
The most ready explanation for clot induced coagulation of plasma is that bound thrombin clats fibrinagen from the free solution. Another possible mechanism is that an existing clot induces thrombin generation in the surrunding plasma. Indeed the shortening of whole blood clotting time (WBCT) has been reported when clots were incubated in native blood $(12,13)$. Positive feedback activation, i.e. enhancement of the rate of thrombin production by the first traces of thrombin formed, is an essential part of the clotting process (14). With the initial sequential activation of clotting factors only trace amounts of thrombin are generated (15). These traces of thrombin have the ability to activate factor $V$, factor VIII $(15-20)$ and platelets $(21,22)$. The activated cofactors $V$ and VIII increase the catalytic capacity of their partner-enzymes (factor $\mathrm{Xa}$ and $\mathrm{X} \mathrm{X}$ ) by several orders of magnitude $(23,24)$. Thrombin action on platelets fosters thrombin formation by exposing procoagulant phospholipids (22) and releasing factor $V$ (25 and references therein). Presumably also the interstices of a platelet aggregate provide a niche in which the products of clotting factor interaction are not diluted by flow phenomena. This ensemble of positive feedback actions of thrombin on cofactors and platelets leads to explosive, nonlinear thrombin generation (26).

The possible positive feedback-function of clot-bound thrombin has not been analyzed until now. In this article we investigate whether clot bound thrombin enhances further thrombin formation by sustaining the activation of factors $V$ and $V I I I$ as well as platelets. To this purpose we compare the influence on thrombin generation of clots produced by thrombin and nonthrombin enzymes. A preliminary report of this work has been presented in 1993, at the 14th ISTH congress (27).

\section{Materials and Methods}

\section{Materials}

Plasma

Normal plasma was prepared by collecting blood from healthy donors on trisodium citrate $(9: 1)$. Platelet rich plasma (PRP) was obtained by single 
centrifugation at $250 \times \mathrm{g}, 15^{\circ} \mathrm{C}, 10 \mathrm{~min}$, while platelet poor plasma (PPP) was obtained by a double centrifugation at $1000 \times \mathrm{g}, 15^{\circ} \mathrm{C}, 15 \mathrm{~min}$ and a third centrifugation at $23,000 \times \mathrm{g}, 4^{\circ} \mathrm{C}, 1$ hour. PPP thus obtained was stored at $-80^{\circ} \mathrm{C}$

Factor VIII deficient plasma was obtained in the same way from a known severe haemophilia A patient who had not received substitution therapy for several weeks.

Depleted plasma is plasma depleted of the vitamin K-dependent coagulation factors by mixing it with $1 / 5$ volume of $\mathrm{Al}(\mathrm{OH})_{3}(25 \%$ in $0.15 \mathrm{M}$ $\mathrm{NaCl}$ ) and incubating at $37^{\circ} \mathrm{C}$ for $5 \mathrm{~min}$, with constant stirring. After centrifuging at high speed in an Eppendorf centrifuge for 2 min the supernatant plasma was recovered. It was checked that no detectable amounts of the factors II, VII, IX and $X$ remained. The factor $V$ concentration was $60 \%$ and the factor VIII concentration $65 \%$ of the original pooled plasma.

Defibrinated plasma is plasma that was defibrinated by mixing with $1 / 50$ volume of Reptilase, letting the clot form at $37^{\circ} \mathrm{C}$ for $10 \mathrm{~min}$ and keeping the clotted plasma for additional $10 \mathrm{~min}$ at $0-4^{\circ} \mathrm{C}$. Fibrin thus formed was discarded by winding on a plastic spatula. For further details see ref. 28

Reagents

Buffer A: $50 \mathrm{mM}$ Tris $\mathrm{HCl}, 100 \mathrm{mM} \mathrm{NaCl}, 0.5 \mathrm{~g} / \mathrm{l}$ Bovine Serum Albumin (BSA; Lot: A-7030, Sigma), $\mathrm{pH}=7.35$. Buffer $B$ : same as Buffer $A$ with $20 \mathrm{mM}$ EDTA, pH = 7.9. Buffer C: $50 \mathrm{mM}$ Tris $\mathrm{HCl}, 175 \mathrm{mM} \mathrm{NaCl}, 0.5 \mathrm{~g} / \mathrm{l} \mathrm{BSA}, \mathrm{pH}=$ 7.9. The phospholipids vesicles were 20 mole $\%$ phosphatidyl serine (PS) and $80 \mathrm{~mole} \%$ phosphatidyl choline and were prepared as previously described (23). Chromogenic substrate used for thrombin was S2238: H-D-Phe-Pip-ArgPNA.2HCl. Reptilase was supplied by Laboratories Stago (Asnières, France) and Recombinant Tissue Factor by Baxter-Dade (Duidingen, Switzerland). The 4 th International standard heparin (ISH) was obtained from the National Bureau of Standards and Control (London). Recombinant Hirudin (Knoll AG) was a kind gift of Dr. W. Hornberger. Agihal, a purified fraction of Agkistrodon Halys Halys snake venom, that splits fibrinopeptide A from fibrinogen and does 
not activate factors $\mathrm{V}$, VIII or platelets, was obtained from Prof. L. Yukelson (Tashkent, Uzbekistan). Bovine purified factors $V_{\mathrm{b}}$ VIII, $\mathrm{X}$ were kindly provided by Dr. R. Wagenwoord.

\section{Methods}

\section{Preparation of Clots}

Three different types of clot were produced by: recalcification of normal plasma adding $100 \mathrm{nM}$ of thrombin to depleted plasma and adding Reptilase or Agihal to normal plasma.

Normal plasma clots: Platelet poor plasma $(250 \mu$ for one clot) was coagulated by recalcification to a final concentration of $\left.23 \mathrm{mM} \mathrm{CaCl}\right|_{2}$, in a glass tube by adding $12 \mu \mathrm{l}$ of $0.5 \mathrm{M} \mathrm{CaCl}_{2}$ solution and incubation at $37^{\circ} \mathrm{C}$ for $1 / 2 \mathrm{~h}$. The clot was wound on a plastic spatula, dried by blotting and put in human serum for $10 \mathrm{~min}$. In certain experiments heparin was added to this serum to a final concentration of $0.1 \mathrm{U} / \mathrm{ml}$. Subsequently, the clot was washed at least 4 times in $2 \mathrm{ml}$ aliquots of Buffer A over the course of several hours to eliminate any soluble material trapped in the clots. That no unbound thrombin remained with the clot was checked by the absence of detectable amidolytic activity of the last washing buffer on $\mathbf{S} 2238$. This means that less than 0.2 picomole of thrombin could have leaked from a clot into the surrounding fluid during $30 \mathrm{~min}$. The last washing fluid was also tested for its effect in thrombin generation curves.

Thrombin clots in depleted plasma were prepared by adding $10 \mu \mathrm{l}$ of human a-thrombin $(2.5 \mu \mathrm{M})$ to $250 \mu \mathrm{l}$ of plasma depleted of the vitamin $\mathrm{K}$ dependent clotting factors by $\mathrm{Al}(\mathrm{OH})_{3}$ adsorption at the same time as $12 \mu \mathrm{l}$ of $0.5 \mathrm{M} \mathrm{CaCl}_{2}$.

Snake venom clots were prepared from the same volume of plasma by adding $1 / 50$ volume of Reptilase or Agihal. The defibrinated plasma remaining after coagulation by the snake venoms was tested for the activity of the clotting factors and compared to the original plasma. No activation of clotting factors was found. 


\section{Prolongation of Clotting Time by Recombinant Hirudin}

In $120 \mu$ of plasma at $37^{\circ} \mathrm{C}$ supplied with PS/PC ( $1.1 \mu$ linal conc.) and varying concentration of hirudin $(0.05 \mu \mathrm{M}-0.2 \mu \mathrm{M})$ coagulation was triggered with recombinant tissue factor (final dilution $1 / 240$ ) in $100 \mathrm{mM} \mathrm{CaCl}$ and clotting times were recorded. The final concentration of $0.15 \mu \mathrm{M}$ hirudin, extending the clotting time from $31 \mathrm{~s}$ (in absence of hirudin) to 2 min $45 \mathrm{~s}$, was used in our experiments.

\section{Measurement of Thrombin Generation in Plasma}

Thrombin generation curves were obtained as described in detail in references 28-30. In short, to $240 \mu$ of normal or defibrinated plasma was added $40 \mu$ of Buffer $A$ (which may contain any other required substance, e. $g$. hirudin) and $20 \mu \mathrm{IPS} / \mathrm{PC}(20 \mu \mathrm{M})$. The mixture was incubated at $37^{\circ} \mathrm{C}$ for 5 min and coagulation was triggered with $60 \mu \mathrm{l}$ of triggering solution. Triggering solution A (extrinsic pathway) is recombinant tissue factor (final dilution 1/240) in $100 \mathrm{mM} \mathrm{CaCl}_{2}$ (16.7 $\mathrm{mM}$ final conc.). Under our conditions this dilution of thromboplastin yields a clotting time of around $31 \mathrm{~s}$ in non-defibrinated plasma in the absence of hirudin. This trigger is used to study factor $V$ activation. Hirudin ( $150 \mathrm{nM}$ final concentration) has to be present, as will be discussed in the experimental section. The activation of factor VIII was studied using trigger $\mathrm{B}$ (intrinsic pathway), consisting of factor $\mathrm{XXa}(12 \mathrm{nM})$, and PS/PC $(12 \mu \mathrm{M})$ and $\mathrm{Ca}^{2+}(1.5 \mathrm{mM})$. Of this trigger $38 \mu \mathrm{l}$ was taken in the same pipette as $22 \mu \mathrm{l}$ $\mathrm{Ca}^{2+}(250 \mathrm{mM})$ to obtain $60 \mu$ of recalcifying trigger. In the case of PRP, 240 $\mu l$ of plasma was diluted with $60 \mu \mathrm{l}$ Buffer $A$ and coagulation was triggered with $60 \mu \mathrm{laCl} \mathrm{Ca}_{2}$, to obtain $16.7 \mathrm{mM}$ final concentration.

After addition of the trigger, $10 \mu$ of reaction mixture was subsampled at equally spaced intervals $(5,10$ or $15 \mathrm{~s})$ in prewarmed $\left(37^{\circ} \mathrm{C}\right)$ cuvettes with 490 $\mu l$ of Buffer B containing $200 \mu \mathrm{M}$ of $\$ 2238$. As soon as the mixture coagulated, the clot was wound on a small spatula and removed. The reaction was stopped by the addition of $300 \mu \mathrm{l}$ of $1 \mathrm{M}$ citric acid after about two minutes. The optical density was read at $405 \mathrm{~nm}$. The spectrophotometer as well as the 
subsampling and the stopping pipette were connected to a personal computer that calculated the increase of $O D$ in time from the $O D$ and the moment of subsampling and stopping. From the OD/min values the amidolytic activity was calculated by comparing with a standard calibration curve of active site titrated human $\alpha$-thrombin. The lag time of thrombin formation is defined as the moment at which the thrombin concentration rises from a 0-5 nM level to a 10-20 nM level, because we observed that in fibrin containing plasma at the moment of clotting the thrombin concentration arrived at that level.

Clots or other substances of which the influence on thrombin generation was tested, were added to the reaction mixture $90 \mathrm{~s}$ after triggering coagulation. Unless otherwise indicated, three clots have been used.

For ease of presentation, in cases where the only essential difference between the curves was a shift in time, i. e. a shortening of the lag-time, we have also rendered the results as that shortening only (Tables 2 and 3 ).

\section{Measurement of the Thrombin Potential}

The thrombin potential is defined as the area under the thrombin generation curve (29). It is a measure of the amount of any substrate that the thrombin generated can potentially convert during its existence in a free form. It has been determined by calculation of the area under the thrombin generation curves that we determined.

\section{Measurement of Prothrombin and $\alpha_{2}$-Macroglobulin-thrombin Complex}

Prothrombin was determined as described in ref 28. Briefly, a $10 \mu \mathrm{l}$ sample was incubated for $5 \mathrm{~min}$ in cuvettes containing $415 \mu \mathrm{l} \mathrm{Buffer} \mathrm{B}$ and 50 ul staphylocoagulase, giving a final concentration of $300 \mathrm{nM}$, i. e. a molar excess of staphylocoagulase over the highest prothrombin value to be expected. The amidolytic activity that generates is due to the stoichiometric staphylocoagulase-thrombin complex formed (31). This complex has the same specific activity on chromogenic substrate as thrombin has (28). The total amidolytic activity was measured after addition of $\$ 2238$ to a final concentration of $200 \mu \mathrm{M}$. In samples in which thrombin has been present the 
thrombin is partitioned between its different inhibitors, antithrombin IIIs $\alpha_{2}$ macroglobulin and others. The $\alpha_{2}$-macroglobulin-thrombin complex retains thrombin-like amidolytic activity. It has 0.556 times the specific activity of thrombin under our experimental conditions (28). The amount of total prothrombin present in plasma sample was calculated from the total amidolytic activity minus the activity of thrombin complexed with $\alpha_{2}$-macroglobulin as measured in sample to which no staphylocoagulase had been added.

\section{Determination of Thrombin/Antithrombin III Complex (TAT)}

TAT levels were determined using an enzyme immunoassay (Enzygnost TAT, Behring, Germany) working on the sandwich principle; $100 \mu \mathrm{l}$ of $1 / 4000$ diluted samples of serum were incubated for $30 \mathrm{~min}$ in tubes coated with rabbit antibodies to human TAT. The tubes were washed and peroxidase-conjugated antibodies to human ATIII were added. After a $30 \mathrm{~min}$ incubation, tubes were washed again and peroxidase substrate o-phenylenediamine $2 \mathrm{HCl}$ was introduced in the tubes. They were stored in the dark for 30 min after which the substrate conversion was stopped by adding $0.5 \mathrm{~N}$ sulphuric acid and absorbency measured at $492 \mathrm{~nm}$. The TAT concentrations in the samples were obtained via the reference curve provided by the manufacturer.

\section{Results}

\section{Thrombin Adsorption on the Forming Clot}

The amount of prothrombin consumed during the coagulation of plasma was not significantly influenced by the presence or absence of fibrinogen (Table 1). Nevertheless, in absence of fibrinogen, the thrombin generation curve is significantly higher than in its presence (Fig. 1, upper frame). The area under the thrombin-time curve is $31 \pm 3 \%$ (mean $\pm S E M, n=10$ ) lower in the presence than in the absence of the forming clot. Also the amount of thrombin found in the form of TAT complexes or bound to $\alpha_{2}$-macroglobulin is 
lower after coagulation of normal plasma than after thrombin generation in defibrinated plasma (Table 1).

Table 1 Thrombin related variables after thrombin generation in normal and defibrinated plasma

\begin{tabular}{lcc}
\hline & Normal & Defibrinated \\
\hline Prothrombin consumed (\%) & $93.9 \pm 1.8$ & $93.8 \pm 0.6$ \\
$\alpha_{2}$ Macroglobulin-thrombin (\%) & $4.3 \pm 0.3$ & $11.0 \pm 0.4^{*}$ \\
TAT complexes (\%) & $61.5 \pm 0.4$ & $63.9 \pm 0.3^{*}$ \\
Thrombin potential (nM min) & $356 \pm 8.2$ & $511 \pm 10.1^{\star}$
\end{tabular}

Results are expressed $\pm \mathrm{SDM} ; \mathrm{n}=10$. The molar concentration of the original prothrombin in the plasma, is the $100 \%$ value.

* Indicates statistical significance at a $p<0.05$ level

These results show that prothrombin is converted that does not appear as amidolytic activity during thrombin generation and that is not accounted for by the amount of TAT complexes formed or by the amount of $\alpha_{2}$-macroglobulinthrombin complexes formed. This suggests that during coagulation a significant amount of thrombin is bound to the forming fibrin clot. The phenomenon is also observed in the presence of heparin (Fig. 2). Heparin catalyses the AT III-thrombin interaction. The free thrombin observed is therefore lower than without heparin, both in the presence and the absence of fibrin(ogen). The difference between the two curves is smaller in the presence of heparin than in its absence. This suggests that in the presence of theparin less thrombin is adsorbed on the clot. Additional evidence for binding of thrombin to the clot is found in the fact that a thrombin generation curve of fibrin containing plasma shows a dip at the moment that the clot is forming in situ, which is not seen in a curve from defibrinated plasma (Fig. 1). This can be seen clearly from the details of the first minutes of the graph (Fig. 1, lower frame). 

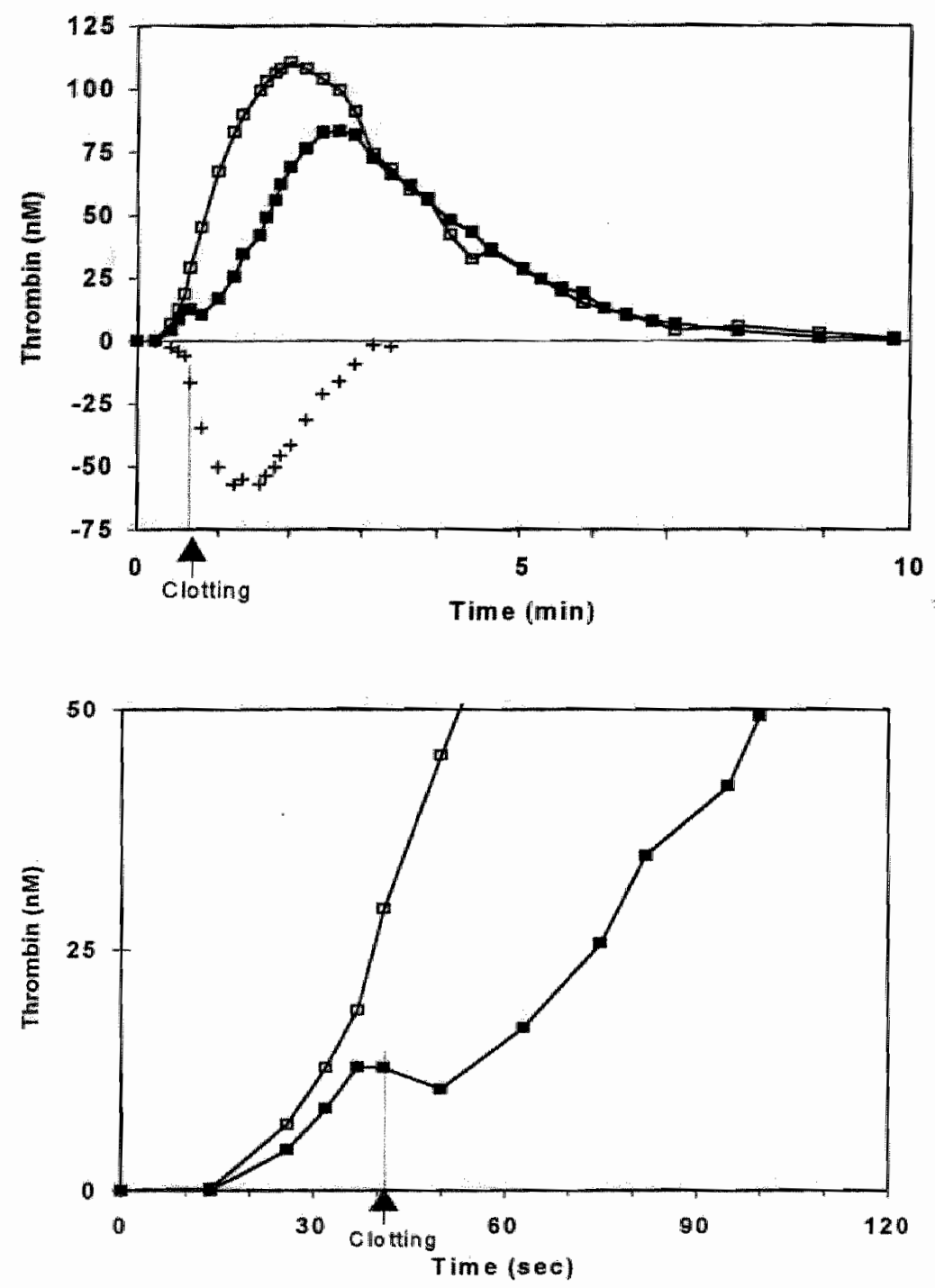

Fig. 1 The influence of fibrin formation on extrinsic thrombin generation. Thrombin generation was triggered in normal pooled PPP with recombinant tissue factor $(1 / 240), \mathrm{CaCl}_{2}(16.7 \mathrm{mM})$ and phospholipids ( $\left.P S / P C_{n} 1.1 \mu \mathrm{M}\right)$. Amidolytic activity was determined in subsamples taken at $15 \mathrm{~s}$ intervals. From the amidolytic activity the thrombin activity was calculated (28). The experiment was performed in (c) normal plasma and in the (D) same plasma defibrinated with reptilase. The difference of the two curves is represented below the time axis $(+)$. Lower frame: Details of the first minutes. 


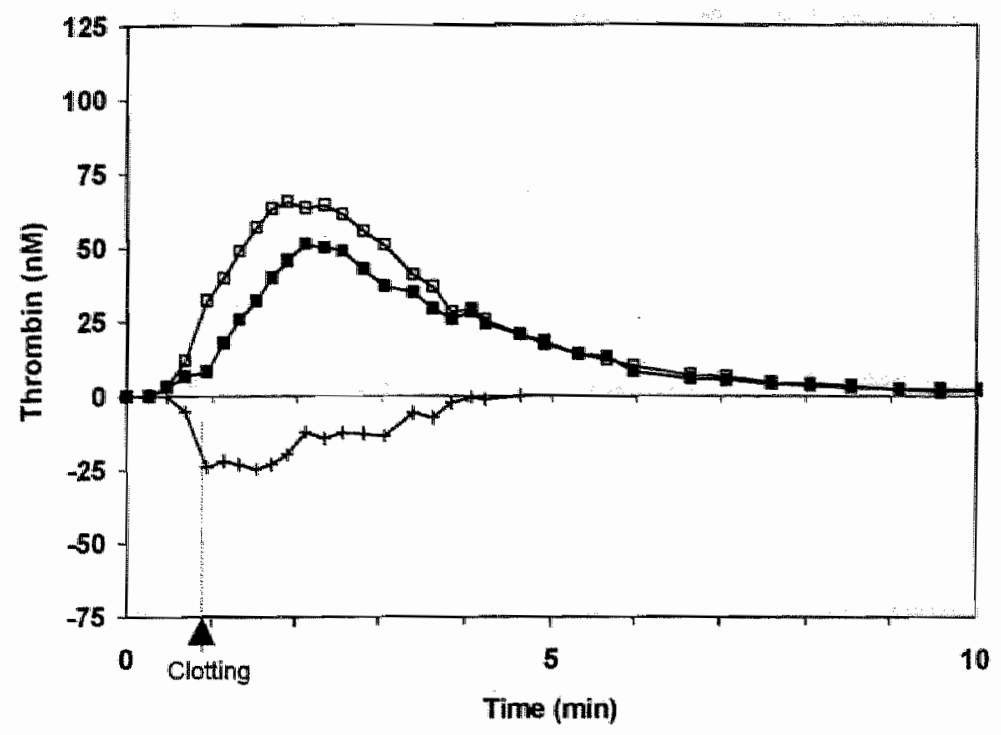

Fig 2 The influence of fibrin formation on thrombin generation in the presence of heparin. The experiment of Fig. 1 was repeated in the presence of $0.041 \mathrm{UJ} / \mathrm{m} / \mathrm{of}$ unfractionated heparin in (a) normal plasma and in the (D) same plasma defibrinated with reptilase.

\section{Effect of the Clot on the Coagulation of Fibrinogen}

That fibrin bound thrombin directly attacks fibrinogen has been proven by the demonstration of clot-dependent generation of fibrinopeptides (8-10). This is not likely to be a sufficient explanation for the procoagulant effect observed, because newly formed fibrin would soon build a considerable diffusion barrier that will prevent the access of further fibrinogen to the bound thrombin. We have tried to induce coagulation of non-recalcified normal plasma by the addition of normal clots. If the clots were well washed and incubated in serum, such as was our standard procedure for making them, no coagulation was ever observed in 12 out of 12 experiments even after $1 \mathrm{~h}$. So indeed the bulk of fibrinogen remains unconverted. 


\section{Effect of the Clot on Factor V Activation}

To investigate the possibility that clot bound thrombin can mediate feedback activation of factor $V$ in clotting plasma, we needed a system in which factor VIII was guaranteed to play no role. Therefore we used extrinsic thrombin generation measurements carried out in factor VIII deficient plasma.

Reinforcement of feedback activation reactions in the generation of thrombin show as shortening of the lag-time before the burst of thrombin occurs, inhibition of the feedback activation causes prolongation of the lagtime $(14,32,33)$. However, no perceptible lag-phase is seen in extrinsic coagulation (34) not even at small time resolutions and low (up to 1/4000 diluted) thromboplastin concentrations. A delay of thrombin generation can however be induced by hirudin. It has been shown to be caused by retardation of the feedback activation of factor $V$ by thrombin (35).

We observed that addition of clots to the system shortens this hirudin induced delay (Fig. 3). This must be attributed to the clot causing prothrombinase activity. In principle any of the three components of prothrombinase, i. e factor $\mathrm{Xa}$, factor $\mathrm{Va}$ or procoagulant phospholipids may be provided by the clot. Factor Xa activity indeed has been demonstrated to be contained in the clot (36). We observed that clots, produced by addition of thrombin (100 nM) to plasma devoid of factors II, Vil, IX and $X$, did cause shortening of the delay (Table 2). This shows that factor $\mathrm{Xa}$ is not required for the observed shortening. It has been shown before that during the initial phase of the reaction (i. e. before the thrombin burst takes place), in the extrinsic system under our conditions factor $X a$ is present in excess over factor $\mathrm{Va}(37)$. This makes it very unlikely that factor Xa activity from the normal clot would be the rate limiting reactant that shortens the lag time.

The only phospholipids that could be present in the clots are the traces that may be present in the normal PPP from which the clots were made. In the thrombin generation experiments phospholipids are added to a final concentration $>1 \mu \mathrm{M}$. Therefore possible phospholipid concentrations in the clots are several orders of magnitude lower and cannot influence thrombin generation any further than the added phospholipid does. It therefore is also 

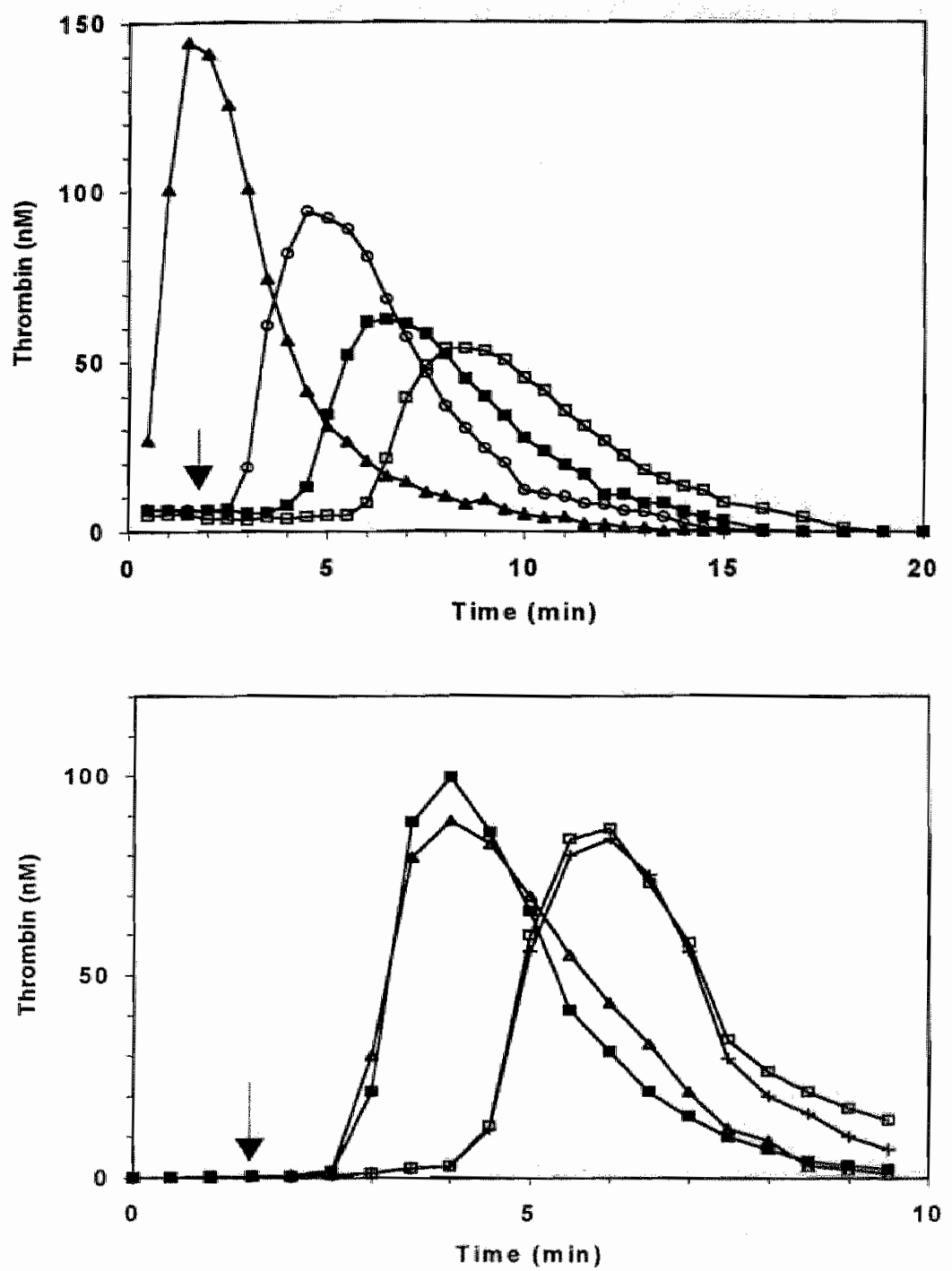

Fig. 3 Effect of plasma clots on extrinsic thrombin generation in defibrinated factor VIII deficient plasma. The experimental setup was the same as in Fig. 1 with subsamples taken at $30 \mathrm{~s}$ intervals, $0.15 \mu \mathrm{M}$ hirudin was added to induce a lagphase. Upper frame: (A) control without hirudin; (D) control; (M) normal clots added at $t=90 \mathrm{~s}$; (O) $10 \mathrm{nM}$ factor $\mathrm{Va}$ added at $t=90 \mathrm{~s}$. Lower frame: (D) control; $(+)$ control plus $10 \mathrm{nM}$ factor $V$ added; ( $)$ control plus $10 \mathrm{nM}$ factor $V$ previously incubated with normal clots and $\mathrm{Ca}^{2+}(5 \mathrm{mM}) ;(\Delta)$ as the previous one but with clots preincubated in heparinised serum. All additions were done at $\mathrm{t}=90 \mathrm{~s}$ (arrow). 
highly unlikely that the clots contribute to the prothrombinase action by bringing phospholipids to the reaction mixture. This left factor $\mathrm{V}$ activation as the most likely cause of the advancement of the thrombin burst. We, therefore, attempted to demonstrate factor $V$ activation by the clots.

In the first place we saw that the effect of a clot can be mimicked by the addition of factor $\mathrm{Va}$ (10 $\mathrm{nM}$ final concentration) whereas non-activated factor $\checkmark$ has no activity (Table 2). Then we showed that non-activated factor $V$ in which 3 clots were incubated $\left(10 \mathrm{~min}, 37^{\circ} \mathrm{C}, 5 \mathrm{mM} \mathrm{Ca}{ }^{2+}\right)$ and then discarded, has a similar effect as activated factor $V$ has (Fig. 3, lower frame). The factor $\checkmark$ preparation used or buffer into which clots had been incubated, as well as the factor $V$ preparation incubated with reptilase clots were all inactive.

Table 2 Shortening of hirudin induced lag time in extrinsic thrombin generation on different additions

\begin{tabular}{lc}
\hline Addition & $\begin{array}{c}\text { Shortening of the } \\
\text { lag phase (s) }\end{array}$ \\
\hline None & NS \\
Clot from recalcified plasma & $78-89$ \\
Thrombin-clot in FII, FVII, FIX and FX depleted plasma & $77-93$ \\
Reptilase or Agihal clot & NS \\
Factor $V$ & NS \\
Thrombin activated factor V & $174-197$ \\
Factor $V$ preincubated with normal clots & $96-118$ \\
Factor $V$ preincubated with reptilase clots & NS \\
Factor $V$ preincubated with PPACK clots & NS \\
Factor $V$ preincubated with last washing fluid & NS \\
\hline
\end{tabular}

The lag times were obtained from thrombin generation experiments as in Fig. 3. The adidition was always done at $t=1.5 \mathrm{~min}$. Each experiment was repeated 4 to 6 times. No statistics were done but the range of results is given. NS indicates that the difference of lag time measured was less than the sampling interval, i. e. 30 s. 
Incubating clots for several hours in serum to which $0.1 \mathrm{U} / \mathrm{ml}$ of heparin is added did not diminish their activity. When factor $V$ was preincubated with clots formed by reptilase the lag phase was not shortened. Clot induced factor Va generation was also measured directly, in normal plasma as well as in plasma depleted of the vitamin $K$ - dependent clotting factors. The plasma was recalcified at $t=0$ and clots were added at $t=90$. Every minute $10 \mu$ aliquots were drawn and diluted 200 -fold in tubes on ice, containing Buffer $\mathrm{C}$ with 0.1 $\mathrm{U} / \mathrm{ml}$ of heparin and $5 \mathrm{mM} \mathrm{CaCl}$. From these tubes $10 \mu$ aliquots were transferred to prewarmed cuvettes containing $105 \mu \mathrm{l}$ of buffer $\mathrm{C}$ and an excess of constituents of prothrombinase [human factor Xa $20 \mathrm{pM}, \mathrm{PS} / \mathrm{PC} 10 \mu \mathrm{M}$, and $\mathrm{CaCl}_{2} 5 \mathrm{mM}$ (final conc.)]. After $1 \min , 10 \mu \mathrm{l}$ of human prothrombin (200 $\mathrm{nM}$ final conc.) was added. At $3 \min 350 \mu$ of Buffer $B$ was added to stop thrombin generation. Then thrombin was measured via its amidolytic activity on S2238 (see Methods). The amount of Va generated was calculated by reading on a standard curve generated by titration of purified factor Va with active site titrated factor $\mathrm{Xa}$ in the presence of phospholipid. The results show that in normal plasma a tremendous increase in factor Va occurs (Fig. 4, top), this coincides with the burst of thrombin. This is to be expected because factor Va causes thrombin formation, but freshly generated thrombin activates factor $V$. It was impossible to analyse this type of curve in terms of the precise temporal relationships between the rise of both activities. In order to demonstrate that clots directly activate factor $V$ in a plasma medium, we repeated the experiment in plasma from which the vitamin $K$-dependent factors had been removed. It was seen (Fig. 4, lower frame) that normal clots are capable to activate traces of factor $V$. The effect in itself is modest. To demonstrate factor $V$ activation more convincingly the depleted plasma was supplied with additional factor $\mathrm{V}(70 \mathrm{nM})$ and indeed an enhancement in $\mathrm{Va}$ concentration could be seen (Fig. 4, lower frame). The bulk of factor $V a$ generation in normal plasma must be considered to be secondary to thrombin formation. The importance of the small activation of factor $V$ by the clot is that it starts a positive feedback loop by causing the generation of traces of free thrombin that in their turn cause further factor $V$ activation. The effect of clots 

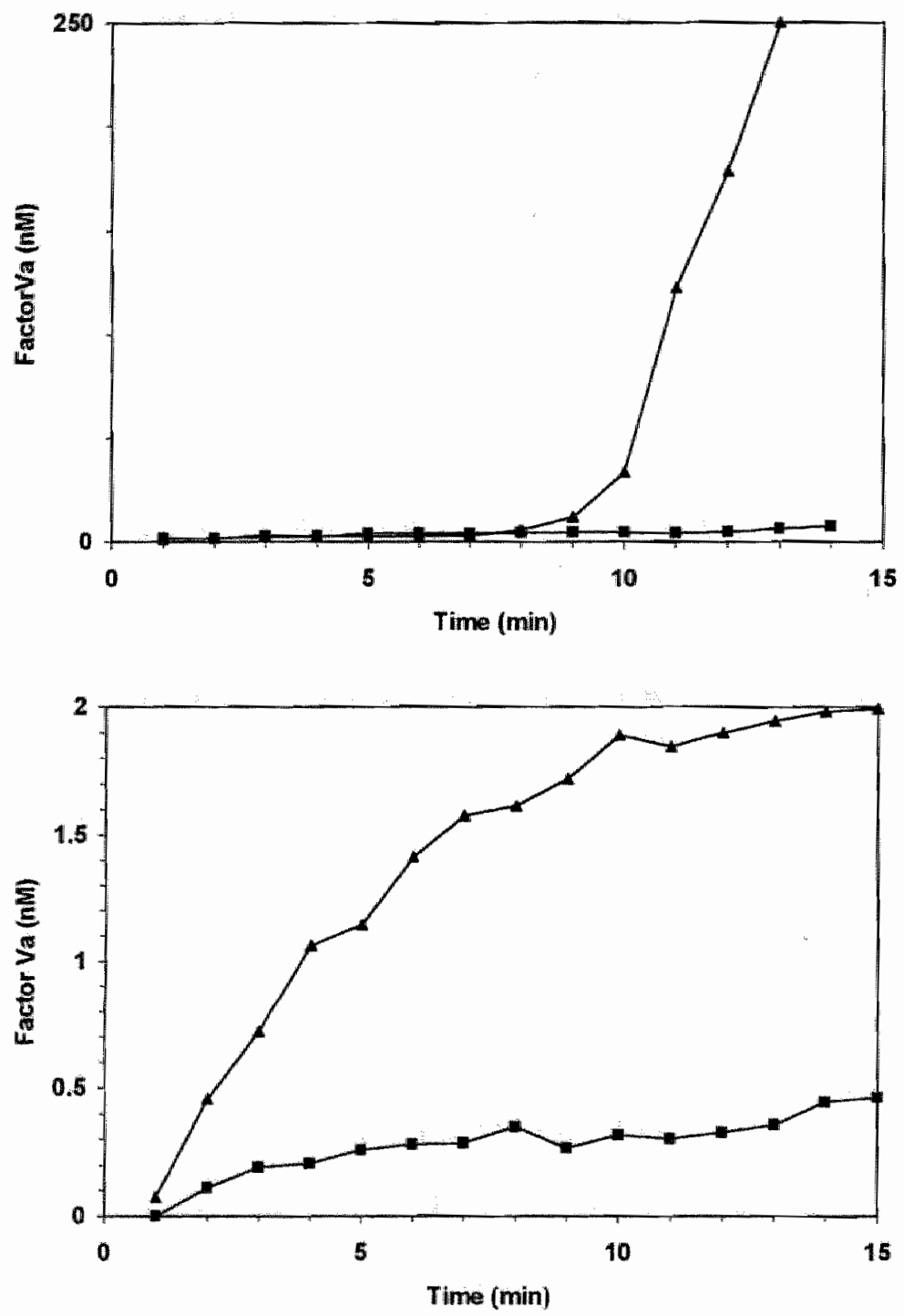

Fig. 4 The influence of normal plasma clots on factor Va generation in plasma. The development of activated factor $V$ was measured in defibrinated normal pooled plasma, in subsamples taken at 1 min intervals after recalcification and simultaneous addition of three normal clots. Upper frame: ( $\mathbf{U}$ ) control without clots; ( $\mathbf{\Delta}$ ) clots added at zero time. Lower frame: ( $\mathbf{m}$ ) clots added at $\mathrm{t}=0$ to plasma depleted of factors 11 , VII, $I X$ and $X ;(\Delta)$ idem with additional factor $V(70 \mathrm{nM})$. See text for experimental details. 
that had been incubated in heparinised serum $(0.1 \mathrm{U} / \mathrm{ml})$ for over $1 \mathrm{~h}$ was identical to that of clots from normal plasma.

\section{Effect of the Clot on Factor VIII}

When thrombin generation is initiated with incomplete tenase (containing $\mathrm{IXa}, \mathrm{PS} / \mathrm{PC}$ and $\mathrm{Ca}^{2+}$ ) instead of tissue factor, clotting occurs via the intrinsic pathway but the contact phase is short circuited (32). A lag phase is always observed, because initial traces of thrombin have to activate factor VIII in order to induce the thrombin burst $(32,37,38)$. The effect of various types of clot on these factor VIII dependent lag times are completely comparable to those obtained in a factor $V$ dependent system (Fig. 5, Table 3). We interpreted that, analogously to factor $V$, factor VIII is also activated by thrombin adsorbed on a clot. Indeed, preincubation of a factor VIII preparation ( $15 \mathrm{nM}$ in $1 \mathrm{mM} \mathrm{CaCl}$ ) with 3 clots for $1 \mathrm{~min}$ at $37^{\circ} \mathrm{C}$ under gentle stirring, induces the capacity to shorten the lag time, as did thrombin activated factor VIII (Fig. 5, lower frame). The factor VIll preparation itself or buffer into which clots had been incubated as well as the factor VIII preparation incubated with reptilase clots were all inactive. Again clots incubated (1 h) in heparinised serum $(0.1 \mathrm{U} / \mathrm{ml})$ were as active as normal clots were. 

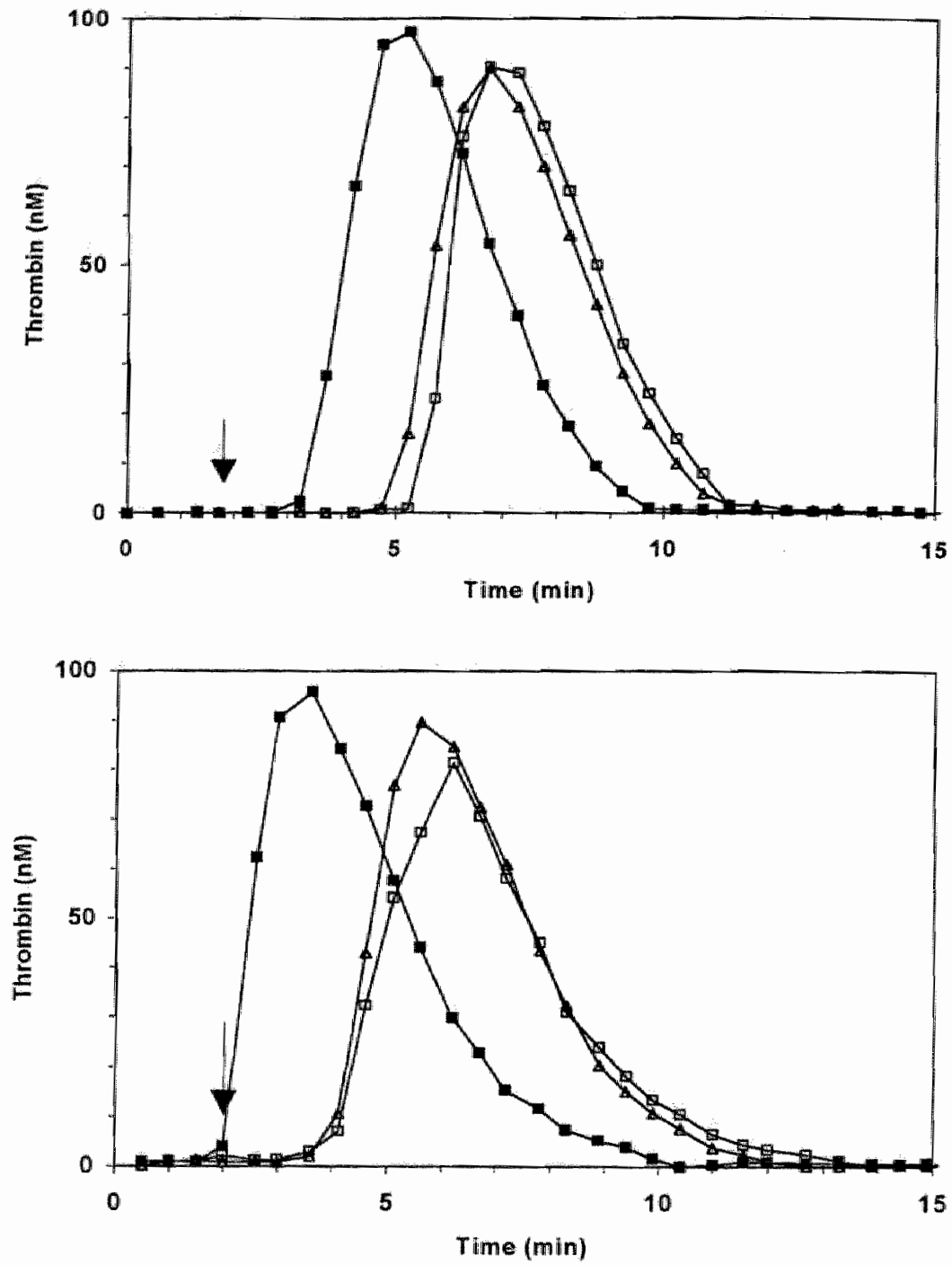

Fig. 5 Effect of plasma clats on intrinsic thrombin generation. Thrombin generation was measured in defibrinated normal pool plasma. It was triggered with $\mathrm{Ca}^{24}$, factor IXa and phospholipids (incomplete tenase) as described in the methods section. All additions were done at $\mathrm{t}=90 \mathrm{~s}$. Upper frame: $(\square)$ control; ( $(\mathbf{D})$ normal plasma clots added; $(\Delta)$ reptilase clots added. Lower frame: (a) control; ( $(\square)$ addition of factor VIII, 10 mi of a $15 \mathrm{nM}$ solution in $1 \mathrm{mM} \mathrm{CaCl}$ in which 3 normal clots were incubated at $37^{\circ} \mathrm{C}$ for $1 \mathrm{~min} ;(\Delta)$ the same but factor VIII not incubated with clots. 
Table 3 Shortening of the lag time in intrinsic thrombin generation on different additions

\begin{tabular}{|c|c|}
\hline Addition & $\begin{array}{l}\text { Shortening of the lag } \\
\text { phase (s) }\end{array}$ \\
\hline None & $\overline{N S}$ \\
\hline Clot from recalcified plasma & $111-134$ \\
\hline Clot by thrombin in depleted plasma & $97-121$ \\
\hline Snake venom clot & NS \\
\hline Factor VIII & NS \\
\hline Thrombin activated factor VIII & $128-147$ \\
\hline Factor VIII preincubated with normal clots & $98-113$ \\
\hline Factor VIII preincubated with reptilase clots & NS \\
\hline Factor VIIl preincubated with PPACK clots & NS \\
\hline Factor VIII preincubated with last washing fluid & NS \\
\hline
\end{tabular}

Activation of Platelets by the Clot

In PRP triggered with $\mathrm{Ca}^{2+}$, there is a prolonged lag-phase to the thrombin burst that has been shown to be caused by the time required for the platelets to provide the necessary procoagulant phospholipid surface under influence of traces of thrombin formed (30). The addition of a clot again shortens this lag time of the thrombin burst, also when the clot has been incubated for $1 \mathrm{~h}$ in heparinised serum (Fig. 6, upper frame). The interesting and unexpected finding however was that any clot also clots formed by reptilase and Agihal, that are inactive in platelet free systems, shorten the lag phase in PRP like a thrombin induced clot does (Fig. 6, lower frame). It thus seems that the presence of thrombin adsorbed on the clot is not an essential requirement in the case of platelet activation, in other words that fibrin alone is capable to induce procoagulant activity in platelets. 

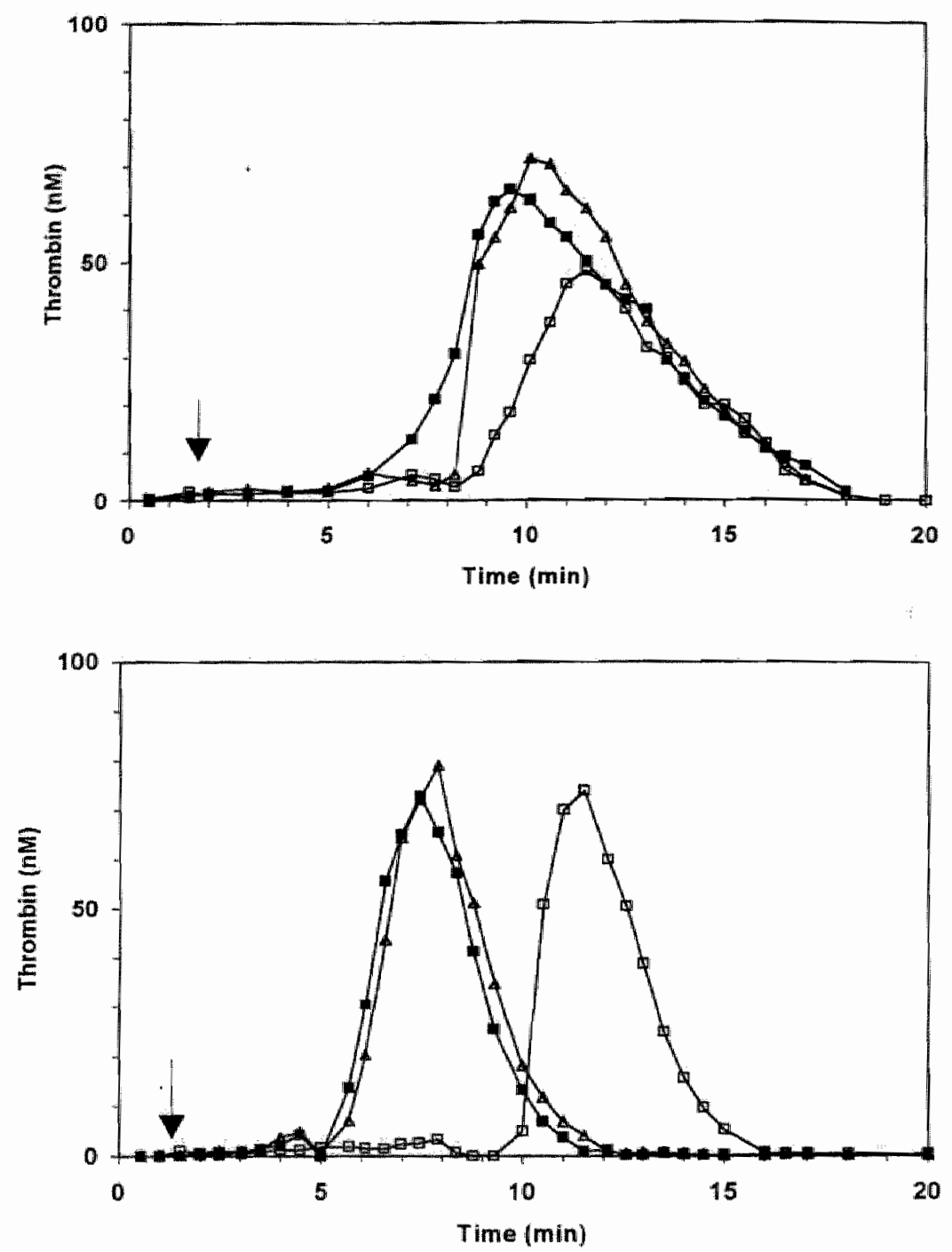

Fig.6 Effect of clot addition on thrombin generation carried out in platelet rich plasma. Thrombin generation was triggered in PRP from a normal donor by addition of $\mathrm{CaCl}_{2}(16.7 \mathrm{mM}$ ). All additions were done at $\mathrm{t}=90 \mathrm{~s}$ (arrow). Upper frame: ( $\square$ ) control; ( normal plasma clots added; $(\Delta)$ addition of clots incubated in serum plus $0.1 \mathrm{U} / \mathrm{ml}$ of heparin. Lower frame: $(\square)$ control; ( $)$ reptilase clots added; ( $\Delta$ ) addition of thrombin clots from plasma depleted in factors $\mathrm{II}, \mathrm{VII}, \mathrm{X}$ and $\mathrm{X}$. 


\section{Discussion}

The fact that a clot even hours after it has been formed, induces further coagulation of plasma, is known since the 19th century. In fact it was this observation that led Buchanan to postulate the existence of thrombin (13). The phenomenon is presumably not without importance for the pathophysiology of thrombosis, because it may well be a model of one of the mechanisms of in vivo thrombus growth. Thrombus growth is one of the major problems in the management of thrombosis, so clot induced coagulation and its inhibition by antithrombotic drugs deserves detailed attention.

That thrombin adsorbs onto fibrin during coagulation is known from the literature (see Introduction) and it also appears from Fig. 1 , in which it is seen that, from the moment on that a clot forms the amount of free thrombin in triggered defibrinated plasma is significantly higher than in non-defibrinated (i.e. normal) plasma. In the presence of heparin the arnounts of free thrombin detected are generally lower, due to the increased scavenging of thrombin by AT 1II. Also the difference between the curves in the presence and in the absence of thrombin is smaller, which means that less thrombin is adsorbed on the clot. In the presence of heparin the competition between fibrin and AT III for free thrombin evidently shifts in favour of AT III. Even if AT III (-heparin) is unable to inhibit thrombin that is bound to fibrin, it will cause less thrombin to be bound to fibrin during the coagulation process. Hypothetically this could be a beneficial effect of heparin prophylaxis and treatment. Our experiments confirm that heparin does not in any way inhibit the activity of thrombin once it is adsorbed to the clot.

From Table 1 it can be seen that the difference between thrombin generation in the presence and in the absence of fibrin(ogen) cannot be explained by a lack of prothrombin conversion. It is also seen in this table that the level of the main thrombin-inhibitor complexes (TAT and $\alpha_{2}$ M-thrombin) that form in the presence of fibrin are lower than in non-defibrinated plasma. Evidently clotting fibrinogen competes for free thrombin with the other physiological inhibitors in an irreversible process. This is also seen when 
heparin is present (Fig. 2). The question of how fibrin competes with antithrombin III in absence and in presence of heparin is at present under further investigation in our laboratory.

In order to investigate the action of a clot on the clotting system in more detail we prepared clots by recalcification of normal PPP in a glass tube ("normal clots"'). By using the intrinsic pathway without adding an other trigger than recalcification we prevented the presence of exogenous procoagulant substances such as kaolin, phospholipids or tissue factor. In order to inhibit free thrombin, all clots were incubated for 10 to $30 \mathrm{~min}$ in serum, in some experiments spiked with heparin $(0.1 \mathrm{U} / \mathrm{ml})$. We observed that well washed clots that were left in their serum for $10 \mathrm{~min}$ or more never induced coagulation in plasma that was not recalcified. This in our opinion excludes the possibility that significant free thrombin is contained in our clots and it also shows that bound thrombin does not act on the great mass of fibrinogen in a solution. Probably the bound thrombin causes some fibrin formation at the clot-solute interface, otherwise the fibrinopeptide generation by washed clots $(8-10)$ is difficult to explain.

We also made clots by addition of $100 \mathrm{nM}$ of thrombin to plasma depleted of the vitamin K-dependent clotting factors by $\mathrm{Al}(\mathrm{OH})_{3}$ adsorption. These clots ("depleted plasma clots") have been introduced because they will not contain factor $X a$. This factor has been shown to be contained in clots from normal plasma (36). Factor $X a$ can activate factors $V(39,40)$ and VIII $(41,42)$, be it that factor $V$ activation by factor Xa has only been demonstrated in purified systems and in the presence of phospholipids, and that, in plasma, thrombin may still be considered to be the only effective activator of factors $\mathrm{V}$ and VIII (19). It nevertheless was necessary to test clots without factor Xa, because it has been reported that clots contain factor Xa which would be able to activate prothrombin (36). In clots made of depleted plasma factor Xa cannot be present.

A third type of clots ("snake venom clots") were made by the addition to plasma of non-thrombin fibrinogen clotting enzymes from Bothrops Atrox (Reptilase) or Agkistrodon Halys Halys (Agihal). It was checked that both snake venom fractions, at the concentrations used, do not activate factors $V$ 
and VIII or platelets. Also we made "reptilase clots" from plasma depleted of the vitamin K-dependent clotting factors by $\mathrm{Al}(\mathrm{OH})_{3}$ adsorption. No differences were ever found between the clots made by the different snake venoms, nor between snake venom clots from normal and from depleted plasma.

\section{Clots and Intrinsic Coagulation, the Activation of Factor VIII}

In the intrinsic system triggered with factor IXa and phospholipid a lagphase is always seen to precede a burst of thrombin formation. We have previously shown that this lag represents the time necessary for traces of thrombin to activate sufficient factor VIII $(32,37,38)$. Shortening of the lagtime therefore can be interpreted in terms of factor Villa formation if short circuiting by activation of a factor on a lower level can be excluded. The fact that factor $\mathrm{XXa}$ is an efficient trigger and that no thrombin generation is seen before $12 \mathrm{~min}$ if only phospholipids and $\mathrm{Ca}^{2+}$ are added excludes such a short circuit. The key observation was that thrombin induced clots shorten the lag time whereas venom induced clots do not (Fig. 5, Table 2). The fact that clots from depleted plasma act like normal clots do, shows in addition that factor Xa is not likely to play a role in the shortening mechanism. As a positive control we added thrombin activated factor VIII, which shortened the lag-time whereas the same factor VIII preparation when not activated by thrombin did not. Thrombin clots, also when incubated in heparin containing serum or when produced by adding thrombin to depleted plasma, induced activity in the factor VIII preparation that was comparable to that caused by free thrombin.

\section{Clots and Extrinsic Coagulation, the Activation of Factor $V$}

It is an as yet unresolved problem why factor $V$ activation does not cause a similar lag phase in extrinsic coagulation as factor VIII activation does in the intrinsic pathway. Diminished thrombin production, such as seen in orally anticoagulated plasma does induce such a lag phase. Enhanced thrombin inactivation, such as induced by heparin does not. This is reflected by the well known fact that oral anticoagulation prolongs the thromboplastin time whereas heparin administration does not. This suggests that, in extrinsic thrombin generation, there exists a form of thrombin that is capable of 
activating factor $V$ whereas it is not inhibited by AT III-heparin. Meizothrombin has been shown to be insensitive to the action of heparin (43). It will remain bound to the phospholipid surface because it still contains the C-terminal part of prothrombin through which the molecule binds to negatively charged phospholipids. The feedback activation therefore could take place at the phospholipid surface. This problem is at present under investigation in our laboratory. The natural explanation of the existence of a lag time in the intrinsic system then would be that factor VIII, unlike factor $\mathrm{V}$, remains in the fluid phase, i. e. cannot enter the "compartment" because it is bound to von Willebrand factor.

To investigate the clot induced activation of factor $V$ we had to induce a lag time in the extrinsic system. The addition of hirudin does cause such a lagtime in the extrinsic system, probably because hirudin does inhibit meizothrombin. It has been shown before (35) that this lag-phase is caused by retardation of thrombin generation and not by immediate inactivation of normally formed thrombin we checked this previous result by incubating samples taken at the end of the lag-time with staphylocoagulase, they invariably developed an amidolytic activity of $>85 \%$ of the mixture at $t=0$, in accordance with the earlier results. We used factor VIII deficient plasma in order to rule out any side effects via the intrinsic pathway.

We found essentially the same results as with factor VIII and the intrinsic system: again thrombin induced clots shorten the lag time whereas venom induced clots do not. This in itself shows nothing more than enhancement of prothrombinase activity at an earlier moment than in the absence of a clot, which can in theory be due to any component of the prothrombinase complex. It is unlikely however that it should be due to factor $X$ activation because it has been shown that under our experimental conditions, during the lag phase, factor $X a$ is present in large excess over factor $\mathrm{Va}$ (34). Also it is not likely that phospholipids are supplied by the clot (see above). Anyhow, in that case there would be no reason for the difference between thrombin induced and venom induced clots.

Elevating the concentration of factor $V$ in plasma did not change the lagtime. However when the factor $V$ preparation was incubated with the clots and 
then added to the plasma without the clots, marked shortening could be again observed.

The generation of factor $\mathrm{Va}$ by addition of a thrombin induced clot could be demonstrated in normal plasma and in plasma depleted of clotting factors II, VII, IX and X. The burst of factor Va production in normal plasma is in all probability secondary to thrombin generation, but factor Va generation in depleted plasma can only be explained by a direct action of the clot on factor $\mathrm{V}$.

We conclude that the thrombin adsorbed on a clot during its formation but not the fibrin itself enhances prothrombinase activity via the activation of plasmatic factor $V$. Heparin is neither able to inhibit thrombin present on a clot nor to prevent thrombin to adsorb on a forming clot.

\section{The Activation of Platelets}

We have previously shown that thrombin generation in PRP is critically dependent upon the phospholipids exposed by thrombin activation of the platelets (30), in other words that the lag-time in clotting PRP is the time necessary for traces of thrombin to make the platelets expose procoagulant phospholipids. The negatively charged phospholipids, in practice mostly phosphatidylserine (PS), are normally practically exclusively present in the inner leaflet of the platelet plasma membrane and therefore not exposed to plasma Bevers et al. have demonstrated that platelets dispose of a mechanism, thus far unique to these cells, that causes a transbilayer movement of the PS to the outside of the activated platelet, the "flip-flop" mechanism (22). Also is PS exposed in microvesicles shed by activated platelets $(44,45)$. It has been shown that in isolated platelets thrombin and collagen are each capable to induce the flip-flop reaction (in the presence of $\mathrm{Ca}^{2+}$ ) but that combination of the two is much more potent than each of the two alone (22). In PRP however we found that thrombin alone is capable to cause a maximal procoagulant effect and that the addition of collagen does not significantly increase the procoagulant response (30).

Rather surprisingly, all clots exhibited an activating influence on the platelets during thrombin generation in PRP, not only the thrombin induced 
clots but also those clots obtained by reptilase and Agihal that do not contain thrombin. This indicates that the flip-flop reaction of platelets, contrary to the activation of factors $\mathrm{V}$ and $\mathrm{VIII}$ is not obligatorily restricted to the presence of thrombin on the clot. One can surmise that fibrin has a similar type of action on platelets as collagen has. If this is true then fibrin(ogen) would be a kind of cofactor to the flip-flop inducing action of thrombin in plasma. This hypothesis has to be substantiated by the demonstration of the effect of thrombin and/or fibrinogen and/or fibrin on the transbilayer movement in isolated platelets. such experiments are on their way now in our laboratory.

in summary: our findings demonstrate that thrombin induced clots initiate coagulation in plasma by activation of plasma cofactor proteins. This may cause generation of more thrombin at the site of a thrombus and hence thrombus growth. The fact that heparin does not inhibit this process may limit the usefulness of heparin as an antithrombotic. In general, potential antithromboties should be characterised as to their ability to inhibit these positive feedback reactions. Even more intriguing than the role of clot bound thrombin in the feedback activation of clotting factors is the activation of platelets by fibrin to which no thrombin can be adsorbed, i. e. the collagen like action of fibrin. This once more indicates how intricately interwoven clottingand platelet reactions are. On a practical level it underlines the rationale of anticoagulation as antithrombotic therapy and suggests that inhibitors of fibrinplatelet interactions would make interesting antithrombotics.

\section{Acknowledgements}

We thank "De Broeders van Den Beijaard" for their kind donations of blood. Our gratitude is due for $\mathrm{Dr}$. Theo Lindhout and Ron Blezer for their help in the measurement of TAT complex, and for Simone Wielders for her help in the measurement of prothrombin consumption. We thank Dr. Chr. W. Hemker for his remarks on the history of thrombin discovery. 


\section{References}

1. Blombäck $B$, Hessel $B$, Hogg D, Therkildsen $L$. A two step fibrinogen fibrin transition in blood coagulation. Nature 1978; 275: 501-5.

2. Liu $\mathrm{CY}$, Nossel $\mathrm{HL}$, Kaplan $\mathrm{KL}$. The binding of thrombin by fibrin. J Biol Chem 1979; 254: 10421-5.

3. Kaminski M, McDonagh J. Inhibited thrombins, interactions with fibrinogen and fibrin. Biochem J 1987; 242: 881-7.

4. Wilner GD, Danitz MP, Mudd $S_{1}, H$ sieh $K_{1}$. Fenton JW. Selective immobilization of a-thrombin by surface bound fibrin. J Lab Clin Med 1981; $97 ; 403-11$.

5. Hogg $\mathrm{PI}$, Jackson CM. Fibrin monomer protects thrombin from inactivation by heparin antithrombin III: Implications for heparin efficacy. Proc Natl Acad Sci USA 1989: 86: $3619-23$.

6. Liu YC, Kaplan LK, Makowitz HA, Nossel LH. Thermodynamic characterization of thrombin binding by cross linked and non cross linked fibrin in the presence and absence of $\mathrm{Ca}^{2+}$. The Journal of Biol Chem 1980; 255; 7627-30.

7. Seegers WH. Prothrombin. Massachusetts: Harvard University Press 1962" $\mathrm{pp} 286$ and following.

8. Weitz $\mathrm{Jl}$, Hudoba $\mathrm{M}$, Massel $\mathrm{D}$, Maraganore $\mathrm{J}$, Hirsh $\mathrm{J}$. Clot bound thrombin is protected from inhibition by heparin antithrombin III but is susceptible to inactivation by antithrombin III independent inhibitors. J Clin Invest 1990" 86 : 385-91.

9. Francis WC, Markham ER, Barlow HG, Florack MT, Dobrzynski MD, Marder JV. Thrombin activity of fibrin thrombi and soluble plasmic derivatives. J Lab Clin Med 1983: 102: 220-30.

10. Prins $M H$, Weitz $\mathrm{Jl}$. Heparin inhibits the amplification of coagulation mediated by clat-bound thrombin. Thromb Haemost 1991; 65 : 759, abstract 319 .

11. Bendayan $P$, Boccalion $H$, Dupouy $D$, Boneu $B$. Dermatan sulfate is a more potent inhibitor of clot-bound thrombin than unfractionated and low molecular weight heparins. Thromb Haemost 1994; 71: 576-80.

12. Bendayan $P$, Boneu $B$, Boccalon $H$. Dermatan sulfate is a more potent inhibitor of clot bound thrombin than unfractionated and low molecular weight heparins, Poster presentation XIVth Congress of the Intemational Society on Thromb Haemost, New York; USA 1993.

13. Buchanan A. Original communications on the coagulation of the blood and other fibriniferous liquids, London Med Gaz, 1845.

14. Hemker HC. Feedback mechanisms in blood coagulation and their inhibition by heparins. In: FEBS symposium. H. C. Hemker, ed. Haemostasis vol. 21, 1991. 
15. Hurlet Birk Jensen $A$, Béguin $S$, Josso F. Factor $V$ and Vlll activation (in vivo) during bleeding. Evidence of thrombin formation at the early stage of haemostasis. Path Biol 1976; 24: 6-10.

16. Newcomb TF, Hoshida M. Factor $V$ and thrombin. Scad J Clin Lab Invest 1965; 17 (Suppl 84): 61-9.

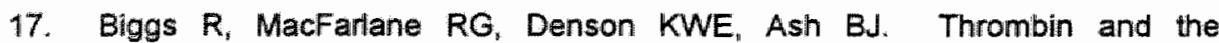
interactions of factors VIII and IX. Brit J Haemat 1965; 11: 276-95.

18. Suzuki $K_{v}$ Dahlbäck $B$, Stenflo J. Thrombin catalysed activation of human coagulation factor $V$. J Biol Chem 1982; 257 : 6556-64.

19. Pieters $\mathrm{J}$, Lindhout $T$, Hemker HC. In situ generated thrombin is the only enzyme that effectively activates factor $V / I I I$ and factor $V$ in thromboplastin activated plasma. Blood 1989; 74: 1021-4.

20. Rapaport SI, Hjort PF, Patch MJ. Further evidence that thrombin activation of factor VIII is an essential step in intrinsic clotting. Scand J Clin Lab Invest 1965; 17 (Supp)): 84-8.

21. Davey MG, Luscher EF. Action of thrombin and other proteolytic enzymes on blood platelets. Nature 1967; 216: 857-8.

22. Bevers EM, Comfurius P, Van Rijn JLML, Hemker HC, Zwaal RFA. Generation of Prothrombin converting activity and the exposure of phosphatidylserine at the outer surface of platelets. Eur J Biochem 1982; 122: 429-36.

23. Rosing J, Tans G, Govers-Riemslag JWP, Zwaal RFA, Hemker HC. The role of phospholipids and factor $\mathrm{Va}$ in the prothrombinase complex. J Biol Chem $1980 ; 255$ (1): $274-83$.

24. Van Diejien $G$, Tans $G$, Rosing J, Hemker HC. The role of phospholipid and factor Villa in the activation of bovine factor $X$. J Biol Chem 1981; 256:3433-42.

25. Baruch D, Hemker HC, Lindhout T. Kinetics of thrombin-induced release and activation of platelet factor $V$. Eur J Biochem 1986; 154: 213-8.

26. Willems $G M$, Lindhout $T$, Hermens WT, Hemker HC. Simulation model for thrombin generation in plasma. Haemostasis 1991; 21: 197-207.

27. Béguin $S$, Kessels $H_{1}$, Hemker HC. Feedback reactions in blood coagulation are mediated by fibrin bound thrombin which is not inhibited by heparin (abstract). Thromb Haemost 1993; 69: 811.

28. Hemker $\mathrm{HC}$, Willems $\mathrm{GM}_{4}$ Beguin $\mathrm{S}$. A computer assisted method to obtain the prothrombin activation vellocity in whole plasma independent of thrombin decay processes, Thromb Haemost 1986; 56: 9-17.

29. Hemker $H C$, Wielders $S_{n}$ Béguin $S$. The thrombin potential, a parameter to assess the effect of antithrombotic drugs on thrombin generation. In: 
Fraxiparine. Bounameaux $H$, Samama M, ten Cate JW, eds. New York, Stuttgart: Schattauer 1990; pp 89-101.

30. Béguin S. Lindhout T. Hemker HC. The effect of trace amounts of tissue factor on thrombin generation in platelet rich plasma, its inhibition by heparin. Thromb Haemost $1989 ; 61$ (1): 25-9.

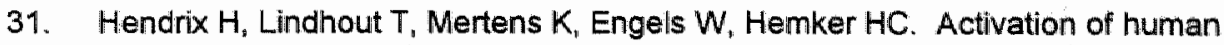
prothrombin by stoichiometric leveis of staphylocoagulase. J Biol Chem 1983; 258: $3637-44$.

32. Béguin $S$, Dol F, Hemker $H C$. Factor IXa inhibition contributes to heparin effect. Thromb Haemost 199 1; 66 (3): 306-9.

33. Kessels $H$, Béguin $S$, Hemker $H C$. The role of thrombin feedback reactions and factor $\mathrm{Xa}$ in clotting human plasma (abstract). Thromb Hemost 1993; 69: 810.

34. Hemker HC, Béguin S. The mode of action of heparins in vitro and in vivo. Heparin and Related Polysaccharides. New York: Plenum Press 1992.

35. Lindhout $T$, Blezer $R$, Hemker $H C$. The anticoagulant mechanism of action of recombinant hirudin (CGP 39393) in plasma. Thromb Haemost 1990; 64 (3): 464-8.

36. Eisenberg PR, Siegel JE, Abendschein DR, Miletich JP. Importance of factor $X a$ in determining the procoagulant activity of whole-blood clots, $J$ Clin Invest 1993; 91: 1877-83.

37. Hemker HC. The mode of action of heparin in plasma. In: Xith Cangress Thrombosis Haemostasis, Brussels. Verstraete $M$, Vermylen J, Lijnen HR, Arnout J, eds. Leuven: Leuven University Press 1987; pp 17-36.

38. Béguin $S$, Lindhout $T$, Hemker $H C$. The mode of action of heparin in plasma, Thromb Haemost 1988; 60: 457-62.

39. Foster WB, Nesheim ME, Mann KG. The factor Xa catalysed activation of factor V. J Biol Chem 1983; 254: 13970.

40. Monkovic DB, Tracy $P B$. Activation of human factor $V$ by factor $X a$ and thrombin. Biochemistry 1990; $29: 1118-28$.

41. Vehar GA, Davie EW. Preparation and properties of bovine factor VIII (Antihemophilic factor). Biochemistry 1980;19(3): 401-10.

42. Lollar $P$, Knutson GJ, Fass DN. Activation of porcine factor VIll by thrombin and factor Xa. Biochemistry 1985; $24: 8056-64$.

43. Schoen $P$, Lindhout $T$. The in situ inhibition of prothrombinase-formed human $\alpha$-thrombin and meizothrombin (des fragment 1) by andthrombin III and heparin. J Biol Chem 1987; 262: 11268-74.

44. Sandberg $H_{*}$ Andersson LO, Hoglund S. Isolation and characterisation of lipid- 
protein particles containing platelet factor 3 released from human platelets. Biochem ل1 1982; 203: 303-11.

45. Simms P, Wiedmer T. Esmon CT. Weiss HJ, Shatil SJ. Assembly of the platelet prothrombinase complex is linked to vesiculation of the platelet plasma membrane. J Biol Chem 1989; 264: 17049-53. 


\section{Chapter 3}

\section{The Effect of Fibrin Clots and Clot-Bound Thrombin on the Development of Platelet Procoagulant Activity*}

\section{Summary}

We tested different types of clot for their ability to provoke procoagulant activity in platelets: normal clots from platelet poor plasma (des AABB- or fibrin II clots), similar clots in which the adsorbed thrombin has been inhibited by hirudin, and clots obtained by the action of two snake venom enzymes that release only fibrinopeptide $A$ (des AA- or fibrin I clots). Analogous clots from fibrinogen solutions were also tested.

In platelet rich plasma (PRP), where platelet coagulant phospholipids (PCP) are rate limiting for thrombin generation, the addition of any type of clot enhances the generation of thrombin thus it induces the appearance of PCP. Clots containing active adsorbed thrombin are the most potent ones in this respect. Lactate dehydrogenase $(\mathrm{LDH})$ levels do not increase in the course of the thrombin generation so the platelets are not damaged in the process. Noncentrifugable PCP could be demonstrated to appear during the process, so the production of procoagulant phospholipid microparticles must be part of the mechanism. Membrane transbilayer phosphatidyl serine movement (flip-flop) can not be demonstrated in PRP as the activated platelets are caught in the emerging clat.

In order to demonstrate flip-flop, we tried to investigate the influence of clats on washed platelets. However, contrary to platelets in a plasma milieu, isclated platelets are damaged by fibrin clots, especially in the presence of thrombin, as can be judged from the appearance of LDH.

\footnotetext{
* Based on : Kumar R., Béguin S. and Hemker H.C. Thromb Haemost 1995;74(3):962-8.
} 
We conclude that, in PRP, clots induce the appearance of PCP from platelets by vesiculation, possibly accompanied by flip-flop and that thrombin accelerates the process but is not an absolute requirement.

\section{Introduction}

It is becoming increasingly evident that primary haemostasis through platellet activation and aggregation and secondary haemostasis through clotting are processes that amplify each other in all types of haemostatic and thrombotic events (see ref 1 for a review). A powerful resonance loop establishes itself at a site of vessel injury because thrombin very effectively activates platelets and activated platelets accelerate thrombin generation by exposing a procoagulant phospholipid surface $(2-4)$ and releasing platelet factor $V(5-7)$. Thus, the formation of thrombin and platelet activation are interdependent processes and it is not easy to dissociate the role of one from another.

In the process of clotting of fibrinogen by thrombin, a certain amount of thrombin is adsorbed on the fibrin (8-11). Clot-bound thrombin still exhibits catalytic activity since it has been reported to catalyze the release of FPA from fibrinogen (12-14), to hydrolyse chromogenic substrates (13) and to shorten the coagulation time of blood and plasma (14-16). The fibrin clot thus behaves as a reservoir of enzymatically-active thrombin, more significantly so as the inhibition characteristics of bound thrombin by plasma antithrombins have been demonstrated to be much different from fluid phase thrombin, notably that this thrombin is insensitive to antithrombin $(11,12,15)$. There also arises the question, whether the adsorbed thrombin still could function in the thrombinmediated feedback reactions that are so typical for the coagulation mechanism. Recently we have reported $(17,18)$ that clot-bound thrombin could indeed further enhance the thrombin formation by sustaining the activation of plasma cofactor proteins factor $\mathrm{V}$ and VIII. We have also observed that in 
platelet rich plasma (PRP) clots significantly lower the lag phase prior to the burst of thrombin generation, indicating that platelets are activated by clots.

The present chapter investigates the influence of clots produced by thrombin and non thrombin enzymes on the stimulation of the platelets. It has been shown that the major platelet surface receptor GPIlb/lila ( $\alpha_{\|} / b_{3} \beta_{3}$ integrin) is activated by a variety of extracellular matrices including fibrin (19) leading to highly adherent behaviour of the platelets. The clot may also induce the platelet release reaction (14). Because there are several forms of platelet activation that do not lead to the exposure of procoagulant surfaces $(20)$, it remains to be seen how the procoagulant behaviour of the platelets is affected by clots and clot bound thrombin. To this end, in the work presented here, we have studied the effect of different types of clots on the generation of platelet prothrombin converting activity in platelet rich plasma and in suspensions of washed platelets and compared it with the effect of well known platelet activators such as $\mathrm{Ca}^{2+-j o n o p h o r e ~} \mathrm{~A} 23187$ or Ila and collagen, alone or in combination.

\section{Materials and Methods}

\section{Materials}

Fatty acid free bovine serum albumin (BSA), ovalbumin (grade V) and Calcilum ionophore, A23187 were purchased from Sigma (St. Louis, MO). Horse tendan collagen (type 1) was from Hormon Chemie (Munich, Germany). Chromogenic substrate used for thrombin was S2238: H-D-Phe-Pip-ArgpNA.2HCl. Purified fibrinogen was obtained from Kordia (Leiden, The Netherlands). Reptilase was supplied by Laboratories Stago (Asnières, France) and Agihal, a purified fraction of Agkistrodon halys halys snake venom, that splits fibrinopeptide A from fibrinogen was obtained from Prof. $L$. Yukelson (Tashkent, Uzbekistan). Recombinant hirudin (Knoll AG) was a kind gift of Dr. W. Hornberger. 


\section{Plasma}

PRP for thrombin generation experiments was obtained by centrifugation at $250 \mathrm{~g}, 15^{\circ} \mathrm{C}, 10$ minutes of freshly drawn citrated blood (1 volume trisodium citrate $0.13 \mathrm{M}$ to 9 volumes blood) of healthy donor. The platelet count was adjusted to $3^{*} 10^{8} / \mathrm{ml}$ with homologous platellet poor plasma (PPP) obtained by double centrifugation of PRP at $1000 \mathrm{~g}, 15^{\circ} \mathrm{C}$, $10 \mathrm{~min}$.

PRP for the measurement of generation of platelet procoagulant activity was obtained from blood taken $5: 1$ on ACD (183 mM glucose $80 \mathrm{mM}$ trisodium citrate, $52 \mathrm{mM}$ Citric acid) centrifuged under the same conditions as described above. The platelet count in this case was adjusted to $1^{*} 10^{8} / \mathrm{ml}$.

\section{Platelet Preparations}

Six volumes of blood drawn from healthy donors by venipuncture was collected on one volume of an anticoagulant mixture consisting of $42 \mathrm{mM}$ EDTA, $42 \mathrm{mM}$ trisodium citrate, $25 \mathrm{mM} \mathrm{NaOH}$ ( $\mathrm{pH} \mathrm{6.6).} \mathrm{The} \mathrm{blood} \mathrm{was}$ centrifuged for 15 minutes at $250 \mathrm{~g}$. The platelet rich supernatant thus abtained was subsequently centrifuged for $5 \mathrm{~min}$ at $160 \mathrm{~g}$ to remove any remaining erythrocytes and leukocytes. The PRP was further centrifuged for 15 minutes at $500 \mathrm{~g}$ and the platelet pellet hence recovered was resuspended in 19 volumes buffer (pH 6.6) consisting of $25 \mathrm{mM} \mathrm{HEPES}, 136 \mathrm{mM} \mathrm{NaCl}, 2.68$ $\mathrm{mM} \mathrm{KCl}, 1.7 \mathrm{mM} \mathrm{MgCl} 2,25 \mathrm{mM}$ glucose, $0.5 \% \mathrm{BSA}$ and 1 volume anticoagulant mixture(see above). Platelets were thus washed twice centrifuging at $500 \mathrm{~g}$ for $15 \mathrm{~min}$ and were finally resuspended in 1 volume Hepes buffer ( $\mathrm{pH} \mathrm{6.6)}$ and 4 volumes of same Hepes buffer (pH 7.5). The platelet concentrations were determined using a Coulter counter. All the platelet handling was done at room temperature.

\section{Proteins}

Human prothrombin was purified according to Discipio et al (21). Thrombin was purified from prothrombin after activation with factor $\mathrm{Xa}$ as described by Rosing et al (22). The thrombin concentration was determined by active site titration according to Chase and Shaw (23). Bovine factor $\mathrm{Xa}$ was 
prepared from factor $X_{2}$ using $R V W-X$ according to method of Fujikawa et al (24). Factor $X a$ concentrations were calculated after active site titration according to Smith (25). Bovine factor $V$ was purified by the procedure described by Dähiback (26) and Suzuki et al (27) with minor modifications as explained in Ref. 28. Factor $\mathrm{Va}$ was prepared by activation of factor $\mathrm{V}$ with thrombin and concentrations of Va were determined kinetically as described by Lindhout et al (29).

\section{Methods}

\section{Preparation of clots}

Plasma clots: PPP (250 $\mu$ l for one clat) was coagulated by recalcification to a final concentration of $23 \mathrm{mM} \mathrm{CaCl}_{2}$ in a glass tube and incubated at $37^{\circ} \mathrm{C}$ for $1 / 2$ hour. The clot was wound on a plastic spatula, dried and incubated in the (human) serum for $10 \mathrm{~min}$. The clot was then extensively washed in $2 \mathrm{ml}$ of Buffer $\mathrm{A}$ that was changed three times in order to eliminate any soluble material trapped in the clot. That no unbound thrombin remained with the clot was checked by the absence of amidolytic activity of last washing buffer on $\mathrm{S} 2238$.

Purified fibrinogen clots were prepared from $250 \mu \mathrm{ll}$ of $3 \mathrm{mg} / \mathrm{ml}$ fibrinogen solution in $150 \mathrm{mM} \mathrm{NaCl}$, by adding $\mathrm{CaCl}_{2}(23 \mathrm{mM})$ and $1 / 50$ volume of Reptilase or Agihal solution or, in some cases, $30 \mathrm{nM}$ lla. Extensive washing of the clots was practised in all the cases. Non cross linked fibrin clots i.e. des AA fibrin obtained by the action of snake venoms that only release fibrinopeptide A have been referred as fibrin I clots while des AABB fibrin clots (cross linked) as fibrin II clots.

\section{Measurement of thrombin generation in PRP}

This was done as previously described (30). Briefly, $240 \mu$ of PRP was diluted with $60 \mu$ of Buffer $\mathrm{A}(50 \mathrm{mM}$ Tris $\mathrm{HCl}, 100 \mathrm{mM} \mathrm{NaCl}, 0.5 \%$ BSA; pH 7.35) and coagulation was triggered with $60 \mu \mathrm{l} \mathrm{CaCl} 2$ (final concentration 16.7 $\mathrm{mM}$ ). The clots were added to the reaction mixture 90 seconds after triggering 
coagulation. The reaction mixture was continuously stirred by a small spatula and $10 \mu l$ subsamples were drawn at equally spaced intervals and diluted in prewarmed $\left(37^{\circ} \mathrm{C}\right.$ ) cuvettes containing $490 \mathrm{\mu l}$ of Buffer B (Buffer A with $20 \mathrm{mM}$

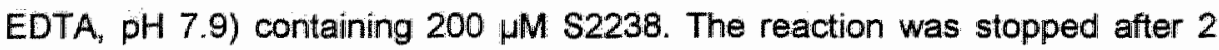
minutes by adding $300 \mu \mathrm{l}$ of $1 \mathrm{M}$ Citric acid. As soon as the reaction mixture coagulated, the clot was wound on the spatula and discarded. From the rate of change of optical density measured at $405 \mathrm{~nm}$, the amidolytic activity was calculated by comparing with a standard calibration curve made with active site-titrated human $\alpha$-thrombin.

\section{Measurement of Platelet Prothrombin Converting Activity}

In washed platelet suspensions: The reaction mixture consisted of 343 $\mu l$ of washed platelet suspension with platelet count $0.5^{*} 10^{8} / \mathrm{ml}$ to which $7 \mu$ of $100 \mathrm{mM} \mathrm{CaCl} / 2$ was added. The mixture was magnetically stirred at $37^{\circ} \mathrm{C}$ at 350 rev/min with teflon coated stirring bars. A stirring assembly was used which allowed to stir 7 reaction mixtures simultaneously at $37^{\circ} \mathrm{C}$. After 3 minutes prewarming, platelet activation was initiated by adding a platelet stimulator. The generation of platelet prothrombin-converting activity was determined by transferring a $10 \mu$ sample from the platelet activation mixture to $240 \mu$ of an assay mixture containing $3 \mathrm{nM}$ factor $\mathrm{Va}, 5 \mathrm{nM}$ factor $\mathrm{Xa}$ and 1 $\mu \mathrm{M}$ prothrombin in $25 \mathrm{mM}$ Hepes ( $\mathrm{pH} 7.7$ ), $175 \mathrm{mM} \mathrm{NaCl}, 5 \mathrm{mg}$ BSA/ml, $2 \mathrm{mM}$ $\mathrm{CaCl}_{2}$. A Reference prothombinase blank was measured by transferring a 10 $\mu$ Hepes buffer $\mathrm{pH} 6.6$ aliquot to the prothombinase mixture instead of the platelet activation mixture.

The formation of thrombin was stopped after 1 min by transferring $10 \mu l$ aliquots to cuvettes (at $37^{\circ} \mathrm{C}$ ) with $990 \mu$ l buffer $(50 \mathrm{mM}$ Tris, $175 \mathrm{mM} \mathrm{NaCl}, 0.5$

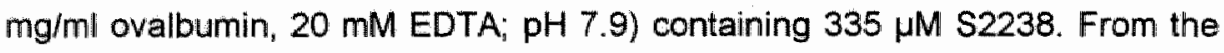
absorbance change recorded at $405 \mathrm{~nm}$, the amount of thrombin formed is calculated via a calibration curve made with known amounts of thrombin. The time course of generation of platelet prothrombin-converting activity was then determined by samples taken from the platelet activation mixture at various time intervals. Controls with non-stimulated platelets were always run in 
parallel. Finally, the amount of thrombin formed in the prothombinase blank was subtracted from all the readings.

In PRP: $100 \mu$ of PRP, 1:6.7 diluted in Tris buffer A (see above) was incubated for 5 minutes with or without clots. $50 \mu$ l subsample from PRP was then transferred to $100 \mu \mathrm{l}$ of an assay mixture containing $0.45 \mathrm{nM}$ factor $\mathrm{Xa}$, $10.5 \mathrm{nM}$ factor $\mathrm{Va}, 3 \mu \mathrm{M}$ Prothrombin and $12 \mathrm{mM} \mathrm{Ca}^{2+}$ in Tris buffer A. At 4 min, $10 \mu l$ of subsample was taken to the cuvette containing $465 \mu l$ of Tris buffer B ( see above). The amount of thrombin formed was calculated from the absorbance change measurement at $405 \mathrm{~nm}$ after the addition of $25 \mu$ l of $\mathrm{S} 2238(4 \mathrm{mM})$.

Release of Platelet Lactate Dehydrogenase ( $(\mathrm{DH})$

Samples were assayed for the release of platelet LDH by using a commercially available kit (Boehringer, Mannheim). 200 $\mu \mathrm{l}$ PRP or the activated platelet suspension was centrifuged at $9000 \mathrm{~g}$ for $3 \mathrm{~min}$ in an Eppendorf centrifuge $5 \mu \mathrm{l}$ of the supernatant was added to a cuvette with 125 $\mu \mathrm{l}$ of a buffer containing $51.7 \mathrm{mM}$ Phosphate buffer ( $\mathrm{pH} 7.5$ ), $0.19 \mathrm{mM} \mathrm{NADH}$ and $0.6 \mathrm{mM}$ Pyruvate. The activity of LDH was calculated from the absorbancy change at $334 \mathrm{~nm}$. The total LDH content of the platelets was determined in a platelet suspension that was sonicated for $1 \mathrm{~min}$.

\section{Results}

The influence of clots on thrombin generation in PRP

In recalcified PRP, there is a prolonged lag phase prior to the thrombin burst. Lag times preceding thrombin generation in a plasma milieu have been shown to be caused by the time required for a) factor $V$ and/or VIII activation and b) for the generation of a platelet procoagulant surface under influence of traces of thrombin formed. We have shown previously that in PRP, under the conditions used here, the appearance of procoagulant phospholipids on/from the platelets is rate limiting for thrombin generation (30). The presence of 
plasma clots considerably shortens the lag time that precedes the thrombin burst in PRP (Fig. 1). Surprisingly, this effect is not critically dependent upon the presence of thrombin, clots generated by thrombin-like venom enzymes such as reptilase and Agihal, also shorten the lag phase in PRP. Since Agihal and reptilase-clots (fibrin I clots) have been shown to be unable to promote factor $V$ or VIII activation (18), this confirms the rate limiting role of platelet procoagulant phospholipids. This strongly suggests a direct effect of fibrin on the generation of platelet procoagulant activity. To test this hypothesis, we have studied the influence of fibrin clots on the generation of platelet procoagulant activity under conditions where no thrombin could be formed, i.e. in suspensions of washed platelets.

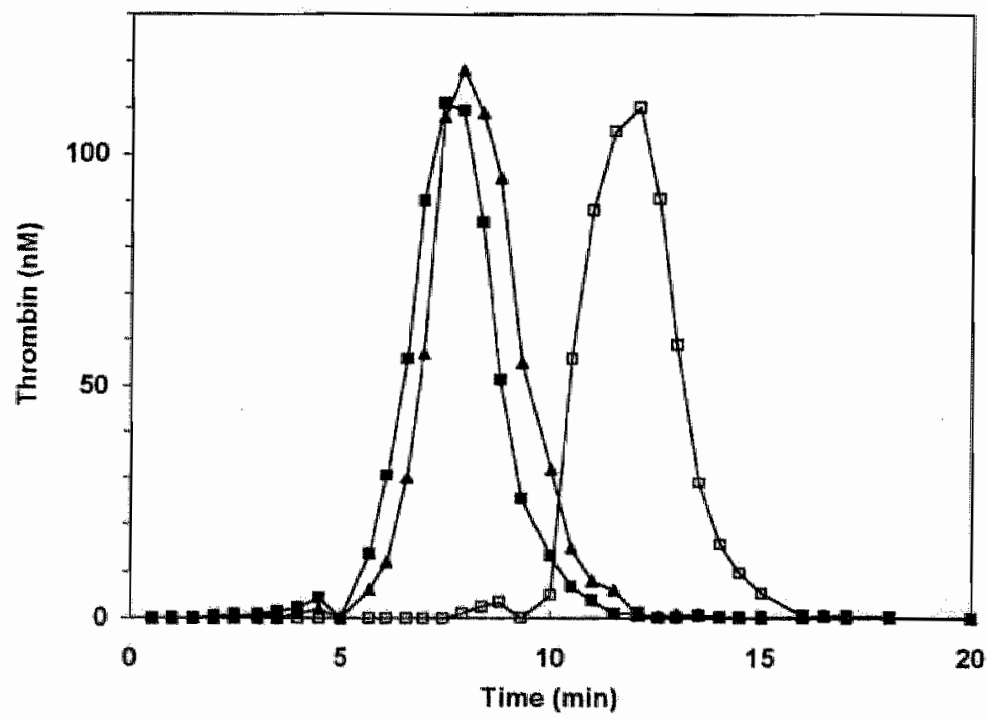

Fig. 1 The effect of fibrin clots on thrombin generation in PRP. Thrombin generation was triggered in PRP (platelet count $3^{*} 10^{8} / \mathrm{ml}$ ) by the addition of $\mathrm{CaCl}_{2}(16.7 \mathrm{mM}$ ). The clots were added at $t=90 \mathrm{~s}$. The amidolytic activity was determined in subsamples taken at $30 \mathrm{~s}$ intervals from which the thrombin activity was calculated (30). () Control without clots. (U) 3 Clots obtained by recalcifying plasma were added. (A) 3 Clots obtained from purified fibrinogen by adding Agihal (Fibrin I clots) were added. 
The effect of plasma clots on the prothrombin-converting activity of washed platelets

Plasma clots were added to a washed platelet suspension and after different time intervals aliquots were drawn and transferred to assay mixtures

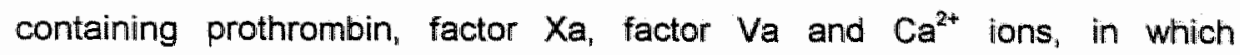
procoagulant lipid was the rate limiting component of prothrombinase. In this way the time course of generation of procoagulant activity (i.e. prothrombinase activity) in the platelet suspension was followed. The ability of clots to induce platelet procoagulant activity was compared with that the established platelet activators, thrombin and the ionophore A23187 (Fig. 2). The incubation of platelets with clots results in an immediate appearance of procoagulant activity

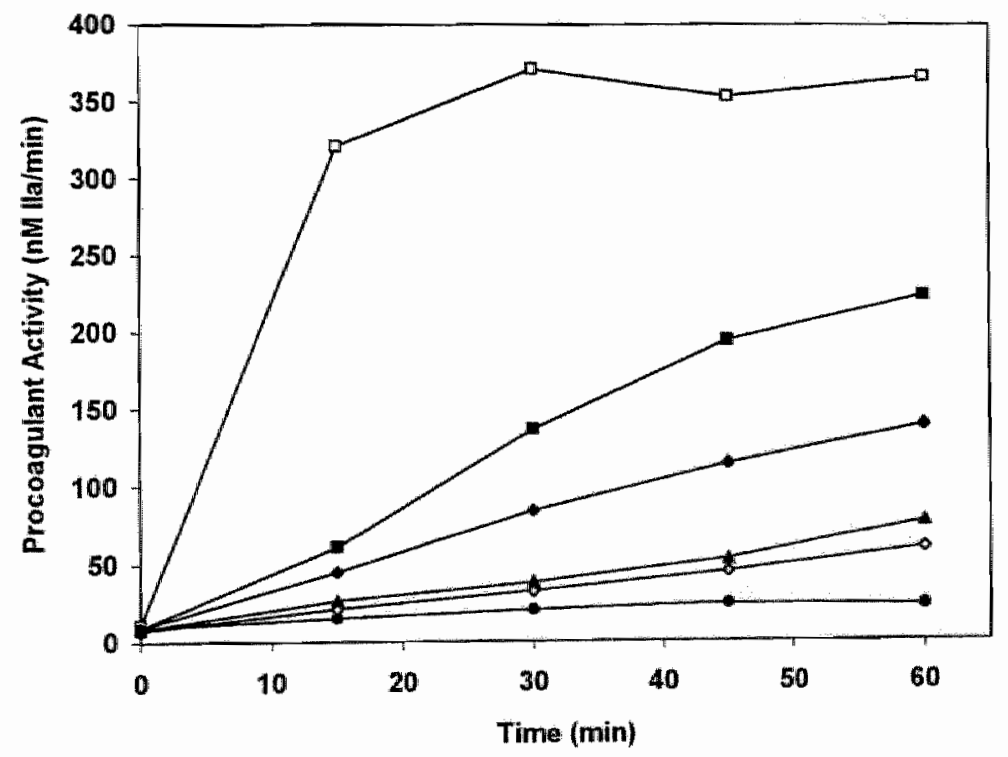

Fig. 2 Time course of platelet prothrombin converting activity in washed platelet suspensions. The stimulators were added to the platelet suspension (platelet count $0.5^{*} 10^{8} / \mathrm{ml}$ ) in the presence of $2 \mathrm{mM} \mathrm{Ca}{ }^{2+}$. Prothrombin activation was measured at 1 $\mu \mathrm{M}$ Prothrombin, $5 \mathrm{nM}$ Xa, $3 \mathrm{nM}$ Va as described in detail in materials and methods. The various platelet activators shown are (D) 4 HM A23187, (D) 3 plasma clots, ( $) 2$ plasma clots, (A) 1 plasma clot, $(\diamond) 28 n M$ lla. The control platelets $(\bullet)$ were without any stimulator. Representative experiment of six so performed. 
that linearly increases in time and that is proportional with the number of clots present in the platelet suspension. Platelets incubated with one plasma clot exhibit a 3-fold higher prothrombin-converting activity than control platelets. Activation of platelets with $30 \mathrm{nM}$ thrombin causes approximately the same effect as one clot. The stimulation by 3 plasma clots results in a linear increase that within one hour attains the level of $60 \%$ of the maximum procoagulant activity reached in platelet suspensions activated with the $\mathrm{Ca}$-ionophore A23187. The initial rate of generation of procoagulant activity by the ionophore is, however, much higher than that obtained in the presence of clots.

The prothrombin-converting activities induced by plasma clots and other agonists (Ila, collagen, lla plus collagen and A23187) are summarized in Table 1.

Table 1 Platelet procoagulant activity provoked by different triggers in washed platelet suspensions

\begin{tabular}{lcc}
\hline Trigger & Level at $t=60$ & Range \\
\hline Unstimulated & $23 \pm 5(n=13)$ & $17-33$ \\
Thrombin & $66 \pm 21(n=6)$ & $34-95$ \\
Collagen & $99 \pm 46(n=3)$ & $62-165$ \\
Thromb+Coll. & $138 \pm 20(n=3)$ & $118-158$ \\
1 clot & $72 \pm 20(n=6)$ & $47-101$ \\
2 clots & $91 \pm 38(n=6)$ & $70-168$ \\
3 clots & $286 \pm 68(n=13)$ & $84-450$ \\
A23187 & $414 \pm 70(n=12)$ & $394-536$
\end{tabular}

The amount of lla formed $(\mathrm{nM})$ after 60 minutes of platelet activation in the absence or presence of various stimulators. The results are represented as Avg. \pm SD (number of times the experiment is done). To express, the donor dependent scatter the range obtained is also given. Experimental conditions are the same as in legend of Fig. 2. The concentrations of stimulants were: $\| l a(30 \mathrm{nM})$, Collagen $(10 \mu \mathrm{g} / \mathrm{ml})$, lla/collagen

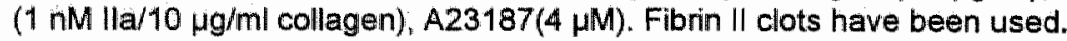


Under the conditions chosen in this experiment the capacity of the various activators to induce platelet procaagulant activity is in the order: A23187 $>3$ clots $>\| l a$ plus collagen $>$ collagen $\geq 2$ clots $>1$ clot $\geq \|$ la $>$ no activator.

To check whether the generation of platelet procoagulant activity should be attributed to the clot itself or to a factor released from clots the control experiments presented in Table 2 were performed. Clots incubated with buffer in the absence of platelets do not induce any prothombinase activity. This means that clots do not release a factor that on itself stimulates prothrombin activation. The supernatant of clots incubated in buffer was unable to generate prothrombin-converting activity in platelet suspensions. This excludes the possibility that some platelet-activating substance extrudes from the clots and shows that physical interaction between clots and platelets is a prerequilsite for the generation of clot-induced procoagulant activity in platelet suspensions.

Another essential feature of clot-induced platelet procoagulant activity is the requirement for stirring during the incubation of platelets with the clot. $A$

Table 2 Requirements for the generation of prothrombin-converting activity in platelet-clot suspensions

\begin{tabular}{lcc}
\hline Experiment & Reaction mixture & $\begin{array}{r}\text { Prothrombin-converting } \\
\text { activity (nM lla/min) }\end{array}$ \\
\hline 1 & Buffer & $5 \pm 1$ \\
2 & Supernatant of clot suspension & $6 \pm 2$ \\
3 & Platelets & $8 \pm 1$ \\
4 & Platelets + supernatant of 3 clots & $8 \pm 3$ \\
5 & Platelets +3 clots & $286 \pm 68$
\end{tabular}

Experimental set up was the same as for Fig. 2. In experiments 1 and 3 the reaction mixture consisted of Hepes buffer ( $\mathrm{pH} 6.6$, see materials and methods) and platelet suspension respectively. In experiment 2 , the plasma clots were incubated in buffer in the absence of platelets. For experiment 4 , the plasma clots were incubated in buffer for 30 minutes. The dots were taken out and platelet suspension was added. Finally in experiment 5 , the prothombinase activity was measured when plasma clots were incubated with platelet suspension. In all the experiments $2 \mathrm{mM} \mathrm{Ca}^{2+}$ was added. The results are expressed as Average $\pm S D(n=5$ for first 4 experiments and $n=13$ for experiment 5 ). 
similar requirement has been reported for the generation of platelet prothrombin-converting activity by thrombin, collagen and $A 23187(4,31)$.

In our earlier work $(18)$ it has been attempted to quantify the amount of thrombin adsorbed to the clot by the technique of comparing the thrombin potential, the area under the thrombin time curve in the presence and absence of fibrinoger. The thrombin potential was found to be $31 \pm 3 \%$ (mean \pm SEM, $n=10$ ) lower in the presence than in the absence of fibrinogen with similar amounts of prothrombin being converted This indicates that about $30 \%$ of all the thrombin formed is adsorbed on to fibrin. Indeed it was also seen that the peak level of free thrombin decreases from about $110 \mathrm{nM}$ to about $80 \mathrm{nM}$.

\section{Effect of clots that do not contain thrombin}

The experiments reparted above were performed with clots that are known to contain bound thrombin (i.e. uninhibited fibrin II clots). The experiments in Fig. 1 show that clots obtained by the action of snake venom enzymes on purified fibrinogen (fibrin I clots) are also able to generate platelet procoagulant activity. Fig. 3 shows a time course of generation of prothrombinconverting activity in platelet suspensions in which fibrin I clots were used as platelet agonists. To ensure that venoms by themselves do not influence the reaction, Agihal and Reptilase were added to the platelet activation mixture in $1 / 50$ volume (as for obtaining the clots) and prothombinase activity was measured (Inset graph, Fig. 3). With fibrin I clots, a modest but significant increase of the prothrombin-converting activity was seen, that was, however much lower than that of fibrin II clots. This is indicative for a role of both fibrin (1 or II) and clot-bound thrombin in the generation of procoagulant activity in washed platelet suspensions.

The importance of clot-bound thrombin was further tested by determining the effect of plasma clots that were treated with an inhibitor of thrombin. To this end plasma clots (fibrin II clots) were incubated with $1 \mu \mathrm{M}$ of hirudin for about 2 hours, blotted dry and transferred to the platelet suspension without washing. In this way a small fraction of the hirudin is transferred to the 
platelet activation mixture, in order to ensure complete inhibition of thrombin bound to the clot. Since in our prothrombinase assay the platelet suspension is

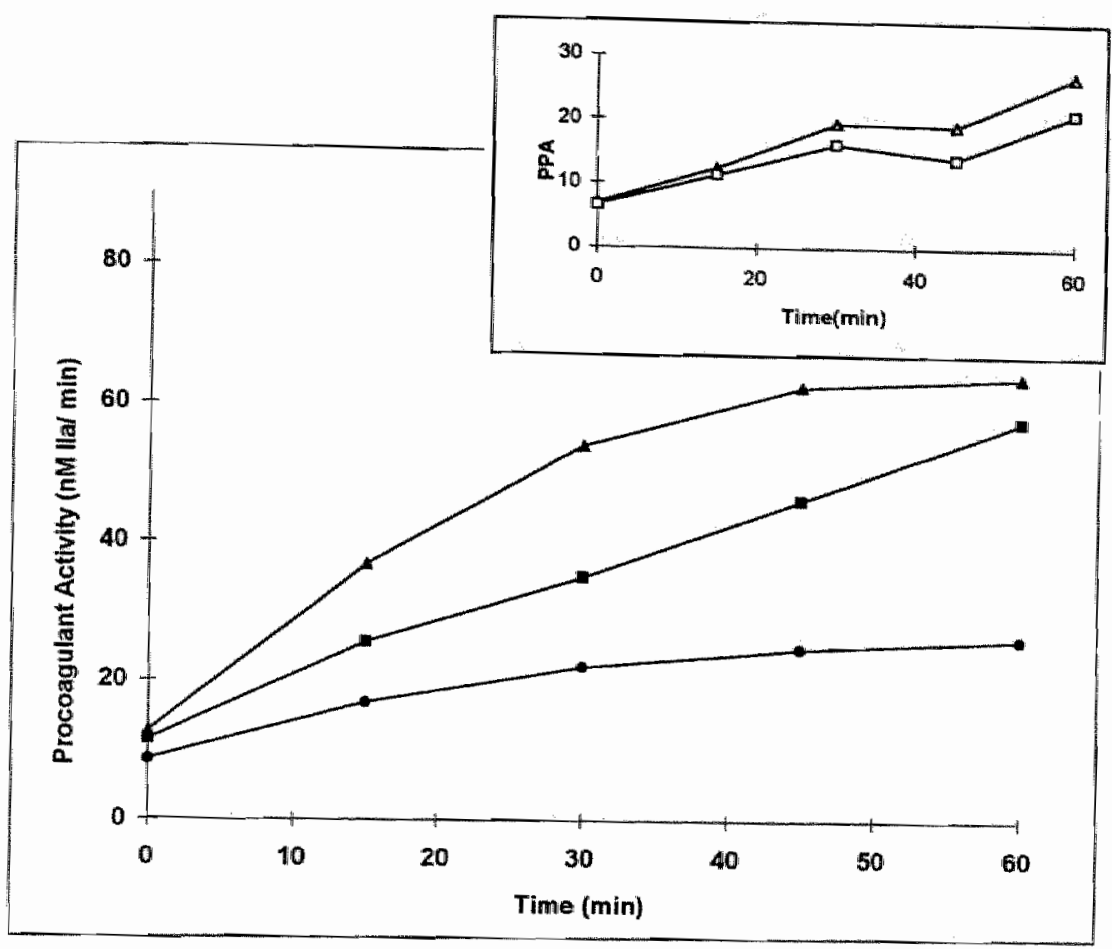

Fig. 3 Effect of addition of Fibrin I clots on platelet prothrombin converting activity in washed platelet suspensions. Experimental set up is the same as in legend of Fig. 2. The clots generated from purified fibrinogen by adding (4) Agihal and (D) Reptilase (Fibrin I clots not containing any thrombin) were used as platelet stimulators. The control platelets (@) were without any stimulator. Unless indicated otherwise, 3 clats have been used in the experiments. The graph represents average values for 6 donors. The inset graph represents the control experiment with $(\Delta)$ Agihal and (D) Reptilase added to the platelet activation mixture in 1/50 volume.

subsampled to a mixture with prothombinase components, the hirudin that is carried over is diluted many times. We determined that the amount of hirudin carried over was less than $1 \mathrm{nM}$ in the final solution which will be too low to inhibit the thrombin formed in the assay mixture. However, to confirm this a control experiment was performed in which $30 \mathrm{nM}$ hirudin was added to the 
platelet mix containing three plasma clots. The time course of generation of platelet prothrombin converting activity was determined by drawing aliquots from the mixture and transferring them to the prothombinase mix. By dilution just over $1 \mathrm{nM}$ hirudin reaches the final solution in this way The amount of thrombin measured after $60 \mathrm{~min}$ of platelet activation was $326 \mathrm{nM}$ which is above the mean of 13 experiments without hirudin and within the mean $\pm 1 S D$ range (Table 1).

Clot associated thrombin activity before and after hirudin treatment was determined by measuring the amidolytic activity on S2238. With three untreated fibrin If clots the thrombin measured after 15 minutes of incubation was $14.8 \mathrm{nM}$ while after hirudin treatment $(1 \mu \mathrm{M})$ the value dropped to 1.28 $\mathrm{nM}$. This residual activity is probably thrombin independent splitting of $\mathbf{S 2 2 3 8}$ because the value observed for fibrin I clots produced without contact with thrombin was $1.15 \mathrm{nM}$.

Table 3 shows that thrombin-containing clots have a significantly higher activity than clots that do not contain thrombin but that the latter anyhow also exhibit activity.

Table 3 Comparison of activities evoked by various clots in washed platelet suspensions

\begin{tabular}{lc}
\hline Agonist & $\begin{array}{c}\text { \% Procoagulant activity } \\
\text { (after 60 min of platelet activation) }\end{array}$ \\
\hline Plasma clots & $100 \pm 9.8$ \\
Fibrinogen + Ila (30 nM) clots & $98 \pm 10.2$ \\
Plasma clots treated Hirudin (1 $\mu \mathrm{M})$ & $26 \pm 4.6$ \\
Fibrin I clots & $21 \pm 4.8$ \\
None & $8 \pm 1.1$ \\
\hline
\end{tabular}

Experimental set up is the same as for Fig. 2. The various clots were obtained as described under methods. For the purpose of comparison the prothombinase activity induced by plasma clots has been taken as $100 \%$ value. The data obtained for 9 donors is expressed as Average \pm SEM. 
The effect of thrombin on the prothrombin-converting activity of platelet-clot suspensions

Washed platelets were incubated for $60 \mathrm{~min}$ in the presence of clots that did not contain active thrombin (fibrin I clots or hirudin-treated plasma clots) prior to the addition of $5 \mathrm{nM}$ thrombin. Fig. 4 shows that the addition of thrombin to platelet suspensions that contain clots causes the platelet procoagulant activity to rise steeply to levels that even exceed those obtained with the Ca-ionophore A23187. Such a rise does not occur when thrombin is added to control platelets incubated without clots. In these experiments the levels of prothrombin-converting activity are much higher than obtained with

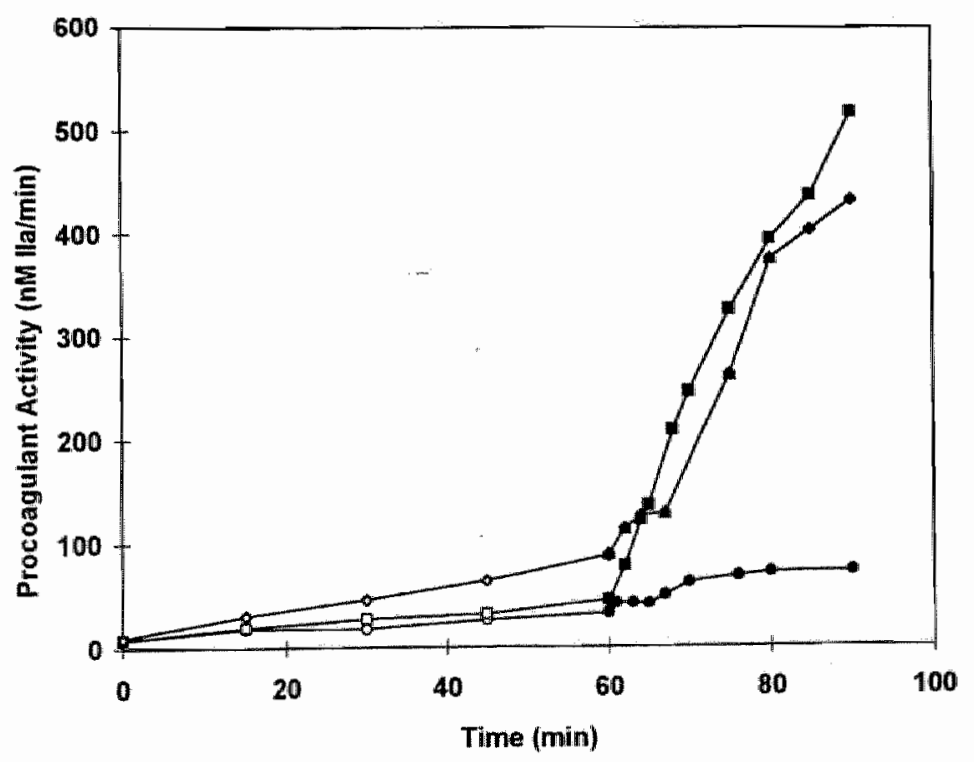

Fig. 4 Effect of addition of lla to Fibrin I clots and hirudin treated clats. Washed platelet suspension was activated by (ㅁ) Fibrin I clots and ( $\hat{v}$ ) plasma clots with inhibited $\|$ la (treated $1 \mu \mathrm{M}$ Hirudin) for $60 \mathrm{~min}$, after which $5 \mathrm{nM}$ lla was added to the platelet activation mixture. The control platelets $(O)$ were without stimulator till $60 \mathrm{~min}$ and then $5 \mathrm{nM}$ lla was added to them. The platelet procoagulant activity was measured as described in legend of Fig. 2. The solid symbols represent the continuations of the same curves after thrombin addition. 
untreated plasma clots. This indicates that the synergistic effect of free thrombin in the generation of fibrin-induced platelet procoagulant activity is much more pronounced than that of clot-bound thrombin.

\section{Leakage of Lactate Dehydrogenase}

Platelet procoagulant activity can result from a transbilayer transport of phosphatidylserine to the outside of the intact membrane (flip-flop), by the shedding of microparticles or by disruption of the cell membrane. As a measure of membrane disruption we used the release of cytoplasmic lactate dehydrogenase. To estimate the contribution of membrane damage to the generation of procoagulant activity we plotted the latter as a function of the release of LDH (Fig. 5). It is seen that the combination of thrombin with clots (of any type) causes procoagulant activity that is accompanied by substantial release of $L D H$, as is, a fortiori, the activity produced by sonication. Thrombin plus collagen, or the Ca-ionophore cause a release of LDH that, for the same amount of procoagulant activity, is only $20 \%$ of maximal. So the platelet procoagulant activity induced by clots in washed platelets is lysis associated.

This imposed LDH measurements in PRP during thrombin generation. The LDH level measured in PPP was $102 \mathrm{~L} / \mathrm{l}$, in sonicated PRP the level was 612 U/l. However for PRP, no significant rise in LDH was obtained (Fig. 6). Knowing the experimental variation of the individual measurements, this means that less than $1 \%$ of the platelets had shed its $\mathrm{LDH}$ during the clotting of PRP. 


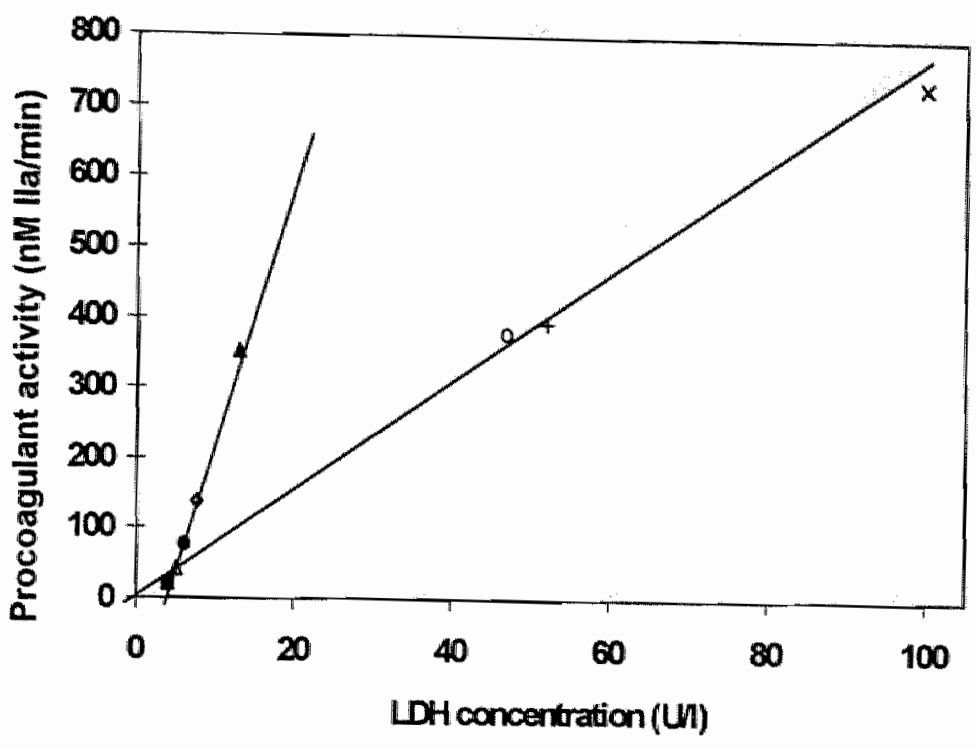

Fig. 5 Prothombinase activity with corresponding Platelet Lactate Dehydrogenase LDH (U/D) obtained after 60 min of platelet activation for washed platelet suspension. Prothombinase activity was measured as described in legend of Fig. 2 . For the measurement of release of platelet lactate dehydrogenase, $200 \mu$ i of activated platelet suspension was centrifuged at $9000 \mathrm{~g}$ for $3 \mathrm{~min}$. Supernatant was added to a cuvette containing Phosphate buffer $(51.7 \mathrm{mM}, \mathrm{pH} 7.5)$, NADH $(0.19 \mathrm{mM})$, Pyurvate $(0.6 \mathrm{mM})$. The activity of $\mathrm{LDH}$ was calculated from the absorbency change at $334 \mathrm{~nm}$. The total LDH content of platelet suspension was determined in the sonicated sample $(x)$. The other points represent the values obtained when the agonist were $(\Delta)$ Fibrin I clots, $(+)$ Fibrin / clots with $5 \mathrm{nM}$ thrombin added to the plateiet activation mixture after $60 \mathrm{~min}$ of platelet activation. (O) Plasma clots ; (O) Plasma clots treated with hirudin, (๖) Thrombin/collagen ( $1 \mathrm{nM}$ thrombin/10 $\mu \mathrm{g} / \mathrm{mi}$ collagen), (4) $\mathrm{Ca}^{2+}$ lonophore and (a) none.

Platelet procoagulant activity generated in PRP in the presence of clots

In order to confirm the action of clots on the disclosure of procoagulant phospholipids by clots, both fibrin I and fibrin II clots were added to PRP and the generation of platelet procoagulant activity was followed in subsamples that were transferred to a prothombinase mixture devoid of phospholipids, as used for washed platelets. Table 4 lists the values obtained after $4 \mathrm{~min}$ of activation. Measurements simultaneously carried for PPP incubated with clots and PRP without clots served as controls. 


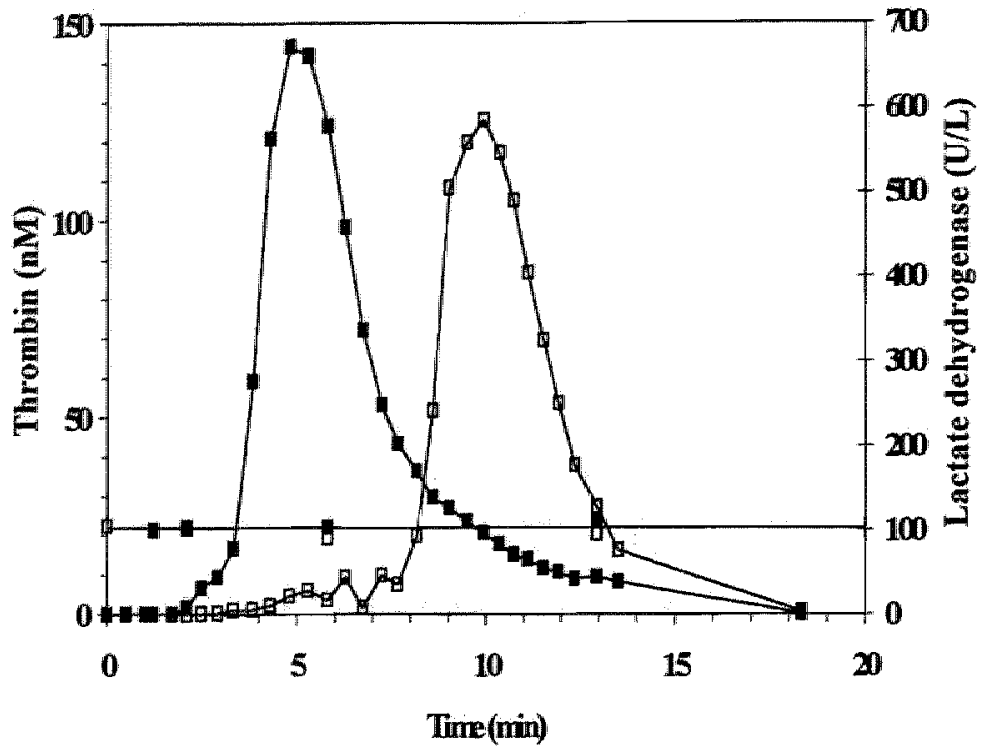

Fig. 6 Measurement of $\mathrm{LDH}$ in PRP simultaneously with thrombin generation experiment. Thrombin generation was triggered in PRP by addition of $\mathrm{CaCl}_{2}$ $(16.7 \mathrm{mM})$. (D) Control without clots. (D) Plasma clots added. PRP samples were drawn from both the parallel experiments at various time intervals and analyzed for the release of $\mathrm{LDH}$ (shown on left $Y$ axis) as described in legends of Fig. 5. The horizontal line represents the base LDH abtained in PPP i.e. $102 \mathrm{U} / \mathrm{L}$ and the points about it give the LDH values measured for the two series in the same symbols. The $L D H$ value obtained for sonicated PRP was $612 \mathrm{U} / \mathrm{L}$.

Table 4 Generation of Platelet Procoagulant Activity in Platelet Rich Plasma on addition of clots

\begin{tabular}{lc}
\hline Reaction Mixture & $\begin{array}{c}\text { Prothrombin Converting Activity } \\
\text { (nM lla / min) }\end{array}$ \\
\hline PRP & $43 \pm 9$ \\
PRP + 3 plasma clots & $151 \pm 34$ \\
PRP + 3 clots from purified fibrinogen & $72 \pm 15$ \\
PPP & $21 \pm 6$
\end{tabular}

For the measurement of platelet procoagulant activity, $100 \mu l$ of $\operatorname{PRP}\left(1^{\star} 10^{8} / \mathrm{ml}\right)$ was diluted 1:6.7 in Tris buffer A (see materials) and incubated with or without clots for 5 min. $50 \mu$ l subsample was transferred to $100 \mu \mathrm{l}$ of prothombinase mixture containing $\mathrm{Xa}(0.45 \mathrm{nM}), \mathrm{Va}(10.5 \mathrm{nM})$, Prothrombin $(3 \mu \mathrm{M}), \mathrm{Ca}^{2+}(12 \mathrm{mM})$. At 4 minutes, the reaction was stopped by taking $10 \mu \mathrm{l}$ subsample to cuvette with $465 \mu \mathrm{l}$ Tris buffer $B$ (with EDTA). The amount of thrombin formed was calculated from the absorbance change at $405 \mathrm{~nm}$ after adding $4 \mathrm{mM} \mathrm{S2238}$. The results are expressed as Average \pm SD for 5 experiments. 


\section{Discussion}

We previously reported that thrombin bound to fibrin is capable to activate factors $V$ and VIII (18). In the course of these experiments it appeared that fibrin clots, even if they did not contain thrombin, foster thrombin generation in platelet rich plasma (PRP). In this article we further investigate the mechanism behind this phenomenon.

Platelets can assist in thrombin generation by exposing procoagulant phospholipid and by releasing factor $V$. Under our experimental conditions, i.e. in 2:3 diluted normal PRP, factor $V$ is present in excess and procoagulant lipids are rate limiting (30). Therefore the release of factor $V$ does not contribute significantly to the thrombin generating capacity of PRP but the availability of procoagulant phospholipid from platelets does. Therefore, if fibrin clots enhance thrombin generation in PRP, these clots must induce the exposure of such phospholipids.

Platelet procoagulant phospholipid activity, also called platelet factor 3 (PF3), is dependent upon the exposure of negatively charged phospholipids. chiefly phosphatidylserine (PS). In the resting platelet, PS is almost exclusively located in the cytoplasmic layer of the cell membrane. Upon activation by thrombin or collagen, and especially if both activators are present, PS is transferred from the inner to the outer monollayer of the intact membrane (3). In this process platelets also shed procoagulant phospholipid particles $(32,33)$. PS also gets exposed when the platelet membrane is disrupted by methods such as freeze thawing or sonication. Such extreme situations however do not occur in vivo and their biological significance seems limited.

Our results show that fibrin clots of any type provoke platelet procoagulant activity in PRP as well as in washed platelet suspensions. Notably non cross-linked fibrin I clots, obtained with snake venom enzymes that only release fibrinopeptide $A$, still exhibit activity. In isolated platelets the presence of thrombin is necessary for a maximal effect (Table 3 ). This may be thrombin already adsorbed to the clot. In plasma, where explosive thrombin 
generation necessarily follows the appearance of platelet procoagulant activity, it is hard to distinguish between the effect of fibrin alone and that of fibrin plus thrombin.

Contrary to what could be expected from its effect on the isolated platelets (3), collagen has been reported not to enhance thrombin generation in PRP (30). The obvious difference between the two situations is that in PRP fibrin is formed by the thrombin generated. We therefore wanted to explore the possibility that fibrin might replace collagen as an inductor of the flip-flop reaction. However, when isolated platelets are stirred with clots, especially if thrombin is present too, they disrupt, as can be judged from their shedding LDH (Fig. 5). This experimental setup therefore is not suitable for the demonstration of flip-flop, and the experiments are inconclusive. In contrast, the induction by clots of procoagulant activity from platelets in PRP is not accompanied by the shedding of $\mathrm{LDH}$. This means that the procoagulant activity is due to PS at the outside of non-disrupted platelets and/or of shedded microparticles. We suppose that the isolation of platelets renders them more vulnerable than platelets in PRP are. We are searching for conditions in which isolated platelets can be incubated with fibrin and thrombin without shedding LDH but thus far we did not find any. For the moment we have no data that make us revise our original hypothesis that fibrin in clotting plasma can play a similar role as collagen does in suspensions of isolated platelets.

Our observations broach the question that how far platelet disruption may be an integral part of the physiological haemostatic reaction. It is not uncommon for cell death to contribute to physiological functions (cf. holocrine secretion) (34) and disrupted platelets are a common phenomenon in EM pictures of the haemostatic plug (35).

In Table 1 we observe a large variation in platelet procoagulant activity. This is only partly due to random experimental error. In fact the experimental variation when calculated from experiments carried out on the same platelet suspension under identical conditions was less than $8 \%$. The remainder of the variation must be ascribed to variation of the platelet reactivity between donors. This suggest that platelet excitability may vary considerably between 
subjects. It would be interesting to do epidemiological studies on platelet reactivity in relation to age, illness and cardiovascular risk.

In conclusion: We have demonstrated that fibrin, both of the $\mathrm{A}$ and $\mathrm{B}$ type, does provoke procoagulant activity in platelets. Thrombin significantly potentiates this phenomenon. When they are in their natural milieu this is not accompanied by platelet breakdown, but isolated platelets are damaged during these experiments. There is a considerable variation in reactivity between donors that remains to be explored.

\section{Acknowledgements}

The authors wish to thank Dr Jan Rosing . Dr Guido Tans and Dr Hu Kai as well as Ms Stella Thomassen for their extensive support and critical discussion of the manuscript. 


\section{References}

1. Hemker, HC. Thrombin Generation, an Essential Step in Haemostasis and Thrombosis. Haemostasis and Thrombosis. 3rd edt. (1993) A.L.Bloom, C.D.Forbes, D.P Thomas, E.G.D. Tuddenham eds. Churchill Livingstone London. ISBN 0-443-04521b, pp. 477-490.

2. Walsh PN. Different requirements for intrinsic factor $\mathrm{Xa}$ forming activity and platelet factor 3 activity and their relationship to platelet aggregation and secretion. $\mathrm{Br} \mathrm{J}$ Haemotol 1978; 40: 311.

3. Bevers EM, Comfurius $P$, van Rijn JLML, Hemker HC, Zwaal RFA. Generation of Prothrombin converting activity and the exposure of phosphatidylserine at the outer surface of platelets. Eur $\rfloor$ Biochem 1982; 122: 429-36.

4. Rosing J, van Rijn JLML, Bevers EM, van Dieijen $G$, Comfurius $P_{n}$ Zwaal RFA. The role of activated human platelets in prothrombin and factor $X$ activation. Blood 1985; 65: 319-32.

5. Miletich JP, Jackson CM, Majerus PW. Properties of the factor Xa binding site on platelets. J Biol Chem 1978; 253: 6908-16.

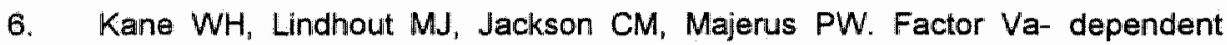
binding of factor Xai to human platelets. J Biol Chem 1980; $255: 1170-74$.

7. Chasney CM, Pifer D, Colman RW. Subcellular localization and secretion of factor $V$ from human platelets. Proc Natl Acad Sci USA 1981; 78: 5180-84.

8. Liu $C Y$, Nossel HL, Kaplan $K L$. The binding of thrombin by fibrin. $J$ Biol Chem 1979; 254: 10421-25.

9. Kaminski M, Mcdonagh J. Inhibited thrombins, interactions with fibrinogen and fibrin. Biochem J 1987; 242: 881-7.

10. Wilner GD, Danitz MP, Mudd $S_{4}$ Hsieh $K$, Fenton JW. Selective immobalization of thrombin by surface bound fibrin. J Lab Clin Med 1981; 97: 403-11.

11. Hogg PJ, Jackson CM. Fibrin monomer protects thrombin from inactivation by heparin antithrombin III: Implications for heparin efficacy. Proc Natl Acad Sci USA 1989; 86: 3619-23.

12. Weitz JI, Hudoba M, Massel D, Maraganore J, Hirsh J. Clot bound thrombin is protected from inhibition by heparin antithrombin III but is susceptible to inactivation by antithrombin III independent inhibitors. J Clin Invest 1990; 86: 385-91.

13. Francis WC, Markham ER, Barlow HG, Florack MT, Dobrzynski MD, Marder JV. Thrombin activity of fibrin thrombi and soluble plasmic derivatives. J Lab Clin Med 1983; 102: 220-30.

14. Prins $M H$, Weitz Jl. Heparin inhibits the amplification of coagulation mediated

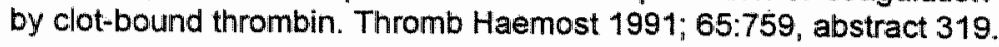


15. Bendayan $P$, Boccalon $H$, Dupouy $D$, Boneu $B$. Dermatan sulfate is a more potent inhibitor of clot-bound thrombin than unfractionated and low molecular weight heparins. Thromb Haemost 1994; $71: 576-80$.

16. Buchanan A. Original communications on the coagulation of the blood and other fibriniferous liquids. London Med Gaz, 1845.

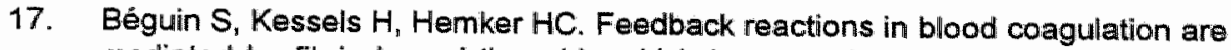
mediated by fibrin bound thrombin which is not inhibited by heparin. Thromb Haemost 1993; 69: 811, Abstract 962.

18. Kumar $R$, Béguin $S$, Hemker HC. The influence of fibrinogen and fibrin on thrombin generation- evidence for feedback activation of the clotting system by clat bound thrombin. Thromb Haemost 1994; 72(5): 713-21.

19. Keiffer $N$. Phillips DR. Platelet membrane glycoproteins: Functions in cellular interactions. Annu Rev Cell Biol 1990; 6: 329-57.

20. Bevers $E$, Comfurius $P$, Zwaal RFA. Changes in membrane phospholipid distribution during platelet activation. Biochim et Biophysica Acta 1983; 736 : 57-66.

21. Discipio RG, Hermodson MA. Yates SG, Davie EW. A comparison of human prothrombin, factor IXa(Christmas factor), factor X(Stuart factor) and protein $S$. Biochemistry 1977;16: 698-706.

22. Rosing J, Tans G, Govers-Riemslag JWP, Zwaal RFA, Hemker HC. The role of phospholipids and factor $\mathrm{Va}$ in the prothombinase complex. J Biol Chem 1980; 255: 274-83.

23. Chase $T \mathrm{~J}$, Shaw E. Comparison of the esterase activities of trypsin, plasmin and thrombin on guanidinobenzoate esters. Titration of the enzymes. Biochemistry 1969; 8: 2212 -24.

24. Fujikawa $K$, Legaz ME, Davie EW. Bowine factor $X 1$ (Stuart factor). Mechanism of activation by protein from Russell's viper venom. Blochemistry 1972; 11: 4892-99.

25. Smith RL. Titration of activated bovine factor $X, J$ Biol Chem $1973 ; 248$ : 2418-23.

26. Dählback $B$. Human coagulation factor $V$ purification and thrombin-catalyzed activation. J Clin invest 1980; 66: 583-91.

27. Suzuki $K$, Dählback $B$, Stenflo J. Thrombin-catalyzed activation of human coagulation factor $V$. J Biol Chem 1982; 257: 6556-64.

28. Tans $G$, Rosing J, Thomassen MCLGD, Heeb MJ, Zwaal RFA, Griffin JH. Comparison of anticoagulant and procoagulant activities of stimulated platelets and platelet derived microparticles. Blood 1991; $77(12): 2641-48$. 
29. Lindhout $T$, Govers-Riemslag JWP, van de Waart $P$, Hernker $H C$, Rosing J. Factor Va-factor $X a$ interactions. Effect of phospholipid vesicles of varying composition. Blochemistry 1982; $21: 5494-5502$.

30. Béguin $\mathrm{S}$, Lindhout $\mathrm{T}$, Hemker HC. The effect of trace amounts of Tissue Factor on Thrombin Generation in Platelet Rich Plasma, its inhibition by Heparin. Thromb and Haemost 1989; 61(1): 25-9.

31. van Rijn JLML, Rosing $J_{*}$ van Dieijen $G$. Activity of human blood platelets in prothrombin and in factor $X$ activation induced by lonophore A23187. Eur $J$ Biochem 1983; 133: 1-10.

32. Schroilt AJ, Zwaal RFA. Transbilayer movement of phospholipids in red cell and platelet memebrane. Biochim Biophys Acta 1991; 1071(3): 313-29.

33. Sandberg $H_{1}$ Andersson LO, Hoglund S. Isolation and characterization of lipidprotien particles containing platelet factor 3 released from human platelets. Biochem J 1982; 203(1): 303-11.

34. Agache $P$, Blanc $D$. Current status in sebum knowledge. Int $J$ Dermatol 1982; 21(6): 304-15.

35. Wester J, Sixma JJ, Geuze $J J$, van der Veen $J$. Morphology of the hemostatic plug in human skin wounds. Transformation of the plug. Laboratory Investigation 1979; 41: 182-192. 


\section{Chapter 4}

\section{Inhibition of Platelet-mediated, Tissue Factor-induced Thrombin Generation by the Mouse/Human Chimeric 7E3 Antibody \\ Potential Implications for the Effect of c7E3 Fab Treatment on Acute Thrombosis and "Clinical Restenosis""}

\section{Summary}

The murine/human chimeric monoclonal antibody fragment (c7E3 Fab) bllocks GPllb/llla and $\alpha_{w} \beta_{3}$ receptors, inhibits platelet aggregation, and decreases the frequency of ischemic events after coronary artery angioplasty in patients at high risk of suffering such events. Although inhibition of platelet aggregation is likely to be the major mechanism of c7E3 Fab's effects, since activated platelets facilitate thrombin generation, it is possible that c7E3 Fab also decreases thrombin generation. To test this hypothesis, the effects of c7E3 Fab and other antiplatelet agents were tested in a thrombin generation assay triggered by tissue factor. c7E3 Fab produced dose-dependent inhibition of thrombin generation, reaching a plateau of $45-50 \%$ inhibition at concentrations $\geq 15 \mu \mathrm{g} / \mathrm{ml}$. It also inhibited thrombin-antithrombin complex formation, prothrombin fragment $F_{1+2}$ generation, platelet-derived growth factor and platelet factor 4 release, incorporation of thrombin into clots, and microparticle formation. Antibody 6D1, which blocks pllatelet GPIb binding of von Willebrand factor, had no effect on thrombin generation, whereas antibody 10E5, which blocks GPIIb/lla but not $\alpha_{4} B_{3}$ receptors decreased thrombin generation by $\sim 25 \%$. Combining antibody LM609, which blocks $\alpha_{4} B_{3}$ receptors, with $10 E 5$ increased the inhibition of thrombin generation to $\sim 32$ $41 \%$. The platelets from three patients with Glanzmann thrombasthenia, who

\footnotetext{
"Based on J.C. Reverter, S. Béguin, H. Kessels, R. Kumar, H.C. Hemker, and B.S. Coller, J. Clin.
} Invest. 1996;98(3):863-74. 
lacked GPIb/llla receptors but had normal or increased $\alpha_{w} B_{3}$ receptors, supported $\sim 21 \%$ less thrombin generation than normial platelets. We conclude that thrombin generation initiated by tissue factor in the presence of platelets is significantly inhibited by c7E3 Fab, most likely in part through both GPIlb/llla and $\alpha_{w} \aleph_{3}$ blockade, and that this effect may contribute to its antithrombotic properties.

\section{Introduction}

Both platelets and coagulation proteins contribute to thrombotic cardiovascular disease via a complex set of interactions, and both antiplatelet agents and anticoagulants are effective against thrombosis. Antiplatelet agents are thought to work primarily by decreasing platelet aggregation, whereas anticoagulants are thought to work primarily by decreasing thrombin formation or inhibiting thrombin after it is formed. However, since activated platelets can facilitate thrombin generation by providing a catalytic surface on which coagulation reactions occur (1) and by relleasing an activated form of Factor $V(2)$ it is possible that antiplatelet agents may also function as anticoagulants in vivo. Both quantitative and qualitative mechanisms may contribute to an anticoagulant effect of potent antiplatelet agents: (a) a decrease in platelet aggregation and platelet thrombus formation may result in a local decrease in both the mass of platelet membranes on which thrombin can be generated and the number of platelets available to release activated Factor V (quantitative effects), and (b) inhibition of the platelet "activation" process may prevent platelet membranes from developing an enhanced catalytic efficiency and may inhibit release and surface expression of activated Factor $V$ (qualitative effects) $(1,2)$.

The murine/human chimeric $7 E 3$ monoclonal antibody fragment (c7E3 Fab) blocks platelet GPIIb/llla and $\alpha_{v} \beta_{3}$ vitronectin receptors, producing inhibition of platelet aggregation and platelet thrombus formation (3). Data from the recent Phase III EPIC study indicate that $\mathrm{c} 7 \mathrm{E} 3$ Fab decreases the 
frequency of ischemic events after coronary artery angioplasty or atherectomy in patients at high risk of suffering such events (4). Although the antiplatelet effect of C7E3 Fab in preventing direct mechanical obstruction of the blood vessel by inhibiting platelet aggregation is likely to be the major mechanism for its beneficial effect, it is possible that the potent inhibition of platelet thrombus formation by c7E3 Fab may result in decreased thrombin formation, which in turn could further decrease platelet activation and platelet thrombus formation. Thus, despite being an antiplatelet agent, c7E3 Fab may function as an anticoagulant. Moreover, since thrombin may cause smooth muscle cell migration and intimal hyperplasia (5), processes that may contribute to restenosis, it is possible that decreased thrombin generation by c7E3 Fab may play a role in the modest reduction in clinical restenosis observed after 6 months in C7E3 Fab-treated patients (6).

In vivo studies are required to assess the total impact of c7E3 Fab treatment on thrombin generation after vascular injury. In vitro studies, however, can analyze the effect of C7E3 Fab on the phenomena related to platelet activation that result in enhanced thrombin generation. In the present study, we analyzed the effect of c7E3 Fab and other antiplatelet agents on platelet-dependent, tissue factor-induced thrombin production using modifications of a well characterized thrombin generation assay $(7-10)$.

\section{Methods}

Chemicals. BSA, purified human thrombin, hirudin, $N G, \mathrm{O}^{2}$-dibutyryl-adenosine $3^{\prime}: 5$-cyclic monophosphoric acid (dibutyryl cyclic AMP, DB-cAMP), 3-isobutylmethyl-xanthine (MTX), prostaglandin $I_{z}$ (prostacyclin), Triton X-100, paraformaldehyde, and DMSO were obtained from Sigma Chemical Co. (St. Louis, MO). ADP and arachidonic acid were from Chrono-Log Corp. (Havertown, PA). H-D-Phe-Pip-Arg-pNA (S-2238) and human plasmin were from Chromogenix (Mölndal, Swaden). Aspirin was obtained from Mallinckrodt Inc. (Paris, KY). Ionophore A23187, aprotinin, and human 
fibrinogen were from Calbiochem Corp. (La Jolla, CA). N-2 hydroxyethyipiperazine-N"-2-ethanesulphonic acid (Hepes) was from Eastman Kodak Co. (Rochester, NY). lodogen, papain, and sulfosuccinimidyl 6-(bi-otinamido) hexanoate (NHS-LC-Biotin) were from Pierce Chemical Co. (Rockford, IL). Reptilase was from Stago (Asnieres, France). Other chemicals were from Sigma Chemical Co. or Fisher Scientific Co. (Pittsburgh, PA). Calpeptin was from Alexis (Läufelfingen, Switzerland).

Antibodies. Purified murine monoclonal antibodies 10E5 [antiGPIlb/llla $\left(\alpha_{1 b} \beta_{3} ; C D\right.$ 41/CD61)] (11), 7E3 [(anti- GPIlb/lla + $a_{4} \beta_{3} ; C D$ 41/CD61 + CD 51/CD 61)] (12), 6D1 (anti-GPIba; CD 42b) (13), 6F1 [antiGPla/lla $\left(\alpha_{2} \beta_{1} ; C D 49 b\right)$ ] (14), and $7 H 2$ [anti-GPIlla $\left(\beta_{3} ; C D\right.$ 61)], which partially inhibits fibrinogen binding to platelets and platelet aggregation (15), have been previously described. $7 \mathrm{H} 2 \mathrm{Fab}$, which has little effect on fibrinogen binding or platelet aggregation, was obtained by enzymatic digestion with immobilized papain as previously described (15). c7E3 Fab (anti- GPIIb/llla $\left.+\alpha_{V} B_{3}\right)(16)$, the drug used in the EPIC trial $(4,6)$, was obtained from Centocor (Malvern, PA). Antibody LM609 (anti- $\alpha v B_{3}$, which inhibits $\alpha_{v} \beta_{3}$ function; CD51/CD62), and antibody LM142 (anti- $\alpha v$, which does not inhibit $\alpha_{v} B_{3}$ function; CD51) (17) were generously provided by Dr. David Cheresh (The Scripps Research Institute, La Jolla, CA). Antibodies 10E5 and LM609 were converted into Fab fragments by digestion with ficin according to the manufacturer's directions (Pierce Chemical Co.). Antibody AP3 (anti-GPIlla; CD 61) (18) was generously provided by Dr. Peter Newman (Blood Center of Southeastern Wisconsin, Milwaukee, WI). Antibodies were diluted from stock solutions in $0.15 \mathrm{M} \mathrm{NaCl}, 0.01 \mathrm{M}$ Tris $/ \mathrm{HCl}, 0.05 \%$ sodium azide, $\mathrm{pH} 7.4$, or $0.15 \mathrm{M} \mathrm{NaCl}, 0.01 \mathrm{M}$ sodium phosphate. $0.05 \%$ azide, $\mathrm{pH} 7.4$, with $0.15 \mathrm{M}$ $\mathrm{NaCl}_{1} 0.01 \mathrm{M}$ Tris $/ \mathrm{HCl}, 0.05 \%$ sodium azide, $\mathrm{pH} 7.4$, for use in the assays. In preliminary experiments we determined that azide did not affect the assay results at the concentrations used in the studies.

Biotinylation of antibodies was performed using NHS-LC-Biotin as previously described by Gretch et al. (19). 
Defibrinated and native plasma. $200 \mathrm{ml}$ of blood from each of 15 normal voluntary donors (blood group $A B$ ) was anticoagulated with $0.013 \mathrm{M}$ sodium citrate. Platelet poor plasma (PPP) was made by a double centrifugation $\left(2,000 \mathrm{~g}\right.$ for $10 \mathrm{~min}$ at $22^{\circ} \mathrm{C}$, and then $5,000 \mathrm{~g}$ for $10 \mathrm{~min}$ at $\left.4^{\circ} \mathrm{C}\right)$. The plasmas were pooled, frozen in dry icelethanol and stored at $-20^{\circ} \mathrm{C}$. A single batch of plasma was used for all PPP studies. PPP was defibrinated immediately before use by adding 1/50th vol reptilase, letting the clot form at $37^{\circ} \mathrm{C}$ for $5 \mathrm{~min}$, keeping the clotted plasma at $0^{\circ} \mathrm{C}$ for $10 \mathrm{~min}$, and then removing the clot by centrifugation. No clottable fibrinogen was found after this treatment.

Platelet-rich plasma (PRP) for thrombin generation assays. Blood from normal donors was anticoagulated with citrate as above and centrifuged for 10 $\min$ at $250 \mathrm{~g}$ at $22^{\circ} \mathrm{C}$. The platelet count was adjusted to 300,000 per $\mu l$ with PPP prepared from the PRP.

Gel-filtered platelets. Blood from normal donors was anticoagulated with acid-citrate dextrose formula A (ACD-A) $(8.5: 1.5$, vol/ vol). PRP was obtained by centrifugation ( $3 \mathrm{~min}$ at $800 \mathrm{~g}$ at $22^{\circ} \mathrm{C}$ ), removed, and, after adding $1 / 10$ vol of additional $A C D-A$, centrifuged for $10 \mathrm{~min}$ at $2,100 \mathrm{~g}$ at $22^{\circ} \mathrm{C}$. The platelet pellet was reconstituted with $1 \mathrm{ml}$ of TSBG $[0.05 \mathrm{M}$ Tris $/ \mathrm{HCl}, 0.15 \mathrm{M}$ $\mathrm{NaCl}_{1} 0.5 \% \mathrm{BSA}$ (wt/ vol), $5 \mathrm{mM}$ glucose, $\mathrm{pH}$ 7.4]. Platelets were then gel filtered through Sepharose 2B (Pharmacia Fine Chemicals, Uppsala, Sweden), equilibrated with TSBG, using the same buffer to elute the platelets.

Through the courtesy of Dr. Harvey Weiss (St. Lukes-Roosevelt Hospital, New York), platelets from three patients with Glanzmann thrombasthenia, who lack functional GPIlb/lla receptors as judged by an absence of ADP-induced platelet aggregation, were also gel filtered and studied. All three patients had markedly reduced binding ( $\leq 25 \%$ of normal) of one or more monoclonal antibodies to GPIIb/llla (10E5, 7E3, 7H2) and normal or increased platelet $\alpha_{4} B_{3}$ receptor expression as judged by the binding of radiolabeled antibodies LM609 and/or LM142; the latter studies were performed as previously described (20). One of the patients was studied on two different occasions. 
Peptides. The thrombin receptor-activating peptide, racemic (isoS)FLLRN-NH $\mathrm{H}_{2}$ (iso-T6), was synthesized as previously described (21). RGDF, which inhibits both GPIlb/lla and $\alpha_{y} B_{3}$, was synthesized as previously described (22).

Determination of thrombin generation supported by gel-filtered platelets. Thrombin generation was measured by an adaptation of our previously described techniques (7-10). In $12 \times 75-\mathrm{mm}$ polypropylene tubes (Becton Dickinson, Inc., Rutherford, NJ), $240 \mu$ l of defibrinated plasma was mixed with $50 \mathrm{pl}$ of gel-filtered platelets and $10 \mu$ of buffer $(0.01 \mathrm{M} \mathrm{Tris} / \mathrm{HCl}, 0.15 \mathrm{M} \mathrm{NaCl}$, $0.05 \%$ azide, $\mathrm{pH} 7.4$ ). In some experiments the buffer contained monoclonal antibodies, aspirin, peptides, DB-CAMP, MTX, or prostacyclin. Antibodies were added at 5 to $20 \mu \mathrm{g} / \mathrm{ml}$ final concentrations and incubated for $20 \mathrm{~min}$ at $37^{\circ} \mathrm{C}$. Thrombin generation was initiated by adding $60 \mu$ of recombinant tissue factor (Innovin; Baxter Healthcare Corp., Deerfield, IL) diluted 1:1,500 in $\mathrm{CaCl}_{2},(16.7$ $\mathrm{mM}$ ). The final concentration of tissue factor chosen was $1 / 10$ th that required to clot PPP in $70 \mathrm{~s}(10)$. In some experiments, the volumes of all reagents were increased, but the proportions remained the same. Thrombin generation was assayed at $37^{\circ} \mathrm{C}$ by measuring thrombin amidolytic activity in samples obtained every $30 \mathrm{~s}$ for $15 \mathrm{~min}$. Samples $(10 \mu \mathrm{l})$ were removed from the incubation mixtures and added to a prewarmed $\left(37^{\circ} \mathrm{C}\right)$ mixture of buffer $[465 \mu \mathrm{l}$; $0.1 \mathrm{M} \mathrm{NaCl}, 0.05 \mathrm{M} \mathrm{Tris} / \mathrm{HCl}, 0.05 \%$ BSA (wt/vol), $20 \mathrm{mM}$ EDTA, pH 7.9] and chromogenic thrombin substrate S-2238 $(25 \mu \mathrm{l} ; 4 \mathrm{mM})$. After $3.25 \mathrm{~min}$ at $37^{\circ} \mathrm{C}$, the reaction was stopped by adding $300 \mu \mathrm{ll}$ of $1 \mathrm{M}$ citric acid, and the $O D_{405}$ was determined (Ultrospec III; Pharmacia LKB Biotechnology Inc., Piscataway, $\mathrm{NJ})$. The assay was calibrated by testing known amounts of purified human thrombin in each assay.

Thrombin generation was calculated from the free thrombin amidolytic activity by a computer program that takes into account the effects of thrombin's neutralization by antithrombin III and other serpins, as well as the reaction between thrombin and $\alpha_{2}$-macroglobulin, which results in a complex that retains some chromogenic activity $(8,9,23)$. Thrombin generation was expressed as the thrombin potential; that is, the total area under the curve of 
thrombin concentration vs time. The peak level of thrombin generation was also determined. Results are expressed as absolute values or as a percentage of a control sample that was assayed in parallel. We determined the intraassay coefficient of variation of thrombin potential for the modified assay used in the current study by performing 12 replicates and found it to be $2.9 \%$. Platelets gel filtered $3 \mathrm{~h}$ before use in the assay gave results very similar to platelets used within 30 min of gel filtration $(1.5 \pm 2.4 \%$ decrease; $n$ $=5$ ), and so platelets were used within $3 \mathrm{~h}$ of gel filtration in all experiments.

Assay of GPIIb/lla blockade by c7E3 Fab. lodination of c7E3 Fab with ${ }^{125}$ I was performed with lodogen as previously described (20). To assay for GPIIb/llia receptor blockade by c7E3 Fab, $200 \mu$ l of defibrinated plasma plus gel-filtered platelets, with or without the addition of c7E3 Fab (5 to $50 \mu \mathrm{g} / \mathrm{ml}$ for $20 \mathrm{~min}$ at $\left.37^{\circ} \mathrm{C}\right)$, was incubated with ${ }^{125}$-labeled c7E3 Fab $(20 \mu \mathrm{g} / \mathrm{ml})$ for 10 $\min$ at $22^{\circ} \mathrm{C}$. Platelet-bound ${ }^{125} \mathrm{I}-\mathrm{c} 7 \mathrm{E} 3 \mathrm{Fab}$ was separated from free ${ }^{125} \mathrm{~J}-\mathrm{c} 7 \mathrm{E} 3$ Fab by centrifugation ( $5 \mathrm{~min}$ at $12,000 \mathrm{~g}$ at $22^{\circ} \mathrm{C}$ ) through $30 \%$ sucrose in a microtube. The platelet bound ${ }^{125}$ I-c7E3 Fab and supernatant ${ }^{125}$ I-c7E3 Fab were determined separately after cutting off the tip of the tube containing the platelet pellet, and used to calculate the number of molecules bound per platelet (24).

Thrombin-antithrombin III (TAT) complexes and prothrombin fragment $1+2\left(F_{T+2}\right)$. TAT complexes and $F_{f+2}$ were determined by ELISA using commercially available kits (Enzygnost; Behring, Marburg, Germany). Samples $(200 \mu \mathrm{l})$ were obtained from thrombin generation assays and thrombin generation was stopped by adding $40 \mu$ of EDTA-hirudin buffer $(0.15$ $\mathrm{M} \mathrm{NaCl}, 0.05 \mathrm{Tris} / \mathrm{HCl}, \mathrm{pH} 7.4$ ) containing $120 \mathrm{mM}$ EDTA and $60 \mathrm{U} / \mathrm{ml}$ hirudin. Samples were immediately centrifuged $\left(10 \mathrm{~min}\right.$ at $2,100 \mathrm{~g}$ at $22^{\circ} \mathrm{C}$ ) and the resultant supernatant fraction rapidly frozen and stored at $-20^{\circ} \mathrm{C}$.

Platelet aggregation and platelet counts. Platelet aggregation studies were carried out in an aggregometer (Chromo-Log Corp.) at $37^{\circ} \mathrm{C}$ with stirring. Citrated PRP or gel-filtered platelets suspended in $138 \mathrm{mM} \mathrm{NaCl}, 2.7 \mathrm{mM} \mathrm{KCl}$, $0.4 \mathrm{mM} \mathrm{NaH} \mathrm{PO}_{4}, 12 \mathrm{mM} \mathrm{NaHCO}, 2 \mathrm{mM} \mathrm{MgCl}, 10 \mathrm{mM}$ Hepes, $5.5 \mathrm{mM}$ glucose, $0.2 \% \mathrm{BSA}$ (wt/vol), plus $0.3 \mathrm{~g} / \mathrm{l}$ of human fibrinogen, $\mathrm{pH} 7.4$, were 
introduced into the aggregometer cuvette at final platelet counts of 300,000 350,000 platelets per microliter. ADP $(10 \mu \mathrm{M})$, arachidonic acid (1 mM), and the thrombin receptor-activating peptide iso-T6 $(5 \mu \mathrm{M})$ were used as agonists.

To assess the production of platelet aggregates with volumes greater than 43 fluring the thrombin generation assay, platelet counts were performed at indicated times by removing $5 \mu$ samples from the incubation mixture, diluting them with $20 \mathrm{ml}$ of diluent (Isoton; Coulter Immunolagy, Hialeah, FL) and analyzing them in a resistive particle counter (Counter Coulter Z1: Coulter Immunology) using lower and upper thresholds of 4 and 43 fl.

Determination of PDGF. PDGF was measured bv radioimmunoassay using ${ }^{125}$ I-PDGF as a standard (Amersharm Corp." Arlington Heights, IL). Samples $(200 \mathrm{pl})$ were obtained from the thrombin generation assay and mixed with EDTA-hirudin buffer as for the TAT assay. Two PDGF positive controls were prepared by, adding $60 \mu$ of buffer containing $60 \mu \mathrm{M}$ iso-T6 or $6 \%$ Triton $X-100$ (vol/vol) instead of tissue factor to the thrombin generation assay and incubating for $15 \mathrm{~min}$ at $37^{\circ} \mathrm{C}$.

Determination of platelet factor 4 (PF4). PF4 was quantified by ELISA. Samples were obtained and thrombin generation was stopped as indicated above for the TAT and PDGF assays. Samples were centrifuged twice $(15 \mathrm{~min}$ at $2,100 \mathrm{~g}$ at $22^{\circ} \mathrm{C}$ ) before freezing.

Microparticle determination by flow cytometry. Samples (50 ul) were obtained from the thrombin generation assay, mixed with 10 jl of EDTA-hirudin buffer, and fixed by adding $1 / 6$ th vol $6 \%$ paraformaldehyde (wt/vol) at $4 \% \mathrm{C}$. Microparticle formation was also investigated in gel-filtered platelets suspended in $137 \mathrm{mM} \mathrm{NaCl}, 2.7 \mathrm{mM} \mathrm{KCl}, 16 \mathrm{mM} \mathrm{NaHCO}, 5 \mathrm{mM} \mathrm{MgCl}_{2}, 35$ mM Hepes, $5.5 \mathrm{mM}$ glucose, 0.2\% BSA (wt/vol). $\left.2.5 \mathrm{mM} \mathrm{CaCl}\right|_{2}, \mathrm{pH} \mathrm{7.4,} \mathrm{and}$ activated with $0.25 \mathrm{U} / \mathrm{ml}$ of thrombin or $5 \mu \mathrm{M}$ ionophore $\mathrm{A} 23187$ for $15 \mathrm{~min}$ at $37^{\circ} \mathrm{C}$. The gel-filtered platelets were then fixed as above. In some experiments, platelets were preincubated $\left(20 \mathrm{~min}\right.$ at $\left.37^{\circ} \mathrm{C}\right)$ with $20 \mu \mathrm{g} / \mathrm{ml}$ of the $\mathrm{c} 7 \mathrm{E} 3 \mathrm{Fab}$ or $10 E 5$ antibodies. 
Platelet microparticles were identified on the basis of their reactivity with antibody 6D1 (anti-GPIba) and their characteristic light scattering properties. Fixed platelets $(5 \mu \mathrm{ll})$ were incubated with biotin-labeled $6 \mathrm{D} 1(20 \mu \mathrm{g} / \mathrm{ml})$ for 30 $\min$ at $22^{\circ} \mathrm{C}$, and then $10 \mu \mathrm{ll}$ of FITC streptavidin (Becton Dickinson, Inc) was added and incubated for $30 \mathrm{~min}$ at $22^{\circ} \mathrm{C}$. Samples were then diluted in PBS (0.01 $\mathrm{M}$ sodium phosphate, $0.15 \mathrm{mM} \mathrm{NaCl}, \mathrm{pH} 7.4)$. To assess the absolute number of microparticles present in a sample, $5 \mu$ l of a suspension containing $1.35 \times 10^{5}$ fluorescent beads of $6.6 \mu \mathrm{m}$ diameter (Becton Dickinson, Inc.) were added to each diluted sample immediately before flow cytometric analysis to serve as an internal standard. The concentration of beads was determined by microscopy using a hemacytometer (American Optical Scientific Instruments, Buffalo, NY).

Samples were analyzed in a flow cytometer (EPICS Profile; Coulter Immunology) using software supplied by the manufacturer (EPICS Profile Software, version 2.4). The instrument was equipped with a $100 \mathrm{~mW}$ argon laser operated at $15 \mathrm{~mW}$ power at a wavelength of $488 \mathrm{~nm}$. The flow cytometer was calibrated daily using fluorescent beads (Coulter Immunology). Platelets and microparticles were identified as particles giving a positive fluorescent signal at $530 \mathrm{~nm}$ with antibody $6 D 1$. Subsequent analysis was limited to particles that were positive for 6D1 fluorescence. Quadrant analysis in dot-plot histograms was performed by plotting forward angle light scatter (FSC) as a function of side angle light scatter (SSC) at logarithmic settings to separate the added $6.6-\mu \mathrm{m}$ beads (upper FSC, upper SSC), from the microparticles (lower FSC, lower SSC), and platelets, including small aggregates (upper FSC, lower SSC). The location of the platelets was confirmed using PRP in the absence of antibody labeling. The FSC threshold for distinguishing microparticles from platelets was set at $\sim 0.8 \mathrm{pm}$ diameter as calculated using calibrated beads (Becton Dickinson, Inc). A minimum of 10,000 fluorescent particles were analyzed in each sample.

The absolute number of microparticles in a sample was calculated by the equation: (number of beads added to sample / number of beads actually counted) $\times$ number of microparticles actually counted. The percentage of 
microparticles was calculated using the formula: $100 \times$ microparticles actually counted / (microparticles + platelets actually counted).

Thrombin bound to clots. Clots were prepared at $37^{\circ} \mathrm{C}$ by adding $60 \mu \mathrm{l}$ of tissue factor diluted in $\mathrm{CaCl}_{2}$, to $240 \mathrm{pl}$ of citrated PPP. $50 \mu$ l of either buffer or gel-filtered platelets (final concentration $300 \times 10^{9} /$ liter), and $10 \mu \mathrm{l}$ of buffer $(0.01 \mathrm{M} \mathrm{Tris} / \mathrm{HCl}, 0.15 \mathrm{M} \mathrm{NaCl}, \mathrm{pH} 7.4)$ with or without antibodies. Clots were allowed to form for $30 \mathrm{~min}$, and then were gently squeezed against the test tube wall. Clots were then washed overnight with 10 changes of PBS with $0.05 \%$ sodium azide ( $w /$ trol). Clots (estimated vol of $10 \mu l$ ) were then placed in $90 \mu$ l of human plasmin ( 1 casein $\mathrm{U} / \mathrm{mll}$ ) in the same buffer and dissolved for $16 \mathrm{~h}$ at $37^{\circ} \mathrm{C}$. Aprotinin $(50 \mathrm{KIU})$ was then added and $10 \mu \mathrm{l}$ samples were removed and assayed for amidolytic activity as above, but with a 30 -min incubation time. Since the effects of plasmin and aprotinin on thrombin amidolytic activity were found to be only modest $(14.5 \pm 2.5 \%$ decrease, $n=8)$, they were not considered in the analysis.

Determination of thrombin generation in platelet-rich plasma. PRP (240 ul) was incubated with $60 \mu$ of either buffer $[0.1 \mathrm{M} \mathrm{NaCl}, 0.05 \mathrm{M} \mathrm{Tris} / \mathrm{HCl}$, $0.05 \%$ BSA ( $w / / v o l), p H ~ 7.35$ ] alone or buffer containing the monoclonal antibody to be tested, for $10 \mathrm{~min}$ at $37^{\circ} \mathrm{C}$ with gentle stirring. Thrombin generation was initiated by adding either $60 \mu \mathrm{ll}$ of recombinant tissue factor diluted $1: 4,000$ in $0.1 \mathrm{M} \mathrm{CaCl}_{2}$ (this dilution of tissue factor gave clotting time of over $10 \mathrm{~min}$ when added together with $\mathrm{Ca}^{2+}$ to non-defibrinated PPP) or $60 \mu \mathrm{l}$ of $0.1 \mathrm{M} \mathrm{CaCl}_{2}$ alone. Samples were removed and assayed for thrombin activity as described for the gel-filtered platelet assay, except that sampling and stopping was done with pushbutton-equipped pipettes that automatically recorded the incubation time $(\sim 2 \mathrm{~min})$. When the clot formed, it was wound on a plastic spatula and removed.

Statistical analysis. Results are expressed as the mean \pm SD. Student's $t$ test was used for independent or paired data, and ANOVA was used for statistical comparisons. $\mathrm{P}<0.05$ was considered significant. 


\section{Results}

\section{Gel-filtered platelets}

Effect of platelet count and ionophore A23187 activation on thrombin generation

Thrombin potential was profoundly dependent upon the number of platelets present in the incubation mixture (Fig. 1). Increasing the number of platelets resulted in increased thrombin potential $(r=0.90, P<0.002)$, with near maximal thrombin generation at a platelet count of 300,000 per $\mu$. Thus, this concentration was used in the subsequent studies unless otherwise indicated.

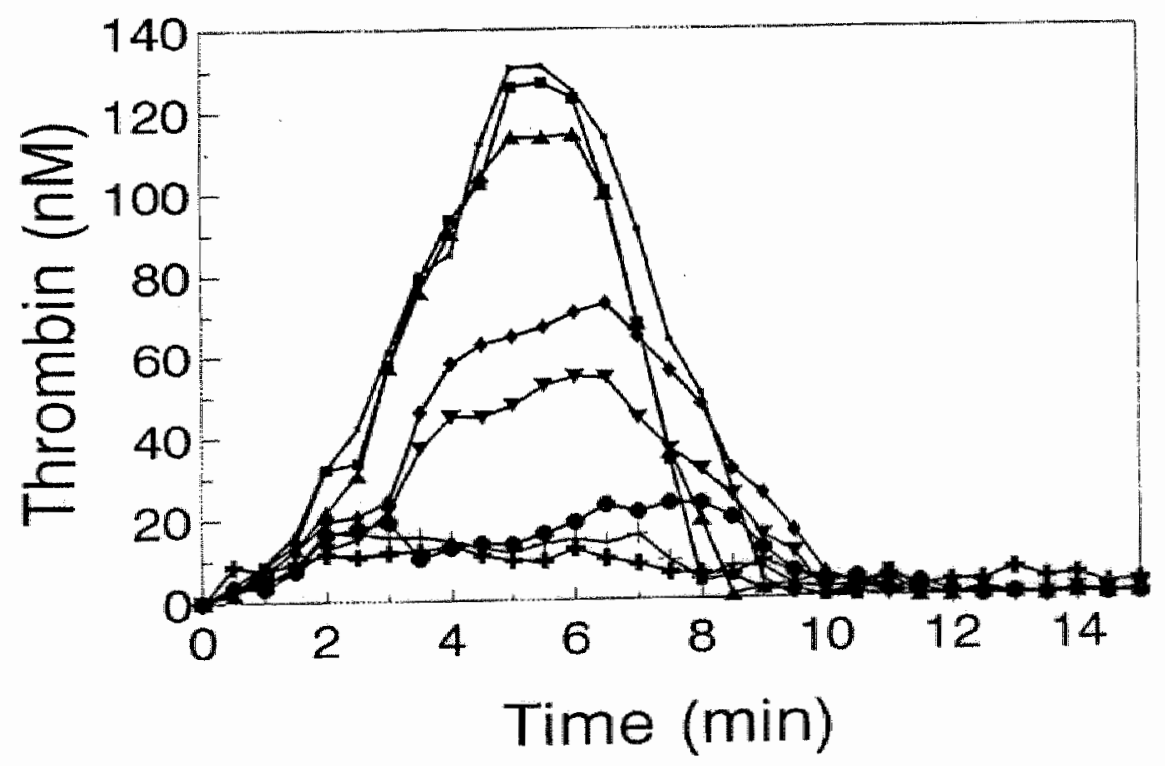

Fig.1 Effect of platelet count on thrombin generation in the reconstituted system. As described in Methods, defibinated plasma and gel-filtered platelets were mixed together and then tissue factor was added at $T=0$. Samples were removed at 30-s intervals and tested for thrombin amidolytic activity. The thrombin generated at each time point was then calculated and plotted at platelet count $(t) 0,(+) 10,(\bullet) 25,(\nabla)$ 50 . (*) $100,(\Delta) 200,(\boldsymbol{*}) 300,(*) 500\left(* 10^{3}\right.$ platelet/ $\mu$ l) There was minimal thrombin generation in the absence of platelets and thrombin generation plateaued at 300-500 $\left({ }^{*} 10^{3}\right.$ platelets/ $\left.\mu \mathrm{l}\right)$. Results are from one of three to six experiments conducted at the different platelet counts. 
When gel-filtered platelets were treated with ionophore A23187 (5 $\mu \mathrm{M})$ for $15 \mathrm{~min}$ at $37^{\circ} \mathrm{C}$ to produce microparticles before beginning the assay, the thrombin potential was increased by $20 \pm 4 \%$ and the peak thrombin concentration was $18 \pm 3 \%$ greater ( $n=4 ; P<0.05$ for both parameters) (Fig. 2).

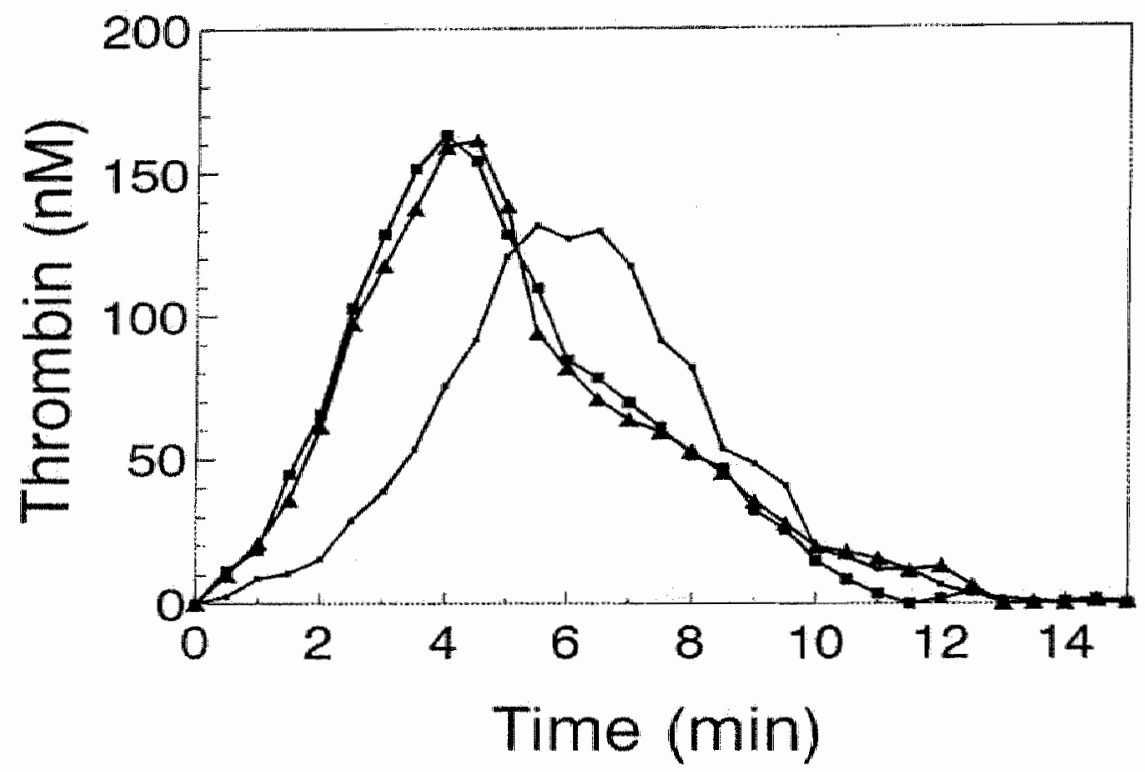

Fig.2 Effect of ionophore A23187 stimulation, alone and in combination with C7E3 Fab, on thrombin generation in the reconstituted system. Thrombin generation was measured as indicated in Methods using: (*) gel-filtered platelets $(300,000$ per $\mu$ ). (c) gel-filtered platelets stimulated with $5 \mu \mathrm{M}$ ionophore $\mathrm{A} 23187$ for $15 \mathrm{~min}$ at $37^{\circ} \mathrm{C}$ (A23187), or (A) gel-filtered platelets stimulated with $A 23187$ followed by incubation with $20 \mu \mathrm{g} / \mathrm{ml}$ c7E3 Fab for $20 \mathrm{~min}$ at $37^{\circ} \mathrm{C}$ (A23187 + c7E3 Fab). lonophore pretreatment resuted in a shortening of the lag time, an increase in peak thrombin concentration, and an increase in the thrombin potential (area under the curve). Addition of $\mathrm{c7E3} \mathrm{Fab}$ to platelets with ionophore did not significantly decrease thrombin generation. Results are from one of three similar experiments. 
Effect of monoclonal antibodies $6 \mathrm{D1}, 6 \mathrm{~F} 1,7 \mathrm{~B}_{2}$, and c7E Fab

The effects of monoclonal antibodies directed against platelet membrane glycoproteins on thrombin generation are shown in Tables 1 and 2 , with selected effects depicted in Fig. 3. Antibodies 6D1 (anti-GPIba) and 6F1

Table 1 Effect of antibodies, heparin, and the peptide RGDF on thrombin generation supported by gel-filtered platelets

\begin{tabular}{|c|c|c|c|}
\hline Antibody or peptide & $\bar{n}$ & Thrombin potential & $\begin{array}{l}\text { Peak thrombin } \\
\text { concentration }\end{array}$ \\
\hline & & $\%$ inhibition* & $\%$ inhibition * \\
\hline 6D1 $(20 \mu \mathrm{g} / \mathrm{ml})$ & 11 & $3 \pm 6^{4}$ & $3 \pm 4$ \\
\hline $6 \mathrm{~F} 1(20 \mu \mathrm{g} / \mathrm{ml})$ & 4 & $3 \pm 9$ & $7 \pm 7$ \\
\hline $10 E 5(20 \mu \mathrm{g} / \mathrm{ml})$ & 18 & $23 \pm 5^{5}$ & $27 \pm 7^{\S}$ \\
\hline TE3 $(20 \mu \mathrm{g} / \mathrm{ml})$ & 10 & $47 \pm 9^{\S \#}$ & $47 \pm 6^{5 / 3}$ \\
\hline c7E3 Fab $(5 \mu \mathrm{g} / \mathrm{ml})$ & 15 & $18 \pm 7^{\Pi}$ & $25 \pm 7^{5}$ \\
\hline c7E3 Fab $(10 \mu \mathrm{g} / \mathrm{ml})$ & 16 & $38 \pm 9^{\S \#}$ & $43 \pm 12^{\S}$ \\
\hline c7E3 Fab $(15 \mu \mathrm{g} / \mathrm{ml})$ & 15 & $47 \pm 5^{\S}$ & $51 \pm 7^{5 *}$ \\
\hline c7E3 Fab $(20 \mu \mathrm{g} / \mathrm{ml})$ & 31 & $47 \pm 5^{\S \#}$ & $50 \pm 7^{5 *}$ \\
\hline c7E3 Fab $(50 \mu \mathrm{g} / \mathrm{ml})$ & 3 & $46 \pm 5^{* * *}$ & $50 \pm 15^{* * *+1}$ \\
\hline RGDF $(50 \mu \mathrm{M})$ & 4 & $24 \pm 5^{\star * *}$ & $32 \pm 6^{\text {n** }}$ \\
\hline $\operatorname{RGDF}(100 \mu \mathrm{M})$ & 4 & $44 \pm 9^{* *}$ & $51 \pm 6^{* *}$ \\
\hline $\operatorname{RGDF}(500 \mu M)$ & 4 & $44 \pm 9^{\text {***}}$ & $52 \pm 5^{\text {** }}$ \\
\hline $7 \mathrm{H} 2(20 \mu \mathrm{g} / \mathrm{ml})$ & 5 & $22 \pm 17^{\star \star *}$ & $30 \pm 13^{* *}$ \\
\hline $7 \mathrm{H} 2 \mathrm{Fab}(20 \mu \mathrm{g} / \mathrm{ml})$ & 5 & $9 \pm 14$ & $15 \pm 14$ \\
\hline AP3 $(20 \mu \mathrm{g} / \mathrm{ml})$ & 4 & $24 \pm 5^{* * *}$ & $31 \pm 4 *$ \\
\hline
\end{tabular}

* Compared to control of gel-filtered platelets; " mean $\pm S \mathrm{SD}_{;}{ }^{* *} P<0.05 ;{ }^{7} \mathrm{P}<0.01$; ${ }^{s} P<0.001$ compared with control; " $P<0.05 ; " P<0.001$ compared with $20 \mu \mathrm{g} / \mathrm{ml}$ $10 E 5$. 
Table 2 Effects of combinations of anti-GPIIb/llla and anti-av $B_{3}$ antibodies on thrombin generation supported by gel-filtered platelets during the thrombin generation assay

\begin{tabular}{|c|c|c|c|}
\hline Antibody & $n$ & $\begin{array}{l}\text { Thrombin } \\
\text { potential }\end{array}$ & $\begin{array}{l}\text { Peak thrombin } \\
\text { concentration }\end{array}$ \\
\hline$A^{*}$ & & $\%$ inhibition ${ }^{*}$ & $\%$ inhibition $^{*}$ \\
\hline $\mathrm{LM} 609(20 \mu \mathrm{g} / \mathrm{ml})$ & 7 & $5 \pm 5^{5}$ & $12 \pm 6$ \\
\hline $10 E 5(20 \mu \mathrm{g} / \mathrm{ml})$ & 7 & $23 \pm 4$ & $26 \pm 8$ \\
\hline 10E5 + LM609 & 7 & $32 \pm 5^{4}$ & $38 \pm 10^{*}$ \\
\hline LM142 $(20 \mu \mathrm{g} / \mathrm{ml})$ & 7 & $1 \pm 4$ & $1 \pm 3$ \\
\hline $10 E 5(20 \mu \mathrm{g} / \mathrm{ml})$ & 7 & $22 \pm 4$ & $27 \pm 10$ \\
\hline $10 \mathrm{E} 5+\mathrm{LM} 142$ & 7 & $23 \pm 4$ & $28 \pm 11$ \\
\hline LM609 $(20 \mu \mathrm{g} / \mathrm{ml})$ & 3 & $6 \pm 2$ & $9 \pm 2$ \\
\hline c7E3 Fab $(20 \mu \mathrm{g} / \mathrm{ml})$ & 3 & $48 \pm 2$ & $46 \pm 3$ \\
\hline C7E3 Fab + LM609 & 3 & $48 \pm 0$ & $40 \pm 2$ \\
\hline LM142 $(20 \mu \mathrm{g} / \mathrm{ml})$ & 3 & $-1 \pm 5$ & $-2 \pm 1$ \\
\hline c7E3 Fab $(20 \mu \mathrm{g} / \mathrm{ml})$ & 3 & $48 \pm 2$ & $46 \pm 3$ \\
\hline c7E3 Fab + LM142 & 3 & $47 \pm 1$ & $41 \pm 3$ \\
\hline \multicolumn{4}{|l|}{$\mathrm{B}$} \\
\hline LM609 $(20 \mu \mathrm{g} / \mathrm{ml})$ & 4 & $6 \pm 5$ & $10 \pm 5$ \\
\hline LM609 Fab $(20 \mu \mathrm{g} / \mathrm{ml})$ & 4 & $5 \pm 4$ & $11 \pm 5$ \\
\hline $10 E 5(20 \mu \mathrm{g} / \mathrm{ml})$ & 4 & $27 \pm 7$ & $28 \pm 10$ \\
\hline $10 \mathrm{E} 5 \mathrm{Fab}(20 \mu \mathrm{g} / \mathrm{ml})$ & 4 & $23 \pm 6$ & $24 \pm 19$ \\
\hline 10E5 + LM609 & 4 & $38 \pm 9^{*}$ & $41 \pm 11^{*}$ \\
\hline $10 E 5 F a b+L M 609 F a b$ & 4 & $41 \pm 10^{n}$ & $43 \pm 7^{\Pi}$ \\
\hline
\end{tabular}

\footnotetext{
" Compared to control of gel-filtered platelets; " experiments in groups A and B were conducted with different antibody preparations and were separated in time by more than $1 \mathrm{yr}^{8}{ }^{8}$ mean $\pm S D{ }^{\#} P<0.01$ compared with $10 E 5$ alone; and ${ }^{\Pi} P<0.01$ compared
} 


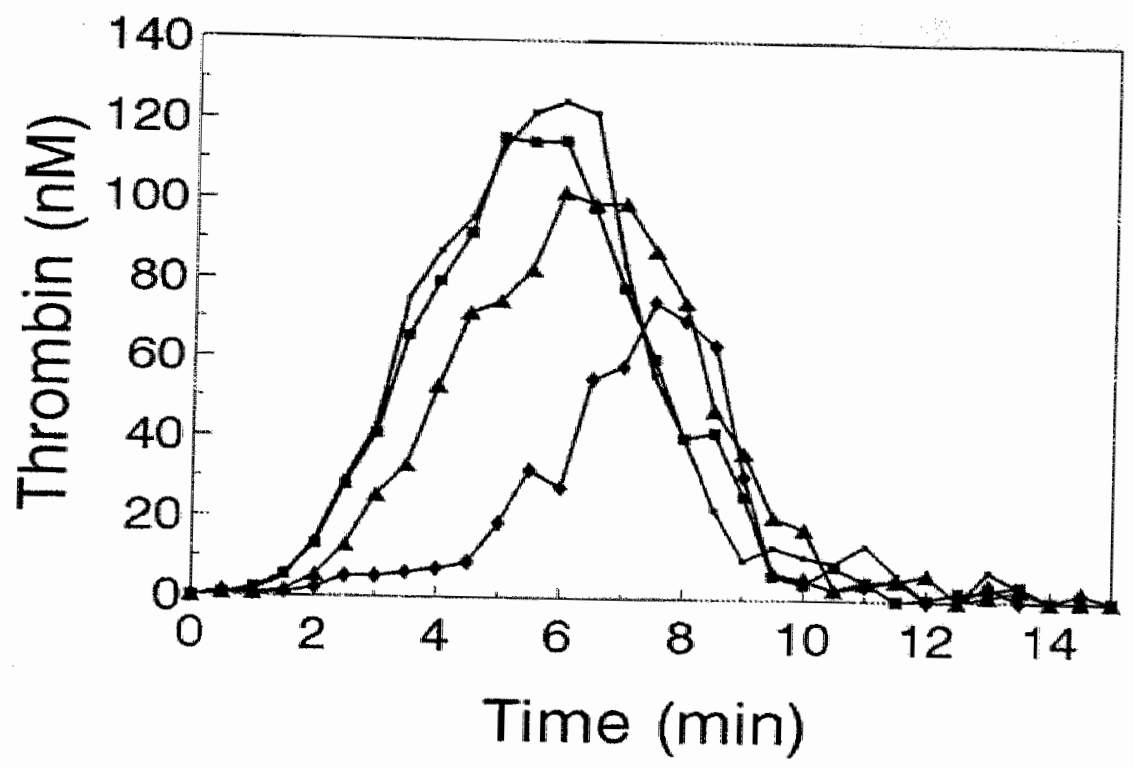

Fig. 3 Effect of monocional antibodies 6D1,10E5, and 7E3 on thrombin generation. Thrombin generation was measured as described in Methods with a final platelet count of 300,000 per $\mu$ l. Samples were either (*) untreated (Control) or preincubated with monoclanal antibodies (a) 6D1 (anti-GPIba), (A) 10E5(anti-GPIlb/lla), or (*) $7 \mathrm{E} 3$ (anti-GPIlb/llla $+\alpha_{w} \beta_{3}$ ) at $20 \mu \mathrm{g} / \mathrm{ml}$. Antibody 6D1 had minimal effect on thrombin potential, $10 E 5$ reduced thrombin potential by $\sim 23 \%$ and 7 E3 decreased thrombin potential by $\sim 47 \%$. Results are of one representative experiment from 10 to 18 separate experiments employing the different antibodies.

(Anti-GPla/lla) had virtually no effect on thrombin generation compared to control (Table 1). Antibody 10E5 (anti-GP IIb/llla) as well as its Fab fragment, in contrast, inhibited both thrombin potential and peak thrombin concentration by $-25 \%$ (Tables 1 and 2). Murine monoclonal $7 E 3 \quad(20 \mu \mathrm{g} / \mathrm{ml})$, which is directed against another epitope on the GPIIb/lla receptor and cross-reacts with the $\alpha_{v} B_{3}$ receptor, was significantly more potent than $10 E 5$ in inhibiting thrombin potential $(47 \%, P<0.001$ compared to inhibition by $10 E 5)$ and peak thrombin generation $(P<0.001$ ). The chimeric Fab fragment of antibody $7 E 3$, c7E3 Fab. produced dose-dependent inhibition of thrombin generation between 5 and $20 \mu \mathrm{g} / \mathrm{ml}$, with no additional inhibition produced by $50 \mu \mathrm{g} / \mathrm{ml}$. 
The results with $C 7 E 3$ Fab were nearly identical to those produced by intact murine 7E3. In contrast to the differences between C7E3 Fab and $10 E 5$ in the thrombin generation assay, both antibodies produced complete inhibition of platelet aggregation induced by ADP or isoT6 in PRP (data not shown).

In other experiments, inhibition of thrombin generation by c7E3 Fab was correlated with GPIlb/llla receptor blockade by c7E3 Fab (Fig. 4). Inhibition

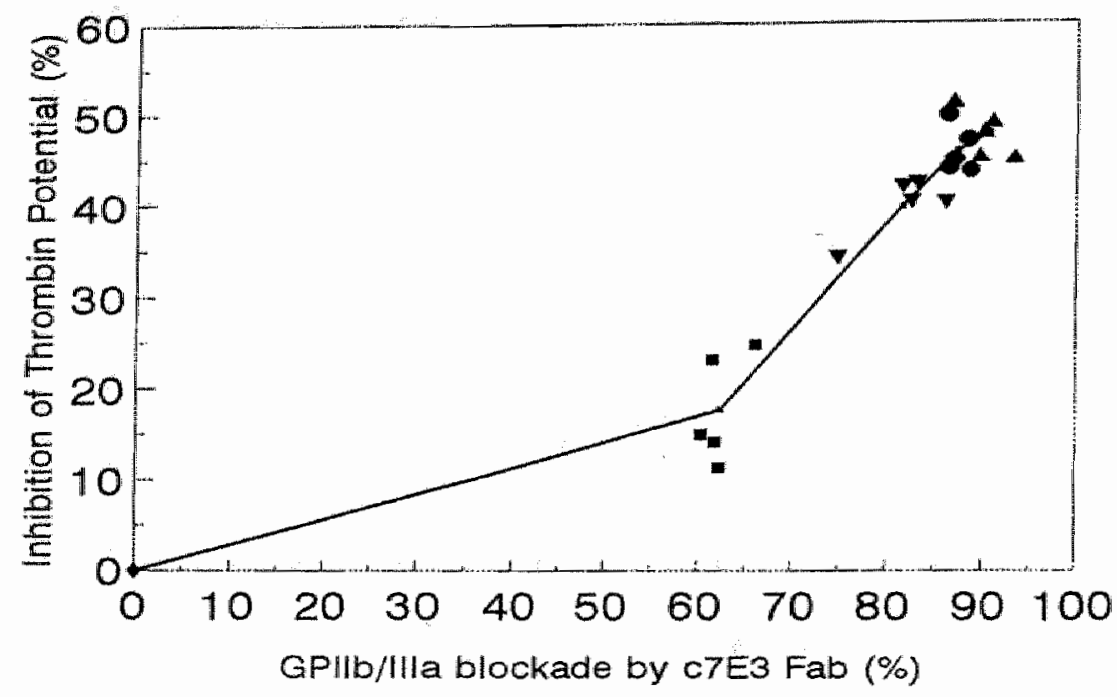

Fig. 4 Correlation between inhibition of thrombin potential by $\mathrm{CPE} 3 \mathrm{Fab}$ and GPIllb/lla receptor blockade. Gel-filtered platelets $(300,000$ per $\mu$ ) were incubated with increasing concentrations of c7E3 Fab for $20 \mathrm{~min}$ at $37^{\circ} \mathrm{C}$ and then tested in both the thrombin generation assay and in the GPIlb/llla receptor blockade assay. The points represent the values at c7E3 Fab concentration of $(\bullet) 0 \mu \mathrm{g} / \mathrm{ml},(\mathbf{m}) 5$

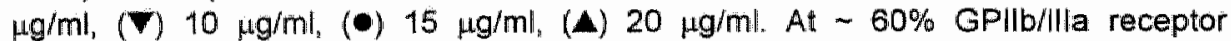
blockade, there was - 15\% inhibition of thrombin potential. At higher levels of c73 Fab, there was nearly a linear relationship between inhibition of thrombin potential and GPIlb/lla receptor blockade, reaching a plateau of $\sim 50 \%$ inhibition at $\sim 90 \%$ receptor blockade. Results are from five similar experiments.

of thrombin generation appeared to follow a threshold pattern, with $\sim 60 \%$ GPlib/lla receptor blockade correlating with just $~ 15 \%$ inhibition of thrombin potential. At higher doses of c7E3 Fab, there was a nearly linear relationship between inhibition of thrombin potential and GPIIb/llla receptor blockade, plateauing at $\sim 50 \%$ inhibition of thrombin potential with $\sim 90 \%$ GPIlb/llla 
receptor blockade. The correlation between thrombin potential and platelet count depicted in Fig. 1 permitted the conversion of the inhibition of thrombin potential by a given concentration of c7E3 Fab into an equivalent platelet count. When expressed in this manner, the highest dose of C7E3 Fab had the same effect as reducing the platelet count from 300,000 per $\mu l$ to $\sim 80,000$ per $\mathrm{ul}_{\mathrm{s}}$ a reduction of $\sim 73 \%$.

To assess the mechanism by which $\mathrm{C7E3}$ Fab inhibits thrombin generation, we performed single-platelet counts from samples obtained throughout the assay to monitor platelet aggregation. The results showed a steady decrease in single platelets or platelet aggregates $<43 \mathrm{fl}$ vol over time in the control experiments, but significantly less decrease over time in samples treated with c7E3 Fab (Table 3). Monoclonal antibody $10 \mathrm{E} 5(20 \mathrm{\mu g} / \mathrm{ml})$ was less effective than C7E3 Fab in preventing the decrease in counts.

Table 3 Effect of monoclonal antibodies on platelet counts during the thrombin generation assay

\begin{tabular}{|c|c|c|c|}
\hline Time & Control & c7E3 Fab & 10E5 \\
\hline $\min$ & $\begin{array}{c}\times 10^{-3} \text { per } \mu l \\
(n=13)\end{array}$ & $\begin{array}{c}20 \mu \mathrm{g} / \mathrm{m} / \times 10^{-3} / \mu \mathrm{\mu l} \\
(\mathrm{n}=12)\end{array}$ & $\begin{array}{c}20 \mathrm{pg} / \mathrm{m} / \times 10^{-3} / \mu \mathrm{l} \\
(\mathrm{n}=4)\end{array}$ \\
\hline 0 & $281 \pm 5^{*}$ & $283 \pm 14$ & $261 \pm 12$ \\
\hline 3 & $188 \pm 20$ & $256 \pm 12^{*}$ & $250 \pm 4^{5}$ \\
\hline 5 & $174 \pm 23$ & $247 \pm 11^{*}$ & $235 \pm 5^{5}$ \\
\hline 10 & $110 \pm 20$ & $243 \pm 12^{*}$ & $209 \pm 3^{\frac{5}{3}}$ \\
\hline 15 & $78 \pm 19$ & $239 \pm 13^{*}$ & $197 \pm 7^{5}$ \\
\hline $\begin{array}{l}\text { Thrombin } \\
\text { potential } \\
\text { inhibition (\%) }\end{array}$ & & $48 \pm 4^{*}$ & $22 \pm 4^{5}$ \\
\hline
\end{tabular}


Studies with platelets from patients with Glanzmann thrombasthenia

To confirm a role for GPllb/lla in supporting thrombin generation in this system, we also studied platelets from three unrelated patients with Glanzmann thrombasthenia. Compared to the results with control platelets, the onset of thrombin generation was delayed, thrombin potential was decreased between $17 \%$ and $26 \%$, and peak thrombin generation was reduced by $15-36 \%$ (Table 4 ). The decrease in thrombin potential with platelets from patients with Glanzmann thrombasthenia (mean $21 \%$ ) was very similar to that of normal platelets treated with antibody $10 \mathrm{E} 5(23 \pm 5 \%)$, but both were less than that observed with c7E3 Fab treatment of normal platelets ( $47 \pm 5 \%$ ).

Table 4 Thrombin Generation using platelets from patients with Glanzmann Thrombasthenia

\begin{tabular}{lcc}
\hline & Thrombin potential & Peak thrombin concentration \\
\hline & $\%$ inhibition ${ }^{*}$ & \% inhibition $^{*}$ \\
Patient 1 & 26 & 36 \\
& 20 & 17 \\
Patient 2 & 17 & 15 \\
Patient 3 & 21 & 23 \\
\hline
\end{tabular}

"Compared to a normal platelet control assayed at the same time.

Effect of monoclonal antibodies $L M 609$ and $L M 142$, alone or in combination with $10 E 5$ or $C 7 E 3$ Fab

The greater ability of 7E3 (than 1OE5) to inhibit thrombin generation in this system, and the similarity in results between 10E5-treated platelets and the platelets from the patients with Glanzmann thrombasthenia, suggested that the binding of $7 E 3$ not only blocks GPIlb/lla, but also interferes with the devilopment of platelet coagulant activity by another mechanism. Potentially, this may be related to $7 E 3^{\prime}$ s crossreactivity with the $\alpha_{w} B_{3}$ vitronectin receptor since $10 E 5$ does not bind to $\alpha_{w} B_{3}$ and the Glanzmann patients we tested had 
normal or increased levels of platelet $\alpha_{v} B_{3}$. To assess this possibility. we tested the effect of the two anti-avis, antibodies, LM609 (which inhibits ligand binding to $\mathrm{a}_{\sqrt{3}} \mathrm{~S}_{3}$ ) and LM142 (which does not inhibit ligand binding), as well as the effect of these antibodies in combination with $10 E 5$ and c7E3 Fab (Table 2). Antibody LM609 $(20 \mu \mathrm{g} / \mathrm{ml})$, as well as its Fab fragment, alone produced slight but significant inhibition of both the thrombin potential and the peak thrombin concentration $(P<0.001$ for both for 14 experiments using intact LM609). In contrast LM142 (20 $\mathrm{gg} / \mathrm{ml})$ had no abservable effect on these parameters. The combination of intact $10 \mathrm{E} 5(20 \mu \mathrm{g} / \mathrm{ml})$ and intact $\mathrm{LM} 609(20$ $\mu \mathrm{g} / \mathrm{ml}$ ) produced significantly more inhibition than $10 E 5$ alone (32 and $38 \%$ decrease in thrombin generation in experimental groups $\mathrm{A}$ and $\mathrm{B}$, respectively) (Table 2), as did the combination of $10 E 5$ Fab and LM609 Fab (41\%). The combination of $10 E 5$ and $L M 142$, however, did not produce more inhibition than 10E5 alone. Neither LM609 nor LM142 increased the inhibition of thrombin potential produced by c7E3 Fab alone.

Effect of RGDF peptide and antibodies against GPllia

The peptide RGDF, which reacts with both GPllb/llla and the $\alpha_{v} \beta_{3}$ vitronectin receptor. inhibited thrombin generation in a dose-response manner (Table 1). The maximal effect, which was achieved at $\sim 100 \mu \mathrm{M}$ was similar to that achieved with c7E3 Fab. The antibodies $7 \mathrm{H} 2$ and AP3 (both anti-GPlla) inhibited thrombin generation in a manner similar to that produced by $10 \mathrm{E} 5$, but less than that caused by $c 7 E 3$ Fab $(P<0.05$ compared to control for both antibodies, Table 1). In contrast, $7 \mathrm{H} 2$ Fab did not show a significant effect on thrombin generation (Table 1).

\section{Effect of other antiplatelet agents}

Incubation of gel-filtered platelets with aspirin $\left(20\right.$ min at $\left.37^{\circ} \mathrm{C}\right)$ at 100 uM or $2 \mathrm{mM}$ produced a modest decrease in thrombin potential and peak thrombin level (Table 5). Similar inhibition was observed when a normal volunteer ingested $325 \mathrm{mg}$ of aspirin and the results of a sample obtained $2 \mathrm{~h}$ later were compared with those from a sample obtained before aspirin 
ingestion. This dose of aspirin completely inhibited arachidonic acid-induced platelet aggregation at the 2 -h time point.

Table 5 Effect of aspirin, dibutyryl cyclic AMP, 2-isobutyl-methyl-xanthine, and prostacyclin on thrombin generation

\begin{tabular}{|c|c|c|c|}
\hline & $\mathrm{n}$ & Thrombin potential & Thrombin Peak \\
\hline & & $\%$ inhibition & $\%$ inhibition \\
\hline $\begin{array}{l}\text { ASA } \\
\text { In vitro* }(100 \mu \mathrm{M})\end{array}$ & 4 & $9 \pm 4$ & $12 \pm 3$ \\
\hline In witro $(2 \mathrm{mM})$ & 5 & $13 \pm 5^{*}$ & $14 \pm 5$ \\
\hline In vivo* $(325 \mathrm{mg})$ & 3 & $12 \pm 3^{*}$ & $17 \pm 6^{*}$ \\
\hline DB-CAMP (1 mM) & 3 & $11 \pm 2$ & $12 \pm 3$ \\
\hline DB-CAMP $(10 \mathrm{mM})$ & 3 & $21 \pm 3^{*}$ & $22 \pm 3^{*}$ \\
\hline DB-CAMP $(20 \mathrm{mM})$ & 3 & $32 \pm 6^{*}$ & $32 \pm 8^{*}$ \\
\hline $\operatorname{MTX}(0.1 \mathrm{mM})$ & 3 & $10 \pm 3$ & $10 \pm 5^{*}$ \\
\hline $\operatorname{MTX}(0.5 \mathrm{mM})$ & 3 & $21 \pm 1^{*}$ & $18 \pm 3^{*}$ \\
\hline $\operatorname{MTX}(1 \mathrm{mM})$ & 3 & $25 \pm 3^{*}$ & $26 \pm 4^{*}$ \\
\hline Prostacyclin (0.01 $\mathrm{MM})$ & 3 & $12 \pm 0^{*}$ & $14 \pm 3^{*}$ \\
\hline Prostacyclin $(0.1 \mu \mathrm{M})$ & 3 & $34 \pm 4^{*}$ & $35 \pm 2^{*}$ \\
\hline
\end{tabular}

Mean \pm SD. ASA, aspirin. "In vitro, aspirim added to gell-filtered platelets before assay; in vivo, blood was obtained from a normal volunteer before and $2 \mathrm{~h}$ after taking $325 \mathrm{mg}$ of aspirin by mouth; and "P $<0.05$ compared with control.

Incubating gel-filtered platelets at $37^{\circ} \mathrm{C}$ for $20 \mathrm{~min}$ with agents able to increase intraplatelet cyclic AMP, including DB-CAMP, 3-MTX, and prostacyclin produced significant inhibition of thrombin generation, but high doses were meeded (Table 5), and none of these agents produced as much inhibition as antibodies $7 \mathrm{E} 3$ and $\mathrm{C} 7 \mathrm{E} 3 \mathrm{Fab}$. 


\section{TAT and $F_{1+2}$}

TAT and $F_{t+2}$ values increased markedly during the thrombin generation assay (Table 6). Preincubation of platelets with $20 \mu \mathrm{g} / \mathrm{ml}$ c7E3 Fab significantly inhibited the production of TAT during the first $10 \mathrm{~min}$, with more than $50 \%$ inhibition at the $10-\mathrm{min}$ point. At $15 \mathrm{~min}$, the TAT value in the $\mathrm{c} 7 \mathrm{E} 3$

Table 6 Effect of c7E3 Fab on thrombin-antithrombin III complex formation, prothrombin fragment ${ }_{1+2}$ production, and release of platelet-derived growth factor and platelet factor 4 during the thrombin generation assay

\begin{tabular}{|c|c|c|c|c|}
\hline & \multicolumn{2}{|c|}{ Control } & \multicolumn{2}{|c|}{ c7E3 Fab } \\
\hline & O Time & $10 \mathrm{~min}$ & O Time & $10 \mathrm{~min}$ \\
\hline & & & \multicolumn{2}{|c|}{$20 \mu \mathrm{g} / \mathrm{m} /$} \\
\hline $\begin{array}{l}\text { Thrombin-antithrombin III } \\
\text { complexes (ng/ml) }(n=6)\end{array}$ & $3 \pm 1^{*}$ & $44,500 \pm 8,200$ & $3 \pm 0$ & $21,800 \pm 1,800^{*}$ \\
\hline $\begin{array}{l}\text { Prothrombin fragment } t_{1+2} \\
\text { (nmol/litre) }(n=6)\end{array}$ & $1 \pm 0$ & $1,290 \pm 160$ & $1 \pm 0$ & $1,030 \pm 80^{\S}$ \\
\hline $\begin{array}{l}\text { Platelet-derived growth factor }{ }^{*} \\
(f \mathrm{~mol} / \mathrm{ml})(n=6)\end{array}$ & $50 \pm 2$ & $1,180 \pm 70$ & $40 \pm 2$ & $980 \pm 90^{5}$ \\
\hline Platelet Factor $4(n g / m i)(n=5)$ & $4 \pm 0$ & $3,370 \pm 70$ & $4 \pm 0$ & $2,740 \pm 120^{*}$ \\
\hline
\end{tabular}

* Mean SD, ${ }^{*}=\mathrm{P}<0.001$ compared with control, ${ }^{\$}=\mathrm{P}<0.01$ compared with control; and ${ }^{*}$ Triton $X-100(1 \%)$ lysis and iso-T6 stimulation $(10 \mu \mathrm{M})$ released $1,510 \pm 250$ and $1,330 \pm 130 \mathrm{fmol} / \mathrm{ml}$ platelet-derived growth factor respectively. Thrombin generation was inhibited by c7E3 Fab by $47 \pm 4^{*}, 47 \pm 4^{*}, 40 \pm 4^{*}$, and $48 \pm 3 \% *$ in the experiments with thrombin-antithrombin III complexes, prothrombin fragment $t_{42}$ production, platelet derived growth factor release and platelet Factor 4 release, respectively.

Fab-treated sample was still less than the control, but the difference was not significant (data not shown). Preincubation of platelets with c7E3 Fab significantly reduced $F_{1+2}$ formation throughout the assay, with reductions of $10-21 \%$. 
Effect of c7E 3 Fab on platelet granule release

The release of the $\alpha$-granule proteins PDGF and PF4 during the thrombin generation assay was also significantly inhibited by c7E3 Fab (Table 6).

\section{Microparticles induced by exagenous thrombin}

The basal level of microparticles in the gel-filtered platelets, measured either as a percentage of platelets + microparticles or as an absolute number, was $4 \pm 1 \%$ and $9 \pm 2 \times 10^{9}$ per liter, respectively $(n=6)$. Activation of gelfiltered platelets with $0.25 \mathrm{U} / \mathrm{ml}$ thrombin $(n=6)$ caused an increase in microparticles $\left(20 \pm 4 \%\right.$ and $43 \pm 10 \times 10^{9}$ per liter, $P<0.001$ for both). Preincubation of platelets with $20 \mu \mathrm{g} / \mathrm{ml}$ c7E3 Fab inhibited microparticle formation nearly completely $\left(4.0 \pm 0.9 \%\right.$ and $9.0 \pm 5.2 \times 10^{9}$ per liter). Preincubation of gel-filtered platelets with $20 \mu \mathrm{g} / \mathrm{ml} 10 \mathrm{E} 5$, however, only partially reduced microparticle formation (10 $\pm 5 \%$ and $33 \pm 15 \times 10^{9}$ per liter). Thus, c7E3 Fab reduced microparticle formation induced by a known amount of thrombin to a greater extent than did $10 \mathrm{E} 5$.

Microparticles induced during the thrombin generation assay

In the control samples, microparticles increased $\sim 6$ - to 8-fold during the assay as judged by both methods of analysis (Table 7). The addition of c7E3 Fab inhibited microparticle formation nearly completely (95 and 100\%, respectively: $P<0.001$ for both), but the addition of $10 E 5$ decreased microparticle formation by only $\sim 35$ to $50 \%$ (Table 7 ). Combining $\mathbb{L}$ M609 with $10 E 5$ produced greater inhibition of thrombin potential, but did not significantly affect microparticle formation. 
Table 7 Effects of $\mathrm{C} 7 \mathrm{E} 3 \mathrm{Fab}$ and $10 \mathrm{E} 5$ on platelet microparticle formation during the thrombin generation assay

\begin{tabular}{|c|c|c|c|c|c|c|c|c|}
\hline \multirow{3}{*}{$\frac{\text { Time }}{m i n}$} & \multicolumn{2}{|c|}{ Control } & \multicolumn{2}{|c|}{$\begin{array}{l}\text { c7E3 Fab } \\
(20 \mathrm{gg} / \mathrm{ml})\end{array}$} & \multicolumn{2}{|c|}{$\begin{array}{c}10 \mathrm{E} 5 \\
(20 \mathrm{\mu g} / \mathrm{ml})\end{array}$} & \multicolumn{2}{|c|}{$\begin{array}{c}10 \mathrm{E} 5+\mathrm{LM} 609 \\
(20 \mathrm{\mu g} / \mathrm{mu})\end{array}$} \\
\hline & \multicolumn{2}{|c|}{$n=8$} & \multicolumn{2}{|c|}{$n=7$} & \multicolumn{2}{|c|}{$n=3$} & \multicolumn{2}{|c|}{$n=3$} \\
\hline & $9 *$ & $\times 10^{-9} /$ litre & $\%$ & $\times 10^{-9}$ hitre & $\%$ & $\times 10^{-9} /$ hitre & $\%$ & $\times 10^{-3} /$ atre \\
\hline 0 & $3 \pm 1^{\text {sิ }}$ & $8 \pm 3$ & $3 \pm 1$ & $9 \pm 3$ & $4 \pm 1$ & $11 \pm 2$ & $4 \pm 1$ & $12 \pm 1$ \\
\hline 5 & $16 \pm 2$ & $44 \pm 5$ & $3 \pm 1^{*}$ & $6 \pm 3^{* 4}$ & $9 \pm 1^{11}$ & $27 \pm 4^{\pi}$ & $9 \pm 1^{17 @ ~}$ & $25 \pm 6^{\mathrm{rl}}$ \\
\hline 10 & $19 \pm 1$ & $46 \pm 9$ & $4 \pm 1^{*}$ & $6 \pm 3^{\#}$ & $11 \pm 1^{\pi @}$ & $26 \pm 2^{\Pi 9}$ & $11 \pm 1^{\mathrm{n} e}$ & $28 \pm 5^{\square @ ~}$ \\
\hline 15 & $23 \pm 1$ & $46 \pm 7$ & $4 \pm 1^{\#}$ & $6 \pm 3^{*}$ & $10 \pm 1^{119}$ & $30 \pm 3^{\text {III }}$ & $10 \pm 1^{n 9}$ & $30+3^{\text {मa }}$ \\
\hline
\end{tabular}

Thrombin potential inhibition (\%)

"Expressed as (100)(number of microparticles)/ (number of platelets + microparticles); "expressed as absolute number of microparticles per liter; ${ }^{\$}$ mean $\pm \mathrm{SD}$; $\mathrm{P}<0.001$ and $\Pi p<0.01$ compared with control; ${ }^{\oplus} \mathrm{P}<0.01$ compared with $\mathrm{c} 7 \mathrm{E} 3 \mathrm{Fab}$; and $\mathrm{P}<$ 0.01 compared with 10E5.

\section{Effect of calpain inhibition}

Since the enzyme calpain has been implicated in microparticle formation (25), we tested the effect of the cell-permeable calpain inhibitor calpeptin (26) on both microparticle formation and thrombin generation (Table 8). At $138 \mu \mathrm{M}$, a dose previously demonstrated to nearly abolish calpain activity in platelets (26), calpeptin significantly inhibited both microparticle formation and thrombin generation, but not as much as c7E3 Fab. Combining calpeptin with c7E3 Fab did not significantly increase the inhibition of thrombin generation.

Effect of c7E3 Fab on thrombin generation of ionophore A23187-treated platelets

In contrast with the results of untreated platelets in the reconstituted system, when the gel-filtered platelets were pretreated with ionophore A23187. c7E3 Fab did not significantly decrease thrombin generation (thrombin potential inhibition $3 \pm 2 \%$ and thrombin peak concentration inhibition $3 \pm 2 \%$; 
$n=3$; NS) (Fig. 3). These data suggest that c7E3 Fab cannot inhibit thrombin generation after platelets are activated and microparticles are formed.

Table 8 Effect of calpeptin (138 $\mathrm{MM}), \mathrm{c7E}$ Fab, and both on platelet microparticle formation and thrombin potential during the thrombin generation test

\begin{tabular}{lcccc}
\hline \multirow{2}{*}{ Time } & \multicolumn{4}{c}{ Microparticle formation } \\
\cline { 2 - 5 } min & Control & Calpeptin & c7E3 Fab & Calpeptin + c7E3 Fab \\
0 & $n=4$ & $n=4$ & $n=4$ & $n=4$ \\
15 & $4 \pm 1^{*}$ & $3 \pm 1$ & $4 \pm 2$ & $3 \pm 1$ \\
0 & $21 \pm 2$ & $8 \pm 3^{*}$ & $4 \pm 2^{\S}$ & $4 \pm 1^{\S}$ \\
15 & $9 \pm 3^{*}$ & $9 \pm 4$ & $8 \pm 3$ & $9 \pm 3$ \\
& $47 \pm 8$ & $17 \pm 6^{*}$ & $10 \pm 3^{\S}$ & $8 \pm 4^{5}$
\end{tabular}

Thrombin potential inhibition \% $29 \pm 10^{*} \quad 43 \pm 7^{n}$ $46 \pm 8^{11}$

"Microparticles reported as percent, ${ }^{*} P<0.05$, ${ }^{\$} P<0.01$, and ${ }^{\pi} P<0.001$ compared with control, and ${ }^{\text {\# }}$ microparticles reported as absolute number $\times 10^{-9}$ per litre.

Thrombin bound to clots

Clots formed for 30 min from native platelet-free plasma in the absence of gel-filtered platelets bound $210 \pm 30$ fmoll of thrombin $(n=12)$. Assuming complete conversion of fibrinogen to fibrin, the clots contained $2.42 \mathrm{nmol}$ of fibrin monomer, yielding a thrombin-to-fibrin molar ratio of 0.09 . Adding gelfiltered platelets to the platelet-free plasma significantly increased the amount of clot-bound thrombin (530 \pm 50 fmol, thrombin-to-fibrin molar ratio $0.22, n=$ $12, \mathrm{P}<0.001)$. Incubating the platelets with c7E3 Fab $(20 \mu \mathrm{g} / \mathrm{ml})$ before clotting was initiated decreased clot-bound thrombin by $43 \%$ ( $300 \pm 50 \mathrm{fmol}$, 
thrombin-to-fibrin molar ratio $0.12, n=12, P<0.001$ compared to untreated gel-filtered platelets).

\section{Platelet-rich plasma}

To insure that the observed effects of antibody $7 \mathrm{E3}$ on the reconstituted gel-filtered platelet-defibrinated plasma system were not unique to the reagents used in that system, experiments were also conducted using PRP. The overall pattern of thrombin generation in PRP was similar to that of the reconstituted system, but the lag time, defined as the time until $10 \mathrm{nM}$ thrombin was generated, was longer, averaging $387 \pm 58 \mathrm{~s}$ (mean $\pm \mathrm{SD} ; \mathrm{n}=23$ ). The shorter lag time in the reconstituted system may reflect slight activation of platelets during gel filtration. As in the reconstituted system, antibody 6D1 (20 $\mu \mathrm{g} / \mathrm{ml}$ ) had little or no effect on thrombin potential or the peak thrombin concentration, while murine $7 E 3$ decreased thrombin generation. The detailed results obtained for the PRP are presented in Appendix.

\section{Discussion}

Platelets can facilitate fibrin formation initiated either by the extrinsic or intrinsic systems, and platelets activated with thrombin or other agonists are better able to facillitate fibrin formation than unactivated platelets (reviewed in reference 1). Based on analysis of individual reactions in the coagulation "cascade", platelets have been estimated to accelerate thrombin generation by 5-6 orders of magnitude (reviewed in reference 1). There is considerable contraversy, however, as to the mechanism(s) responsible for this platelet effect. Proposed mechanisms inciude: (a) Surface exposure of phosphatidylserine and possibly other anionic phospholipids that are ordinarily concentrated in the inner leaflet of the membrane bi-layer (27-29); (b) surface expression of specific receptors for Factors Va and VIlla $(30,31)$; (c) 
microparticle formation, with the concentration of anionic phospholipid receptors for Factors Va or VIlla, or both, on the surface of the microparticles $(32-35)$, although this mechanism has been questioned (36); (d) release of an activated form of Factor $V$ from platelet $\alpha$-granules $(2,37-39)$; (e) facilitation of Factor VIII activation by thrombin and/or factor $\mathrm{Xa} \mathrm{(40-42);} \mathrm{(f)} \mathrm{facilitation} \mathrm{of}$ contact activation (Factors XII and XI) (1); and (g) platelet Factor XI-like activity (1).

Most investigators have suggested that platelets play a dominant role in thrombin generation because: (a) fibrin deposition at sites of vascular injury occurs after platelet adhesion and aggregation (reviewed in reference 43 ); (b) fibrin forms in close proximity to the deposited platelets (44); and (c) severe thrombocytopenia and an inherited disorder affecting the ability of platelets to support thrombin generation result in profound decreases in fibrin deposition in experimental models $(35,44)$. Endothelial cells (45) and monocytes (46), however, as well as altered or abnormal erythrocytes (47), can substitute at least in part for platelets in in vitro assays of thrombin generation. Moreover, exposure of tissue factor on the membrane of a cell may provide an adequate surface for the generation of at least small amounts of thrombin $(7,43)$. Thus, the relative contributions of each of these elements to in vivo thrombin generation remains uncertain. The weight of evidence, however, appears to support a madel in which small amounts of thrombin are generated by a mechanism(s) that does not require platelets, but the explosive generation of thrombin that soon follows does rely on platelets $(7,43)$.

If platelets do make a major contribution to thrombin generation in vivo, one would predict that antiplatelet agents could decrease thrombin generation. This may occur through decreased platelet deposition and/or decreased platelet activation as described above. Moreover, since fibrin can bind thrombin and, in the arterial circulation, fibrin deposition probably initially forms on the platelet framework, decreased platelet deposition may result in decreased fibrin formation, providing a smaller fibrin clot to bind thrombin. Clot-bound thrombin, which is resistant to inactivation by antithrombin $111(48)$, has been implicated in producing: (a) resistance to thrombolysis via activation 
of Factor XIII, leading to fibrin crosslinking and crosslinking of $\alpha_{2}$-antiplasmin to fibrin (49); (b) prolonged thrombogenicity of blood vessels (50); and (c) thrombin-induced smooth muscle cell migration and intimal hyperplasia (5), processes that may contribute to "restenosis" (51). Thus, antiplatelet agents may, in fact, act as anticoagulants, reducing thrombin generation and clotbound thrombin. Moreover, this anticoagulant effect may contribute to their antithrombatic and possible antirestenosis effects.

Only limited data are available on the effect of antiplatelet agents on thrombin generation. Kyrle et al. (52), Hampton et al. (53), and Szczeklik et al. (54) have reported modest decreases in markers of thrombin generation in plasma and wound fluid from patients ingesting various doses of aspirin. Basic-Micic et al. (55) developed an in vitro assay of platelet aggregation and clot formation using PRP anticoagulated with low concentrations of a low molecular weight heparin. Aspirin treatment prolonged the times to aggregation and clot formation. The PRP from a patient with Glanzmann thrombasthenia whose platelets lacked GPIlb/llla, had very long aggregation and clotting times, supporting a contributory role for the GPIIb/llla receptor. Moorehead et al. (56) demonstrated that prostacyclin and the stable prostacyclin derivative carbacyclin prolong the celite-initiated activated clotting time of heparinized whole blood.

We previously demanstrated that aspirin ingestion had a modest inhibitory effect on tissue factor-induced thrombin generation in nonanticoagulated whole blood (10). Both the lag time and peak thrombin generation were affected (lag time, $335 \pm 11 \mathrm{~s}$ before and $372 \pm 13 \mathrm{~s}$ after, $\mathrm{P}<$ 0.005 ; thrombin peak, $163 \pm 8 \mathrm{nM}$ before and $147 \pm 6 \mathrm{nM}$ after, $\mathrm{P}<0.05$ ). The inhibitory effect of aspirin was comparable to adding $0.03 \mathrm{U} / \mathrm{ml}$ of heparin to the mixture. No effect of aspirin ingestion was observed, however, using citrated blood or PRP. In the same system, the stable synthetic prostacyclin derivative ilomedine caused both a delay and reduction in tissue factorinduced thrombin generation when added to either unanticoagulated blood or citrated PRP. 
Limited data are available on the effect of aspirin on in vivo thrombin generation in active vascular disease and vascular injury. Yasu et al. (57) studied patients with unstable angina and found that patients treated with aspirin had a decrease in TAT complexes during the first $24 h$, whereas patients treated with placebo did not. In a brief report of patients undergoing percutaneous coronary artery balloon angioplasty, Andreotli et al. (58) found lower prothrombin $F_{1+2}$ levels post-percutaneous coronary artery balloon angioplasty in patients receiving high dose aspirin compared to patients receiving low dose aspirin.

Agents that block the platelet GPIlb/llla receptor, which include monoclonal antibodies and both peptides and peptido-mimetics based on the arginine-glycine-aspartic acid (RGD) sequence are more potent inhibitors of platelet aggregation and arterial thrombosis than aspirin $(59,60)$. Indirect support for the hypothesis that GPIlb/llla receptor antagonists can result in a decrease in thrombin formation comes from the studies by Cadroy et al. (61), who showed that at arterial shear rates, blockade of GPIlb/llla receptors with murine monoclonal antibody LJ-CP8 nearly abolished ${ }^{125}$-fibrinogen incorporation into thrombi formed on collagen-coated tubing inserted in arteriovenous shunts in baboons. Support for an anticoagulant effect of c7E3 Fab comes from analysis of the activated clotting times in the EPIC study. Moliterno et al. reported that despite receiving similar doses of heparin, patients treated with $\mathrm{C} 7 \mathrm{E} 3$ Fab had longer activated clotting times than patients not treated with $\mathrm{C7E3}$ Fab (62).

Studies of the platelets of patients with Glanzmann thrombasthenia have yielded conflicting data with regard to the ability of the platelets to support thrombin generation. Thus, early studies on the coagulation accelerating activity ("Platelet Factor 3") of platelets from Glanzmann thrombasthenia patients gave variable results, with one group obtaining normal values (63), but most obtaining abnormal results (64-67), suggesting that under certain conditions, platelet activation depends on GPIlb/llla function, whereas under other conditions, platelet activation is independent of GPIIb/llla function. Weiss and Lages found that thrombasthenic platelets supported early thrombin formation after vascular injury as well as normal platelets, but 
there was a suggestion that late thrombin generation may have been reduced (43). In flow chamber studies, however, thrombasthenic platelets supported fibrin deposition as well or better than normall platelets (44).

The results of our studies support the premise that potent antiplatelet agents may function in vivo as anticoagulants by decreasing thrombin generation at sites of vascular injury. Thus, we were able to show nearly a $50 \%$ decrease in thrombin potential with murine $7 \mathrm{E} 3$ in both a gel-filtered platelet system and a PRP system when coagulation was initiated with tissue factor, the most likely trigger for thrombin generation in vivo in both physiologic and pathologic states. In reconstituted system, c7E3 Fab gave results very similar to those of murine $7 \mathrm{E} 3$, excluding a significant role for the Fc region of the molecule. Treatment of platelets with C7E3 Fab also decreased platelet aggregate formation, TAT complex formation, $F_{1+2}$ formation, PDGF and PF4 release, platelet microparticle formation "and clot-bound thrombin. Other antiplatelet agents were also capable of decreasing thrombin generation, but they were not as potent as c7E3 Fab. Off note, both murine c7E3 and C7E3 Fab were more potent in inhibiting thrormbin generation than antibody $10 \mathrm{E} 5$, even though all three antibody preparations block fibrinogen binding to platelets and platelet aggregation to the same extent. Despite the similarities between $7 E 3$ and $10 E 5$, these antibodies have been shown to differ in their ability to inhibit clot retraction $(68,69)$, as well as their ability to inhibit platelet interaction with immobilized RGD peptides (23). Moreover, 7 E3 has been shown to inhibit $\alpha_{v} B_{3}$ vitronectin receptor function, whereas $10 E 5$ does not (20), The reduction in thrombin generation observed with the platelets from all three patients with Glanzmann thrombasthenia tested supports a role for GPllb/llla in thrombin generation. Since the reduction in thrombin generation observed with thrombasthenic platelets was similar to that observed with normal platelets treated with antibody $10 \mathrm{E} 5$, and since we directly determined that the platelets from all three patients have normal to increased numbers of $a_{v} \beta_{3}$ receptors, we considered the possibility that at least part of the difference in behavior between 7E3 and $10 E 5$ may be due to their differences in inhibiting avbs 
To test this hypothesis, we analyzed the effect of combining $7 E 3$ or $10 E 5$ with LMGO9 (anti-avB3 ), which inhibits avB3 function, and LM142 (antiav). which does not inhibit $a_{w} B_{3}$ function. There was sight, but consistent inhibition of thrombin generation by antibody LM609 alone, but none by LM 142 alone. LM609 enhanced the inhibition caused by $10 E 5$ but not the inhibition caused by c7E3 Fab. These data suggest that $7 E 3$ inhibits thrombin generation partly by GPllb/llla inhibition, and partly by ovis inhibition. We cannot exclude the possibility that other mechanisms are also involved because the combined inhibitory effect of $10 E 5$ and $L M 609$ did not quite equal that produced by $7 E 3$ alone. The RGDF peptide, which inhibits both GPIIb/llla receptors and $\alpha_{\mathrm{v}} \mathrm{B}_{3}$ vitronectin receptors, gave results similar to those produced by c7E3 Fab.

Although controversy persists. there is considerable evidence linking microparticle formation with the enhanced generation of thrombin produced by platelets (33-36). It has been proposed that microparticles are particularly rich in anionic phospholipids and receptors for Factors $\mathrm{Va}, \mathrm{VIII}(\mathrm{a})$, and IXa (70). In addition, the patient with a defect in platelet coagulant activity appears to have a decrease in microparticle formation as her primary abnormality (35). Apparently conflicting results of the importance of GPIlb/llla in platelet microparticle formation have been reported. Gemmell et al. (71) found that intact GPIIb/llla is required for platelet microparticle formation induced by thrombin, that the platelets of a patient with Glanzmann thrombasthenia had markedly reduced microparticle formation in response to thrombin, and that murine monoclonal antibodies $7 E 3$ and $A_{2} A_{9}$ (anti-GPIlb/lla) inhibit microparticle formation when platelets are stimulated with thrombin. In sharp contrast, Nomura et al. (72) reported that the platelets of a patient with Glanzmann thrombasthenia produced normal numbers of microparticles in response to thrombin ionophore A23187, and ADP. Moreover, the microparticles supported prothrombin activation normally. There were significant technical differences between the studies of Gemmell et al. and Nomura et al. with regard to the buffers and platelet preparation procedures, and these may have affected the results. Neither study reported the presence 
or absence of $\alpha_{w} \beta_{3}$ on the patient's platelets, and so variations in surface expression of this receptor may also have contributed to the observed differences. The results of the present study are consistent with those of Gemmell et al. (71) in that C7E Fab inhibited microparticle formation. Our data also support a correlation between microparticle formation and thrombin generation since c7E3 Fab inhibited both. Similarly, the calpain inhibitor calpeptin inhibited both microparticle formation and thrombin potential. Moreover, c7E3 Fab did not inhibit thrombin generation when platelets were pretreated with ionophore A23187, an observation consistent with the hypothesis that $\mathrm{CFE} 3 \mathrm{Fab}$ acts proximal to microparticle formation. Additional studies will be required, however, to assess whether the inhibition of microparticle formation by $\mathrm{CFE} 3 \mathrm{Fab}$ is the cause of the decrease in thrombin generation and to define the mechanisms involved.

In conclusion, in addition to its inhibitory effects on platelet aggregation via blockade of GPIIb/llla receptors, c7E3 Fab may also inhibit thrombin generation by decreasing the number of platelets in thrombi and by interfering with the platelet-activation events involved in facilitating thrombin generation. The inhibition of thrombin generation by c7E3 Fab may contribute to both its immediate antithrombotic effect and perhaps to its possible effects on longterm vascular restenosis. 


\section{References}

1. Walsh, P.N., and A.H. Schmaier. Platelet-coagulant protein interactions, in Hemostasis and Thrombosis: Basic Principles and Clinical Practice, 3rd ed. R.W. Colman. J. Hirsh, V.J. Marder, and E.W. Salzman, editors. J.B. Lippincott Co. Philadeliphia. 1994; pp 629-651.

2. Wyshock, E.G., G.J. Stewart, and R.W. Colman. Thrombin-stimulated human platelets express molecular forms of $\alpha$-granule factor $V(F V)$, which differ from FVa. Thromb. Haemost. 1994; 72:947-956.

3. Coller, B.S., K. Anderson, and H.F. Weisman. New antiplatelet agents: platelet GPIIb/llla antagonists. Thiromb. Haemost. 1995; $74: 302-308$.

4. EPIC investigators. Use of a monoclonal antibody directed againtst the platelet glycoprotein Ilib/llla receptor in high risk coronary angioplasty. N. Engl. J. Med. 1994; 330: 956-961.

5. Schwartz, S.M. Serum-derived growth factor is thrombin ? J.Clin. Invest. 1993; 91:94-98.

6. Topol, E.J., R.M. Califf, H,F. Weisman, S.G. Ellis, J.E. Tcheng, S. Worley, R. Ivanhoe, B.S. George, D. Fintel, M. Weston, et al. Randomised trial of coronary intervention with antibody against platelet $\mathrm{lb} / \mathrm{b} / \mathrm{l}$ a integrin for reduction of clinical restenosis: results at six months. Lancet (N. Am. Ed.). 1994; 343: $881-886$.

7. Beguin, S., T. Lindhout, and H.C. Hemker. The effect of trace amounts of tissue factor on thrombin generation in platelet rich plasma, its itihibition by heparin. Thromb. Haemost. 1989;61:25-29.

8. Béguin "S. H. Kessels, F. Dol, and H.C. Hemker. The consumption of antithrombin III during coagulation, its consequences for the calculation of the prothrombinase activity and the standardization of heparin activity. Thromb. Haemost. $1992 ; 68: 136-142$.

9. Hemker, H.C., S. Wielders, H. Kessels, and S. Béguin. Continuous registration of thrombin generation in plasma, its use for the determination of the thrombin potential. Thromb. Haemost. 1993; 70:617-624.

10. Kessels, $H_{1}, S$. Béguin, $H$. Andree, and H.C. Hemker. Measurement of thrombin generation in whole blood. The effect of heparin and aspirin. Thromb. Haemost. 1994; 72:78-83.

11. Coller, B.S., E.l. Peerschke, L.E. Scudder, and C.A. Sullivan. A murine monoclonal antibody that completely blacks the binding of fibrinogen to platelets produces a thrombasthenic-like state in normal platelets and binds to glycoproteins IIb and/or IIla. J. Clin. Invest. 1983; 72:325-338. 
12. Coller, B.S. A new murine monoclonal antibody reports an activationdependent change in the conformation and/or microenvironment of the platelet glycoprotein Ilb/lla complex. J Clin. Invest. 1985; 76:101-108.

13. Coller, B.S., E.I. Peerschke, L.E. Scudder, and C.A. Sullivan. Studies with a murine monoclonal antibody that abolishes ristocetin-induced binding of von Willebrand factor to platelets: additional evidence in support of GPIb as a platelet receptor for von Willebrand factor. Blood. 1983;61:99-110.

14. Coller, B.S., J.H. Beer, L.E. Scudder, and M.H. Steinberg. Collagen-platelet interactions: evidence for a direct interaction of collagen with platelet GPIlb/lla and an indirect interaction with platelet GPIIb/lla mediated by adhesive proteins. Blood. 1989; 74:182-192.

15. Kutok, J.L., and B.S. Coller. Partial inhibition of platelet aggregation and fibrinogen binding by a murine monoclonal antibods, to GPIlla: requirement for antibody bivalency. Thromb. Haemost. 1994;72:964-972.

16. Kohmura, C., H.K. Gold, T. Yasuda, R. Holk, M.A. Nedeiman, J.L. Guerrero, H.L. Weisman, and D. Collen. A chimeric murine/human antibody Fab fragment directed against the platelet GPIlb/lla receptor enhances and sustains arterial thrombolysis with recombinant tissue-type plasminogen activator in baboons. Arterioscler. Thromb. 1993; 13:1837-1842.

17. Cheresh, D.A., and R.C. Spiro. 1987. Biosynthetic and functional properties of an Arg-Gly-Asp-directed receptor involved in human melanoma cell attachment to vitronectin, fibrinogen, and von Willebrand factor. J. Biol. Chem. 262:1770317711.

18. Newman, P.G., R.W. Allen, R.A. Kahn, and T.J. Kunicki. Quantitation of membrane glycoprotein Illa on intact human platelets using the monocional antibody, AP-3. Blood. 1985; 65:227-232.

19. Gretch, D.R., M. Suter, and M.F. Stinski. The use of biotinylated antibodies and steptavidin affinity chromatography to isolate herpes virus hydrophobic proteins or glycoproteins. Anal. Biochem. 1987; 163:270-277.

20. Coller, B.S., D.A. Cheresh, E. Asch, and U. Seligsohn. Platellet vitronectin receptor expression differentiates Iraqi-Jewish from Arab patients with Glanzmann thrombasthenia in Israel. Blood. 1991; 77:75-83.

21. Coller, B.S. K.T. Springer, L.E. Scudder, J.L. Kutok, M. Ceruso, and G.D. Prestwich. Substituting isoserine for serine in the thrombin receptor activation peptide SFLLRN confers resistance to aminopeptidase $M$-induced cleavage inactivation. J. Biol. Chem. 1993; 268:20741-20743.

22. Beer, J.H., K.T. Springer, and B.S. Coller. Immobilized Arg-Gly-Asp (RGD) peptides of varying lengths as structural probes of the platelet glycoprotein Ilb/llla receptor. Blood. 1992; 79:117-128.

23. Hemker, H.C., G.M. Willems, and S. Béguin. Computer assisted method to obtain the prothrombin activation velocity in whole plasma independent of thrombin decay processes. Thromb. Haemost 1986; 56:9-17. 
24. Coller, B.S., and L.E. Scudder. Inhibition of dog platelet function by in vivo infusion of $F(a b)_{2}$ fragments of a monoclonal antibody to the platelet glycoprotein llb/llla receptor. Blood 1985; 66:1456-1459.

25. Fox, J.E.B., C.D. Austin, C.C. Reynolds, and P.K. Steffen. Evidence that agonist-induced activation of calpain causes the shedding of procoagulantcontaining microvesicles from the membrane of aggregating platelets. J. Biol. Chem. $1991 ; 266: 13289-13295$.

26. Tsujinaka T., J. Kajiwara, J. Kambayashi, M Sakon, N. Higuchi, T. Tanaka "and T. Mori. Synthesis of a new cell penetrating calpain inhibitor (calpeptin). Blochem. Biophys. Res. Commun. 1988; 153:1201-1208.

27. Bevers, E.M., P. Comfurius, J.L.M.L. Van Rijn, H.C. Hemker, and R.F.A. Zwaal. Generation of prothrombin-converting activity and the exposure of phosphatidylserine at the outer surface of platelets. Eur. J. Biochem. 1982; 122: 429-436.

28. Thiagarajan, P., and J.F. Tait. Binding of annexin V/ placental anticoagulant protein I to platelets. J Biol. Chem. 1990; 265:17420-17423.

29. Bevers, E.M., P. Comfurius, and R.F.A. Zwaal. Mechanisms involved in platelet procoagulant response. In Mechanisms of Platelet Activation and Control. K.S. Authi et al., editors. Plenum Publishing Corp., New York. 1993; pp 195-207.

30. Majerus, P.W., and J.P. Miletich. Relationship between platelets and coagulation factors in hemostasis. Annu Rev. Med. 1978; 29:41-49.

31. Nesheim, M.E., E. Furmaniak-Kazmierczak, C. Henin, and G. Cot. On the existence of platelet receptors for factor $V(a)$ and factor VIII(a). Thromb. Haemost. 1993 70:80-86.

32. Sandberg, $H_{1}, L,=O$. Andersson, and $S$. Hoglund. Isolation and characterization of lipid-protein particles containing platelet factor 3 released from human platelets. Biochem. J. 1982; 203:303-311.

33. Sims, P.J., E.M. Faioni, T. Wiedmer. and S.J. Shattil. Complement proteins C5b- 9 cause release of membrane vesicles from the platelet surface that are enriched in the membrane receptor for coagulation factor $\mathrm{Va}$ and express prothrombinase activily. J. Biol. Chem. 1988; 263:18205-18212.

34. Sims, P.J., T. Wiedmer. C.T. Esmon. H.J. Weiss, and S.J. Shattil. Assembly of the platelet prothrombinase complex is linked to vesiculation on the platelet plasma membrane. Studies in Scott syndrome: an isolated defect in platelet procoagulant activity. J. Biol. Chem. 1989; 264: 17049-17057.

35. Weiss. H.J. Scott syndrome-a disorder of platelet coagulant activity. Semin. Hematol. 1994; 31:312-319. 
36. Swords, N.A. P.B. Tracy, and K.G. Mann. Intact platelet membranes, not platelel-released microparticles support the procoagulant activity of adherent platelets. Arterioscler. Thromb. 1993; 13:1613-1622.

37. Østerud, B., S.I. Rapaport, and K.K. Lavine. Factor V activity of platelets: evidence for an activated factor $\mathrm{V}$ molecule and for a platelet activator. Blood. $1977 ; 49: 819-834$

38. Baruch, D, H.C. Hemker, and T. Lindhout. Kinetics of thrombin-induced release and activation of platelet factor V. Eur. J. Biochem. 1986; 154:213218.

39. Tracy, P.B., M.E. Nesheim, and K.G. Mann. Proteolytic alterations of factor Va bound to platelets. J. Bial. Chem. 1983; 258:662-669.

40. Hultin, M.B. The modulation of thrombin activation of factor Vill by calcium ions, phospholipids and platelets. Blood. 1985; 66:53-58.

41. Neuenschwander, $P_{.}$, and J. Jesty. A comparison of phospholipid and platelets in the activation of human factor VIII by thrombin and factor Xa, and in the activation factor $X$. Blood. 1988; 72:1761-1770.

42. Rawala-Sheikh, R., S.S. Ahmad, B. Ashby, and P.N. Walsh. Kinetics of coagulation factor $X$ activation by platelet-bound factor $\mid X a$. Biochemistry. 1990; 29:2606-2611.

43. Weiss, H.J., and B. Lages. Studies of thromboxane $B_{2}$, platelet factor 4 , and fibrinopeptide $A$ in bleeding-time blood of patients deficient in von Willebrand factor, platelet glycoproteins Ib and IIb-IIla. and storage granules. Blood. 1993; $82: 481-490$.

44. Weiss, H.J., V.T. Turitto, and H.R. Baumgartner. Role of shear rate and platelets in promoting fibrin formation on rabbit subendothelium. Studies utilizing patients with quantitative and qualitative platelet defects. J. Clin. invest. 1986: $78: 1072-1082$.

45. Jaffe, E.A. Biochemistry, ilmmunology, and cell biology of endothelium. In Hemostasis and Thrombosis: Basic Principles and Clinical Practice, 3rd edition. R.W. Colman, J. Hirsch, V.J. Marder, and E.W. Salzman, editors. J.B. Lippincott Co. Philladelphia. 1994; pp 718-744.

46. Rickles, F.R., and R.L. Edwards. Leukocytes and tumor cells in thrombosis. In Hemostasis and Thrombosis: Basic Principles and Clinical Practice, 3rd edition. R.W. Colman, J. Hirsch, V.J. Marder, and E.W. Salzman. editors. J.B. Lippincott Co. Philadelphia. 1994; 1164-1179.

47. Bevers, E.M., P. Comfurius, and R.F. Zwaal. Platelet procoagulant activity physiological significance and mechanisms of exposure. Blood Rev. 1991: 5:146-154.

48. Weitz, J.I., M. Hudoba, D. Massel, J. Maraganore. and J. Hirsch. Clot- bound thrombin is protected from inhibition by heparin-antithrombin III but is 
susceptible to inactivation by antithrombin 11 -independent inhibitors. J. Clin. Invest. 1990; 86:385-391.

49. Reed, G.L., G.R. Matsueda, and E. Haber. Platelet factor Xlll increases the fibrinolytic resistance of platelet-rich clots by accelerating the crosslinking of aipha 2-antiplasmin to fibrin. Thromb. Haemost. 1992; 68:315-320.

50. Zoldhelyi, P., V. Fuster, and J.H. Chesebro. Antithrombins as conjunctive therapy in arterial thrombolysis. Coron. Artery. Dis. 1992; 3:1003-1009.

51. Anderson, H.V. Restenosis after coronary angioplasty. Disease A Month. 1993; 39:613-670.

52. Kyrle, P.A., J. Westwick, M.F. Scully, V.V. Kakkar, and G.P. Lewis. Investigation of the interaction of blood platelets with the coagulation system at the site of plug formation in vivo in man- effect of low-dose aspirin. Thromb. Haemost. $1987 ; 57: 62-66$.

53. Hampton, K.K., C. Cerletti, L.A. Loizou, F. Bucchi M.B. Donati, J.A. Davies, G. de Gaetano, and C.R.M. Prentice. Coagulation. fibrinolytic and platelet function in patients on long-term therapy with aspirin $300 \mathrm{mg}$ or $1,200 \mathrm{mg}$ daily compared with placebo. Thromb. Haemost. 1990;64:17-20.

54. Szczeklik, A, M. Krzanowski, P. Gora, and J. Radwan. Antiplatelet drugs and generation of thrombin in clotting blood. Blood. 1992; 80:2006-2011.

55. Basic-Micic, M. C. Roman, U. Herpel, E. Kling, B. Scholz, and H.K. Breddin. Platelet-induced thrombin generation time: a new sensitive global assay for platelet function and coagulation. Haemostasis. 1992; 22:309-321.

56. Moorehead, M.T., J.C. Westengard, and B.S. Bull. Platelet involvement in the activated coagulation time of heparinized blood. Anesth. Analg. 1984; 63:394398.

57. Yasu, T., S. Oshima, M. Imanishi, H. Nonogi, K. Haze, M. Juramochi, T. Omae, $Y$. Hayashi. and $S$. Yamamoto. Effects of aspirin DL-lysine on thrombin generation in unstable angina pectoris. Am. J. Cardiol. 1993; 71:1164-1168.

58. Andreotti, F, G.J. Davies, S.P. IJjang, and P. Sritara. High-dose aspirin, thrombin, and coronary angioplasty. Lancet (N. Am. Ed.). 1993; 341:1161.

59. Coller, B.S. Inhibitors of the platelet glycoprotein IIb/lla receptor as a conjunctive therapy for coronary artery disease. Coron. Artery. Dis. 1992; 3 : 1016-1029.

60. Cook, N.S., G. Kottirsch, and H.-G., Zerwes. Platelet glycoprotein Ilb/llla antagonists. Drugs Future. 1994; 19:135-159.

61. Cadroy, Y., S.R. Hanson, B.K. Andrew, U.M. Marzec, B.L. Evatt, T.J. Kunicki. R.R. Montgomery, and L.A. Harker. Relative antithrombotic effects of monoclonal antibodies targeting different platelet glycoprotein-adhesive molecule interactions in nonhuman primates. Blood. 1994; 83:3218-3224. 
62. Moliterno, D.J., R.M. Califf, F.V. Aguirre, K. Anderson, K.N. Sigmon, H.F. Weisman, and E.J Topol. Effect of platelet glycoprotein Ilb/lla integrin blockade on activated clotting time during percutaneous transluminal coronary angioplasty or directional atherectomy (the EPIC trial). Evaluation of c7E3 Fab in the prevention of ischemic complications trial. Am. J. Cardiol. 1995; 75: 559562.

63. Bevers, E.M., P. Comfurius, and H.K. Nieuwenhuis. Platelet prothromin converting activity in hereditary disorders of platelet function. $\mathrm{Br}$. J. Haematol. $1986 ; 63: 335-346$.

64. Hardisty, R.M., K.M. Dormandy, and R.A. Hutton. Thrombasthenia: studies on three cases. Br. J. Haematol. 1964; 10:371-387.

65. Caen "J.P., P.A. Castaldi, and J.C. Leclerc. Congenital bleeding disorders with long bleeding time and normal platelet count. I. Glanzmann's thrombasthenia. Am. J. Med. 1966; 41:4-26.

66. Zucker, M.B., J.H. Pert, and M.W. Hilgartner. Platelet function in a patient with thrombasthenia. Blood. 1966; 28:524-534.

67. Weiss, H.J., and S. Kochwa. Studies of platelet function and proteins in 3 patients with Glanzmann thrombasthenia. J. Lab. Clin. Med. 1968; 7:153-165.

68. Cohen, I. D.L. Burk, and J.G. White. The effect of peptides and monocional antibodies that bind to platelet glycoprotein llib-lila complex on the development of clot tension. Blood. 1989; 73:1880-1887.

69. Carr, M.E. Jr., S.L. Zekert, R.R. Hantgan, and J. Braaten. Glycoprotein IIb/llia blockade inhibits platelet-mediated force development and reduces elastic modulus. Thromb Haemost. 1995; 73:499-505.

70. Hoffman, M., D.M. Monroe, and H.R. Roberts. Coagulation factor $\mathbb{X}$ Xa binding to activated platelets and platelet-derived microparticles: a flow cytometry study. Thromb. Haemost. 1993; 68:74-78.

71. Gemmell, C.H., M.V. Sefton, and E.L. Yeo. Platelet derived microparticle formation, involves glycoprotein IIb/lla. Inhibition by RGDS and Glanzmann's thrombasthenia defect. J. Biol. Chem. 1993; 268:14586-14589.

72. Nomura, S. Y. Komiyama, T. Murakami, A. Funatsu, T. Kokawa, T. Sugo, M. Matsuda, and $K$. Yasunaga. Flow cytometric analysis of surface membrane proteins on activated platelets and plalelet-derived microparticles from healthy and thrombasthenic individuals. Intl. J. Hematol. 1993; 58:203-212. 


\section{Appendix}

\section{Effect of Antibodies Against Platelet Membrane Glycoproteins on the Resonance Loop Between Platelet Activation and Thrombin Generation in Platelet Rich Plasma*}

Thrombin generation in platelet rich plasma (PRP) after recalcification in the presence of trace amounts of tissue factor is limited by the availability of procoagulant phospholipids (7). Trace amounts of thrombin (< $5 \mathrm{nM}$ ) formed early in the reaction activate the platelets that by membrane flip-flop and generation of microparticles, provide the procoagulant phospholipid surface necessary for explosive thrombin production ( $100 \mathrm{nM})$. Thus a positive feedback loop exists in which platelets and thrombin formation mutually activate each other.

We tested the influence of the antibodies against GPIlb/llla or GPIb receptors on thrombin generation in PRP.

Effect of monoclonal antibody 6D1 (anti-GPIba), on thrombin generation

For thrombin generation carried out in the control platelet rich plasma (PRP), the value of thrombin potential was measured to be $433 \pm 32 \mathrm{nM}$ min, peak thrombin concentration $84 \pm 23 \mathrm{nM}$, and the lag time $387 \pm 58 \mathrm{~s}$. (mean \pm $\mathrm{SD}, \mathrm{n}=23$ for the three parameters), When PRP was preincubated with antibady 6D1 (at 10 or $20 \mu \mathrm{g} / \mathrm{ml}$ ), no significant effect was observed on thrombin generation (Fig. A1). In presence of $20 \mu \mathrm{g} / \mathrm{ml} 6 \mathrm{D} 1$, the thrombin potential was inhibited by only $2 \pm 2 \%$ and the peak thrombin concentration by $1.5 \pm 4 \%(n=10$, NS) and there was no detectable change on the lag time (390 $\pm 62 \sin (n=10)$.

\footnotetext{
* Kumar R et al.
} 


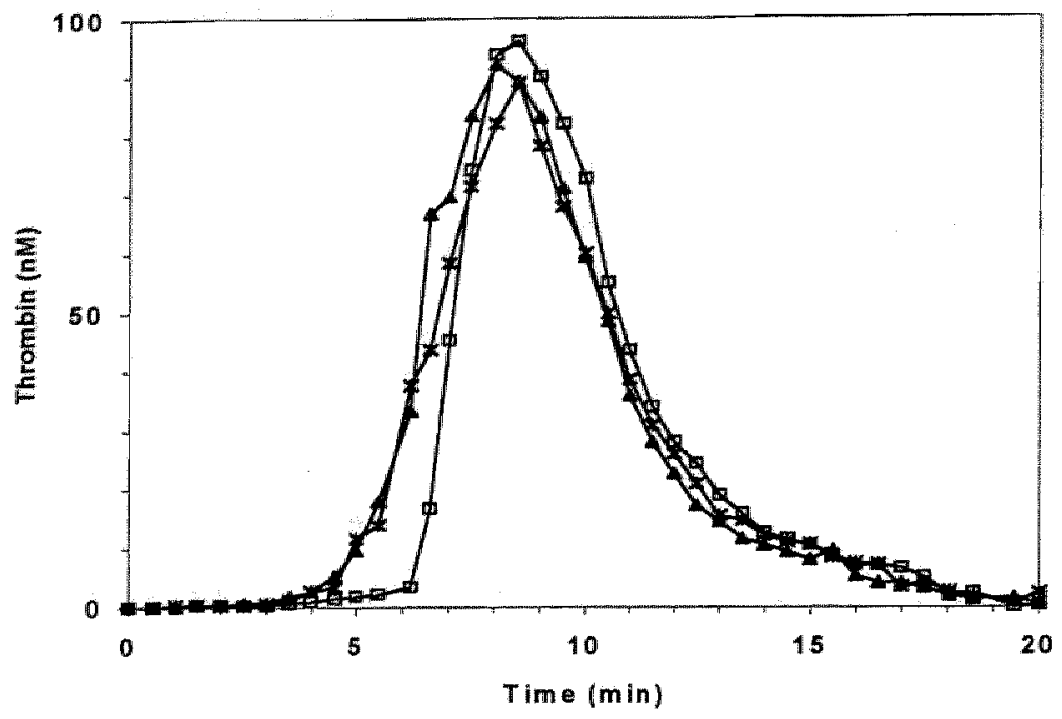

Fig. A1 Effect of antibody 6D1 on thrombin generation in PRP. As described in methods, $240 \mu \mathrm{l}$ af PRP (pl.count adjusted $3^{*} 10^{8} / \mathrm{ml}$ ) was incubated with $60 \mu \mathrm{l}$ of Buffer $A$ in the presence and absence of antibody for 10 min at $37^{\circ} \mathrm{C}$ with gentle stirring. Coagulation was triggered with $60 \mu \mathrm{l}$ of $0.1 \mathrm{M} \mathrm{CaCl}_{2}$ containing $1.8 \mathrm{fM}$ of recombinant tissue factor (this dilution of tissue factor gave a clotting time $>10 \mathrm{~min}$ in platelet poor plasma). The amidolytic activity was determined in subsamples taken at 30 s intervals from which the thrombin activity was calculated (7). ( $\square$ ) Control PRP without antibody, (X) PRP preincubated for $10 \mathrm{~min}$ with antibody 6D1 $(10 \mu \mathrm{g} / \mathrm{ml}),(\mathbf{A})$ PRP preincubated with antilbody 6D1 $(20 \mu \mathrm{g} / \mathrm{ml})$. Representative experiment of 10 so performed.

Effect of monoclonal antibody $7 E 3$ (anti GPIlb/lla+aw $\beta_{3}$ ) on thrombin generation

The antibody $7 E 3$ was found to result in a dose dependent inhibiton of thrombin generation (Fig. A2). The inhibition of thrombin potential in presence of $5 \mu \mathrm{g} / \mathrm{ml} 7 \mathrm{E} 3$ was $15 \pm 4 \%$ and that of peak thrombin concentration was $12 \pm$ $3 \%(n=3)$. The inhibition increased in the presence of $20 \mu \mathrm{g} / \mathrm{ml} 7 \mathrm{E} 3$ and thrombin potential was found to be inhibited by $44 \pm 12 \%$ and the peak thrombin concentration by $40 \pm 9 \%(n=14, P<0.01$ for each). The lag time was also significant prolonged $(630 \pm 65 s, n=14)$. No additional inhibition was 


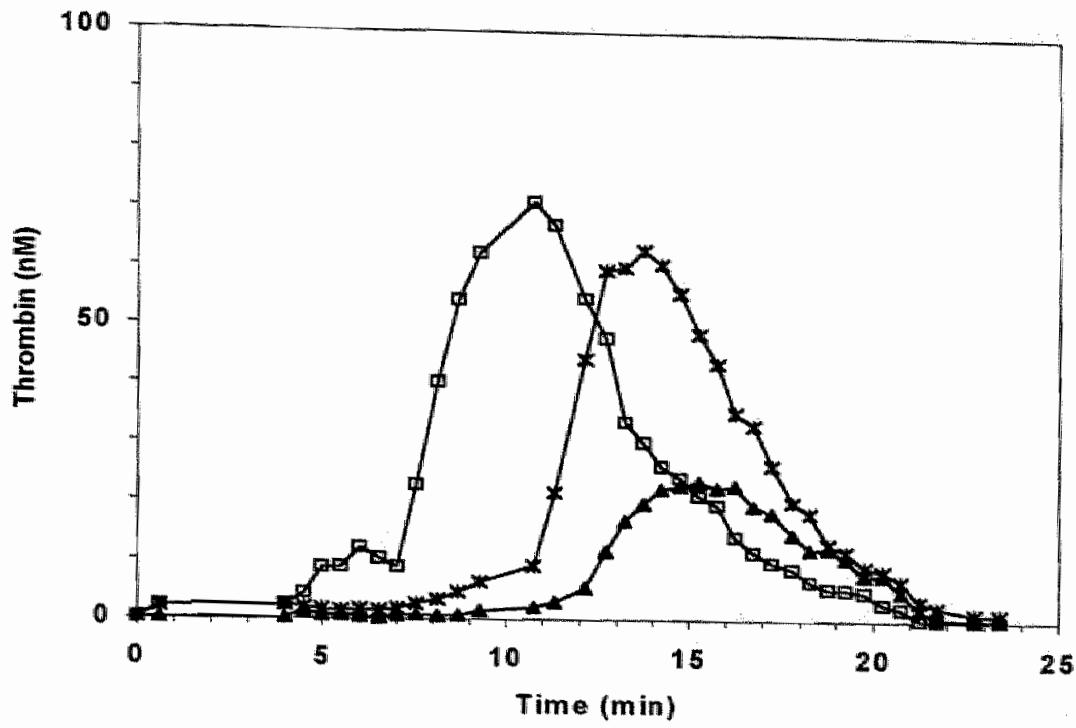

Fig. A2 Effect of monoclonal antibody $7 E 3$ on thrombin generation Experimental set up was similar to that described in legend of Fig. A.1. (G) Control without antibody, (X) $5 \mu \mathrm{g} / \mathrm{ml} 7 \mathrm{E} 3$ added, (A) $20 \mu \mathrm{g} / \mathrm{ml} 7 \mathrm{E3}$ added. Representative experiment of 3 to 14 similar experiments performed.

found on increasing the concentration of $7 \mathrm{E} 3$, i.e. at $50 \mu \mathrm{g} / \mathrm{ml}$ the inhibition of thrombin potential and the peak thrombin concentration was $45 \pm 14 \%$ and 39 $\pm 11 \%(n=3)$ respectively. Fig. A3 represents a comparison of the effects of $6 \mathrm{D} 1$ and $7 \mathrm{E}^{3}$ at $20 \mu \mathrm{g} / \mathrm{ml}$ on thrombin generation.

Effect of c7E3 Fab (Fab fragment of 7 E3 antibody) on thrombin generation

Similar to the effect of $7 E 3$, the c7E3 Fab also produced an inhibition of thrombin generation (Fig. A4). At $10 \mu \mathrm{g} / \mathrm{ml}$, c7E3 Fab reduced the thrombin potential by $9 \pm 2 \%$ and peak thrombin concentration by $10 \pm 1 \%(n=10, P<$ 0.011 . For PRP, the magnitude of inhibition produced by c7E3 Fab antibody was somewhat less than that of $7 \mathrm{E} 3$ specially at low concentrations. Increasing the concentration of c7E3 Fab to $20 \mu \mathrm{g} / \mathrm{m}$ " resulted in an inhibition of thrombin 


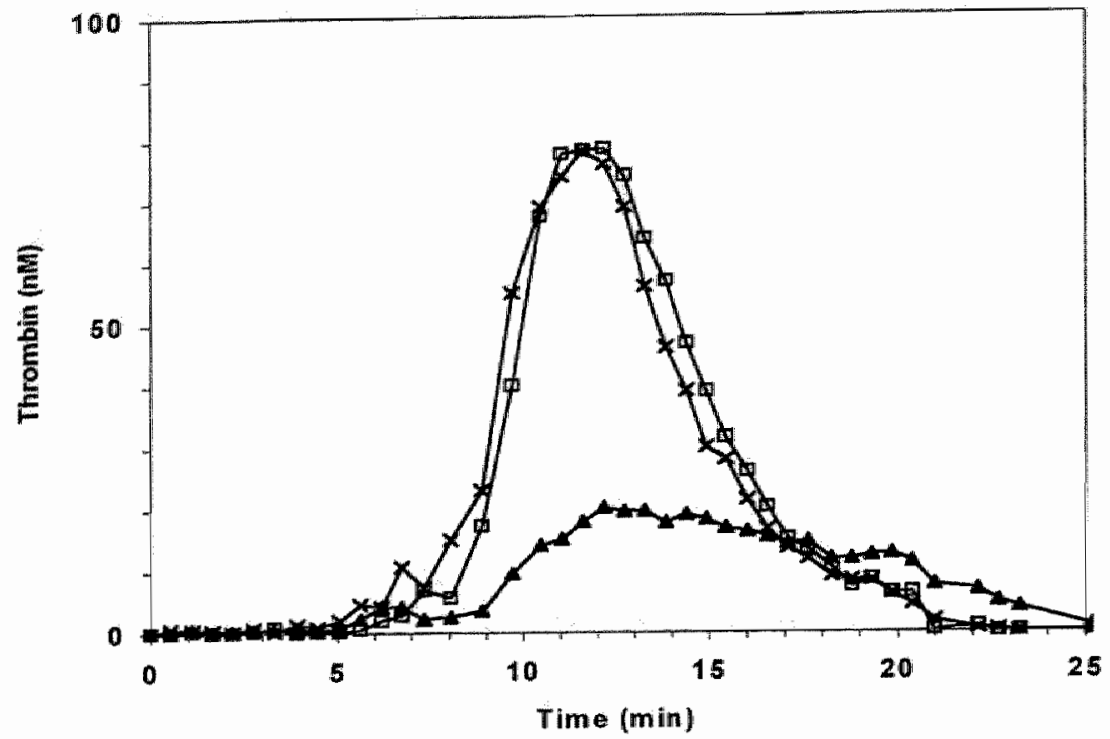

Fig.A3 Comparison of the effect of antibodies $6 \mathrm{D} 1$ and $7 \mathrm{E} 3$ at $20 \mu \mathrm{g} / \mathrm{ml}$ on thrombin generation. Experimental set up was similar to that described in legend of Fig. A1. (D) Controll without antibody. (X) 6D1 added, (A) 7E3 added. Representative experiment of 10 similar performed.

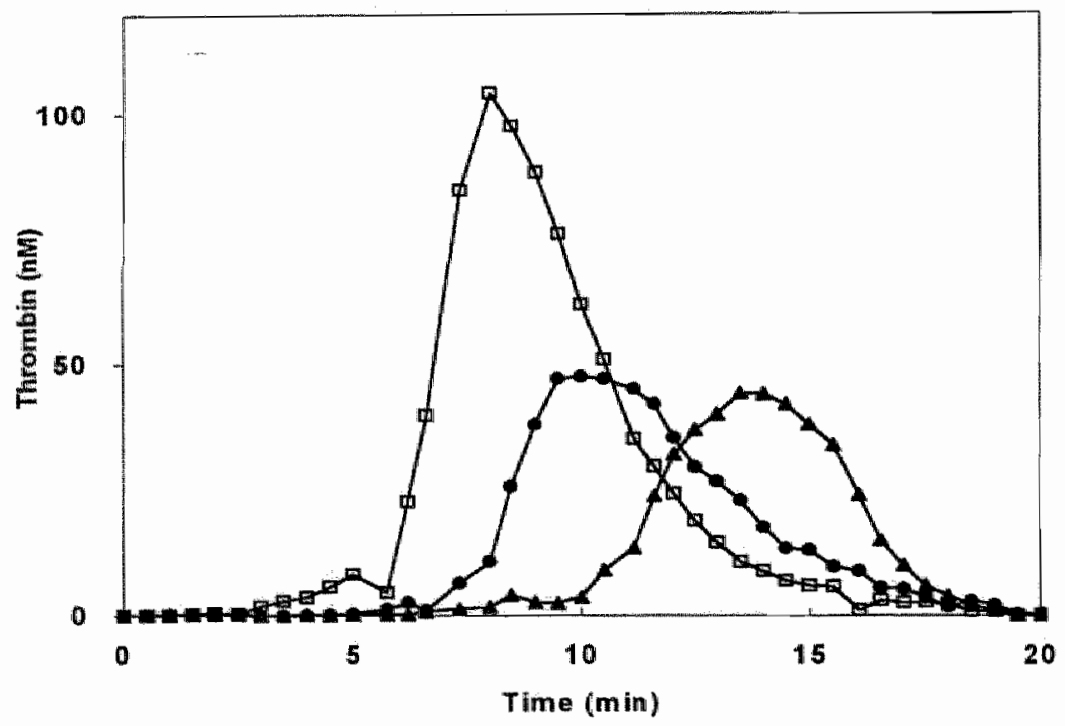

Fig. A4 Comparison of the effect of c7E3 Fab and $7 E 3$ antibodies at $20 \mu \mathrm{g} / \mathrm{ml}$ on thrombin generation. Experimental set up was similar to that described in legend of Fig. A1. (D) Control PRP with equal concentration of 6D1 antibody, ( $\Delta$ ) Control PRP with 7 E3 added, (๑) Control PRP with C7E3 Fab added. Representative experiment of 8 similar experiments performed. 
potential by $35 \pm 14 \%$ and peak thrombin concentration by $38 \pm 12 \%$ while there was an increment in the lag time and it was found to be $502 \pm 76$ s (n 10 , $P<0.01$ ). As for $7 E 3$, no additional inhibition was achieved on increasing the concentration further

The response of C7E3 Fab in PRP was correlated with the variation in the platelet count by studying the PRP from the same donor (Fig. A5). Addition of $20 \mu \mathrm{g} / \mathrm{ml}$ of $\mathrm{c7E} 3 \mathrm{Fab}$ to PRP with platelet count $3^{*} 10^{8} / \mathrm{ml}$ was to result in an equivalent thrombin generation as resulted in PRP having no antibodies and with platelet count $1 * 10^{8} / \mathrm{ml}$.

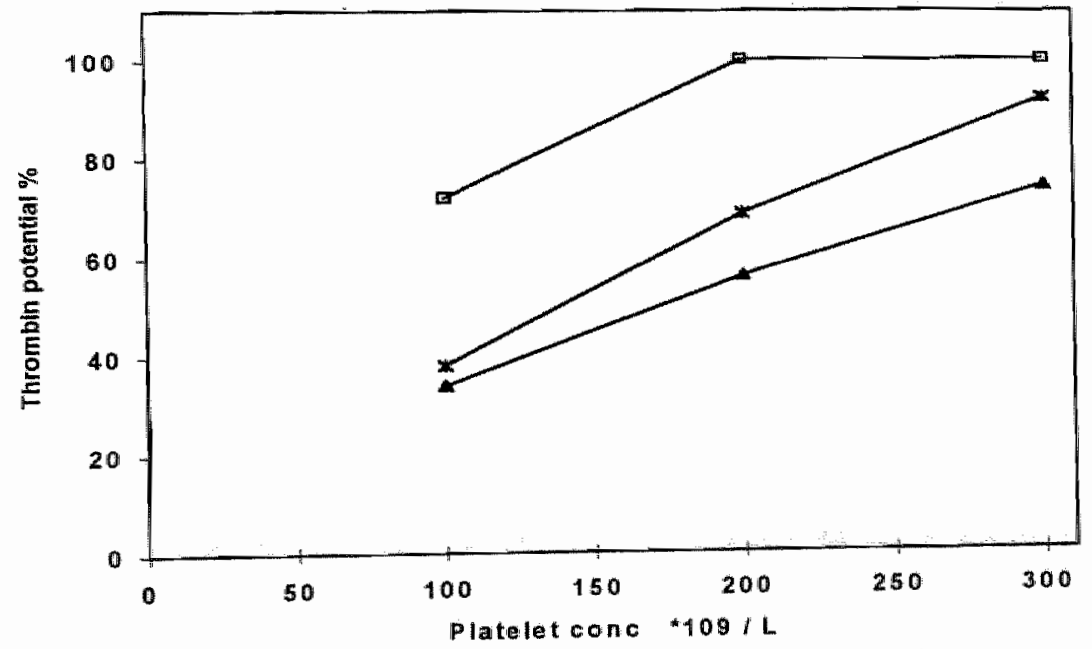

Fig. A5 Correlation of the effect of C7E3 Fab on thrombin potential with platelet count in studies performed on the same donor. Thrombin generation was carried out in an experimental set up similar to that described in legend of Fig. A1 with PRP from the same donor adjusted to different platelet counts. (C) Control PRP without antibody, (X) $10 \mu \mathrm{g} / \mathrm{ml}$ of C7E3 Fab antibody added, (A) $20 \mu \mathrm{g} / \mathrm{ml}$ of $\mathrm{C7E} 3 \mathrm{Fab}$ antibody added. The graph reprsents average of three experiments. 
Measurement of platelet derived procoagulant activity in serum ${ }^{3}$

The effect of antibodies $7 \mathrm{E} 3$ and c7E3 Fab on platelet derived procoagulant activity (PPA) in serum was evaluated in a prothombinase asssay. For this, serum obtained after 30 min of triggering coagulation was collected "centrifuged and the supernatant was stored at $-80^{\circ} \mathrm{C}$. In order to determine PPA, the serum was diluted 1: 6.7. A $50 \mu$ li aliquot was then transferred to $100 \mu \mathrm{l}$ of an assay mixture containing $0.45 \mathrm{nM}$ factor $\mathrm{Xa}, 10.5$ $\mathrm{nM}$ factor $\mathrm{Va}, 3 \mu \mathrm{M}$ prothrombin and $12 \mathrm{mM} \mathrm{Ca}^{24}$ in buffer A. At $4 \mathrm{~min}$ a $10 \mu \mathrm{l}$ subsample was diluted in cuvettes containing $465 \mu$ of buffer $B$. Thrombin concentrations were calculated from dAddt at $405 \mathrm{~nm}$ after the addition of $25 \mu$ l of $\$ 2238$. Under these conditions the velocity of thrombin generation is determined by the amount of procoagulant phospholipid available. Normal serum gave values of $115 \pm 5.5 \mathrm{nM} / \mathrm{min}$ (Mean $\pm \mathrm{SEM}, \mathrm{n}=22$ ). For serum obtained from plasma containing $7 E 3(20 \mu \mathrm{g} / \mathrm{ml})$, an inhibition in PPA by $59 \pm$ $5 \%(n=12)$ and for that containing c7E3 Fab $(20 \mu \mathrm{g} / \mathrm{ml})$ an inhibition in PPA by $44 \pm 15 \%(n=12)$ was found.

Thrombin generation in PRP from patient with Glanzmann thrombasthenia, effect of $7 E 3$ addition

To reinforce the role of platelet GPIIb/llla receptors in the generation of thrombin in whole plasma, thrombin generation in PRP from patient suffering with Glanzmann thrombasthenia (the patient was reported to lack GPIlb/llla receptors but had normal $\alpha_{v} \beta_{3}$ receptors) was studied. When compared with thrombin generation in PRP from normal donor, the thrombin generation in thrombasthenic PRP was seen to be much less (Fig. A6). Thrombin potential and peak thrombin concentration for thrombasthenic PRP were obtained to be - 70\% reduced as compared to normal PRP. Incubation of patient's PRP with $20 \mu \mathrm{g} / \mathrm{ml}$ 7E3 resulted in further inhibition of $\sim 15 \%$. Thrombin generation in platelet poor plasma (PPP) from the patient was found to be same as that in normal PPP (Inset Fig. A6).

\footnotetext{
\$ as done according to the method developed by $\mathrm{Dr} \mathrm{Hu} \mathrm{Kai}, \mathrm{Xi}$ " an Medical University.
} 


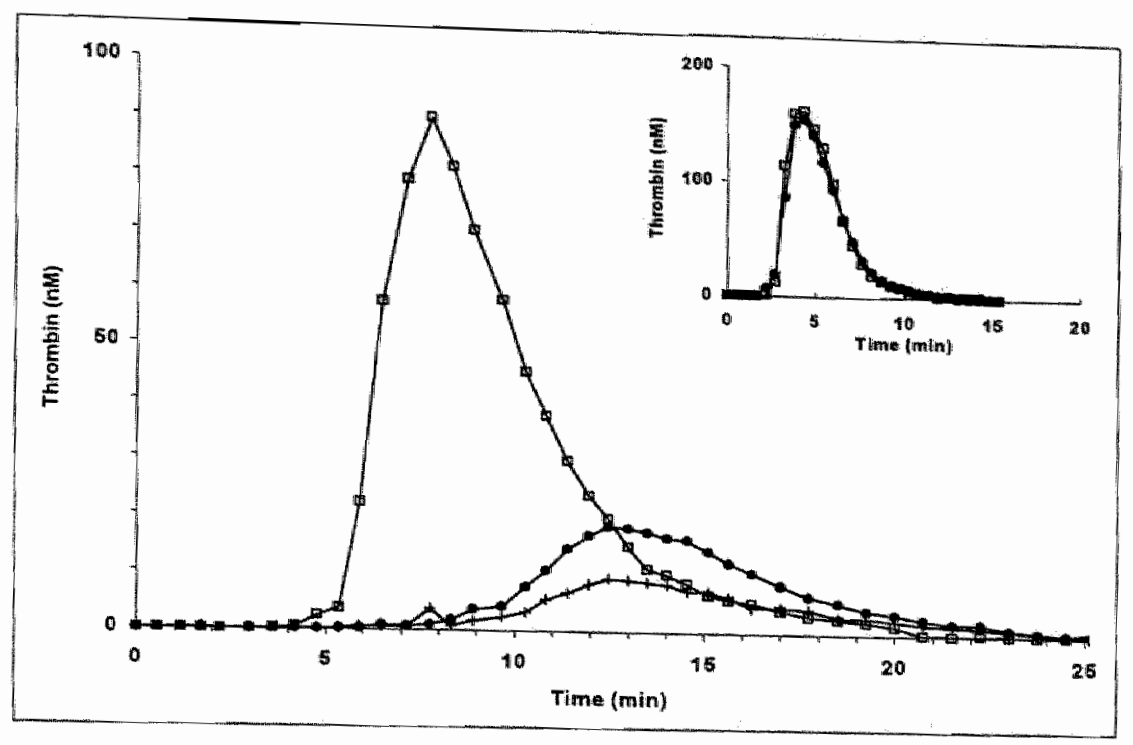

Fig. A6 Thrombin generation in PRP from patient with Glanzmann thrombasthenia (GT) compared with normal donor. Thrombin generation in PRP was carried out in an experimental set up similar to that described in legend of Fig. A1. (G) normal PRP, ( $\bullet)$ GT patient's PRP, (+) GT patient's PRP incubated with $20 \mu \mathrm{g} / \mathrm{mi} 7 \mathrm{~F}$. Inset graph: Thrombin generation in platelet poor plasma (PPP). Thrombin generation was triggered in non-defibrinated PPP by kaolin, PS/PC $(20 \mu \mathrm{M})$ and $\mathrm{Ca}^{2+}$ ( (D) normal PPP, (๑) GT patient's PPP.

In summary, the absence of functional GPllb/lla receptors resulting either from use of antibody $7 \mathrm{E} 3$ or on genetic basis as in Glanzmann thrombasthenia is seen to inhibit the generation of thrombin in PRP. In other words the interference with GPIlb/llla heterodimer damps the positive feedback loop between platelets and thrombin so that the feedback action by the initial traces of thrombin on the availability of platelet procoagulant activity cannot take place. 


\section{Chapter 5}

\section{Fibrin Induced Platelet Procoagulant Activity in Clotting Plasma - Role of GPIIb/lila and GPIb-IX Receptors and von Willebrand Factor}

\section{Summary}

Thrombin generation in platelet rich plasma (PRP) was found to be significantly enhanced by the contact with a fibrin clot, even if the clot does not contain adsorbed thrombin, suggesting that the platelet fibrin interaction initiates the surface expression of procoagulant phospholipids. We investigated the platelet receptors involved in this process by selectively blocking them with monoclonal antibodies [7E3:anti GPIIb/llla- $\alpha_{w} \beta_{3} ; 6 D 1$ : anti GPIb; 6F1: GPla/lla ]. Fibrin clots were prepared from purified fibrinogen with a snake-venom enzyme that does not activate platelets. The addition of the clots to PRP enhanced thrombin generation by $\sim 40 \%$. 7E3 decreased basal thrombin generation in PRP (as previously reported) but it did not prevent the fibrin enhancement. Most remarkably, 6D1 had no effect on basal thrombin generation but completely prevented the enhancing action of fibrin. Antibody 6F1 had no effect on basal thrombin generation or the enhancement produced by fibrin. Platelet procoagulant activity (PPA) in serum and residual prothrombin in serum followed the same patterns. These data suggest that the enhancement in thrombin generation produced by a fibrin clot is mediated through GPIb. To test whether this effect was dependent on von Willebrand factor (WWF) binding to GPIb, WWF deficient plasmas were tested and found to inhibit both the GPIlb/lila and the fibrin-GPIb dependent pathways.

\footnotetext{
- Based on Kumar R et al. (submitted for publication) in collaboration with Prof. B. Coller and Prof. U. Seligsohn.
} 
In Glanzmann thrombasthenia (GT) patients from both the Iraqi-Jewish (deficiency of GPIIb/llla $+\alpha_{4} \beta_{3}$ ) and Arab populations (deficiency of GPIIb/lla and normal or increased $\alpha_{4}\left(\beta_{3}\right)$ thrombin generation was decreased. Adding 7E3 to PRP further reduced thrombin generation in samples from Arab patients. Fibrin addition to PRP enhanced thrombin generation in samples from patients from both populations. In three hypofibrinogenaemia patients tested, thrombin generation was between $37-44 \%$ of normal and addition of fibrin clots almost normalised thrombin generation. $7 E 3$ inhibited thrombin generation in hypofibinogenaemic PRP.

We postulate, on basis of these results, two parallel mechanisms for the development of platelet procoagulant activity, a fibrin-independent one involving GPIIb/Illa receptors, and a fibrin dependent one acting through GPlb receptors. Both pathways require von Willebrand factor.

\section{Introduction}

The formation of an arteriall thrombus involves both platelets and blood coagulation. In the older literature, there is a tendency to see these as consecutive processes, wherein platelets first formed the main body of the thrombus and then fibrin threads formed through the action of the plasmatic coagulation system consolidated the thrombus. Building on these ideas, arterial thrombi were seen as caused by platelet activation and venous thrombi by blood coagulation. More recent research shows this dichotomy to be less strict. Inhibiting thrombin has been shown to be an efficient means to prevent platelet deposition in experimental arterial thrombi (Badimon et al. 1986, 1991. Lam et al. 1986) and anticoagulation by vitamin $\mathrm{K}$ antagonists as well as by heparin has been shown to diminish the reoccurrence of coronary reinfarction (Sixty plus Reinfarction Study Research Group 1980, Neri-Serneri et al. 1987). Thus, both of these agents that diminish the level of active thrombin that develops during the haemostatic reaction, have similar effects in postponing 
coronary reinfarction suggesting a pivotal role for thrombin generation in some forms of arterial thrombotic disease.

On the other hand, inhibiting platelet aggregation via blockade of platelet glycoprotein GPllb/llia $\left(\alpha_{1 b} \beta_{3}\right)$ receptors (Topol and Plow 1993, The EPIC investigators 1994, Coller et al. 1995, ) also inhibits arterial thrombosis. Recently we showed, however, that platelet inhibition by the anti GPllb/llla + $\alpha_{v} \beta_{3}$ monoclonal antibody $7 E 3$ inhibited tissue-factor induced thrombin generation ex vivo by $-47 \%$ (Reverter et al. 1996) raising the possibility that perhaps part of its antithrombotic effects may be due to decreased thrombin generation. The procoagulant action of platelets, in a broad sense, includes the release of clotting factors (notably factor $V$ ) and the exposure of procoagulant phospholipids. In platelet rich plesma (PRP) to which no extraneous procoagulant phospholipids are added, the appearance of procoagulant phospholipids is rate-limiting for thrombin-generation (Béguin et al. 1989). We therefore reserve the term platelet procoagulant activity (PPA) here to indicate the appearance of such phospholipids.

Two processes underlay PPA formation from platelets: a) the transbilayer movement of aminophospholipids (primarily phosphatidyl serine (PS)) from the inner leafle: of the cell-membrane bilayer to the outside ("flipflop") (Bevers et al. 1982, 1983), and b) the shedding of microparticles, derived from the platelet membrane, in which the natural asymmetry of the membrane phospholipids is lost (Sandberg et al. 1982, Schroit and Zwaal 1991). Among the known physiological platelet activators, the combination of thrombin + collagen have been found to bring about flip-flop in washed platelets (Bevers et al. 1982). We recently found that fibrin - even without thrombir being adsorbed to it - is also a potent inducer of PPA. The explosive thrombin generation that occurs in recalcified PRP after a lag-phase (see e.g. Fig. 1) is probably the result of a composite resonance loop in which thrombin converts fibrinogen to fibrin and both thrombin and fibrin activate the platelet to produce PPA (Kumar et al. 1994, 1995).

It thus appears that a fibrin clot is far from being the passive plug that it was previausly thought to be. In vivo, thrombi may grow via a viscious circle in 
Which platelets support thrombin generation and then fibrin deposition, further activates platelets, leading to more thrombin generation and fibrin deposition. Thus not only the adsorbed thrombin (Mahilac et al. 1994) but also the fibrin per se, may play a role in this process.

This chapter addresses the question of which platelet-membrane receptors are involved in the fibrin-platelet interaction that results in enhanced thrombin generation. We investigate the role of the GPIIb/lla receptor, which can bind fibrinogen, WWF and other adhesive ligands (Bennett and Vilarie 1979, Marguerie et al. 1979, Niewiarowski et al. 1981, Plow et al. 1985, Phillips et al. 1988) as well as the GPIb-IX receptor, which can bind WWF and thrombin, and the GPla/lla receptor, which binds collagen. Our studies support a crucial role for WWF in the development of PPA.

\section{Materials and methods}

\section{Materials}

Reagents

The chromogenic substrate used for measuring thrombin was $\mathrm{S2238}$ : $\mathrm{H}$ D-Phe-Pip-Arg-pNA.2HCl. Buffer A: $20 \mathrm{mM}$ Hepes, $150 \mathrm{mM} \mathrm{NaCl}, 0.5 \mathrm{~g} / \mathrm{l}$ bovine serum albumin (BSA; Lot:A-7030, Sigma), $\mathrm{pH}=7.35$. Buffer $B$ : same as buffer $A$ with $20 \mathrm{mM}$ EDTA, $\mathrm{pH}=7.9$. All other chemicals were reagent grade. Synthetic d-arginyl-glycyl-L-asparty/-L-tryptophan (d-RGDW) was obtained from Rhone-Poulenc Rorer, France. A Peptide molecular mass $530 \mathrm{~g} / \mathrm{mo}$ l was used for calculating concentrations. Cytochalasin D was from Kordia (Leiden. The Netherlands). All other reagents were of the highest grade commercially available.

\section{Proteins}

Human purified fibrinogen (free of WWF and plasminogen according to specifications) was supplied by Kordia (Leiden, The Netherlands). Bovine 
factors Xa and $\mathrm{Va}$ and human prothrombin were kindlly provided by $\mathrm{Dr} R$ Wagenvoord (Maastricht University). Recombinant tissue factor was obtained from Baxter-Dade (Dúdingen, Switzerland). Staphylocoagulase was prepared as described (Hendrix et al. 1983).

Agihal, a purified fraction of Agkistrodon halys halys snake-venom that splits fibrinopeptide A from fibrinogen was obtained from Prof $L$. Yukelson (Tashikent, Uzbekistan). Agihal does not activate coagulation factors $V$, Vlll or $X I$, and at concentrations up to one hundred times higher than those used in our experiments, it does not cause platelet activation as judged by $\mathrm{Ca}^{2^{*}}$-influx in fura 2 loaded platelets (results not shown).

Murine monoclonal antibodies 7E3 [anti-GPIllb/llla $+\alpha_{4} \beta_{3}$ ] (Coller 1985), 6D1 [anti-GPlbo] (Coller et al. 1983) and 6F1 (anti-GPla/lla) (Coller et al. 1989), have been previously described in detail. In the present experiments, the final concentrations of the purified antibodies was $20 \mu \mathrm{g} / \mathrm{ml}$, which exceeds the $15 \mu \mathrm{g} / \mathrm{ml}$ at which the $7 \mathrm{E} 3$ inhibition was found to plateau in our previous study (Reverter et al. 1996). We checked that there was no effect of either of these antibodies on thrombin generation in platelet poor plasma.

\section{Methods}

Preparation of plasma

Normal platelet rich plasma (PRP) was obtained by centrifuging freshly drawn citrated blood ( 9 volumes on one volume of $0.13 \mathrm{M}$ trisodium citrate) of apparently healthy donors at $250 \mathrm{~g}, 15^{\circ} \mathrm{C}$ for $10 \mathrm{~min}$. The platelet count was adjusted to $3^{*} 10^{\circ} / \mathrm{ml}$ using autologous platelet poor plasma (PPP) obtained by double centrifugation of PRP at $1000 \mathrm{~g}, 15^{\circ} \mathrm{C}$ for $10 \mathrm{~min}$.

Plasma from volunteers with Glanzmann thrombasthenia, hypofibrinogenaemia, or von Willebrand's disease were similarly prepared. The study included four patients having Glanzmann thrombasthenia of IragiJewish descent (GPIlla defect leading to loss of both GPIIb/llla and $\alpha_{v} B_{3}$ ) and three of Arab descent (GPIlb defect leading to loss of GPIIb/lila bult normal or increased $\alpha_{w} B_{3}$ ) residing in Israel. Details on these cases have been described 
elsewhere. Three patients with hypofibrinogenaemia (two of them from Israel) were studied. By courtesy of Dr Karly Hamulyak (Academic Hospital, Maastricht), plasmas from three patients, one with Glanzmann thrombasthenia, one with hypoffibrinogenaemia, and one with von Willebrand disease type lla were studied. Another von Willebrand patient of type III (described in detail in Eikenboom et al. 1992) was also studied by courtesy of Dr J.Eikenboom.

\section{Preparation of clots}

Fibrin I clots (non-cross linked, des AA fibrin): To $250 \mu \mathrm{l}$ of purified fibrinogen ( $3 \mathrm{mg} / \mathrm{ml}$ ) solution, $5 \mu \mathrm{l}$ of the snake venom protease Agihal was

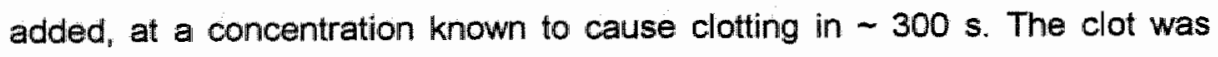
allowed to form at $37^{\circ} \mathrm{C}$ for $30 \mathrm{~min}$ and then collected by winding on a plastic spatula. The clat was blotted dry and washed for at least 30 min in $2 \mathrm{ml}$ aliquots of Buffer $\mathrm{A}$, changed thrice to remove any trapped soluble material.

\section{Measurement of thrombin generation}

Thrombin generation in plasma was carried out as described previously (Hemker et al. 1986, Béguin et al. 1989). In short, for thrombin generation in PPP, to $240 \mu \mathrm{l}$ of non defibrinated PPP was added $20 \mu \mathrm{l}$ of kaolin and $20 \mu \mathrm{l}$ of Buffer $\mathrm{A}$. The mixture was activated for $4 \mathrm{~min}$ at $37^{\circ} \mathrm{C}$ by putting to vortex mix every $30 \mathrm{~s}$. At $4 \mathrm{~min}, 20 \mu \mathrm{l}$ of PS/PC $(20 \mu \mathrm{M})$ were added and at $5 \mathrm{~min}$ the coagulation was triggered by addition of $60 \mu \mathrm{ll}$ of $\mathrm{CaCl}_{2}$ (16.7 mM final concentration). For thrombin generation in PRP, $240 \mu$ l of PRP was incubated with $60 \mu$ of Buffer $A$ or buffer containing the antibody or other additions to be tested for $10 \mathrm{~min}$ at $37^{\circ} \mathrm{C}$ with gentle stirring. Coagulation was initiated by adding $60 \mu$ of $0.1 \mathrm{M} \mathrm{CaCl}_{2}$ to which $1.8 \mathrm{fM}$ of recombinant tissue factor was added in order to compensate for variations in the minute amounts of tissue factor that may get into the blood upon venipuncture. This concentration of tissue factor gives clotting times of over $10 \mathrm{~min}$ when added together with $\mathrm{Ca}^{2+}$ to non-defibrinated PPP in the absence of contact activation. Fibrin clots were added just prior to, or in the minute after, adding calcium and tissue factor; similar results were obtained under either set of conditions. All experiments were carried out within 60 min of venipuncture and four experiments were 
carried out in parallel in order to eliminate the differential effects due to platelet ageing. The reaction mixture was continuously stirred and the evolving clot was wound on a plastic spatula and removed along with the added clots. To measure thrombin, $10 \mu l$ of the reaction mixture was subsampled at 1 min intervals in prewarmed $\left(37^{\circ} \mathrm{C}\right)$ cuvettes with $490 \mu$ l of buffer B containing 200 $\mu \mathrm{M} \mathrm{S2238}$. The reaction was stopped by the addition of $300 \mu$ l of $1 \mathrm{M}$ citric acid after about 2 min and the optical density (OD) was measured at $405 \mathrm{nM}$.

The spectrophotometer and the subsampling and stopping pushbutton equipped pipettes were conected to a personal computer that calculated the increase of OD over time from the original OD and the times of subsampling and stopping. Thrombin amidolytic activities were calculated by comparing the OD/min values of the samples to those of a standard calibration curve prepared using known amounts of human $\alpha$-thrombin (active site titration).

The lag time of thrombin formation is defined as the moment at which the thrombin concentration rises from a 0-5 nM level to a 10-20 $\mathrm{nM}$ level.

To minimize the effect of variation of reactivity of platelets from donors we have compared thrombin generation curves that were obtained in simultaneous experiments on platelets of the same donor. Effects observed in plasma from normal volunteers. were repeated with at least three different volunteers.

Calculation of thrombin generation curves.

The amidolytic activity curves reflect the combined activities of free thrombin and $\alpha_{2}$-macroglobulin bound thrombin together. The latter is formed with a velocity proportional to the concentration of free thrombin. The amidolytic activity at any moment thus consists of the thrombin concentration at that moment and the integral of the free thrombin time course up to that moment multiplied by a proportionality constant (Hemker et al.1986). An algorithm based on these considerations has been used in the computer program that calculated free thrombin curves from the amidolytic activity curves. The endogenous thrombin potential is defined as the area under the thrombin generation curve (Hemker et al. 1990, 1993). In normal PRP. 
measured under our conditions, its value is $411 \pm 13$ nM.min (Mean $\pm S E M$, $n=28$ ).

\section{Measurement of platelet derived procoagulant phospholipids in serum}

After the thrombin generation experiments were ended, the samples were centrifuged at $9000 \mathrm{~g}$ for $1 \mathrm{~min}$ and the supernatant serum was stored at $-80^{\circ} \mathrm{C}$ for later use. In order to determine its platelet-derived procoagulant activity (PPA), the serum was diluted $1: 6.7$ in buffer A. A $50 \mu l$ aliquot was then transferred to $100 \mu \mathrm{l}$ of an assay mixture containing $0.45 \mathrm{nM}$ factor $\mathrm{Xa}$, $10.5 \mathrm{nM}$ factor $\mathrm{Va}, 3 \mathrm{\mu M}$ prothrombin and $12 \mathrm{mM} \mathrm{Ca}{ }^{2+}$ in buffer A. At $4 \mathrm{~min}$, a $10 \mu l$ subsample was diluted in cuvettes containing $465 \mu$ of buffer $B$. Thrombin concentrations were calculated from $\mathrm{dAd} d \mathrm{dt}$ at $405 \mathrm{~nm}$ after the addition of $25 \mu$ l of $\$ 2238$. Under these conditions the velocity of thrombin generation is determined by the amount of procoagulant phospholipid available. Normal serum gave values of $115 \pm 5.5 \mathrm{nM} / \mathrm{min}$ (Mean $\pm S E M$, $n=22)$.

\section{Measurement of residual prothrombin in serum}

Residual prothrombin was assessed as previously described (Hemker et al. 1986). A $10 \mu$ serum sample was incubated for $5 \mathrm{~min}$ in cuvettes containing $415 \mu \mathrm{l}$ buffer $B$ and $50 \mu \mathrm{l}$ staphylocoagulase, giving a final concentration of $300 \mathrm{nM}$, i.e. a molar excess of staphylocoagulase over the highest prothrombin value to be expected. The amidalytic activity generated is due to the formation of a stoichiometric complex between staphylocoagulase and prothrombin (Hendrix et al. 1983). This complex has the same specific activity on chromogenic substrate as thrombin (Kawabata et al. 1985). The total amidolytic activity was measured after addition of $\$ 2238$ to a final concentration of $200 \mu \mathrm{M}$. Since the $\alpha_{2}$-macroglobulin-thrombin complex also contributes to the thrombin like amidolytic activity, the amount of residual prothrombin in serum was calculated from the total amidolytic activity minus the activity of thrombin complexed with $\alpha_{2}$-macroglobulin as measured in a sample to which no staphylocoagulase had been added. 


\section{Results}

Washed platelets undergo significant lysis as judged by release of the cytoplasmic enzyme lactate dehydrogenase when fibrin clots are added, but platelets in PRP do not get damaged (Kumar et al. 1995). This fact limited our observations to those phenomena that reflect development of procoagulant activity in the platelets in coagulating PRP, namely, thrombin generation and the amount of procoagulant microparticles left in the serum. The former is assessed by a number of parameters: the lag-time of thrombin formation, the amount of thrombin formed (peak activity and the area under the thrombin generation curve defined as the endogenous thrombin potential, ETP (Hemker et al. 1990)), and prothrombin consumption. The amount of procoagulant microparticles left in the serum is measured by assaying the non-centrifugable procoagulant phospholipid activity in the serum left after thrombin generation is complete.

The effects of modifying GPIIb/IIla and GPIb/IX activity.

We previously reported that thrombin generation in PRP is inhibited by blocking the GPIIb/llla receptor with the monoclonal antibody $7 \mathrm{E} 3$, or the peptide RGDF. Consistent with these data we also found that thrombin generation was decreased in the PRP of patients with Glanzmann's thrombasthenia (Reverter et al. 1996). In our current series of experiments, blockade of GPIIb/llia receptors by antibody $7 E 3$ or the peptide d-RGDW decreased ETP to $42 \%$ and $60 \%$ of normal respectively (Table 1). This residual activity could be boosted by adding fibrin clots, with the increase being about $50 \%$ relative to the value without clots, which is similar to the percentage increase noted with normal PRP (Fig. 1, Table 1). It therefore seems unlikely that the clot-effect is mediated by the GPIIb/llta receptor. 
The monocional antibody 6F1, which biocks GPla/lla, did not affect thrombin generation either in the presence or the absence of fibrin and thus served as a control (Table 1). When the von Willebrand factor binding domain

Table 1 Effect of GPIlb/llla, GPIb, and GPla/lla receptor blockade on thrombin generation in PRP in presence and absence of a fibrin clot.

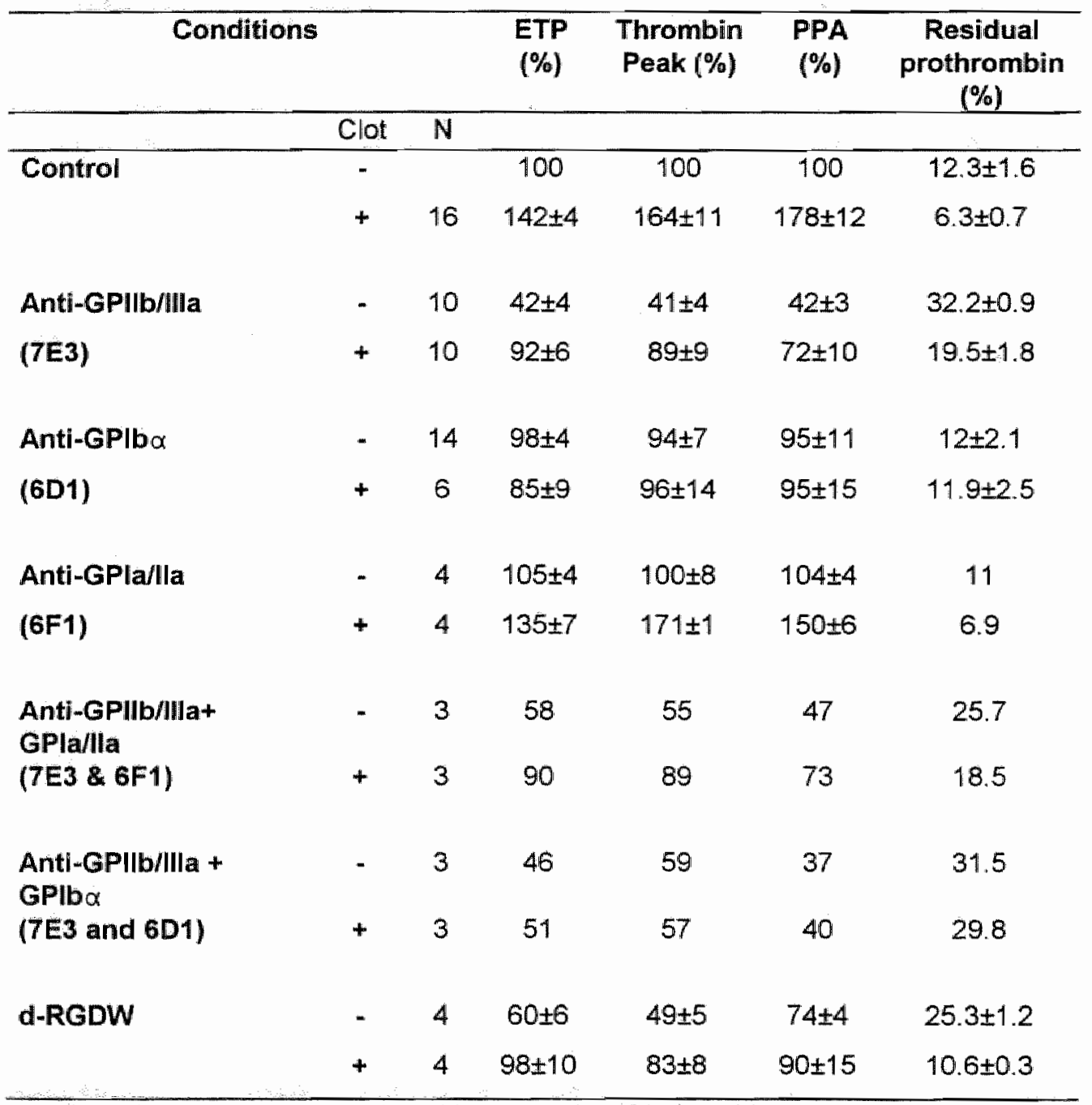

The values of endogenous thrombin potential (ETP), thrombin average peak, platelet procoagulant activity(PPA) in serum and residual prothrombin in serum are given. The final concentration of each monoclonal antibody used was $20 \mu \mathrm{g} / \mathrm{ml}$. d-RGDW was used at $20 \mu \mathrm{M}$. Values are expressed as average \pm SEM and as as a percentage of a normal control assayed concomitantly. No SEM is given if $n<4$, but the values were within $15 \%$ of the mean. 


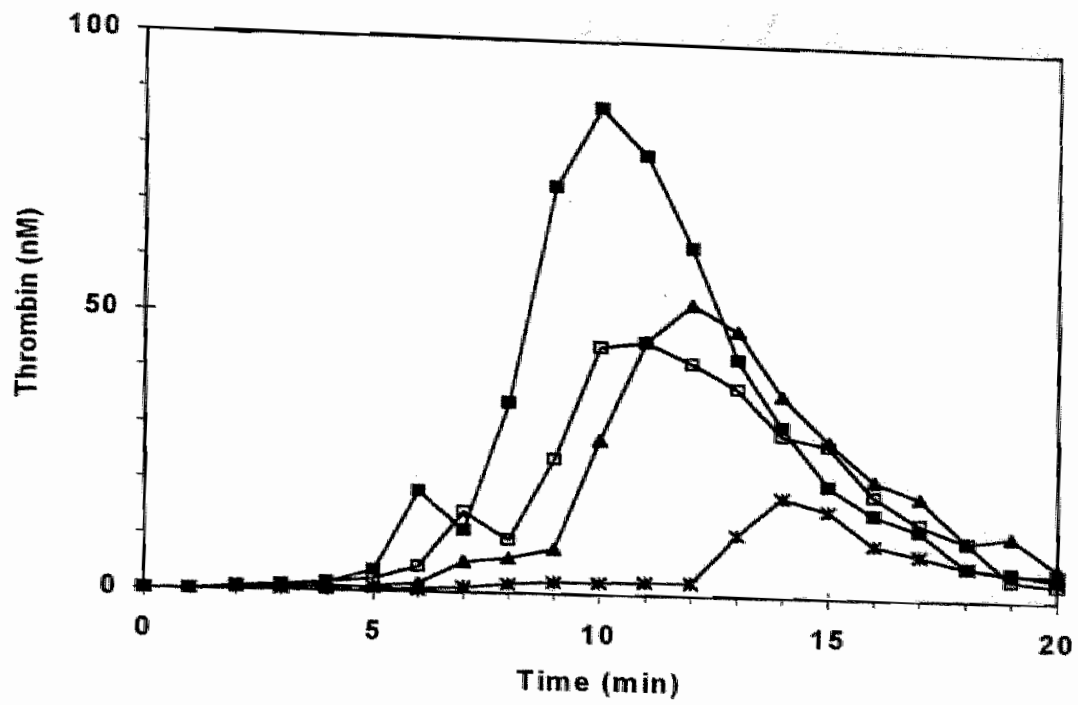

Fig. 1 Effect of blocking GPllbilla receptors on fibrin-induced platelet procoagulant activity. As described in methods, thrombin generation was triggered in PRP (adjusted to $3 * 10^{11} / \mathrm{L}$ ) by the addition of $\mathrm{CaCl}_{2}$ containing $1.8: \mathrm{M}$ recombinant tissue factor. The amidolytic activity was determined in subsamples taken at $1 \mathrm{~min}$ intervals from which thrombin activity was calculated. (a) Control, (a) fibrin clots added ( 3 clots obtained from purified fibrinogen coagulated with snake venom enzyme) just prior to recalcification $\left(T=0\right.$ ). (*) antibody $7 E 3$ (anti-GPIIb/lla $+\alpha_{y} \beta_{3}$ ) added (preincubated with PRP for $10 \mathrm{~min}$ ) at $20 \mu \mathrm{g} / \mathrm{mil}$, (A) $7 \mathrm{E}^{3}$ and fibrin clots added. Representative experiment of ten so performed.

of GPIbo was blocked with antibody 6D1 thrombin generation in the absence of fibrin was unaffected, both in PRP and with washed platelets resuspended in defibrinated normal plasma (Table 1 and Reverter et al. 1996). This antibody, however, rendered the platelets insensitive to the procoagulant enhancing effect of a fibrin clot (Fig. 2, Table 1). When antibodies 7 E3 and 6D1 were combined, the thrombin generation was reduced and fibrin clots were unable to enhance that response (Table 1). It thus seems that there are at least two parallel pathways to render the platelet procoagulant: in the absence of added fibrin via GPllb/lla and via GPIb in its presence. In intact plasma, as soon as thrombin is formed fibrin is also formed and it is likely that both receptors will contribute to the final effect. To explore these relationships 
further we investigated the influence of fibrin generated in situ with thrombin and with Agihal (see below).

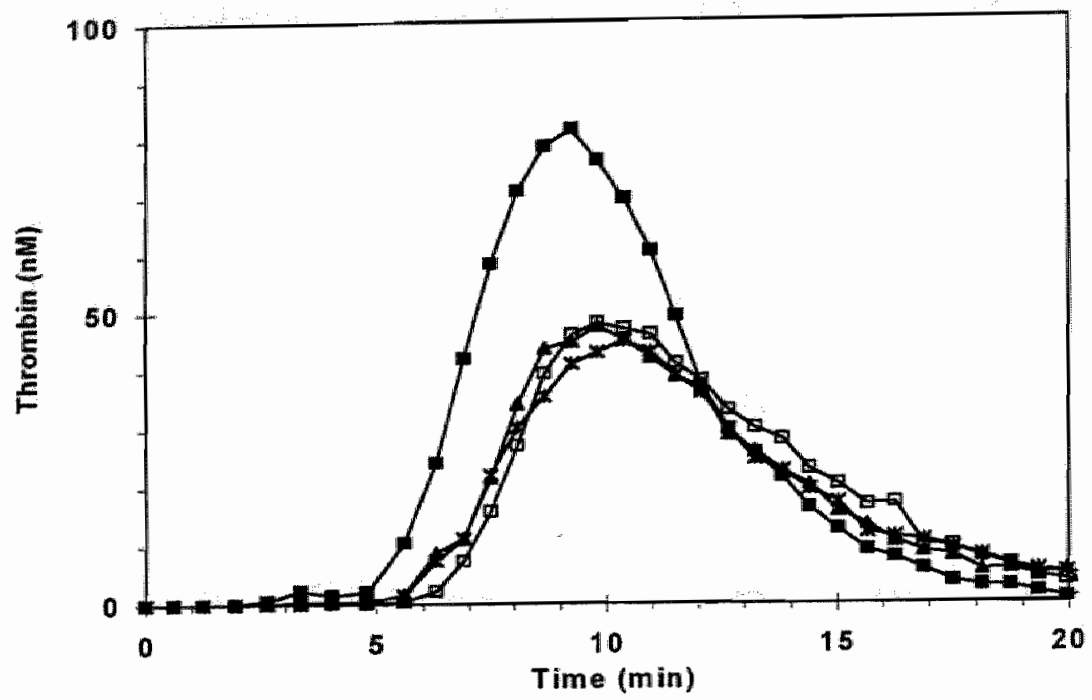

Fig. 2 Effect of blocking GPlba receptors on fibrin-induced platelet procoagulant activity. Thrombin generation was measured in similar experimental set up as described in legend of Fig.1. (ㄷ) Control, ( $(\mathbf{D})$ fibrin clots added, (*) antibody 6D1 (antiGPIba) added (preincubated with PRP for $10 \mathrm{~min}$ ) at $20 \mu \mathrm{g} / \mathrm{ml},(\mathbf{A}) 6 \mathrm{D} 1$ and fibrin clots added. Representative experiment of six so performed.

Since antibody $7 E 3$ blocks both platelet GPllb/llla and $\alpha_{w} B_{3}$ we tried to assess the contributions of each of these receptors by comparing the results using PRP from different patients with Gilanzmann's thrombasthenia. IraqiJewish patients have no detectable GPIIb/llla or $\alpha_{v} \beta_{3}$ whereas Israeli-Arab patients have virtually no GPIIb/llla but approximately twice the normal level of platelet $\alpha_{v} \beta_{3}$ (Coller et al. 1991). In both types thrombin generation is decreased to about the same extent (Table 2). Antibody 7E3 decreased thrombin generation in Arab patient's PRP (from 68 to $59 \%$ and from 35 to $25 \%$ ) (Fig. 3, upper frame), whereas it appeared to have no effect on the IraqiJewish patient B's PRP (from 71 to $70 \%$ ) (Fig. 3, lower frame). Addition of fibrin 
Table 2 Thrombin generation in PRP of normal and Glanzmann thrombasthenia (GT) patients

\begin{tabular}{lcccc}
\hline & $\begin{array}{c}\text { ETP } \\
(\%)\end{array}$ & $\begin{array}{c}\text { Thrombin Average } \\
\text { peak }(\%)\end{array}$ & $\begin{array}{c}\text { PPA in } \\
\text { serum }(\%)\end{array}$ \\
\hline Additions & & & 100 \\
Normal & none & 100 & 100 &
\end{tabular}

$\underline{\text { Arab }}$

A

$\begin{array}{cccc}\text { none } & 68 & 59 & 49 \\ 7 \mathrm{E3} & 59 & 42 & 36 \\ 7 \mathrm{E} 3+\mathrm{clots} & 76 & 69 & 74 \\ \text { none } & 66 & 63 & 55 \\ \text { clots } & 78 & 77 & 102 \\ 6 \mathrm{~F} 1 & 69 & 61 & 58 \\ 6 \mathrm{~F} 1+\text { clots } & 77 & 89 & 93 \\ \text { none } & 70 & 63 & 35 \\ \text { clots } & 101 & 89 & 52 \\ \text { none } & 35 & 26 & 44 \\ \text { clots } & 71 & 56 & 52 \\ 7 \mathrm{E} 3 & 25 & 16 & 28\end{array}$

Iraqi-Jewish

A

B

B

D

$\begin{array}{cccc}\text { none } & 54 & 34 & 27 \\ \text { clots } & 69 & 55 & 41 \\ \text { none } & 71 & 63 & 48 \\ 7 E 3 & 70 & 58 & 45\end{array}$

C

$$
7 E 3+\text { clots }
$$

87

91

61

none $\quad 63$

45

36

$$
7 \text { E3+clots }
$$

77

67

44

D

none

65

47

57

Values are expressed as a percentage of a normal control assayed concomitantly and taken as $100 \%$. Arab GT patients have virtually no GPIlb/lla but overexpressed level of $\alpha_{V} \beta_{3}$, while Iraqi-jewish GT patients have no detectable GPllb/llla or $\alpha_{\mathrm{V}} \beta_{3}$. 

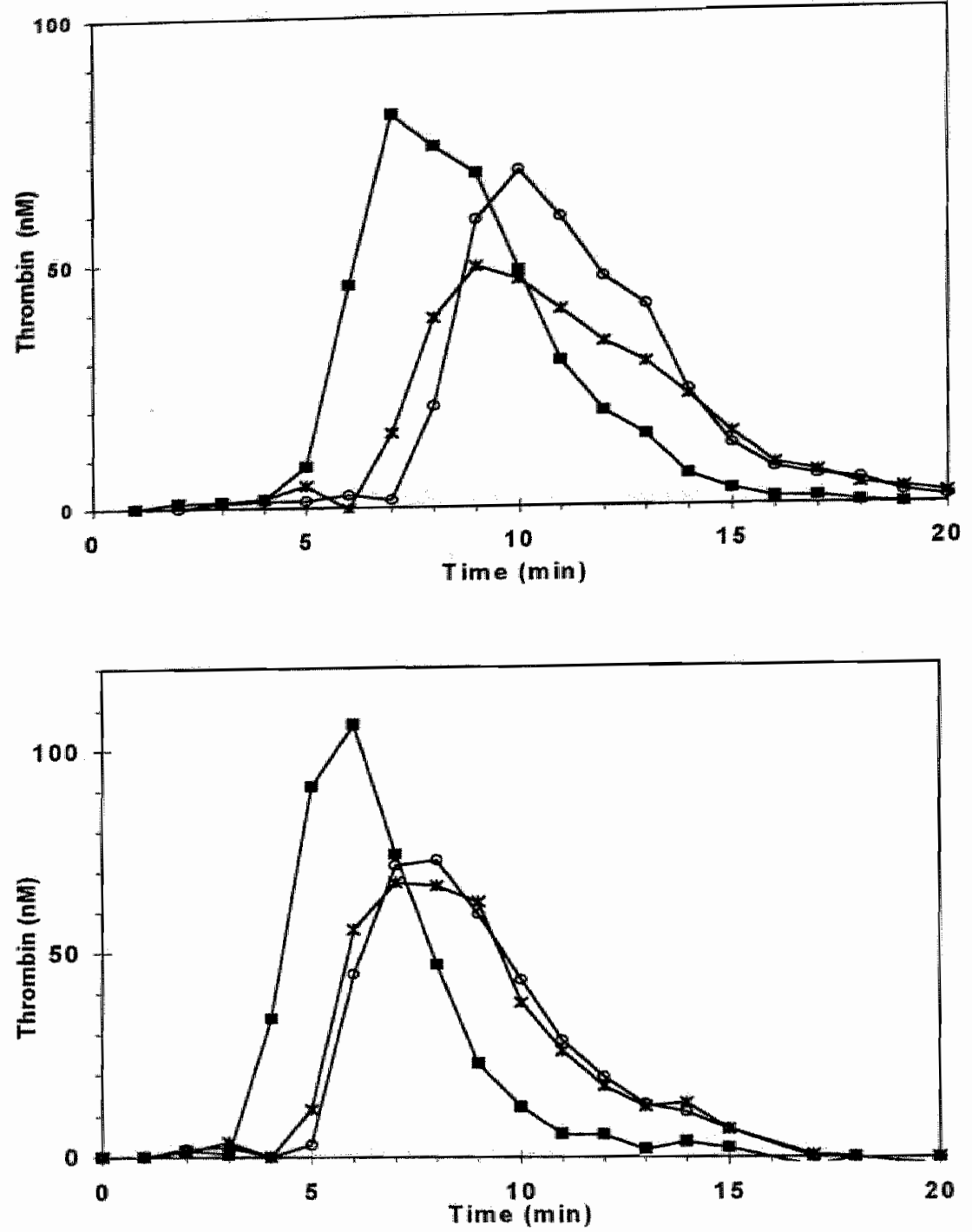

Fig. 3 Thrombin generation in PRP from two types of Glanzmann Thrombasthenia (GT) patients, effect of fibrin. Thrombin generation was measured in similar experimental set up as described in legend of Fig. 1 with PRP of GT patients. Upper frame: Arab type GT (having virtually no GPllb/llla but approximately twice the nomal level of platelet $\alpha_{v} \beta_{3}$ ) (O) GT PRP, (*) GT PRP with antibody 7E3 added, (G) GT PRP with fibrin clots added. Lower frame: Iraqi-Jewish type GT (having no detectable GPlib/lla or $\alpha \beta_{3}$ ) (O) GT PRP, (*) GT PRP with antibody 7E3 added, (1) GT PRP with fibrin clots added. 
clots to either type of patient's PRP resulted in an increase of thrombin generation again indicating that the fibrin-effect is not mediated via the GP IIb/llla receptor.

Observations in hypofibrinogenaemia.

PRP from patients with hypofibrinogenaemia showed a reduced level of thrombin generation with values of $56-63 \%$ of normal (Fig. 4, upper frame, Table 3). A correction could be achieved by the addition of either fibrinogen or

Table 3 Thrombin generation in PRP of normal and hypofibrinogenaemia patients

\begin{tabular}{|c|c|c|c|c|}
\hline & $\begin{array}{l}\text { Fibrinogen } \\
\text { level (mg/L) }\end{array}$ & & ETP $(\%)$ & $\begin{array}{l}\text { PPA in } \\
\text { serum }(\%)\end{array}$ \\
\hline & & Additions & & \\
\hline Normal & $2500-3000$ & none & 100 & 100 \\
\hline \multirow[t]{4}{*}{ Patient A } & 10 & none & 56 & 310 \\
\hline & & clots & 78 & 370 \\
\hline & & fibrinogen & 73 & 204 \\
\hline & & $7 E 3$ & 51 & 245 \\
\hline \multirow[t]{4}{*}{ Patient B } & 22 & none & 63 & 278 \\
\hline & & clots & 85 & 305 \\
\hline & & fibrinogen & 77 & 175 \\
\hline & & d-RGDW & 58 & 516 \\
\hline \multirow[t]{3}{*}{ Patient C } & <detectable & none & 60 & n.d. \\
\hline & & clots & 98 & n.d. \\
\hline & & $7 E 3$ & 33 & n.d. \\
\hline
\end{tabular}

Values are expressed as a percentage of a normal control assayed concomitantly and taken as $100 \%$. 

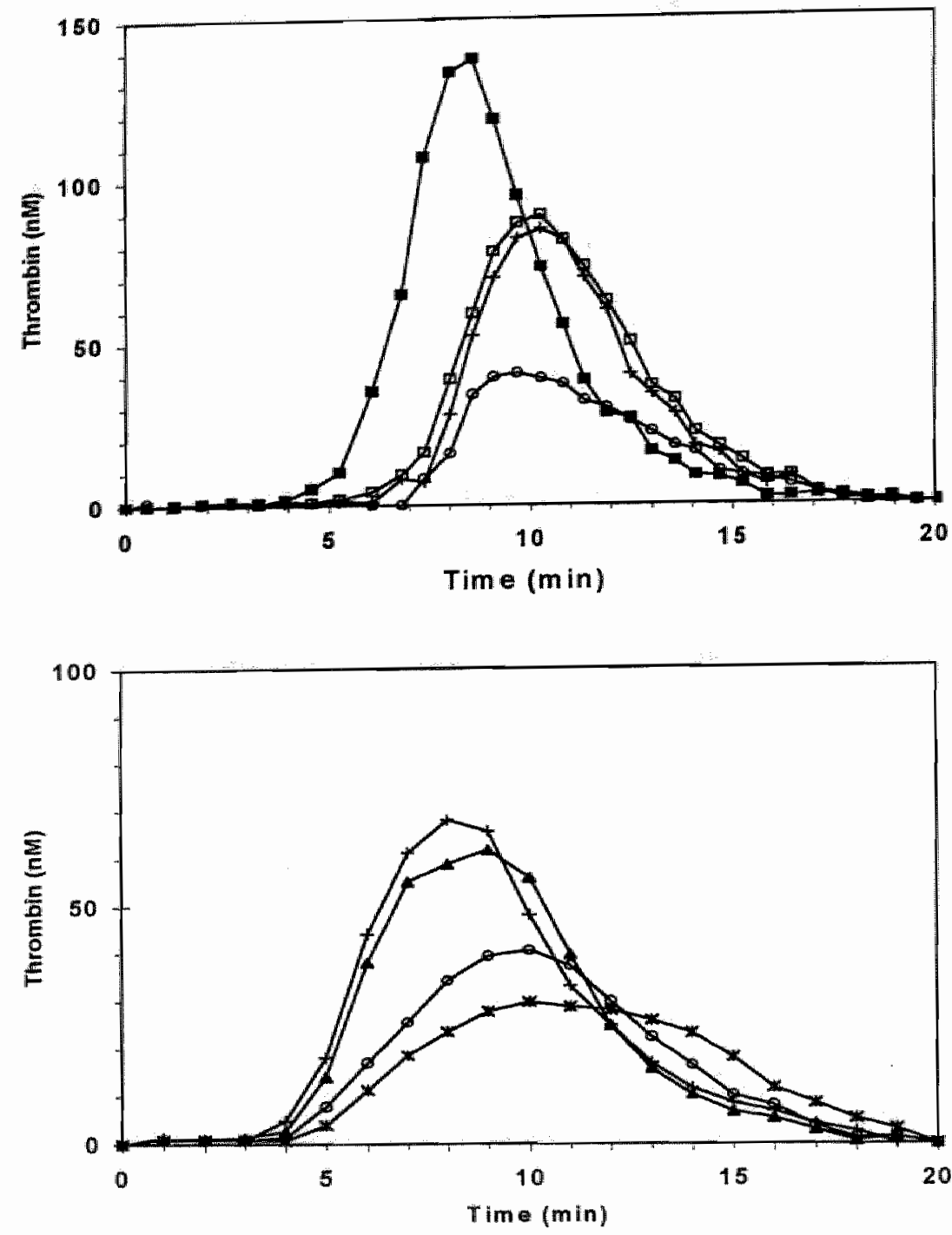

Fig 4 Thrombin generation in hypofibrinogenaemic PRP, effect of fibrin. Thrombin generation was measured in similar experimental set up as described in legend of Fig. 1 with normal and hypofibrinogenaemic PRP. Upper frame: (O) normal PRP, (D) normal PRP with fibrin clots added, (O) hypofibrinogenaemic PRP, (+) hypofibrinogenaemic PRP with fibrin clots added. Lower frame: hypofibrinogenaemic PRP (O) alone or $(\boldsymbol{A})$ with fibrinogen at $\sim 3 \mathrm{mg} / \mathrm{ml}$ added of $(+)$ with fibrin clots added or (*) with 7 E3 antibody added.

fibrin (Fig. 4, lower frame). In the most severely affected patient addition of $7 E 3$ inhibited thrombin generation from 60 to $33 \%$ of normal, whereas in the 
patient with $10 \mathrm{mg} / \mathrm{L}$ of plasma fibrinogen, $7 \mathrm{E} 3$ decreased thrombin generation only from 56 to $51 \%$. In the patient with $22 \mathrm{mg} / \mathrm{L}$ of fibrinogen, d-RGDW decreased thrombin generation from 63 to $58 \%$. In PPP the thrombin generation was found to be same as control. In contrast to the other experiments, in which inhibition of thrombin generation and low PPA in serum always went together, in these patients PPA in serum was high as compared to the controll (see discussion).

It thus seems that a normal fibrinogen content is required for normal thrombin generation. Whether this is due to fibrinogen or to fibrin can not be determined from these experiments. If it is fibrin, then it must be nascent fibrin generated during the experiment. In order to see whether such fibrin indeed

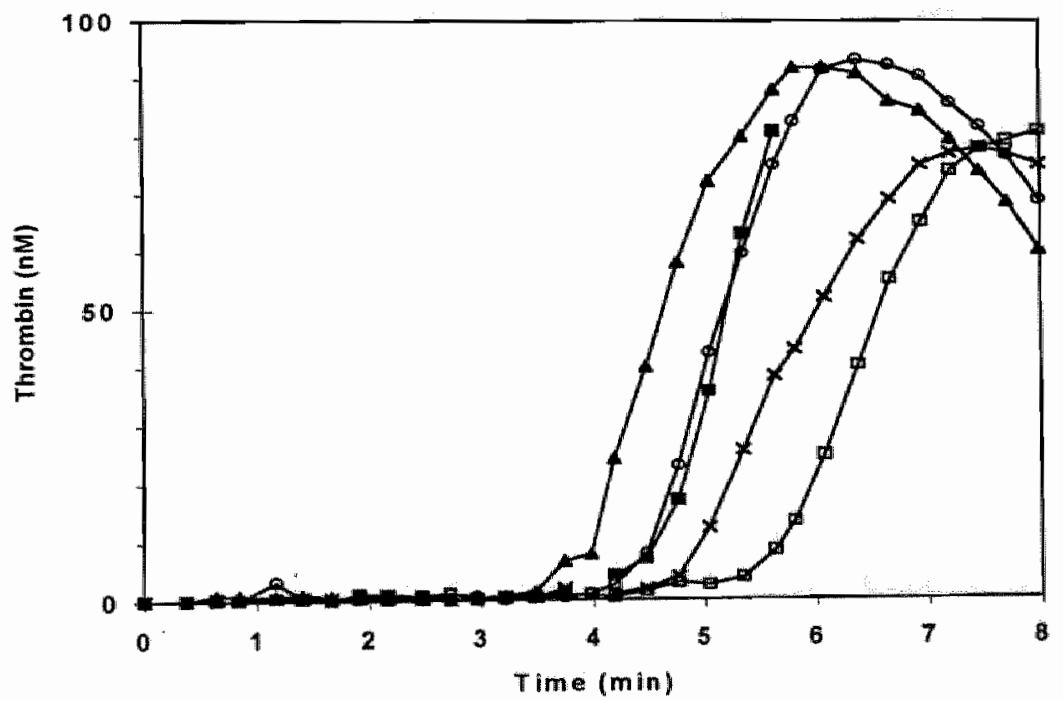

Fig. 5 Addition of snake venom Agihal to generate nascent fibrin strands. Thrombin generation was triggered in PRP by the addition of $\mathrm{CaCl}_{2}$ containing $1.8 \mathrm{fM}$ recombinant tissue factor. The amidolytic activity was determined in subsamples taken at $20 \mathrm{~s}$ intervals (for detailed generation of first minutes of the graph) from which thrombin activity was calculated. Agihal, a purified fraction of Agistrodon halys halys snake venom where added was at $T=1 \mathrm{~min} 30 \mathrm{~s}$ after recalcification. (D) Control without Agihal, (D) without Agihal and with fibrin clots added, $(X) 0.5 \mu \mathrm{g} / \mathrm{ml}$ of Agihal (giving a clotting time of $1 \mathrm{~min} 54 \mathrm{~s}$ in PRP) added, (O) $1 \mu \mathrm{g} / \mathrm{ml}$ of Agihal (clotting time of $56 \mathrm{~s}$ ) added, (A) $2 \mu \mathrm{g} / \mathrm{ml}$ of Agihal (clotting time $<20 \mathrm{~s}$ ) added. 
Table 4 Difference between the effects of Agihal (snake venom) or thrombin on clotting time of PRP

\begin{tabular}{|c|c|c|c|c|}
\hline & Buffer & & $\begin{array}{c}\text { Agihal } \\
(0.2 \mu \mathrm{g} / \mathrm{ml})\end{array}$ & $\begin{array}{c}\text { Thrombin } \\
(2.5 \mathrm{nM})\end{array}$ \\
\hline $\operatorname{PPP}(-\mathrm{Ca} 2+)$ & - & & $5 \min 20 \mathrm{~s}$ & $5 \mathrm{~min} 15 \mathrm{~s}$ \\
\hline PRP (- $\mathrm{Ca} 2+)$ & - & & $5 \min 2 s$ & $6 \mathrm{~min} 50 \mathrm{~s}$ \\
\hline $\mathrm{PRP}(+\mathrm{Ca} 2+)$ & $8 \min 6 s$ & $>$ & $3 \min 26 \mathrm{~s}>$ & $1 \min 42 \mathrm{~s}$ \\
\hline
\end{tabular}

Clotting time were measured in plastic tube in the similar system as that of thrombin generation after adjusting the thrombin and Agihal concentrations to obtain comparable values in PPP.

influences thrombin generation, we added the clotting enzyme from Agkistrodon venom (at a dose that was equally effective as thrombin in directly clotting plasma fibrinogen) after recalcification (Fig. 5, Table 4). Although the venom does not activate platelets directly, the appearance of fibrin shortened the clotting time in PRP to a greater extent than in PPP suggesting an effect mediated through the platelets. Thrombin however, shortens the clotting time of PRP much more than the snake venom does, when $\mathrm{Ca}^{2+}$ is present. This suggests that thrombin, in a $\mathrm{Ca}^{2+}$-dependent process, acts directly on the platelets in addition to acting indirectly via the generation of fibrin.

Two entirely different circumstances that both inhibit clot retraction, namely lack of functioning GPIlb/llla receptors and lack of fibrin(-ogen) both result in decreased thrombin generation. It cannot be excluded a priori that the development of PPA is related to clot retraction. We therefore investigated the effect of inhibiting clot retraction by preventing actomyosin polymerisation with cytochalasin D (10 $\mu \mathrm{M})$. This again caused inhibition of thrombin generation in PRP (Fig. 6) but not in PPP. PPA in serum was measured to be $41+1 \%$ of the controll. 


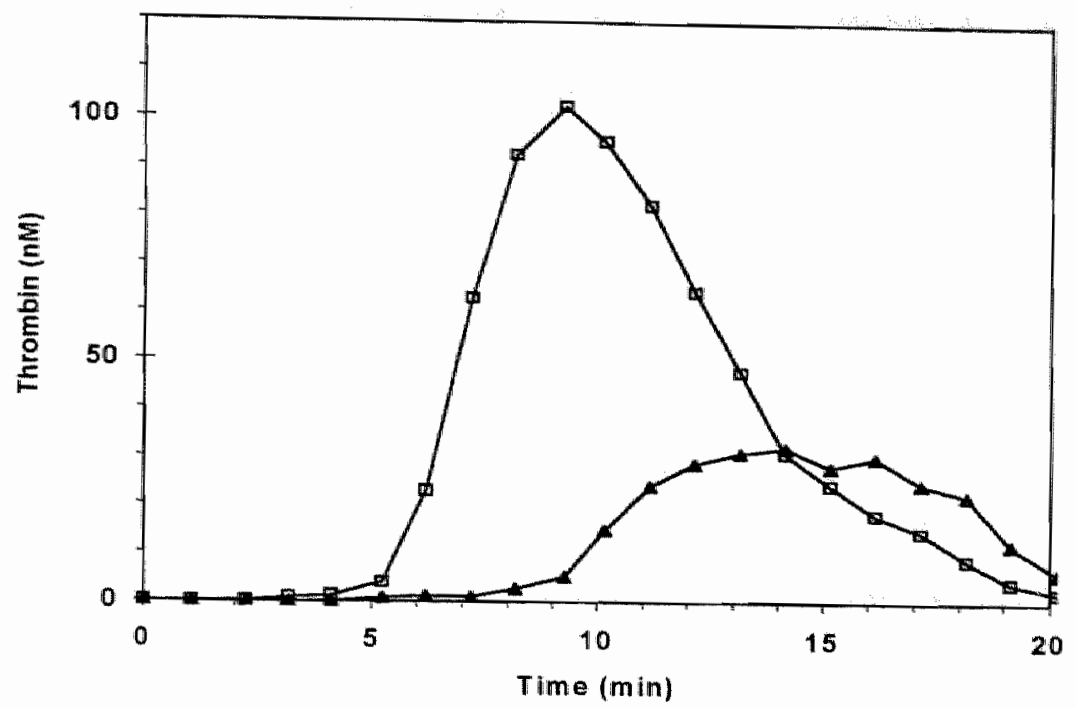

Fig. 6 Effect of addition of cytochalasin-D on thrombin generation in PRP. Thrombin generation was measured in similar experimental set up as described in legend of Fig. 1. Cytochalasin-D which inhibits clot retraction by preventing actornyosin polymerisation was added. (C) Control without cytochalasin-D, (A) cytochalasin-D (10 $\mu \mathrm{M})$ added.

Experiments with modified von Willebrand factor activity.

The interaction between GPIb and fibrin is known to be mediated by von Willebrand factor (VWF) (Loscalzo et al. 1986). We therefore investigated the effect on thrombin generation of reducing VWF activity in plasma with a neutralising antibody. Not only did VWF neutralisation prevent the enhancement produced by fibrin, but unexpectedly it also diminished baseline thrombin generation (Fig. 7, upper frame). Addition of a frozen and thawed platelet lysate in addition to the WWF antibody restored normal thrombin generation. In contrast, thrombin generation in PPP was unaffected by WWF neutralisation (Fig. 7, lower frame).

Experiments were done with PRP of patients with mild and severe von Willebrand disease. In a patient with mild VWD (type $\| \mathrm{a},-30 \%$ of FVIII and $4 \%$ of WWF activity), thrombin generation in PRP was seen to be $\sim 60 \%$ of a normal control, with an additional inhibition (to $\sim 80 \%$ ) upon addition of the 

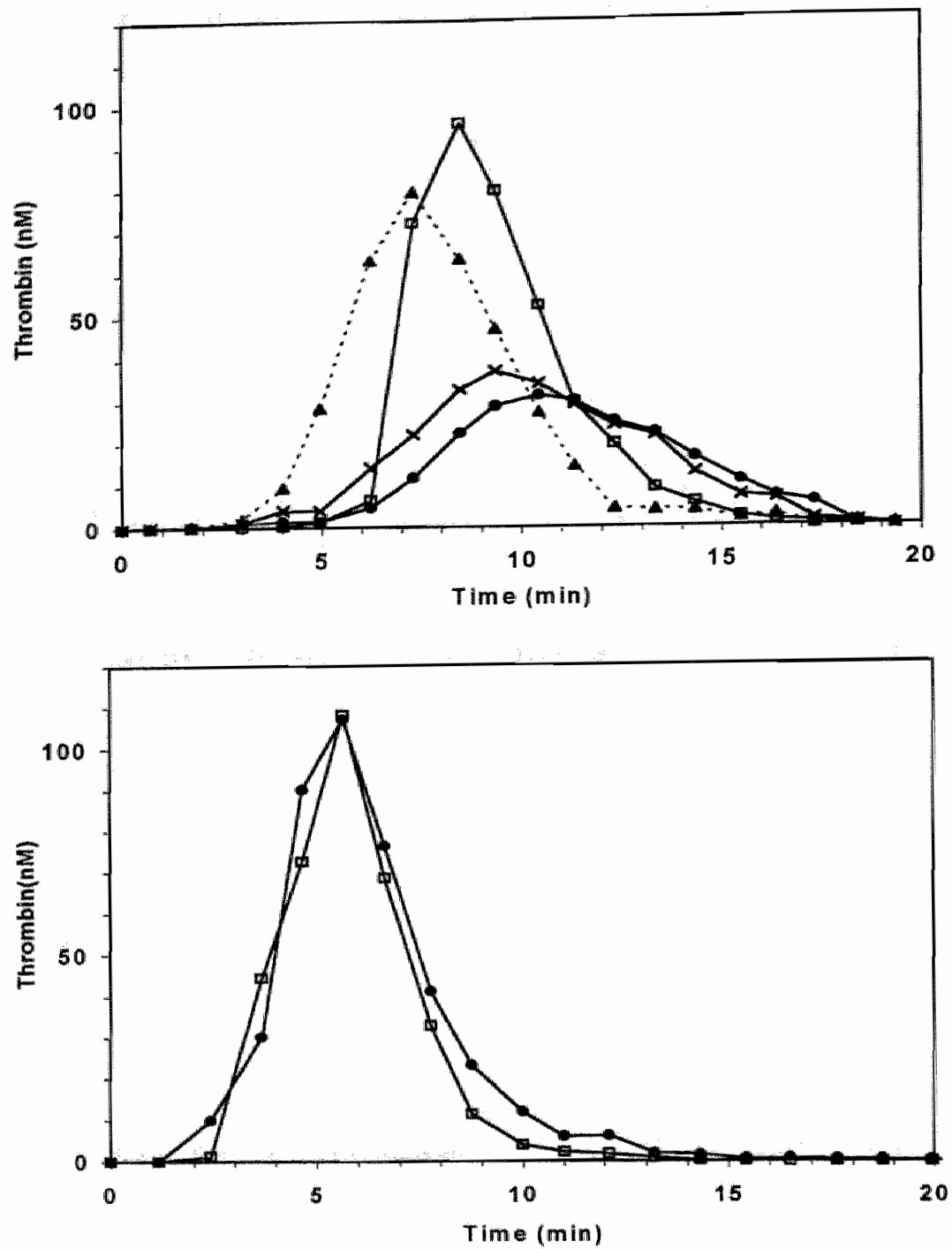

Fig. 7 Effect on thrombin generation of reducing von Willebrand factor (WWF) activity in plasma. Plasma was preincubated for $10 \mathrm{~min}$ with WWF neutralising antibody $(\sim 10$ $\mathrm{mg} / \mathrm{ml})$ in some experiments. Upper frame: Thrombin generation in PRP. Experimental set up was similar to as described in legend of Fig.1. (D) PRP with IgG rabbit serum, (-) PRP preincubated with WWF antibody $(\sim 10 \mathrm{mg} / \mathrm{ml}$, concentration that gave inhibition $>60 \%$ of thrombin potential in PRP), (X) PRP preincubated with VWF antibody and added fibrin clots. (A) PRP preincubated with VWF antibody and to which a frozen and thawed platelet lysate (from pl. suspension having $2^{* 1} 10^{7} \mathrm{pl} / \mathrm{ml}$ ) was added at $T=90 \mathrm{~s}$ after recalcification. Lower frame: Intrinsic thrombin generation in platelet poor plasma (PPP). As described in detail in methods, thrombin generation was triggered in non defibrinated PPP by kaolin, PSIPC and $\mathrm{Ca}^{2+}$. (D) PPP with IgG rabbit serum, (-) PPP with WWF antibody added. 
VWF antibody (Fig. 8). Thrombin generation in PPP of the patient was seen to be normal (Fig 8 , inset), showing that the inhibition observed in PRP of the patient can be attributed to deficiency of WWF.

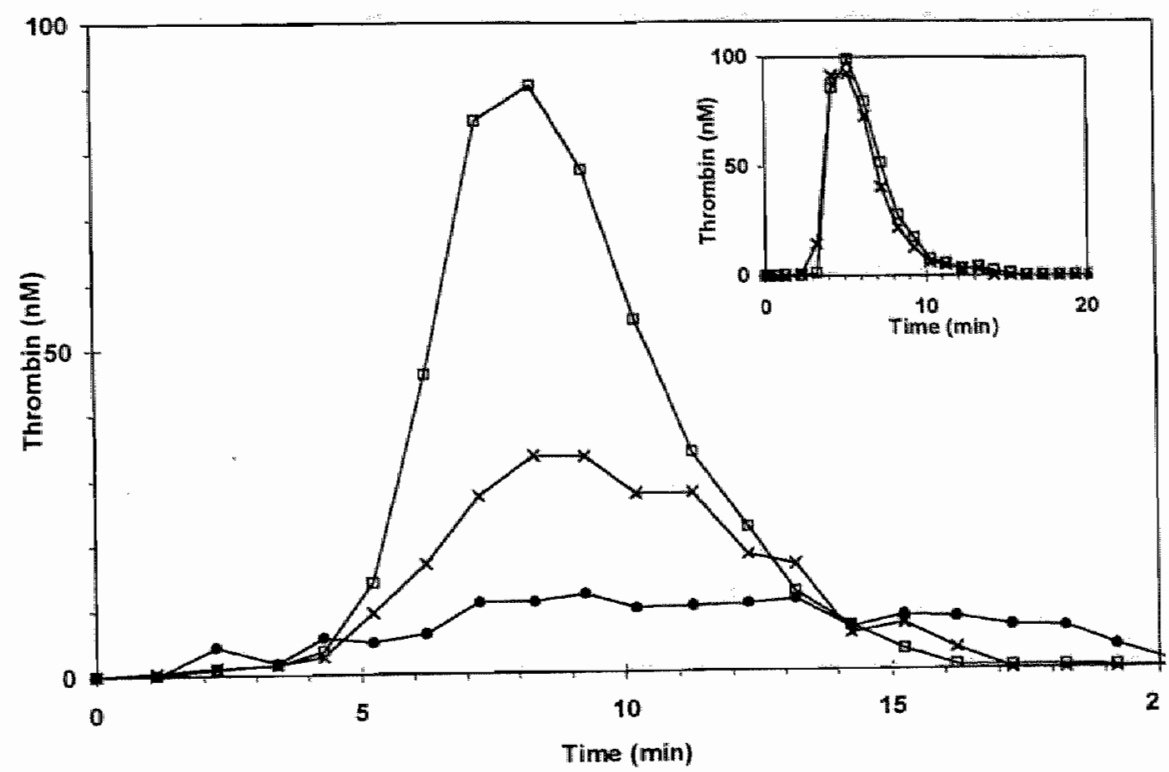

Fig. 8 Thrombin generation in PRP of patient with type lla mild deficiency af WWE. Thrombin generation was triggered in normal or patient's PRP by the adidition of $\mathrm{CaCl}_{2}$ containing $1.8 \mathrm{fM}$ recombinant tissue factor. The patient was reported to have type Ila von Willebrand disease (WWD) with $30 \%$ of FVIII and $\sim 4 \%$ of WWF activity. (D) Normal PRP with IgG rabbit serum (X) wWD patient's PRP with $\mathrm{IgG}$ rabbit serum (•) WWD patient's PRP preincubated with WWF antibody $(10 \mathrm{mg} / \mathrm{ml})$. Inset graph shows the thrombin generation in intrinsically triggered non defibrinated PPP (by kaolin, $P S / P C$ and $\mathrm{Ca}^{2+}$ ) for (O) control or (X) WWD patient.

For a type III severe WWD patient ( $<1 \%$ of VWF and FVIII), thrombin generation in PRP was more severely inhibited than in the PRP of the patient with mild WWD (Fig.9, upper frame). Addition of $100 \%$ recombinant factor VIII 

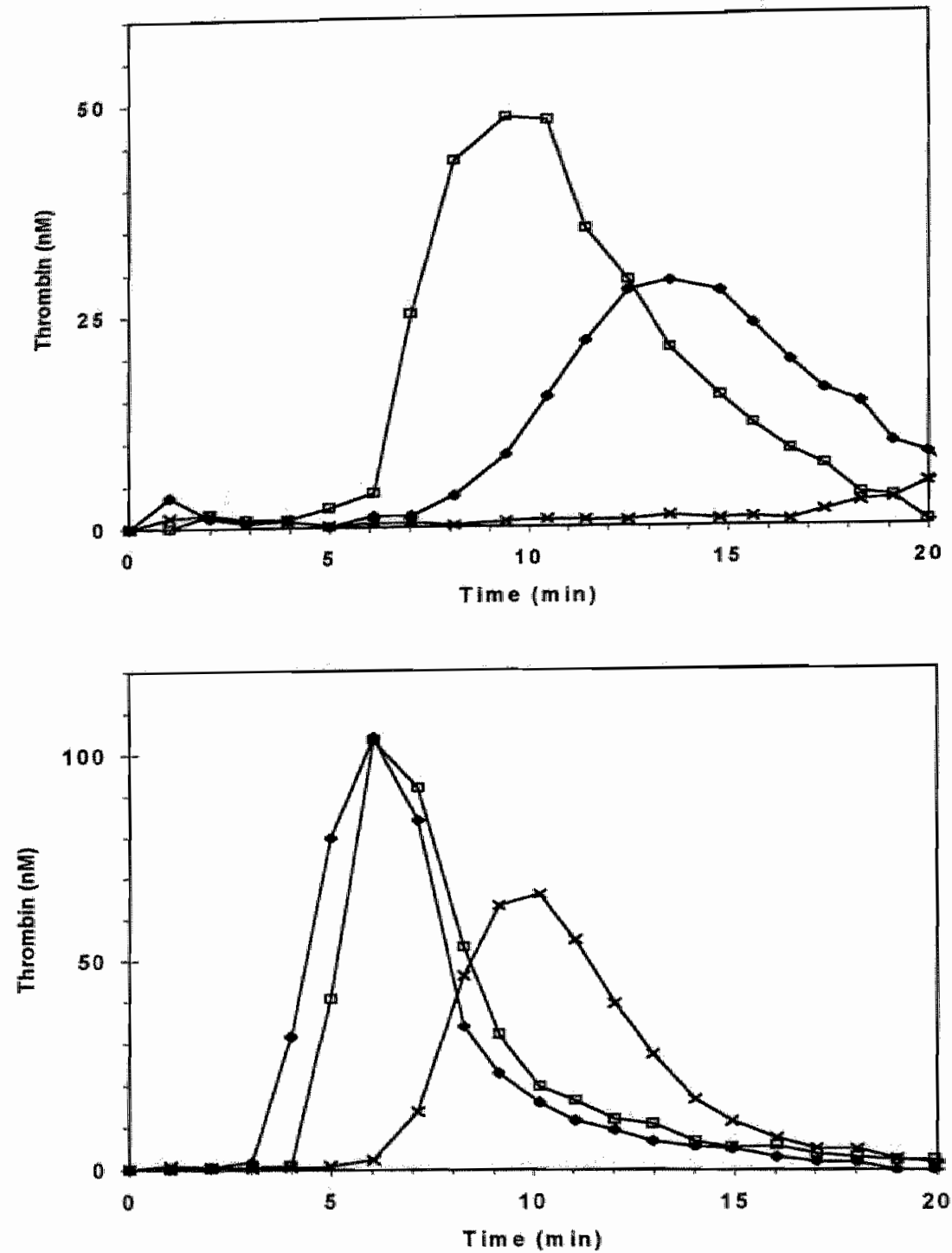

Fig.9 Thrombin generation in plasma of patient with type III severe deficiency of WWF. Experimental set up for thrombin generation in normal or patient's plasma was similar to as described in legend of Fig. 8. The patient was reported to have severe type III von Willebrand disease (WWD) with $<1 \%$ of FVIII and VWF activity. Upper frame: Thrombin generation in platelet rich plasma (PRP). (C) Normal PRP, (X) wWD patient's PRP, ( $\$$ ) WWD patient's PRP added with 100\% rFVIII. Lower frame: Thrombin generation in intrinsically triggered non defibrinated platelet poor plasma (PPP). (D) Normal PPP, (X) VWD patient's PPP ( 4 ) VWD patient's PPP added with $100 \%$ rFVIII. 
(rFVIII) normalised the intrinsic thrombin generation in PPP (Fig.9, lower frame) but did not restore thrombin generation in PRP (Fig 9 , upper frame). Addition of $100 \%$ rFVIII increased thrombin generation in PRP but an inhibition of $40 \%$ remained. To the PRP of this patient we also added $2.5 \%$ of recombinant factor VIII and the same amount of platelet poor plasma, thus supplying both FVIII and VWF (Fig. 10). The addition of FVIII was seen to be without effect while the normal plasma restored thrombin generation. Addition of either normal or patient platelet lysate enhanced thrombin generation indicating that the appearance of procoagulant phospholipids is truly rate limiting.

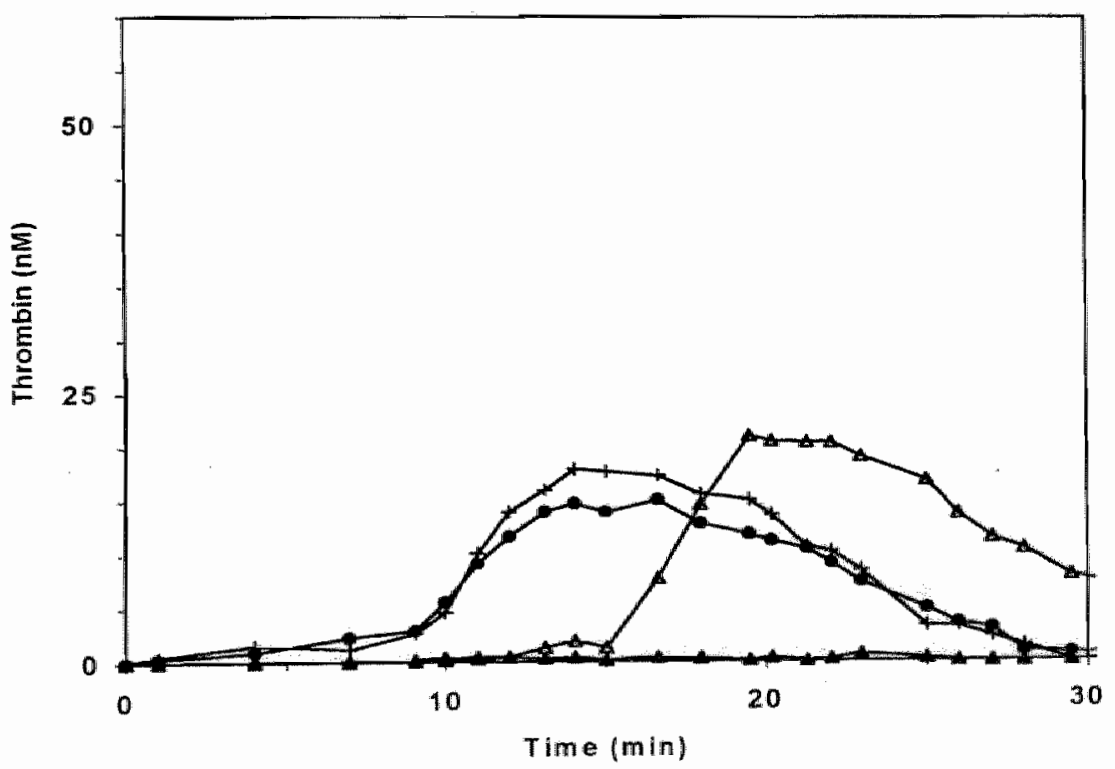

Fig. 10 Thrombin generation in PRP of patient with type 111 severe deficiency of WWF. Thrombin generation in PRP of the patient with type III severe VWD described in legend of Fig. 9 was carried out. (A) WWD patient's PRP added with $2.5 \%$ rFVIII, $(\Delta)$ WWD patient's PRP adjusted with $2.5 \%$ normal platelet poor plasma (to supply $2.5 \%$ of VWF and FVIII), (+) WWD patient's PRP adjusted with $2.5 \%$ normal platelet poor plasma and with a frozen and thawed platelet lysate from normal plasma added at $T=90 \mathrm{~s}$ after recalcification, (-) WWD patient's PRP adjusted with $2.5 \%$ normal platelet poor plasma and with a frozen and thawed platelet lysate from patient plasma added at $\mathrm{T}=90 \mathrm{~s}$ after recalcification. 


\section{Discussion}

The studly of thrombin generation in PRP allows the observation of interactions between the cellular- and the plasmatic components of the blood coagulation system, which may escape attention if PPP and washed platelets are studied separately. It allowed us to observe: a) that blocking the GPIlb/llla receptor of platelets inhibits normal thrombin generation (Reverter et al. 1996) and b) that fibrin can induce PPA (Kumar et al. 1995). In this article we investigate which membrane-receptors play a role in the process by which fibrin renders platelets procoagulant.

\section{Experimental approach.}

In isolated platelets the transbilayer movement of aminophospholipids mediated by thrombin and collagen could be directly assessed by determining changes of the phospholipid composition of the outer membrane-bilayer leaflet (Bevers et al. 1982). Fibrin causes partial lysis of washed platelets and thus the exposure of aminophospholipids that accompanies cell damage cannot be distinguished from that occurring as a result of platelet activation (Kumar et al. 1995). Techniques for the direct identification of the procoagulant phospholipids can therefore not be used to study the procoagulant effect of fibrin on washed platelets. Platelets in their plasma milieu are not lysed by fibrin, so for the study of the fibrin effect we chose PRP. In the first place we used the generation of thrombin in recalcified PRP, because we had previously shown that under these conditions PPA is the rate limiting component for the appearance of thrombin (Béguin et al. 1989). In the second place we used the amount of lipid-related procoagulant activity that was found in the reaction medium ("serum") left after thrombin generation is over. Thirdly we measured the amount of prothrombin in the serum that had not been converted into thrombin.

Thrombin generation in PRP is characterised by a lag phase of several minutes, followed by a burst of activity, that then disappears under the 
influence of the natural antithrombins. The burst has been shown to indicate PPA production and not activation of factors $V$ or VIII (Béguin et al. 1989). Varying the number of platelets in PRP shows that $300 \times 10^{9}$ platelets per $\mathrm{L}$ suffice for near maximal thrombin generation (Reverter et al. 1996), and therefore we adjusted our PRPs to $300 \times 10^{9}$ platelets per $\mathrm{L}$.

Coagulation of plasma occurs when $10-20 \mathrm{nM}$ thrombin is formed, i.e. at the beginning of the thrombin-burst. Within 1 min after the start of the thrombin burst the fibrinogen in the plasma is converted to fibrin. In order to allow further subsampling, the formed clot - together with any added clots - is immediately removed. Despite the removal of a substantial amount of platelet material in the minute following coagulation, thrombin generation continues, indicating that already shortly after the start of thrombin generation PPA is present in excess. In the removed clot the platelets are caught. No particles of the size of platelets or larger are found in the serum after the end of the experiment, but to preclude the presence of any larger platelet remnants, the serum was centrifuged. The procoagulant microparticles remain however and can be assessed in the serum.

In the normal coagulation process almost all prothrombin is consumed (Soulier 1948) but insufficient PPA development limits prothrombin consumption (Soulier et Larrieu 1952, Alagille et Soulier 1957). In plasma in which the plasmatic clotting factors are normal, the level of residual prothrombin in the serum therefore is an indirect measure of the PPA that developed. In all instances the three parameters used showed parallel changes, except in experiments where fibrinogen was too low to form a clot, which case will be discussed separately.

The role of platelet receptors.

Platelet mediated thrombin generation is inhibited by blocking GPIIb/lla (Reverter et al. 1996), which receptor is not only known to bind fibrinogen (Plow et al. 1985), but also polymerizing fibrin (Tuszynski et al. 1984, Hantgan 1988) and clotted fibrin under static (Cohen et al.1982, Hantgan et al. 1985) or flow conditions (Hantgan et al. 1990, Jen 1990). Nevertheless fibrin retains its 
stimulating effect in the presence of a GPIlb/lla blocking antibody as well as when added to the PRP of Glanzmann patients (Fig. 1, Table 1,2). In this respect there is no difference between the two types of Glanzmann patients tested (Fig. 3). The presence or the absence of GPIIb/llla does not seem to make any difference as to the susceptibility to fibrin induced activation. (Table 1. Fig. 1).

The absolute increase in thrombin generation produced by fibrin may seem to be less in the absence of functional GPllb/llla receptors than in their presence, but in view of the fact that thrombin generation does not quantitatively reflect platelet activation, we hesitate to draw mechanistic conclusions from this observation.

Platelets are known to bind to fibrin (and other fibres) through WWF and GPlb. Blocking GPIb with the monoclonal 6D1 had no effect on normal thrombin generation but the enhancing effect of fibrin was completely abolished (Fig. 2, Table 1), so the fibrin effect seems to be mediated via this receptor.

The fact that in normal PRP blocking GPlb will not inhibit PPA shows that the GPIlb/llla dependent mechanism is the leading one as long as there is no fibrin present. This is in accordance with the observation that the development of PPA is critically dependent upon the presence of traces of thrombin, GPllb/llla being activated by. thrombin and GPlb not. The experiments of Table 4 indicate that if snake venom and thrombin are added at concentrations that induce similar fibrin formation in PPP, thrombin is a much more potent activator in PRP, but only if $\mathrm{Ca}^{++}$-ions are present. This shows that thrombin in PRP and in the absence of a preformed clot can activate platelets directly although it may also subsequently act through forming fibrin. When fibrin is added, GP $\|$ b mediates additional mechanisms that lead to enhanced platelet coagulant activity, resulting in a shortening of the lag time and increased ETP.

Loss of GPllb/lla + $\alpha_{V} \beta_{3}$, function either on genetic basis as in Glanzmann thrombasthenia or by use of monoclonal antibodies, decreases platelet coagulant activity by $\sim 45 \%$ (Table 1, Table 2 ). Blocking GPIb in 
addition to GPllb/lla $+\alpha_{w} \beta_{3}$ does not increase the inhibition caused by blocking GPIIb/llla $+\alpha_{v} \beta_{3}$ (Table 1). However, because the generation of PPA is not quantitatively reflected by thrombin generation (nor by microparticle formation and by prothrombin consumption), it is difficult to estimate the contribution of both pathways in clotting normal PRP.

It is interesting to note that the decrease in platelet coagulant activity in both Arab and Iraqi-Jewish patients was similar (Table 2) which indicates that $\alpha_{v} \beta_{3}$ does not play a major role. On the other hand, only the Arab patients, whose platelets contain $\alpha_{v} \beta_{3}$, had a further decrease in platelet coagulant activity when 7E3 was added. These data are consistent with our previous studies suggesting a small, but unmistakable contribution of $\alpha_{w} \beta_{3}$ to the development of platelet coagulant activity.

The results of PPA in serum and the consumption of prothrombin follow the same pattern of inhibition as does thrombin generation. This suggets that microvesiculation is not only dependent upon GPIlb/llla activity but also upon the GPIb-fibrin interaction. This agrees with the study by Nomura et al (1996) suggesting that microparticle generation after stimulation of platelets by collagen plus thrombin occurred via two mechanisms, only one of which is dependent upon $\alpha_{115} \beta_{3}$.

The amount of procoagulant microvesicles is clearly higher than expected if there is not enough fibrinogen to form a normal clot. This may be due to direct sticking of procoagulant phospholipid material to fibrin as observed by Siljander et al. (1996). This mechanism might remove a certain amount of microvesicles from the medium when the clot is taken out, which evidently would not take place if no or a very small clot was formed.

\section{The role of $\mathrm{VWF}$}

Since GPIb-IX is a receptor of WWF, it was natural also to investigate the effect of inhibiting WWF on thrombin generation in PRP. We therefore expected that absence of functional vWF would intibit the fibrin-effect. It came as a surprise however, that when WWF is inactivated by a neutralising antibody that in addition to the inhibitory effect on fibrin clot dependent enhancement of 
platelet coagulant activity, baseline thrombin generation was also strongly inhibited (Fig. 7). This can not be explained by inhibition of WWF-mediated GPIb-fibrin interaction alone. Neither can it be attributed to a WWF-mediated effect on factor VIII because a) no influence of the antibody is seen in contactactivated PPP; b) the inhibition is not corrected by adding factor VIII, and c) the inhibition is prevented by adding a platelet homogenate or a phospholipid preparation (Fig. 9, 10).

Several authors have found that the physical interactions between fibrin and the platelet (sticking to fibrin, incorporation in a clot) are VWF dependent (Loscalzo et al. 1986, Hantgan et al. 1990, Jen et al. 1990). it now appears that these interactions facilitate procoagulant activity. This suggests a mechanism in which VWF binds to fibrin, aquires the form necessary for interaction with GPIb, and then mediates platelet attachment that induces the expression of PPA in the platelet membrane. Our results also indicate a potential role of WWF in the GPIIb/lla-dependent mechanism, which could be mediated through the WWF binding site on GPIlb/llla.

By its function in both the GPIlb/llla- and the GPIb dependent mechanism, VWF appears to play a very important role in the generation of thrombin in PRP. This function, that is independent of its function as a carrier of factor VIII has hitherto remained unrecognised.

The role of fibrinogen.

We observed that thrombin generation in hypofibrinogenaemic PRP is significantly less than in control plasma (Table 3). Absence of fibrinogen in the plasma can interfere with platelet function at different levels. In the first place fibrinogen is required for GPIlb//lla-mediated aggregation and retraction and in the second place newly formed fibrin fibres might play the same role as an added clot. Finally, platelets from hypofibrinogenaemic patients lack intraplatelet fibrinogen, which may play a unique role in platelet function (McDonagh and Carrell 1987).

Since blockade of GPlb did not alter basal thrombin generation in PRP, it is unlikely that the fibrin formed during this process contributes significantly to the development of PPA. Thus, the inhibition of thrombin generation in 
patients with hypofibrinogenaemia is unlikely to be caused by the absence of fibrin and more likely due to the absence of fibrinogen. This may be plasmatic fibrinogen or fibrinogen contained in the platelets. It is unlikely that intraplatelet fibrinogen is crucial since similar results were obtained with patients treated with 7 E3 (which does not affect intraplatelet fibrinogen during brief incubation) and platelets with Glanzmann thrombasthenia, whose platelets have very little intraplatelet fibrinogen.

We have previously observed that thrombin generation is not diminished when washed platelets are resuspended in PPP (Reverter et al. 1996). This can be interpreted in two ways: either internal fibrinogen of the platelets can stand in for plasma fibrinogen or washed platelet preparations contain a small percentage of slightly damaged cells that already support generation of traces of thrombin, which then further activates the undamaged platelets via a fibrinogen independent pathway. The fact that lag times are short in the plasma containing resuspended platelets (Reverter et al. 1996) favours the latter interpretation.

Also pertinent to the role of fibrinogen is the observation that in all cases there appears to be an association between clot retraction and thrombin generation. Thus, GPllb/llla receptor absence or blockade, as well as hypofibrinogenaemia and cytochalasin-D all decrease both thrombin generation and clot retraction. This raises the possibility that the movement of clot retraction, perpendicular to the membrane may result in scrambling of the phospholipids and perhaps vesiculation. The data of Siljander et al. (1996), who observed that especially those fibrin strands are covered with platelet membrane remnants that are in direct contact with platelets are consistent with such a mechanism.

\section{Acknowledgements}

We are grateful to Prof. U Seligsohn, Dr. Karly Hamulayk and Dr. J Eikenboom for providing us the opportunity to study the plasma from patients with congential diseases. We are equally indebted to the patients for their kind consent to donate blood for our studies. Our thanks are due to Dr J A van Mourik for providing us the antibodies. We also thank $\mathrm{Dr} H \mathrm{Hu}$ Kail for his method of measurement of microparticle procoagulant activity. 


\section{References}

Badimon L, Badimon JJ, Galvez A, Chesbro JH, Fuster $V$. Influence of arterial damage and wall shear rate on platelet deposition: Ex vivo study in a swine model. Arteriosclerosis 1986; $6: 312-20$.

Badimon $L$, Badimon $J J$, Lassila $R$, Heras $M$, Chesbro $J H$, Fuster $V$. Thrombin regulation of platelet interaction with damaged vessel wall and isolated collagen type 1 at arterial flow conditions in a porcine model: effects of hirudins, heparin and calcium chelation. Blood 1991; 78 : 423-34.

Beguin $S_{\text {, Lindhout }} T_{\text {" Hemker }} \mathrm{HC}$. The effect of trace amounts of tissue factor on thrombin generation in PRP, its inhibition by heparin. Thromb Haemost 1989;61:25-9.

Bennett JS, Vilaire G. Exposure of platelet fibrinogen receptors by ADP and epinephrine. J Clin Invest 1979;64:1393-1401.

Bevers EM, Comfurius P, van Rijn $I L M L$, Hemker $H C$, Zwaal RFA. Generation of Prothrombin converting activity and the exposure of phosphatidylserine at the outer surface of platelets. Eur J Biochem 1982;122:429-36.

Bevers $E$, Comfurius $P$, Zwaal RFA. Changes in membrane phospholipid distribution during platelet activation. Biochim Blophys Acta 1983;736:57-66.

Cohen I, Gerrard JM, White JG. Ultrastructure of clots during isometric conditions. J Cell Biol 1982:93:775-87.

Caller BS. A new murine monoclonal antibody reports an activation-dependent change in the conformation and/or microenvoirnment of the platelet GPIIb/lla complex.J Clin Invest 1985;76:101-8.

Coller $\mathrm{BS}_{n}$ Anderson $\mathrm{K}$, Weisman HF. New antiplatelet agents : platelet GPIIb/llla antagonists. Thromb Haemost 1995;74:302-8.

Coller BS, Peerschike El, Scudider LE, Sullivan CA. Studies with a murine monoclonal antibody that abolishes ristocetin-induced binding of von Willebrand factor to platelets: additional evidence in support of GPIb as a platelet receptor for von Willebrand factor. Bllood 1983;61:99-110.

Coller BS, Beer JH, Scudder LE, Steinberg MH. Collagen platelet interactions:evidence for a direct interaction of collagen with platelet GPla/lla and an indirect interaction with platelet GPIIb/llla mediated by adhesive proteins. Blood $1989 ; 74: 182-92$.

Coller BS, Cheresh DA, Asch E, Seligson U. Platelet vitronectin receptor expression differentiates Iraqi-Jewish from Arab patients with Glanzmann thrombasthenia in Israel. Blood 1991;77:75-83.

Eikenboom JCJ, van Amstel HKP. Reitsma PH, Briet E.Mutations in severe, type III von Willebrand's disease in the Dutch population: candidate missence and nonsense mutations associated with reduced levels of von Willebrand factor messenger RNA. Thromb Haemost 1992;68:448-454. 
Hantgan RR. Fibrin protofibril and fibrinogen binding to ADP-stimulated platelets:evidence for a common mechanism. Biochim Biophys Acta 1988;968:24-35.

Hantgan RR, Taylor RG, Lewis JC. Platelet interact with fibrin only after activation. Blood 1985;65:1299-

Hantgan RR, Hindriks G, Taylor RG, Sixma $J J$, De Groot PG. Glycoprotein $\mathbf{l b}_{\text {, von }}$ Willebrand factor and Glycoprotein IIb-Illa are all involved in platelet adhesion to fibrin in flowing whole blood. Blood 1990;76:345-53.

Hendrix $H$, Lindhout $T$, Mertens $K$, Engels $W$, Hemker HC. Activation of human prothrombin by stoichiometric levels of staphylocoagulase. $J$ Biol Chem $1983 ; 258: 3637-44$

Hemker $\mathrm{HC}$, Willems $\mathrm{GM}$, Béguin $\mathrm{S}$. A computer assisted method to obtain the prothrombin activation velocity in whole plasma independent of thrombin decay processes. Thromb Haemost 1986;56:9-17.

Hemker $\mathrm{HC}$, Wielders $S$, Béguin $S$. The thrombin potential, a parameter to assess the effect of antithrombotic drugs on thrombin generation. In: Fraxiparin, Bounameaux $H$ et al eds. Schattaurer 1990, pp 89-101.

Hemker HC. Thrombin generation, an essential step in haemostasis and thrombosis.In: Haemostasis and Thrombosis.3rd edt. Bloom AL, Forbes CD, Thomas DP "Tuddenham EGD (edts). London:Churchill Livingstone 1993.ISBN 0-443-04521b; 477-90.

Jen CJ, Hu SJ, Wu HJ, Lin TS, Mao CW. Platelet-fibrin interaction in the suspension and under flow conditions. Adw Exp Med Biol 1990;281:277-85.

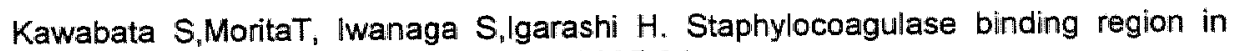
human prothrombin. J Biochem 1985;97:325-31.

Kumar R, Béguin S, Hemker $\mathrm{HC}$. The influence of fibrinogen and fibrin on thrombin generation-evidence for feedback activation of the clotting system by clot bound thrombin. Thromb Haemost 1994;72:713-21.

Kumar $R, B$ éguin $S$, Hemker HC. The effect of fibrin clots and clot bound thrombin on the development of platelet procoagulant activity. Thromb Haemost 1995; $74: 962$ 8.

Lam JYT, Chesbro JH, Steele PM, Dewanjee MK, Badimon L. Fuster V. Deep arterial injury during experimental angioplasty: Relationship to a positive Indium-labeled platelet scintigram quantitative platelet deposition and mural thrombus. Journall of the American College of Cardiolagy 1986;8:1380.

Loscalzo J, Inbal A, Handin Rl. von Willebrand protein facilitates platelet incorporation in polymerizing fibrin. $J$ Clin Invest 1986;78:1112-19.

Mailhac A, Badimon $J J_{1}$ Fallon JT, Fernandez-Ortiz A, Meyer D, Chesbro JH, Fuster $V$. Badimon L. Effect of an eccentric severe stenosis on fibrin(ogen) deposition on severely damaged vessel wall in arterial thrombosis. Relative contribution of fibrin(ogen) and platelets. Circulation 1994; $90: 988-95$. 
Marguerie GA, Plow EF, Edgington Ts. Human platelets posses an inducible and saturable receptor specific for fibrinogen. I Biol Chem 1979; 254:5357-63.

McDonagh J, Carrell N. Disorders of fibrinogen structure and function. In: Hemostasis and Thrombosis. Basic Principles and Clinical Practice. Colman RW et all eds, 2 nd edition, J.B.Lippincott company, Philadelphia, PA 1987; pp 301-17.

Neri-Serneri GG, Rovelli $F$, Gensine $G F$, Pirelli $S$, Canovali $M$, Fortini $A$. Effectiveness of low-dose heparin in prevention of myocardial reinfarction. Lancet $1987 ; 25: 937-42$.

Niewiarowski S, Budzynski AZ, Morinelli TA, Buudzynski TM, Stewart GJ. Exposure of fibrinogen receptor on human platelets by proteolytic enzymes. J Biol Chem $1981 ; 256: 917-25$.

Nomura $S_{i}$ Komiyama $Y_{;}$; Matsuura $E_{;}$Xie $G L_{;}$Katsura $K_{;}$Miyake $T_{*}$ Miyazaki $Y_{\text {; }}$ Kagawa $H$; Koike $T_{\text {; }}$ Fukuhara $S$. Participation of $\alpha_{11 b} \beta_{3}$ in platelet microparticle generation by collagen plus thrombin. Haemostasis $1996 ; 26: 31-7$.

Plow EF, McEver RP, Coller BS, Woods VL, Marguerie GA, Ginsberg MH. Related binding mechanism for fibrinogen, fibronectin, von Willebrand factor and thrombospondin on thrombin stimulated human platelets. Blood 1985;66:724-27.

Phillips DR, Charo IF, Parise LV, Fitzgerald LA. The platelet membrane glycoprotien Ilb-lla complex. Blood 1988;71:831-43.

Reverter JC. Beguin $S$, Kessels $H$, Kumar R, Hemker HC, Coller BS. Inhibition of platelet mediated tissue factor induced, thrombin generation by the mouse/human chimeric 7E3 antibody: Potential implications for the effect of $\mathrm{C} 7 \mathrm{E} 3$. Fab treatment on acute thrombosis and "Clinicall Restenosis". J. Clin Invest 1996; 98, 863-74.

Sandberg $H$, Anderson $L$, Hoglund $S$. Isolation and characterization of llipid-protein particles containing platelet factor 3 released from human platelets. Biochem $J$ 1982;203: 303.

Schroit AJ, Zwaal RFA. Transbilayer movement of phospholipids in red cell and platelet membraine. Biochim Biophys Acta 1991;1071:313-29.

Siljander P, Carpen O, Lassila R. Platelet-derived microparticles associate with fibrin during thrombosis. Blood 1996;87:4651-63.

Sixty-Plus Reinfaction Study Research Group. A double blind trial to asses long-term oral anticoagulant therapy in eldery patients after myocardial infarction. Lancet 1980 ; 2: $989-9.4$.

Topol EJ, Plow EF. Clinical trials of platelet receptor inhibitors. Thromb Haemost 1993;70:94-98.

The EPIC Investigators. Use of a monoclonal antibody directed against the platelet glycoprotien llb/lla receptor in high risk coronary angioplasty. N Engl J Med 1994;330:956-61. 


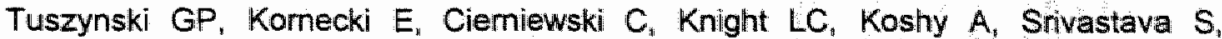
Niewiarowski S, Walsh PN. Association of fibrin with the platelet cycloskeleton. J Biol Chem 1984;259:5247-54. 


\section{Chapter 6}

\section{Summary and Conclusions}

The self propagating nature of the thrombus is generally recognised. Despite the numerous studies on the nature of the thrombus and the ways it appears and disappears, the reason behind its inherent thrombogenicity is only partly resolved (1-3). The end product of the haemostatic mechanism, i. e. a haemostatic plug or a thrombus, consists of the remnants of activated platelets and fibrin, the last actors remaining after a long interplay of plasmatic- and cellular haemostasis (4-6). For a long time it was thought that platelet-plug formation and fibrinogen clotting were alternative ways by which a blood vessel could be occluded, the one mediated by aggregation the other by thrombin. Nowadays it is recognised that the two are tightly interwoven. Thrombin is essential in platelet activation and platelet activation is instrumental in thrombin formation. Although the relative contribution of fibrin and platelets may vary according to the circumstances (e.g. flow conditions), the role of thrombin in the formation of clot and thrombus has no longer to be defended. The work of Badimon and Fuster for instance has shown in an animal model that thrombin bound to a fresh thrombus is a primary activator of accreting platelets $(7)$. This raised the question whether thrombin adsorbed on a clot $(8-10)$ could partake in the feedback activation reactions that are so typical of thrombin formation (11).

In chapter 2 , it is seen that in platelet poor plasma (PPP), clots both increased and accelerated thrombin generation because the adsorbed thrombin activates factors $V$ and VIII. In platelet rich plasma this thrombin also activated platelets. Does this provide a full explanation? To answer this question we eliminated the effect of fibrin-bound thrombin and investigated the influence of clots made from purified human fibrinogen by the action of agihal. 
This enzyme, purified from the venom of the snake Agkistrodon halys halys, is devoid of any activating effect towards platelets since it did not promote calcium influx in platelets even at high concentration. Nor did we observe any effect on thrombin generation in PPP or on the activity of coagulating factors $\mathrm{V}, \mathrm{VIII}$ and $\mathrm{XI}$. Venom-induced fibrin clots were without any effect on thrombin generation in PPP. In platelet rich plasma (PRP), however they increased thrombin generation to the same extent as thrombin-containing clots did, despite the absence of thrombin or of thrombin-like activity. Does this suggest that thrombin-free fibrin is an activator of platelets even when no thrombin is adsorbed? Before answering this question we first define the platelet activation in the context of a thrombin generation experiment.

\section{Expression of platelet procoagulant activity}

Activation of platelets is the result of various complicated sequences of events. Our primary interest was the function of platelets in the coagulation system and we considered the platelets to be activated when they provide a procoagulant phospholipid surface for the anchorage of the factor $\mathrm{Xa}$ - and prothrombin activating enzyme complexes $(12,13)$. This platelet reaction is dependent on the appearance of phospholipids (phosphatidyl serine (PS), phosphatidyl ethanolamine (PE)) on the outer membrane surface that are normally found at the inside. Bevers et al. (14) were the first to describe the "flip-flop" mechanism, in which the platelet, when adequately triggered, loses the normal asymmetry of the phospholipids in its membrane. This causes PS and PE to appear at the outside and thus induces the platelet surface to become procoagulant. Activated platelets also shed procoagulant inicrovesicles (15). It should be noted that flip-flop and microvesiculation are relatively late events in platelet activation. A trigger like ADP for instance induces shape change, release and aggregation but does not cause the platelet to become procoagulant. Flip-flop and vesiculation create (phospholipid-) binding sites for factors VIIla, IXa, Xa and Va, thereby allowing the anchorage of tenase and prothrombinase complexes. In a suspension of isolated platelets, procoagulant activity can be brought about by collagen and 
thrombin; the combined action of these triggers being much more efficient than each of them alone (14). Exposure of procoagulant activity can also be caused by non-physiological triggers such as $\mathrm{Ca}^{++}$-ionophore (14) and by cell damage (freeze-thawing, ultrasonication).

In our experiments on thrombin generation in PRP, no phospholipids were added, so that the availability of piatelet procoagulant phospholipids is rate-limiting for the coagulation reactions. Under these circumstances, minute traces of thrombin $(<1 \mathrm{nM})$ generated during the lag phase of the reaction, trigger the platelets to expose PS/PE which then provokes complete thrombin generation $(16,17)$. It has been seen that the addition of collagen to the plasma had no enhancing effect whatsoever on the action of the first traces of thrombin (17). What, in plasma, replaces the collagen function? is it indeed fibrin, as suggested above? Flip-flop cannot be demonstrated directly in PRP because the activated platelets are caught in the emerging clot. In order to demonstrate this process we investigated the influence of clots on washed platelets in chapter 3 . However, unlike platelets in a plasma medium isolated platelets appear to be damaged by fibrin clots, especially in the presence of thrombin, as judged from the release of lactate dehydrogenase. Therefore, further experiments were conducted in plasma.

The role of fibrin in thrombin generation was further investigated by performing experiments with PRP from patients with congenital hypofibrinogenaemia ( $<10 \%$ of the normal fibrinogen content). In these patients, thrombin generation in platelet poor plasma with phospholipids added, was normal or even higher than normal because no thrombin was retained onto formed fibrin. In PRP of the patient on the contrary, less than half of the normal amount of thrombin appeared (chapter 5), suggesting that fibrin(ogen) is required for the development of procoagulant activity. The addition of soluble fibrinogen or of a fibrin-clot restored thrombin generation to normal, which indicates that fibrin is necessary for platelet activation. We then addressed the question whether this effect is due to thrombin bound to the clot or to fibrin itself. It was observed that also in the hypofibrinogenaemia patient, thrombin-free fibrin normalised thrombin generation as well as thrombin containing fibrin. This excludes possible indirect effects due to 
activation of factors $\mathrm{V}$, VIII or XI. A thrombin-free fibrin clot corrected the defect in hypofibrinogenaemia even better than addition of fibrinogen. We infer that indeed fibrin may replace collagen as a platelet activator in PRP. If this is the case, then platelets adhering to the fibrin-surface of a thrombus may become new foci of thrombin generation and thus contribute to further thrombus growth. We note in passing that because isolated platelets carry their own fibrinogen, it is not excluded that fibrin also is involved in the effect of thrombin on the flip-flop of washed platelets.

\section{Platelet receptors and fibrin-induced procoagulant activity}

Once we had established that in plasma (and possibly in vivo) fibrin can play the role of collagen in provoking procoagulant activity in platelets, the next question was what the underlying mechanism of the fibrin effect is. The intricate intracellular mechanisms that brings about flip-flop have been described since the phenomenon has been discovered (18-22). We have limited our investigations to the extracellular aspects of the mechanism: which receptor(s) on the platelet membrane may be involved in this activation process? Glycoprotein IIb/llla (integrin $\alpha_{116} \beta_{3}$ ), the main fibrinogen receptor, seems an obvious candidate (23-25). Therefore, we measured thrombin generation in PRP of Glanzmann thrombasthenia patients as well as in normal PRP to which a monoclonal antibody against GPIIb/llla (7E3) had been added (chapter 4). We found that absence of functional GPIlb/llla had clear inhibitory effects on both thrombin generation and the amount of procoagulant microvesicles formed. (e.g. measured by their activity in a prothrombinase assay). However, the addition of the monoclonal antibody $7 E 3$, although inhibitory in the absence of added fibrin, did not prevent the fibrin effect (chapter 5). Regardless of the presence or the absence of the antibody, fibrin increased thrombin formation by about $40 \%$ relative to the activity without fibrin. This indicates that, although GPIlb/llla has a function in the platelet procoagulant response, the fibrin effect is not linked to this receptor. There must therefore be another actor. A next candidate is the glycoprotein $I b-V-I X$ complex (GPIb for short), which has been recognised as a von Willebrand 
factor receptor and a second receptor for thrombin (23-25). We had found however in chapter 4 , that inhibition of GPIb by the monaclonal antibody GD1 did not affect thrombin generation. It therefore came as a surprise that it nevertheless prevented the fibrin effect (chapter 5). Connections between GPIb and fibrin had been observed before. Loscalzo et al, (26) in 1986 demonstrated that this receptor was involved in the incorporation of platelets in clots and concluded that, in a plasma system, GPIb would act as a fibrin receptor. They also observed that von Willebrand factor serves as a link between polymerising fibrin and platelets.

Our observations suggest that at least two platelet membrane glycoprotein complexes are involved in the procoagulant response of platelets in plasma: the fibrinogen receptor GPIIb/llla and the receptor GPlb, the latter being responsible for the stimulating effect of fibrin.

\section{The role of von Willebrand factor}

The interaction between fibrin and GPIb is known to be mediated by von Willebrand factor (26-29). We have therefore also investigated the role of von Willebrand protein in the formation of thrombin in PRP (later part of chapter 5). We expected that, in the absence of von Willebrand factor, as when GPID is blocked, fibrin would no longer increase thrombin formation. Neutralisation of von Willebrand factor with a polyclonal antibody (not affecting factor VIII, i.e. without effects in PPP) largely reduced the production of thrombin, not only in the presence of a fibrin-clot but also in its absence. Observations in the PRP of type II and type III von Willebrand patients, supplemented with factor VIII, corroborated these observations. The inhibition could be shortcircuited by adding, to PRP, extra procoagulant phospholipid in the form of a frozen and thawed platelet lysate (either normal platelets or platelets from a type III-von Willebrand patient). The effect of neutralising von Willebrand factor was almost complete and much larger than that of blocking either GPIb or GPIIb/lla, which indicates that not only the GPIb- but also the GPIIb/lla mediated mechanism is von Willebrand factor dependent. 
We thus concluded that von Willebrand protein is required for the generation of thrombin in PRP because it plays a role in the generation of platelet procoagulant activity. So whereas in platelet free plasma with phospholipids added, von Willebrand is only involved in coagulation because of its carrier function for factor VIII, in PRP it becomes a clotting factor in its own right. This new role of von Willebrand factor, acting under the very low shear-rate conditions of a thrombin generation test ${ }_{0}$ further blurs the distinction between primary and secondary haemostasis.

\section{Conclusions}

In clotting PRP the interaction between fibrin and platelets, through von Willebrand factor and GPIb, plays a significant role in the generation of thrombin. This strongly suggests that fibrin in vivo may play a role similar to that of collagen, indeed there is a striking similarity between the platellet response to both types of fibre, if the effect of thrombin is excluded (Fig. 1). Fibrin thus appears not at all as the inert material that it was thought to be (30) but participates in a resonance loop which, through its snowball effect, may contribute to thrombus growth beyond the first layer of platelets sticking to collagen. In vivo of course the effects of thrombin are superimposed upon those of fibrin, especially because thrombin adsorbs to fibrin and in this form resists inhibition by antithrombin. 


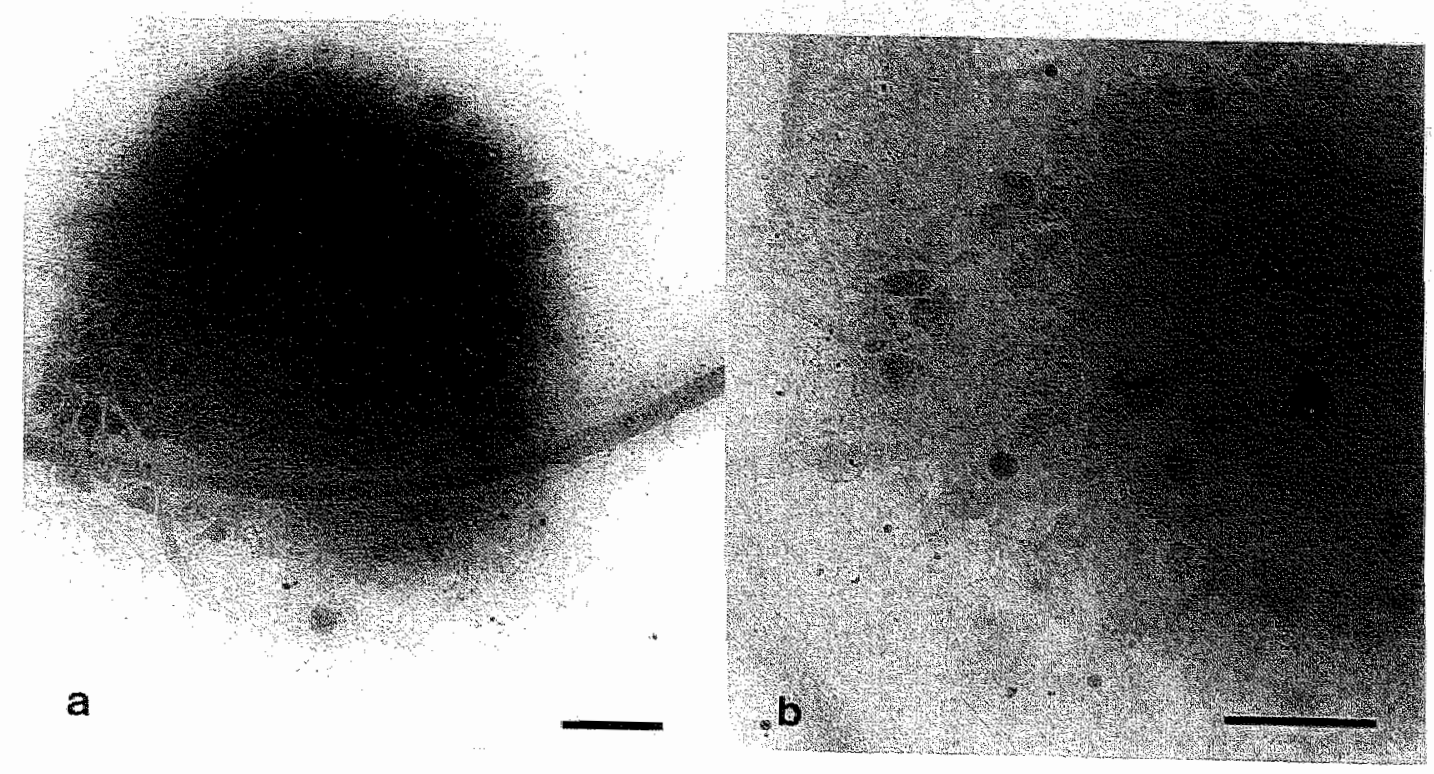

Figure 1 Platelets activated by collagen-and by fibrin-fibres. Collagen (a) and fibrin (b) fibres were attached to a grid (copper, 700 mesh, hexagonal pattern). The grids were dipped for $1 \mathrm{~min}$ in PRP, from blood containing $5 \mu \mathrm{M}$ hirudin and $5 \mu \mathrm{M}$ PPACK but no citrate. After gently blotting away excess suspending medium and washing in Hepes-buffered saline, the grids were vitrified in liquid/solid ethane and observed at $170^{\circ} \mathrm{C}$ after cryo-transfer to the electron microscope (Phillps CM12 operating at 120 kV). Bar represents $1 \mu \mathrm{M}$.

Our results are in agreement with earlier studies that stressed the importance of thrombin, either free or adsorbed onto fibrin. They do introduce, however, elements in the thrombin generation process that until now were not recognised as such: fibrin, GPlb and von Willebrand factor (Fig. 2).

von Willebrand factor seems a necessary mediator in the mechanism that brings about platelet procoagulant activity via GPllb/lla as well as via GPIb and fibrin. Thus, in PRP (and possibly in vivo) von Willebrand factor assumes the role of a clotting factor, independent of its being a carrier of factor VIII. If there are more (e.g. thrombin mediated) mechanisms to produce platelet procoagulant activity they must also be dependent upon von Willebrand factor, because inhibition of the latter is capable to prevent thrombin generation in platelet rich plasma almost completely. 


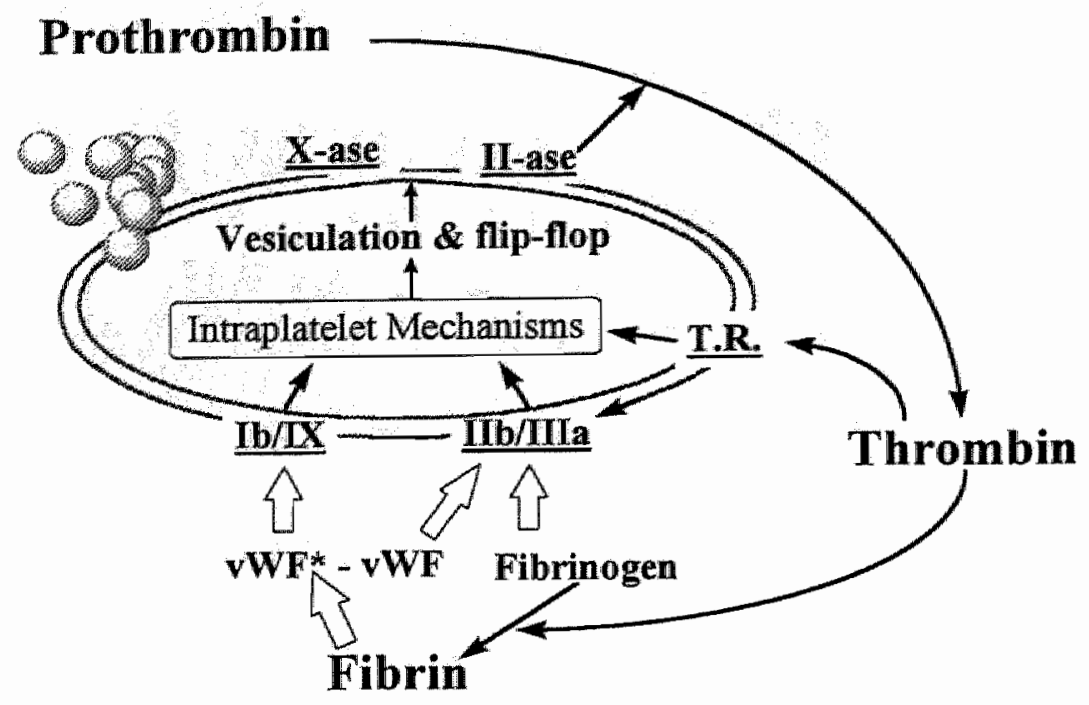

Figure 2: A tentative scheme of the interactions between the platelet, fibrin and von Willebrand factor that lead to thrombin generation. $X$-ase: Factor $X$ converting enzyme complex; It-ase: prothrombin converting enzyme; T.R.: Thrombin receptor; WWF: von Willebrand factor; WWF*: von Willebrand factor adsorbed on fibrin.

Many questions remain unanswered, e.g. what is the precise role of von Willebrand factor in the GPIIb/llla dependant production of procoagulant phospholipids? What are the intracellular signals triggered by GPIIb/llla and GPIb? What are the intra-platelet mechanisms responsible for flip-flop and vesiculation? What is the role of the internal fibrinogen and von Willebrand factor of the platelet in these processes? What is the role of the other receptors, e.g. those of thrombin? What makes the activating effect of a clot or thrombus stop in vivo? What is the effect of fibrinolysis? Can the activating effect of a thrombus in vivo be sufficiently reduced by inhibition of the adsorbed thrombin only? etc.

Several of these questions would carry us far beyond the domain from which we started: the mechanism of thrombin generation. If we pose them, it is 
because we hope that specialists in other domains will become interested in solving them.

Below, we recapitulate briefly the results presented in this thesis:

- Thrombin bound to fibrin, is capable to activate clotting factors $V$ and VIII as well as blood platelets.

- Fibrin to which no thrombin is bound is capable to activate procoagulant phospholipid activity (PPA) in platelets in the presence of plasma.

- Glycoprotein IIb/llla, the fibrinogen receptor at the platelet membrane surface is required for the full development of PPA but the fibrin effect is not mediated through this receptor.

- The fibrin effect is mediated via glycoprotein $\mathrm{lb}$.

- von Willebrand factor is required for both the fibrin-GPIb and the GPIIb/llla dependent pathway for the generation of PPA.

Our results thus demonstrate the existence of a resonance loop involving thrombin, fibrin and blood platelets, in which won Willebrand factor plays an essentiall role.

We think that the recognition of this mechanism contributes to the understanding of why an occluding haemostatic plug forms and why a thrombus grows. 


\section{References}

1. Baumgartner $\mathrm{HR}_{\text {w }}$ Sakariassen $\mathrm{KS}$. Factors controlling thrombus formation on arterial lesions. Ann NY Acad Sci 1985;454:162-177.

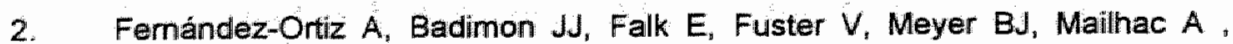
Weng $D$, Badimon $L$. Characterization of the relative thrombogenicity of atherosclerotic plaque components: Implications for consequences of plaque rupture. J Am Coll Cardiol 1994;23:1569-79.

3. Meyer BJ, Badimon JJ, Mailhac A, Fernández-Ortiz A, Chesebro JH, Fuster $V_{2}$ Badimon $L$. Inhibition of growth of thrombus on fresh mural thrombus. Targeting optimal therapy. Circulation 1994;90:2432-8.

4. Hovig $T$, Jorgensen L, Packham MA, Mustard JF. Platelet adhesion to fibrin and collagen. J Lab Clin Med 1968;71:29-40.

5. Nlewiarowski S, Regoeczi E, Steward GJ, Senyi AF, Mustard JF. Platelet interaction with polymerizing fibrin. J Clin Invest 1972;51:685-700.

6. Sixma $\mathrm{JJ}$ and Wester $\mathrm{J}$. The hemostatic plug. Seminars in Hematology. $1977 ; 14,265-99$.

7. Mailhac A, Badimon JJ, Fallon JT, Fernández-Ortiz A, Meyer B, Chesebro JH, Fuster $V_{1}$ Badimon L. Effect of an eccentric severe stenosis on fibrin(ogen) deposition on severely damaged vessel wall in arterial thrombosis. Relative contribution of fibrin(ogen) and platelets. Circulation 1994;90:988-95.

8. Seegers $W H$, Nieft $M$, Loomis EC. Note on the adsorption of thrombin on fibrin. Science 1945;101, 520-21

9. Liu CY, Nossel HL, Kaplan KL. The binding of thrombin by fibrin. J. Biol Chem $1979 ; 254: 10421-5$.

10. Francis CW, Markham RE, Barlow GH, Florack TM, Dobrzynski DM, Marder VJ. Thrombin activity of fibrin thrombi and soluble plasmic derivatives. J Lab Clin Med 1983;102:220-30

11. Béguin $S$, Kessels $H$, Hemker $H C$. Feedback reactions in blood coagulation are mediated by fibrin bound thrombin which is not inhibited by heparin. XIVth 1. S. T. H. Congress 1993. Abstract 962.

12. Hemker HC, Esnouf MP, Hemker PW, Swart ACW, MacFarlane RG. Formation of prothrombin converting activity. Nature 1967;215:248-251.

13. Rosing J"Tans G, Govers-Riemslag JWP, Zwaal RFA, Hemker HC. The role of phospho-lipids and factor $V a$ in the prothrombinase complex. J. Biol Chem $1980 ; 255: 274-83$.

14. Bevers EM, Comfurius P, van Rijn JLML, Hemker HC, Zwaall RFA. Generation of prothrombin converting activity and the exposure of 
phosphatidylserine at the outer surface of platelets. Eur $\rfloor$ Biochem $1982 ; 122: 429-36$

15. Sims P J, Wiedmer T, Esmon C T, Weiss H J, Shattil SJ. Assembly of the platelet prothrombinase complex is linked to vesiculation on the platelet plasma membrane. Studies in Scott syndrome: an isolated defect in platelet procoagulant activity. J. Biol Chem 1989; 264: 17049-57.

16. Béguin S. Thrombinoscopy. Ph D Thesis Maastricht University 1987.

17. Béguin $S$, Lindhout $T$, Hemker HC. The effect of trace amounts of tissue factor on thrombin generation in platelet rich plasma, its inhibition by heparin. Thomb Haemost 1989; 61: 25-9.

18. Comfurius P, Senden JMG, Tilly RHJ, Schroit AJ, Bevers EM, Zwaal RFA. Loss of membrane phospholipid asymmetry in platelets and red cells may be associated with calcium-induced shedding of plasma membrane and inhibition of aminophospholipid translocase. Biochim Biophys Acta 1990;1026:153-160.

19. Schroit AJ, Zwaal RFA. Transbilayer movement of phospholipids in red cell and platelet membrane. Biochim Biophys Acta 1991;1071:313-29.

20. Bevers EM, Comfurius P, Zwaal RFA. Mechanisms involved in platelet procoagulant response. In: Mechanisms of Platelet Activation and Control. K S Authi et al. eds. Plenum Publishing Corp.; New York. 1994; pp 195-207.

21. Smeets $E F$, Comfurius $\mathbb{P}$, Bevers $E M$, Zwaal RFA. Calcium-induced transbilayer scrambling of fluorescent phospholipid analogs in platelets and erythrocytes. Biochim Biophys Acta 1994:1195:281-86.

22. Comfurius $P$, Willamson $P$, Smeets EF, Schelgel RA, Bevers EM, Zwaal RFA. Reconstitution of phospholipid scramblase activity from human blood platelets. Biochemistry 1996;35:7631-34.

23. Hynes RO. The complexity of platelet adhesion to extracellular matrices. Thromb Haemost 1991;66:40-3.

24. Nurden A T. Human platelet membrane glycoproteins. In Haemostasis and Thrombasis, A L Bloom, C D Forbes, D P Thomas and E G D Tuddenham eds. Churchill Livingstone, Edinburgh etc. 1994; pp 115-166.

25. Coller B S. Inherited disorders of platelet function. In: Haemostasis and Thrombosis, A L Bloom, C D Forbes, D P Thomas and E G D Tuddenham eds. Churchill Livingstone, Edinburgh etc. 1994; pp 721-766.

26. Loscalzo J, Inbal A, Handin $\mathrm{RI}$, von Willebrand protein facilitates platelet incorporation in polymerizing fibrin. J. Clin Invest 1986;78:1112-9.

27. Coller BS, Peerschike EI, Scudder LE, Sullivan CA. Studies with a murine monoclonal antibody that abolishes ristocetin-induced binding of von Willebrand factor to platelets: additional evidence in support of GPIb as a platelet receptor for von Willebrand factor. Blood 1983;61:99-110. 
28. Fressinaud E, Baruch D, Girma JP, Sakariassen $K S$, Baumgartner HR, Meyer $D$ :von Willebrand factor-mediated platelet adhesion to collagen involves platelet membrane glycoproteín IIb/lla as well as glycoprotein Ib. J Lab Clin Med 1988;112:58-67.

29. Meyer D. Girma J-P. von Willebrand factor. Structure and function. Thromb Haemos $1993 ; 70: 99-104$.

30. Blomback $B$. Fibrinogen and fibrin -Proteins with complex roles in haemostasis and thrombosis. Thromb Res 1996; 83:1-75. 


\section{Hoofdstuk 6}

\section{Samenvatting in het Nederlands ${ }^{1}$}

Het is algemeen bekend dat een thrombus de neiging heeft te groeien. Ondanks veel onderzoek is het mechanisme van dit verschijnsel nog niet geheel duidelijk (1-3). Zowel een thrombus als een haemostatische prop is het eindproduct van het haemostatisch mechanisme en bestaat uit fibrine, met daaraan geadsorbeerde eiwitten en uit de resten van bloedplaatjes (4-6). De verhouding tussen deze componenten kan sterk wisselen. Daarom is lange tijd gedacht dat de vorming van een plaatjesprop en de vorming van een fibrinestolsel alternatieve manieren waren waarop een vat kon worden afgesloten. Tegenwoordig wordt meer en meer erkend dat beide processen onlosmakelijk met elkaar zijn verbonden. Het enzym dat fibrine doet ontstaan, thrombine, is essentieel voor de activering van bloedplaatjes en geactiveerde bloedplaatjes spelen een centrale rol bij de vorming van thrombine. Of fibrine dan wel plaatjes het hoofdbestanddeel van een thrombus witmaken lijkt veeleer een gevolg van de omstandigheden (stroming b.v.) waaronder het thrombus ontstaat dan van een verschil in het mechanisme dat tot afsluiting leidt. De wederzijdse activering van plaatjes en het thrombinegenererend ("stollings-") mechanisme leidt tot positieve tegenkoppeling en daarmee tot het explosieve ontstaan van vaatafsluiting dat essentieel is voor de haemostase en dat funest kan zijn bij thrombose. Het in dit proefschrift beschreven onderzoek draagt bij tot het herkennen van verschillende nieuwe tegenkoppelingslussen in dit proces.

De belangrijke rol van thrombine, ook bij het ontstaan van een plaatjesrijk thrombus, hoeft niet meer verdedigd te worden. Het werk van Badimon en Fuster bijvoorbeeld heeft laten zien dat, in een diermodel van de vorming van het arterieele - plaatjesrijke - thrombus, het thrombine dat

De referenties zijn gelijk aan die van de engelstalige samenvatting. 
gebonden is aan het fibrine in een vers thrombus de verdere aanhechting van plaatjes aan het thrombusoppervlak sterk bevordert (7). Dit leidde tot de vraag naar de rol van aan fibrine gebonden thrombine in het stollingsproces.

Het is bekend dat thrombine, het eindpunt van de stollingscascade, een sterk positieve invloed heeft op zijn eigen ontstaan, doordat het de factoren $V$ en VIII activeert en omdat het plaatjes procoagulant kan maken (811). Onze eerste vraagstelling was of dit ook gold voor thrombine dat gebonden is aan fibrine, d.w.z. aan het stolsel dat het heeft veroorzaakt. Deze vraag is te meer interessant omdat aan fibrine gebonden thrombine immuun is voor inactivering door de belangrijkste thrombineremmer van plasma, het antithrombine en daarmee voor de werking van het belangrijkste antithromboticum: heparine. In hoofdstuk 2 wordt aangetoond dat gebonden thrombine inderdaad deze factoren kan activeren. Bovendien bleek dat een stolsel ook in staat is om procoagulante eigenschappen op te roepen in bloedplaatjes. Deze reactie was tot onze verrassing echter niet gebonden aan de aanwezigheid van thrombine op het stolsel. Plaatjes bleken ook te kumnen worden geactiveerd door stolsels waarin geen thrombine aanwezig is, zoals die kunnen worden verkregen door remming van geadsorbeerd thrombine of met Agihal, een enzym uit slangengif dat, behalve de stolling van fibrinogeen, geen andere werkingen heeft op het stollingssysteem of op de bloedplaatjes.

De omzetting van prothrombine in thrombine, maar ook de activering van factor $X$, heeft obligaat plaats aan de interfase van een procoagulant phospholipide en de oplossing waarin de stollingsfactoren zich bevinden (12, 13). Om procoagulant te zijn moet het phospholipide oppervlak negatief geladen (amino-)phospholipiden bevatten, voornamelijk phosphatidyl serine (PS). Circulerende bloedcellen zijn niet procoagulant omdat het PS zich bevindt aan de binnenzijde van de celmembraan. De cruciale rol van de bloedplaatjes in de bloedstolling is het beschikbaar maken van procoagulante phospholipiden. (Wij melden terloops de uitstoot van factor $V$ uit bloedplaatjes, een proces dat in onze experimenten niet snelheidsbeperkend is). Bevers et al. hebben aangetoond dat in geactiveerde bloedplaatjes een translocatie van het PS van de binnenzijde naar de buitenzijde van de 
membraan plaatsvindt, waardoor zil procoagulant worden ("flip-flop", 14). Ook produceren bloedplaatjes bilj activering procoagulante micro-partikels, d.W.z. membraanfragmenten met PS aan de buitenkant waarop activering van prothrombine en factor $X$ kan plaatsvinden (15). Van de vele plaatjesactivatoren waren alleen collageen en thrombine bekend als veroorzakers van de procoagulante reactie in geisoleerde plaatjes (14). Toch bleek al vroeg dat in plaatjesrijk plasma thrombine wél, maar collageen geen effect had op de (plaatjesafhankelijke) ontwikkeling van thrombine (16, 17). Dit, tesamen met de resultaten van hoofdstuk 2 deed veronderstellen dat fibrine de plaats van collageen kon innemen en, onafhankelijk van thrombine, plaatjes procoagulant kon maken. Een poging om, in navolging van Bevers et al. (14) direct aan te tonen dat fibrine een invloed heeft op de phospholipidesamenstelling van de buitenkant van de plaatjesmembraan mislukte, omdat gewassen plaatjes door fibrine beschadigd worden, zoals bleek uit het vrijkomen van het intracellulaire enzym melkzuurdehydrogenase. Plaatjes in hun natuurijik milieu, plasma, waren echter wel bestand tegen de aanwezigheid van fibrine. Het procoagulant worden van de plaatjes moest dus worden afgeleid uit hun invloed op de thrombinevorming in plasma. In hoofdstuk 3 komen wij tot de conclusie dat fibrine inderdaad, net zoals colageen, in staat is om bloedplaatjes procoagulant te maken en dat deze functie onafhankelijk is van de aanwezigheid van thrombine op het fibrine, ofschoon thrombine het effect wel stimuleert. Hiermee was aangetoond dat fibrine niet het inerte eindproduct is van het stollingsproces maar een actieve rol speelt bij het ontstaan van thrombine, dus bij de groei van een thrombus.

Deze rol van het fibrine werd verder bevestigd door experimenten in het plasma van patienten met een aangeboren hypo-fibrinogeenaemie (hoofdstuk 5). Deze patiënten vertonen een verminderde thrombinegeneratie ( $<50 \%$ van normaal) in PRP, die even goed hersteld kan worden door het toevoegen van fibrinogeen als door het toevoegen van een (thrombine-vrij) fibrinestolsel. In PPP, waaraan lipiden van buitenaf moeten worden toegevoegd, is de thrombinegeneratie van deze patienten normaal. Omdat 
bloedplaatjes intracellulair fibrinogeen bevatten moet het niet uitgesloten geacht worden dat fibrine ook een rol speelt bij de procoagulante reactie van gewassen plaatjes.

De volgende vraag is die naar het mechanisme van de procoagulante reactie van de plaatjes. Sinds de ontdekking van de plaatjes flip-flop is het onderliggende intracellulaire mechanisme nog maar zeer gedeeltelijk opgehelderd (18-22). Wij hebben ons onderzoek beperkt tot het extracellulaire mechanisme, d.w.z. tot de vraag welke membraanreceptoren van het plaatje bij de procoagulante reactie een rol spelen.

De meest voor de hand liggende candidaat leek glycoproteine Ilb/llla (GP Ilb/llla), de fibrinogeenreceptor die actief wordt door de werking van thrombine op plaatjes en die verantwoordelijk is voor de vorming van plaatjesaggregaten via fibrinogeenbruggen (23-25). Wij vonden dat blokkeren van GPIlb/lla door een specifiek antilichaam, maar ook de congenitale afwezigheid van deze receptor in de thrombasthenie van Glanzmann een remmend effect (maximaal ongeveer 50\%) heeft op de thrombinevorming in plaatjesrijk plasma (hoofdstuk 4). Het defect in de vorming van plaafjesprocoagulante activiteit kwam ook tot uiting door verminderde vorming van micropartikels. Fibrine bleek echter nog steeds in staat om de aldus geremde thrombinevorming te stimuleren. GPIlb/llla speelt dus wel een rol bij de vorming van de plaatjes procoagulante activiteit, maar het fibrine-effect loopt niet via deze receptor.

Een volgende candidaat is glycoproterne Ib/lX (kortweg GPIb). Deze receptor bindt de von Willebrand factor, maar alleen nadat deze een conformatieverandering heeft ondergaan, b.v. door het binden aan collageen aan ristocytine of aan fibrine (23-26). Blokkeren van deze receptor met een monoclonaal antilichaam heeft geen effect op de normale thrombinegeneratie in de afwezigheid van fibrine (hoofdstuk 3) maar verhindert het fibrine-effect (hoofdstuk 4).

Onze observaties doen vermoeden dat er tenminste twee receptoren betrokken zijn bij de procoagulante respons van bloedplaatjes. De eerste sporen van thrombine die ontstaan activeren GPIlb/llla en induceren zo 
verder thrombinevorming. Als echter fibrine aanwezig is vòrdat thrombine verschijnt, activeert dat de plaatjes, zij het eerst na enige minuten. De tijdsrelatie tussen de verschillende activeringsmechanismen kon verder worden bevestigd door het toevoegen van sporen thrombine en agihal aan gerecalcificeerd PRP. Toevoeging van sporen thrombine (1 - $5 \mathrm{nM}$ ) leidt tot onmiddeilijk verkorting van de latentietijd van de massieve thrombinevorming $(100 \mathrm{nM})$, toevoeging van sporen van de thrombineremmer hirudine leidt tot verlenging. Toevoeging van het stollingsenzym agihal, dat zelf zonder effect is op bloedplaatjes, activeert de plaatjes ook, maar via het gevormde stolsel. Concentraties van thrombine en van agihal die in PPP dezelfde stollingstijd veroorzaken zijn in PRP heel verschillend: daar is het thrombine veel actiever.

Omdat van GPIb bekend is dat het de receptor is voor von Willebrand factor (26-29) hebben wij ook onderzocht hoe de thrombinevorming in PRP reageerde op neutralisering van dit eiwit met een antilichaam. Wij verwachtten dat het fibrine-effect teniet gedaan zou worden, op dezelfde wijze als door een antilichaam tegen GPIb. Groot was onze verbazing toen bleek dat inactiveren van de von Willebrand factor een sterk remmend effect had, ook zonder dat fibrine was toegevoegd. Observaties bij patienten met de ziekte van von Willebrand bevestigden dat deze factor practisch obligaat is voor de thrombinegeneratie in PRP, onafhankelijk of die wordt uitgelokt via GPIlb/llla (thrombine) of via GPIb (fibrine). Wij konden laten zien dat deze functie onafhankelijk is van de draagsterfunctie van von Willebrand factor voor stollingsfactor VIII. Tot nu toe werd de rol van von Willebrand factor vooral gezien bij de hechting van plaatjes aan bindweefsel bij hoge stroomsnelheden van het bloed. De nieuwe rol van deze factor, bij lage afschuifspanning, in het procoagulante mechanisme van de bloedplaatjes maakt dat de traditionele scheiding tussen primaire en secundaire haemostase, d.w.z. tussen een plaatjesafhankelijk mechanisme en het stollingsmechanisme, verder vervaagt.

Samenvattend hebben wij aangetoond dat fibrine niet moet worden gezien als het inerte materiaal dat een vat als een kurk afsluit (30). Het is een 
sterke activator van verdere fibrinevorming doordat het a) via het gebonden thrombine de stollingsfactoren $V$ en VIII maar ook bloedplaatjes activeert en b) een eigenstandig activerend effect heeft op de bloedplaatjes, dat uitgeoefend wordt via de membraanreceptor GPIb en de von Willebrand factor. Verder is gebleken dat de von Willebrand factor onontbeerilik is voor de vorming van thrombine in plaatjesrijk plasma - en dus waarschijnlijk in vivo - omdat het noodzakelijk is voor de tot stand koming van de procoagulante reactie van de plaatjes. 


\section{Curriculum Vitae}

Rachana Kumar was born on 29 April 1964 in New Delhi, Indlia. She finished her secondary education in 1981 and obtained her B.Sc. (Hons) Physics in 1984 from Hindu College, Delhi. She graduated with an MSc. in Physics from the University of Delhi in 1986. After teaching undergraduate courses at Rajdhani College for the 198687 term, she joined the Solid State Physics Laboratory of the Defence R\&D Organization in Delhi as a Scientist in 1987 and began working in the field of infrared detectors. In 1991, she returned to teaching at the Delhi University as Lecturer at the Kalindi College. Since August 1993, she has been on leave of absence from her job in India to work in the Department of Biochemistry at the Maastricht University on her doctoral research. She has received the National Scholarship and the Delhi University's K.S. Krishnan Gold Medal for her performance in Bachelor and Masters courses respectively, in addition to Dr Meghnad Saha Award from the Government of India for her popular science writings. 


\section{Acknowledgements}

I have accumulated intellectual and personal debt to many in the course of completion of this work. In particular I would like to thank:

Prof. Dr. H. Coen Hemker, my promoter, for giving me an opportunity to do research in his department. I have learnt much from his profound knowledge. This work has constantly benefited from his invaluable suggestions for new experiments and exacting intellectual comments on the drafts. By always listening to my half formed ideas and interpretations, he helped me build self confidence, so important to complete this work.

Dr. Suzette Béguin, my co-promotor, for giving me immense propelling support and enthusiastic daily direction. I am indebted to her for patiently explaining to me the intricacies of blood coagulation and always sparing time for discussion and fruitful suggestions.

Prof. Coller, Prof. Hermens, Dr. J. Heemskerk for their very useful comments on the earlier draft of this thesis.

Prof. dr. Stockbrügger, Prof. Coller, Dr. Heemskerk, Prof. Seligsohn, Prof. Struijker Boudier, Prof van der Vusse for critically evaluating this thesis.

Dr. P. Frederik and P. Bomans for their help with the electron microscopy experiments.

Dr. R. Wagenvoord for kindly providing the purified factors.

Professor Charles Cooper for putting me in touch with Professor Hemker through the Office of the Rector, Maastricht University, and thus enabling me to benefit from this association.

The Dutch Organisation for Scientific Research (NWO) for partly supporting the experiments conducted in this work under a programme grant (NWO-900-526-192).

Simone, for her expert technical help and cooperation. She has been my resource person whenever I encountered any problem.

Khaled, for his constant cooperation in thrombin generation tests. His light hearted conversation and brotherly goodwill often helped to unknot the stress of heavy experiments.

Dirk, for his generous support and advice whenever I needed it.

Irene, for enthusiastic participation in a part of this work. 
Hu Kai, Han Kessels, Marion, Paul Devilée, Rhett, for providing friendly and conducive work errvironment.

Gerrie, for providing advice in preparation of the manuscript.

To all the people who agreed to donate blood for our daily requirement of PRP experiments. Prof Hemker; Khaled, and Simone were always most kind to offer their arm in the hour of crisis.

Trees, Gertie, Mariet for not only providing secretarial assistance but also solutions to many problems a foreigner student faces.

My father, whose dream of many years that I complete Ph.D. was my source of light at the other end of the tunnel. His perpetual encouragement and bearing with our long absence when he most needed us made it possible to complete this work.

Our daughter, Nandini for spending long hours of solitude playing while I was busy at the computer.

My husband, Nagesh for his constant support and understanding in all possible ways. 